\title{
Moving towards an energy efficient future
}

\author{
Citation for published version (APA):
}

Zhong, S. (2017). Moving towards an energy efficient future: essays on energy efficiency, technology and development. [Doctoral Thesis, Maastricht University]. Datawyse / Universitaire Pers Maastricht. https://doi.org/10.26481/dis.20170614sz

Document status and date:

Published: 01/01/2017

DOI:

$10.26481 /$ dis.20170614sz

Document Version:

Publisher's PDF, also known as Version of record

\section{Please check the document version of this publication:}

- A submitted manuscript is the version of the article upon submission and before peer-review. There can be important differences between the submitted version and the official published version of record.

People interested in the research are advised to contact the author for the final version of the publication, or visit the DOI to the publisher's website.

- The final author version and the galley proof are versions of the publication after peer review.

- The final published version features the final layout of the paper including the volume, issue and page numbers.

Link to publication

\footnotetext{
General rights rights.

- You may freely distribute the URL identifying the publication in the public portal. please follow below link for the End User Agreement:

www.umlib.nl/taverne-license

Take down policy

If you believe that this document breaches copyright please contact us at:

repository@maastrichtuniversity.nl

providing details and we will investigate your claim.
}

Copyright and moral rights for the publications made accessible in the public portal are retained by the authors and/or other copyright owners and it is a condition of accessing publications that users recognise and abide by the legal requirements associated with these

- Users may download and print one copy of any publication from the public portal for the purpose of private study or research.

- You may not further distribute the material or use it for any profit-making activity or commercial gain

If the publication is distributed under the terms of Article $25 \mathrm{fa}$ of the Dutch Copyright Act, indicated by the "Taverne" license above, 


\section{Moving Towards an Energy Efficient Future:}

Essays on Energy Efficiency, Technology and Development 


\title{
Moving Towards an Energy Efficient Future:
}

\section{Essays on Energy Efficiency, Technology and Development}

\author{
DISSERTATION \\ To obtain the degree of Doctor at Maastricht University, \\ on the authority of the Rector Magnificus, \\ Prof. Dr. Rianne M. Letschert \\ in accordance with the decision of the Board of Deans, \\ to be defended in public \\ on Wednesday 14 June 2017, at 12:00 hours
}

by

Sheng Zhong 
Supervisor:

Prof. Dr. Bart Verspagen

\section{Co-supervisor:}

Dr. Nicola Cantore (UNIDO)

\section{Assessment Committee:}

Prof. Dr. Shyama Ramani (chair).

Prof Dr. Bart Los, University of Groningen.

Dr. Neil Foster-McGregor.

Dr. Dirk Willem te Velde, Overseas Development Institute, United Kingdom. 
To my parents 



\section{Acknowledgements}

This dissertation could not have been completed without generous support and encouragement from supervisors, colleagues, friends and family. It is far more than a product of five years of hard work. Many wonderful people greatly contributed to it.

First and foremost, I would like to express my deepest gratitude to my supervisor, Prof. Bart Verspagen, and co-supervisor, Dr. Nicola Cantore. It is my honor to have had the opportunity to work with them. During our meetings and discussions, Prof. Verspagen helped me a lot to find out my research and career paths and handle the complexities of Ph.D. research. I am deeply grateful for his time, trust and patience. During my visit at UNIDO, Dr. Cantore gave me the golden opportunity to participate in the UNIDO report and helped me to improve my research. Working with Prof. Verspagen and Dr. Cantore has taught me a lot and will prepare me to be a qualified economist. Thank you so much!

Next I would like to thank the members of the assessment committee: Prof. Dr. Shyama Ramani (chair), Prof. Dr. Bart Los, Dr. Neil Foster-McGregor and Dr. Dirk Willem te Velde - who took their valuable time to evaluate my thesis.

This Ph.D. project was funded by the United Nations Industrial Development Organization (UNIDO). I want to thank the Department of Policy, Research and Statistics of UNIDO and the UNIDO Institute for Capacity Development for providing valuable research opportunities and a pleasant and simulating environment during my visit as an intern. Chapters 2, 3 and 4 have been included in the UNIDO Inclusive and Sustainable Industrial Development Working Paper Series. In particular, part of Chapter 2 was developed and written when I was doing my internship at the Department of Policy, Research and Statistics at UNIDO, and it served as a background paper for the UNIDO Industrial Development Report 2016. I benefited a lot from intellectual exchanges with inspiring colleagues at UNIDO. In particular, I am thankful to Dr. Ludovico Alcorta, Dr. Nicola Cantore, Dr. Michele Clara, Dr. Dong Guo, and Dr. Nobuya Haraguchi. I also owe thanks to the administrative staff and editorial board at the department. Without UNIDO's generous support, this research project would not have been possible.

I am equally thankful to the School of Business and Economics, Maastricht Graduate School of Governance, Faculty of Arts and Social Sciences and University College Maastricht for granting me the great teaching and supervision experience I gained as a tutor 
and supervisor in the bachelor's and master's programs. I also wish to thank the University of Groningen for providing the World Input-Output Database (WIOD), the Metropolitan Area Planning Council of Massachusetts for providing the amazing Massachusetts Vehicle Census data and UNU-MERIT for providing the full version of EPO PATSTAT database.

In the process of finalizing the research proposal and writing this thesis, I greatly benefited from many insightful and helpful comments and suggestions from faculty members. I would like to thank Prof. Robin Cowan, Prof. Franziska Gassmann, Prof. Fred Gault, Prof. Can Huang, Dr. Michiko lizuka, Prof. René Kemp, Dr. Lutz Krebs, Dr. Mindel van de Laar, Dr. Önder Nomaler, Prof. Pierre Mohnen, Dr. Tatiana Skripka, Prof. Adam Szirmai, Dr. Lili Wang and Dr. Thomas Ziesemer. I am particularly grateful to Prof. Pierre Mohnen, one of my referees, for providing great guidance and support for my academic research as well as job search. The results and findings of this thesis have already been disseminated with a wide range of audiences within and beyond academia in workshops and international conferences. I received many helpful comments regarding the literature, methodology, data and results. I am also thankful to all the audiences who contributed to improving this thesis.

This thesis would not have been possible without the support from all the administrative and technical staff. A very profound gratitude goes to Eveline in de Braek, who always encourages me and takes good care of all the Ph.D. fellows. Her emotional support and practical advice are greatly appreciated. Thank you Eveline! Also, I would like to thank Ad Notten, Herman Pijpers and Mourik Jan Heupink for providing great technical support in dealing with large datasets. I am thankful to Sueli Brodin for proofreading this thesis. I would also like to thank Danny Beckers, Wilma Coenegrachts, Mieke Drossaert, Ingeborg Eijssen-de Beer, Marlies Haak, Howard Hudson, Monique Raedts, Susan Roggen, Ingrid Scheffers, Mitie Stenders, and Marc Vleugels.

Lots of wonderful colleagues and friends at UNU-MERIT also supported me in the last five years and made my Ph.D. journey a memorable and unique experience. In particular I would like to express my special thanks of gratitude to the wonderful 2012 Ph.D. fellows: Ayokunu Adedokun, Saba Afeworki, Eva Bartekova, Tobias Broich, Carla Buil, Juan Carlos Castillo, Hans-Erik Edsand, Stefania Innocenti, Eriko Katashiro, Martin Kügemann, Gintare Mazeikaite, Biljana Meshkovska, Tigist Mekonnen Melesse, Thuy Nguyen, Raquel Tsukada, Ralf-Martin Soe and Caroline Wehner. A special appreciation goes to my previous and current spectacular office mates: Juan (the other UNIDO fellow), Stefania, Sachin, Eva, Tigist, Jenny, Inez, Iulia, Giulia, and Danilo. I am extremely lucky because I met you in this journey and so happy to have so many fond memories together.

Furthermore, thanks to all other colleagues and friends I have met in this journey: Tamara A. Kool, Mueid Al Raee, Elvis Avenyo, Sachin Badkas, Elisa Calza, Beatriz Calzada 
Olvera, Alison Cathles, Hugo Confraria, Giacomo Domini, Iulia Falcan, Andrea FrancoCorrea, Francesca Guadagno, Jun Hou, Ibrahima Kaba, Mary Kaltenberg, François Lafond, Alejandro Lavopa, Nga Le Thi Quynh, Paula Nagler, Clotilde Mahé, Julieta Marotta, Ortrun Merkle, Daniel Opolot, Jinhyuck Park, Tatevik Poghosyan, Iman Rajabzadeh, Inez Roosen, Giulia Rossello, Francesca Rubiconto, Shuan Sadre Ghazi, Danilo Sartorello Spinola, Simone Sasso, Jennifer Taborda Martinez, Tamer Taha, Eszter Timar, Giorgio Triulzi, Rose Vincent, Jennifer Waidler, Soazic Elise Wang Sonne, Eduardo Urias, Pui-hang Wong and Jinjin Zhao. Thank you for greatly contributing to making my research journey a wonderful one.

Finally and most importantly, I would like to express my sincere gratitude to my parents, who always believe in me and have endured my absence from family for so many years. Thank you so much for your love, support and giving me the freedom to chase my dreams. 



\section{Summary}

As an influential development paradigm, sustainable development has gained broad support from various governments and organizations at regional, national and global levels. It is a process involving many important dimensions and its study requires efforts from researchers from all the disciplines of natural and social sciences. In this thesis, we focus on energy efficiency, a key element in the pursuit of sustainable development. The dynamics of energy efficiency is an evolutionary process that involves industries, technologies and institutions. Therefore, it requires a wide range of policies, aimed at both macro and micro levels. It is of primary importance to have a careful economic study of all the detailed processes that are involved in the policy-relevant areas. Numerous programs, funds, facilities related to energy efficiency have been implemented so far and are still ongoing. In the study of energy efficiency, many policy-relevant areas that require numerous research and financial inputs and careful empirical analysis are involved. Due to data availability and the feasibility of this study to be effectively conducted, as an early step, we narrow down our research at micro and macro levels to the following aspects: energy consumption and energy efficiency at sectoral and country levels, aggregate vehicle energy efficiency (regional level) and the technologies related to energy efficiency in the fields of power station, ICT in buildings and vehicles. We hope that our results can shed light on the relevant policies and studies in the future.

Using large datasets, this dissertation provides a comprehensive narrative of how energy efficiency and the technologies related to energy efficiency evolve over time. We develop a new analytical framework and several measures for crucial factors affecting energy consumption and energy efficiency in trade at sectoral and country levels. Based on big data of individual vehicles and their owners, we design an empirical statistical approach to estimate regional aggregate vehicle energy efficiency that is formed by the technological characteristics and collective behaviors of micro-agents (e.g., purchase and usage of vehicles and migration), and describe the life cycle and restructuring of the vehicle population. Also, we identify the technological trajectories of technologies related to energy efficiency, and develop some measures for whether a country can be classified as an incumbent country or a latecomer country, and for how much a country contributes to technological development. The approaches used in this dissertation that build aggregate or macro measures on the basis of detailed and micro large datasets are of great value for the study of economic, industrial and scientific evolution. The 
optimal path method in this dissertation based on the patent citation networks may inspire studies in any other technological fields, and enable policymakers as well as investors to monitor technological development and discover business opportunities. The precise empirical evidence provided by this dissertation can assist policymakers in finding tailored solutions to the real world problems.

In Chapter 2 we review the decomposition techniques commonly used in energy and environmental economics, and propose a new decomposition method in the inputoutput framework to identify crucial factors affecting the growth of energy consumption and energy efficiency. We take into account trade relations and intermediate inputs in production that are mostly neglected by traditional methods. Unlike prior studies, we develop two perspectives: energy directly used for production or household consumption purposes, and energy embodied in the products consumed by economies and households. We also apply the analysis to all the major economies and sectors in the world. The results show that energy consumption increases caused by economic development can be roughly offset by reducing the energy intensity and lowering energy intensity is the overwhelming factor behind the decline in aggregate energy intensity in most economies, while trade in intermediate inputs has a small effect in changing energy consumption. We also find that the gaps of energy intensity between economies tend to narrow down and the relationship between energy intensity and GDP per capita is strictly decreasing.

The methods used in Chapter 3 are developed based on firm productivity literature and convergence analysis in development economics. We particularly focus on vehicles, a typical durable product consuming energy. By tracking every vehicle, we estimate regional aggregate vehicle energy efficiency based on the usage and energy efficiency of every individual vehicle. By doing so, we do not have the issues of heterogeneity and representative agent. We also estimate the entry effect of new vehicles, the reallocation of energy efficiency vehicles and the Ergodic distribution of aggregate vehicle energy efficiency. Additionally we check the socio-economic factors affecting the distribution of vehicles over locations and vehicle exit event. The availability of the big data makes this paper one of first few papers estimating regional energy efficiency for vehicles. Our results confirm the importance of structural change in the vehicle population, the convergence of aggregate vehicle energy efficiency between municipalities and the crucial role of socio-economic factors in shaping vehicle distribution.

In Chapter 4, using up-to-date bibliographical and citation information of patents from the European Patent Office, we study the technological evolution of three fields on energy efficiency classified by the OECD ENV-TECH list: power station, ICT in buildings and vehicles. We construct patent citation datasets for these fields, and identify the optimal technological paths by maximizing total search pair count (SPC) weights in the citation networks. We also develop new measures to evaluate countries' role (incum- 
bent or latecomer) and contribution in these fields. The results show that latecomer countries tend to contribute less to the main technological trajectories in the fields of energy efficiency, while those counties with large bested interests in the dominant technological trajectories are also the ones that contribute more. This paper is an early attempt of quantifying technological development of the OECD ENV-TECH list. The methods used in this chapter can be applied to any other fields. 



\section{Contents}

Acknowledgements

Summary

List of Figures

List of Tables

Chapter 1 Introduction

$\begin{array}{ll}1.1 \text { Motivation } & 27\end{array}$

1.2 Economic development and environmental sustainability 33

1.3 Energy efficiency paradox and technology 36

1.4 Policies and Initiatives on Energy Efficiency: An Overview 39

1.5 Thesis outline 46

Chapter 2 Energy Consumption, Energy Intensity and Economic Development between 1995 and 2009: A Structural Decomposition Approach 49

2.1 Introduction

2.2 Literature Review $\quad 54$

2.2.1 Energy consumption and energy intensity 54

2.2.2 Environmental Kuznets Curve and the role of technology 55

2.2.3 Major decomposition techniques $\quad 57$

2.2.3.1 Production function based econometric method $\quad 57$

2.2.3.2 Index Decomposition Analysis (IDA) 57

2.2.3.3 Structural Decomposition Analysis (SDA) $\quad 59$

2.3 Methodology $\quad 61$

2.3.1 Data $\quad 61$

2.3.2 Supply side and demand side 63

2.3.3 Decomposition approaches 64

2.3.3.1 Structural decomposition of energy consumption at economy level 64

2.3.3.2 Structural decomposition of energy intensity at economy level $\quad 67$

2.3.3.3 Supply side and demand side at economy level 68

2.3.3.4 Structural decomposition of energy consumption and energy intensity at sectoral level $\quad 69$

$\begin{array}{ll}\text { 2.3.4 Computing procedures } & 71\end{array}$

$\begin{array}{ll}\text { 2.3.4.1 The deflating strategy: chain mechanism } & 71\end{array}$

2.3.4.2 Taking into account results from two methods 71 
2.3.5 Understanding the decomposition factors 72

2.3.6 Convergence analysis of energy intensity at economy level 73

2.3.7 Environmental Kuznets Curve: multilevel mixed-effect model 74

2.4 Results $\quad 75$

2.4.1 Structural decomposition results of energy consumption at economy level $\quad 75$

2.4.1.1 Supply side $\quad 75$

$\begin{array}{ll}\text { 2.4.1.2 Demand side } & 77\end{array}$

2.4.1.3 Basic conclusions $\quad 79$

2.4.2 Structural decomposition results of energy intensity at economy level 81

$\begin{array}{ll}\text { 2.4.2.1 Supply side } & 81\end{array}$

2.4.2.2 Demand side $\quad 83$

2.4.2.3 Convergence analysis $\quad 85$

2.4.3 Structural decomposition results at sectoral level 87

2.4.3.1 Performance: energy consumption and energy intensity at sectoral level 88

2.4.3.2 Structural decomposition of energy consumption at sectoral level 89

2.4.3.3 Structural decomposition of energy intensity at sectoral level 91

2.4.4 Multilevel Mixed-Effect Model 92

2.5 Conclusions $\quad 94$

Appendix 2.1 Definitions of Economies and Sectors in WIOD 98

Appendix 2.2 Full Decomposition Results 101

Appendix 2.3 Econometric Analysis Results $\quad 111$

Chapter 3 The dynamics of vehicle energy efficiency: Evidence from the Massachusetts Vehicle Census $\quad 115$

3.1 Introduction $\quad 117$

$\begin{array}{ll}3.2 \text { Literature review } & 120\end{array}$

3.3 Data and methodology $\quad 122$

3.3.1 Data description $\quad 122$

3.3.2 Aggregate vehicle energy efficiency and its decomposition over the period 2008q1 - 2011q4 123

3.3.3 Decomposition of growth of aggregate vehicle energy efficiency between 2008q4 and 2010q4 125

3.3.4 Convergence and transition of aggregate vehicle energy efficiency $\quad 129$ 3.3.4.1 Econometric approach 130

3.3.4.2 Distribution approach 131

3.4 Results 132

3.4.1 Decomposition of aggregate vehicle energy efficiency over the period $2008 q 1-2011 q 4$ 
3.4.2 Decomposition of growth of aggregate vehicle energy efficiency between $2008 q 4$ and $2010 q 4$

3.4.3 Convergence and transition of aggregate vehicle energy efficiency 143

$\begin{array}{ll}\text { 3.4.4 Number of vehicles } & 148\end{array}$

3.4.5 Determinants of exit from the state $\quad 150$

3.5 Conclusions 153

Chapter 4 The Role of Technological Trajectories in Catching-up-based Development: An Application to Energy Efficiency Technologies 157

4.1 Introduction $\quad 159$

4.2 Technological trajectories $\quad 161$

4.3 Patent citation networks 163

4.4 Data $\quad 165$

4.5 Results $\quad 172$

4.5.1 Power stations $\quad 173$

4.5.2 ICT energy efficiency in buildings 177

4.5.3 Energy efficiency technologies related to vehicles 179

4.5.4 How countries relate to the technological profiles 183

4.6 Conclusions and discussion 186

$\begin{array}{lll}\text { Chapter } 5 \text { Conclusions } & 191\end{array}$

5.1 Summary, contributions and main findings 193

$\begin{array}{ll}5.2 \text { Policy implications and further research } & 199\end{array}$

$\begin{array}{ll}\text { Valorisation } & 203\end{array}$

$\begin{array}{ll}\text { About the Author } & 207\end{array}$

$\begin{array}{ll}\text { References } & 209\end{array}$

UNU-MERIT/MGSoG Dissertation Series $\quad 218$ 



\section{List of Figures}

Figure 1.1 Global energy intensity and GDP per capita, 1990 - 2015

Figure 1.2 Global CO2 emission intensity and GPD per capita, 1990 - 2015

Figure 1.3 Global share of fossil fuel energy consumption and GDP per capita, $1960-2015$

Figure 1.4 Energy intensity by income group, $1990-2012$

Figure 1.5 Selected sectors' shares of CO2 emissions, $1960-2013$

Figure 2.1 Supply side and demand side energy consumption for selected economies, 1995-2009 53

Figure 2.2 WIOT data structure for a single year 63

Figure 2.3 Energy transaction matrix structure for a single year $\quad 64$

Figure 2.4 Structural decomposition of supply side energy consumption of selected economies (log points) 80

Figure 2.5 Structural decomposition of demand side energy consumption of selected economies (log points) 81

Figure 2.6 Structural decomposition of supply side energy intensity of selected economies (log points) 83

Figure 2.7 Structural decomposition of demand side energy intensity of selected economies (log points) 85

Figure 2.8 Convergence analysis for supply side relative energy intensity 86

Figure 2.9 Convergence analysis for demand side relative energy intensity 86

Figure 2.10 Performance in energy consumption and energy intensity from 1995 to 2009

Figure 2.11 Structural decomposition of energy consumption at sectoral level from 1995 to 2009

Figure 2.12 Structural decomposition of energy intensity at sectoral level from 1995 to 2009

Figure 2.13 Predictions of multilevel mixed-effect model for supply side and demand side energy intensity

Figure 2.14 Supply side energy intensity and GDP per capita-prediction of fixed portion

Figure 2.15 Demand side energy intensity and GDP per capita-prediction of fixed portion

Figure 2.16 Structural decomposition of supply side energy consumption in the EU (log points)

Figure 2.17 Structural decomposition of demand side energy consumption in the EU (log points) 
Figure 2.18 Structural decomposition of supply side energy intensity in the EU

(log points)

Figure 2.19 Structural decomposition of demand side energy intensity in the EU (log points)

Figure 3.1 Total number of vehicles in Massachusetts; 2008q1 - 2011q4

Figure 3.2 Decomposition of state level aggregate MPG over the period 2008q1 $2011 q 4$

Figure 3.3 Histogram graphs of decomposition of growth of aggregate vehicle energy efficiency at municipality level using Method 3, 2008q4 - 2010q4

Figure 3.4 Massachusetts, growth of aggregate vehicle energy efficiency at municipality level between 2008q4 and 2010q4

Figure 3.5 Massachusetts, municipality clusters based on five factors between 2008 and 2010

Figure 3.6 The relationship between relative aggregate MPG in 2008q1 and growth of relative aggregate MPG; OLS and nonparametric approach

Figure 3.7 The relationship between relative aggregate MPG in 2008q1 and growth of relative aggregate MPG; OLS and bootstrapping quantile regression

Figure 3.8 Comparison between initial distribution and Ergodic distribution

Figure 4.1 The relationship between patent publication, patent application and patent family in PATSTAT

Figure 4.2 Development of the citation network for power stations

Figure 4.3 Development of the citation network for energy efficiency technologies, ICT in buildings

Figure 4.4 Development of the citation network for energy efficiency technologies related to vehicles

Figure 4.5 Evolution of the importance of the largest component, power stations citations network

Figure 4.6 Evolution of the importance of the largest component, ICT citations network

Figure 4.7 Evolution of the importance of the largest component, vehicle energy efficiency citations network

Figure 4.8 Top main paths, 1984 - 2013, power stations field, colors indicate 13 vOS clusters

Figure 4.9 Top main paths, 1988 - 2013, ICT energy efficiency field, colors indicate 10 VOS clusters

Figure 4.10 Top main paths, 1978 - 2013, vehicle energy efficiency field, colors indicate 11 VOS clusters 


\section{List of Tables}

Table 1.1 Market and behavioral failures related to energy efficiency and potential policy responses

Table 1.2 Selected U.S. energy efficiency related policies

Table 1.3 Selected policy documents related to energy efficiency

Table 1.4 Energy Efficiency in the United Nations Sustainable Development Goals (SDGs)

Table 1.5 Selected global programs, funds, facilities and mechanisms related to energy efficiency

Table 2.1 Structural decomposition of supply side energy consumption of selected economies

Table 2.2 Structural decomposition of demand side energy consumption of selected economies

Table 2.3: Structural decomposition of supply side energy intensity of selected economies

Table 2.4 Structural decomposition of demand side energy intensity of selected economies

Table 2.5 Structural decomposition results of energy consumption and energy intensity, $1995-2009$

Table 2.6 Multilevel mixed-effect model results for supply side and demand side

Table 2.7 List of economies in WIOD

Table 2.8 List of sectors in WIOD; industry and manufacturing technological level classifications

Table 2.9 Full structural decomposition results of supply side energy consumption in the EU

Table 2.10 Full structural decomposition results of demand side energy consumption in the EU

Table 2.11 Full structural decomposition results of supply side energy intensity in the EU

Table 2.12 Full structural decomposition results of demand side energy intensity in the EU

Table 2.13 Full structural decomposition results of energy consumption at sectoral level, 1995 to 2009

Table 2.14 Full structural decomposition results of energy intensity at sectoral level, 1995 to 2009

Table 2.15 Convergence analysis for supply side relative energy intensity

Table 2.16 Convergence analysis for demand side relative energy intensity

Table 2.17 Multilevel mixed-effect model for supply side energy intensity 
Table 2.18 Multilevel mixed-effect model for demand side energy intensity

Table 3.1 Summary statistics of vehicles in Massachusetts between 2008q4 and $2010 q 4$

Table 3.2 Entry and exit of vehicles in a certain municipality

Table 3.3 Two alternative methods of decomposition of aggregate vehicle energy efficiency growth

Table 3.4 Decomposition of state level aggregate MPG over the period 2008q1 $2011 q 4$

Table 3.5 Decomposition of aggregate vehicle energy efficiency at state level between 2008q4 and 2010q4

Table 3.6 Summary of decomposition of growth of aggregate vehicle energy efficiency on municipal level using Method 3, 2008q4 - 2010q4

Table 3.7 Mean value of the five variables used in cluster analysis

Table 3.8 Mean value of the five variables by cluster

Table 3.9 The relationship between relative aggregate MPG in 2008q1 and growth of relative aggregate MPG; OLS and quantile regression at 25\%,50\% and $75 \%$ quantile

Table 3.10 Group bounds based on municipality level relative aggregate vehicle energy efficiency in 2008q1, relative to the state level

Table 3.11 One period transition matrix of municipality level relative aggregate vehicle energy efficiency; relative to the state level; 2008q1-2011q4

Table 3.12 Random-effects negative binomial regression, using number of vehicles as dependent variable, 2008 - 2011

Table 3.13 Probit regression results for initially existing vehicle's staying or exiting decision

Table 4.1 PATSTAT tables used in the analysis (2014 April version)

Table 4.2a. Climate change mitigation technologies related to energy generation, transmission and distribution

Table 4.2b. Climate change mitigation technologies related to transportation

Table 4.2c. Climate change mitigation technologies related to buildings

Table 4.3 Number of patents and age for power station technology, by country

Table 4.4 Clusters in the top main paths graphs of the power stations field, 1984 $-2013$

Table 4.5 Number of patents and age for energy efficiency technologies related to ICT in buildings, by country

Table 4.6 Clusters in the top main paths graphs of the ICT energy efficiency field, $1988-2013$

Table 4.7 Number of patents and age for energy efficiency technologies related to vehicles, by country

Table 4.8 Clusters in the top main paths graphs of the vehicle energy efficiency field, $1978-2013$ 
Table 4.9 Regression results for forward linkages 

Chapter

1

Introduction 



\subsection{MOTIVATION}

Can economic development be sustainable over time? How can sustainable development be achieved through efforts from governments and civil societies? In a narrow sense, these questions are of fundamental importance for those economists who study economic growth in major fields of economics such as development economics, macroeconomics, and international economics and there is a large and influential literature on the determinants of economic growth. ${ }^{1}$ Also, these questions remain central for policymakers; the answers are crucial for designing development policies and strategies. Since the 1990s the idea of sustainable development has gained broad support from a wide range of governments and organizations at regional, national and global levels, and without a doubt, become the new development paradigm (Lele, 1991), famous examples including the United Nations Millennium Development Goals (MDGs) (United Nations, 2000) and more recently, the United Nations Sustainable Development Goals (SDGs) (United Nations, 2015). Given this background, the aim of this thesis is to provide thorough economic analyses and contribute to the literature as well as policymaking on sustainable development, on the basis of large datasets. Sustainable development is a dynamic process that involves lots of critical dimensions. ${ }^{2}$ Analyzing all the aspects of sustainable development, however, goes beyond the scope of this work. This thesis focuses more particularly on energy efficiency and the related technology aspect.

Over the past few years, energy efficiency has been given an increasing attention and embraced as a key element of sustainable development because of concerns about global climate change (Jaffe \& Kerr, 2015; Jaffe \& Stavins, 1994a; Patterson, 1996), wellknown examples including the EU 2020 Strategy (European Commission, 2010) and the United Nations SDGs. To see the importance of the issues of energy efficiency, the following simple examples are helpful.

Figure 1.1 below shows the global GDP per capita (ppp, constant 2011 international US dollars) and the global energy efficiency, measured as the amount of primary energy consumption per unit of GDP (ppp, constant 2011 international US dollars) over the period 1990 - 2015. It is evident that overall the global GDP per capita has increased greatly (rising from around 9000 US dollars in 1990 to about 14600 US dollars in 2015), while the global energy efficiency has been improved a lot in the face of large increases

\footnotetext{
${ }^{1}$ For example, saving rate and population growth emphasized by the Solow model (Mankiw, Romer, \& Weil, 1992), social infrastructure like institutions and government policies (Acemoglu, Johnson, \& Robinson, 2001; R. E. Hall \& Jones, 1999), the effect of geographical endowments through institutions (Easterly \& Levine, 2003), corruption (Mauro, 1995), social capital (Knack \& Keefer, 1997), financial development (King \& Levine, 1993), trade (Frankel \& Romer, 1999), FDI and absorptive capability of the advanced technologies (Borensztein, De Gregorio, \& Lee, 1998), the endogenous growth models including the stock of human capital (Romer, 1990) and technological innovation (Aghion \& Howitt, 1992) (see Verspagen (1992) for a discussion). ${ }^{2}$ Lele (1991) summarizes the semantics of sustainable development concept that includes sustaining economic growth and achieving ecological and social sustainability.
} 
in production scale and population that consume energy, ${ }^{3}$ since the energy needed for producing one unit of GDP has kept decreasing. Figure 1.2 presents a similar empirical pattern for global $\mathrm{CO} 2$ emission intensity, measured by the amount of $\mathrm{CO} 2$ emissions in creating one unit of GDP, since most $\mathrm{CO} 2$ emissions are generated from energy consumption. These two figures show the achievements in the pursuit of sustainable development. One possible explanation for these phenomena is the directed technological change and innovation toward clean inputs with relevant policy interventions (Acemoglu, Aghion, Bursztyn, \& Hemous, 2012).

Figure 1.3, in contrast, shows a challenge for sustainable development. It plots the share of global fossil fuel energy consumption in the total energy consumption and GDP per capita (constant 2010 US dollars) over 1960 - 2015. Overall the world heavily relies on the unrenewable fossil fuels: their share in the total energy consumption is above $80 \%$ most of the time. The share sharply dropped from about $95 \%$ to $85 \%$ between the late 1960s and the early 1970s. However, it shows that beginning in the late 1970s the share decreased more slowly than before, and beginning in the 2000s, the share began to increase again. The fossil fuels' share in $2013(81.2 \%)$ is very close to the share in 1982. If the growing trend continues and the heavy dependency on fossil fuels remains in the future, the prospect of sustainable development would be greatly challenged.

The energy efficiency significantly varies across countries. Figure 1.4 provides an empirical fact of energy efficiency by income group over $1990-2012 .{ }^{4}$ It is evident that although there is a tendency for the energy intensity to fall in all the income groups, there is still a large discrepancy between different income groups. The high income economies are the most energy efficient, below the world level. The energy intensity of the lower middle income economies is slightly smaller than the world level in general. The low income economies and the upper middle income economies that have the largest share in global population, however, perform worse than the world level in all the years in terms of energy efficiency. The huge gap between the least developed economies and more advanced economies remains.

Also, the dynamics of energy consumption behave very differently across sectors. Figure 1.5 plots the $\mathrm{CO} 2$ emissions from combustion of fuels (as a proxy for energy consumption) for selected sectors over 1960 - 2013. The two largest CO2 emission sources are manufacturing and construction, and transport. The share of $\mathrm{CO} 2$ emissions from manufacturing and construction has declined significantly since 1960, but began to

\footnotetext{
${ }^{3}$ Over the same time period, the global GDP in 2015 has increased by about $130 \%$ compared to that in 1990 , and the global population has doubled as well, growing from about 3 billion in 1990 to more than 7 billion in 2015.

${ }^{4}$ The income group criteria are defined by the World Bank as follows: low income economies are those in which 2015 GNI per capita was US dollars 1025 or less; lower middle income economies are those in which 2015 GNI per capita was between US dollars 1026 and US dollars 4035; upper middle income economies are those in which 2015 GNI per capita was between US dollars 4036 and US dollars 12475; high income economies are those in which 2015 GNI per capita was US dollars 12476 or more.
} 
increase again in the years 2000s to the 1990 level. The share of CO2 emissions from transport has not fluctuated very much and has seen a small increase at the end of the period. A steep decrease is found in the share for residential buildings and commercial and public services, while the share for other sectors has been quite flat over the entire period.

The examples illustrated above document a variety of critical issues of sustainable development where energy efficiency is given a great attention. Although the aggregate statistics at the world level indicate a promising prospect of sustainable development that involves increasing energy efficiency, the further empirical investigations on the structure of global energy consumption and different types of countries and sectors clearly show the challenges of high dependency of fossil fuels and large discrepancies across countries and sectors. They suggest that sustainable development is a process that involves a wide range of dimensions and that tailored strategies or policies corresponding to these dimensions are strongly needed. However, there is a lack of datadriven and micro-founded studies of those detailed processes that are hidden in the aggregate dynamics.

This thesis therefore wants to fill this gap by providing rigorous and precise studies that are built on detailed information at both micro and macro levels using large datasets. Although there are many other fascinating aspects in the process of sustainable development, we pay a special attention to energy efficiency and the technologies involved, not only because of a concern of data availability as well as financial and time constraints, but also because energy is one of the most important inputs of economic activities. Furthermore, technological change and policy instruments can play central roles in the improvement of energy efficiency (Acemoglu et al., 2012; Allcott \& Mullainathan, 2010; Jaffe, Newell, \& Stavins, 2002). As a result, the dynamics of energy efficiency can reflect the evolution of technology in relevant fields and provide useful recipes for the design of development policies and strategies. We develop several statistical approaches and analytical frameworks on the basis of large datasets to answer the following fundamental research questions:

(1) How do the aggregate energy consumption, aggregate energy efficiency and technologies related to energy efficiency evolve as time progresses?

(2) What are the driving factors that affect the growth of aggregate energy consumption and aggregate energy efficiency across sectors, regions and economies? How do countries perform in the technological fields related to energy efficiency?

The aggregate energy consumption and aggregate energy efficiency in the first research question refer to these variables at the regional, sectoral and country levels. Unlike most prior studies on energy issues that use the aggregate data directly, in this thesis, we present a series of statistical methods that rigorously "construct" the aggregate 
variables of interest over time and their growth using big data on (1) transactions between various sectors and economies, and (2) technological characteristics and behaviors of micro-agents. On the other hand, we are also interested in the evolution of technology related to energy efficiency. To measure scientific and technological development, R\&D expenditure is commonly used but using this indicator would lead to systematic measurement problems (Adams \& Griliches, 1996; Griliches, 1988). A more suitable indicator of measuring technology is patent (Griliches, 1990) ${ }^{5}$, in particular for climate- or environment-related technologies (Haščič \& Migotto, 2015; Haščič, Silva, \& Johnstone, 2015). The citations built on patents can be a very useful measure of the "importance" of patents, for example, in terms of market value (B. H. Hall, Jaffe, \& Trajtenberg, 2005), which on the other hand implies that the value of a certain patent varies and can be precisely assessed. Additionally, patent citations, in fact, are a collection of complex and noisy signals of the presence of knowledge spillovers (Jaffe, Trajtenberg, \& Fogarty, 2000). Consequently, in this work we make use of the newly developed big data on patents and employ an optimization technique for citation networks, mainly based on the literature (J. S. Liu \& Lu, 2012; J. S. Liu, Lu, Lu, \& Lin, 2013; Verspagen, 2007). By doing so we successfully identify the most important or valuable patents and their citation relations from large and complex citation networks, which we define as technological trajectories, a notion used by (Dosi, 1982, 1988).

The purpose of the first research question is not to precisely forecast or predict the variables of interest in the future, but to better describe the historical and current dynamics, investigate crucial empirical patterns, and eventually lead to a comprehensive aggregate level of surveillance on critical indicators closely related to sustainable development. Quantifying the dynamics of aggregate energy consumption and aggregate energy efficiency further enables us to derive the proper expressions of their growth, which would be of great importance to have an in-depth understanding of the mechanism that leads to the dynamics at different levels, such as the following question: What are the driving factors that lead to differentials across sectors, regions and economies? Additionally, the analysis is helpful to answer the following related questions: Do regions and economies perform very differently in terms of energy consumption and energy efficiency? If so, is there a tendency for these gaps between regions and economies to narrow over time? To answer these questions, we adopt well-developed econometric methods (Barro, 1991; Barro \& SalaiMartin, 1991, 1992) and the distribution approach (Quah, 1993a, 1993b, 1996, 1997) from the research of convergence in development economics. Identifying the technological trajectories of energy efficiency technologies also allows us to understand countries' profiles in the relevant technological fields of interest, since the patent records we use have rich biographical and register

\footnotetext{
${ }^{5}$ In addition, Keller (2004) presents three widely used indirect approaches to measure technology: (1) inputs (R\&D), (2) outputs (patents), and (3) the effect of technology (higher productivity). In this thesis, the output approach is the preferred one.
} 
information. To do that we carefully analyze the patents related to the technological trajectories through citations, and design several measures for (1) whether a country can be classified as an incumbent or a latecomer country, (2) how much a country contributes to the technological development in the fields under research, and (3) how much a country is interested in the relevant technological fields.

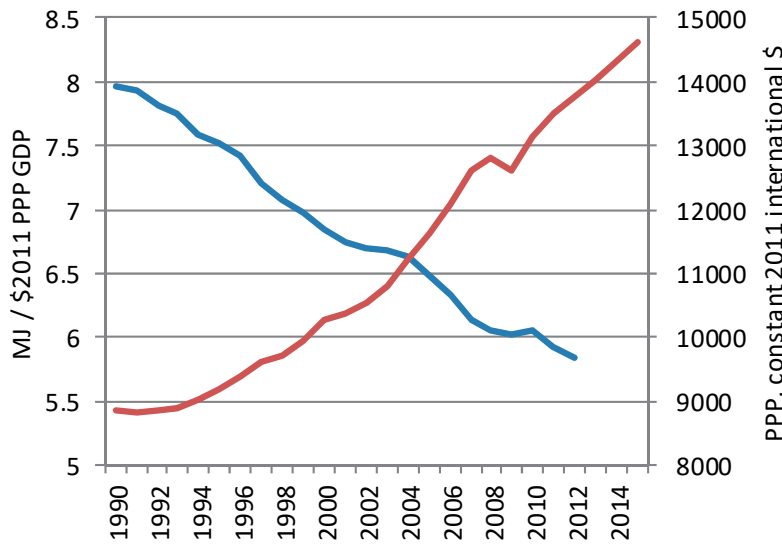

Energy intensity level of primary energy

GDP per capita

Figure 1.1 Global energy intensity and GDP per capita, 1990 - 2015

Source: World Development Indicators, the World Bank.

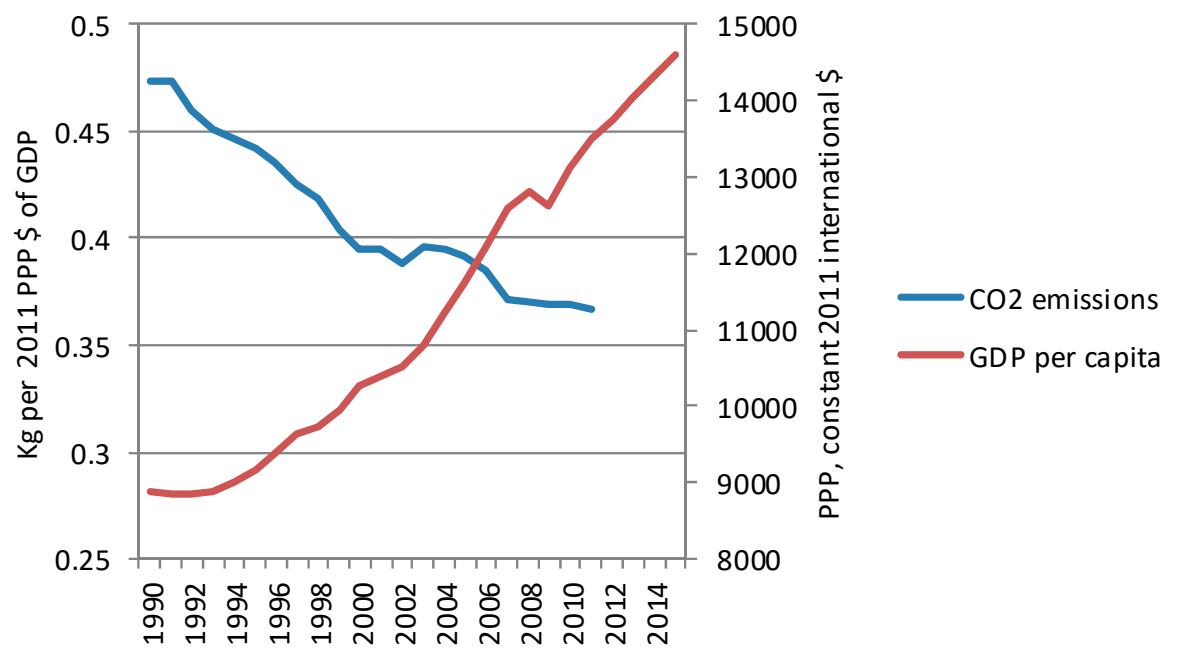

Figure 1.2 Global CO2 emission intensity and GPD per capita, 1990 - 2015

Source: World Development Indicators, the World Bank. 


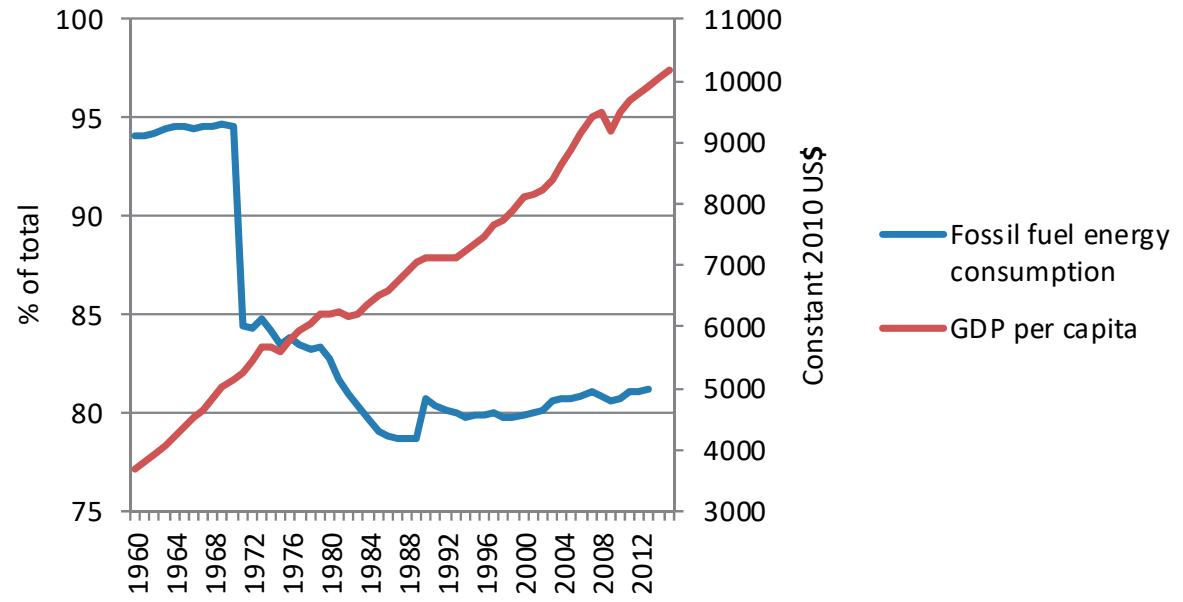

Figure 1.3 Global share of fossil fuel energy consumption and GDP per capita, 1960 - 2015

Source: World Development Indicators, the World Bank. Note that fossil fuel comprises coal, oil, petroleum, and natural gas products.

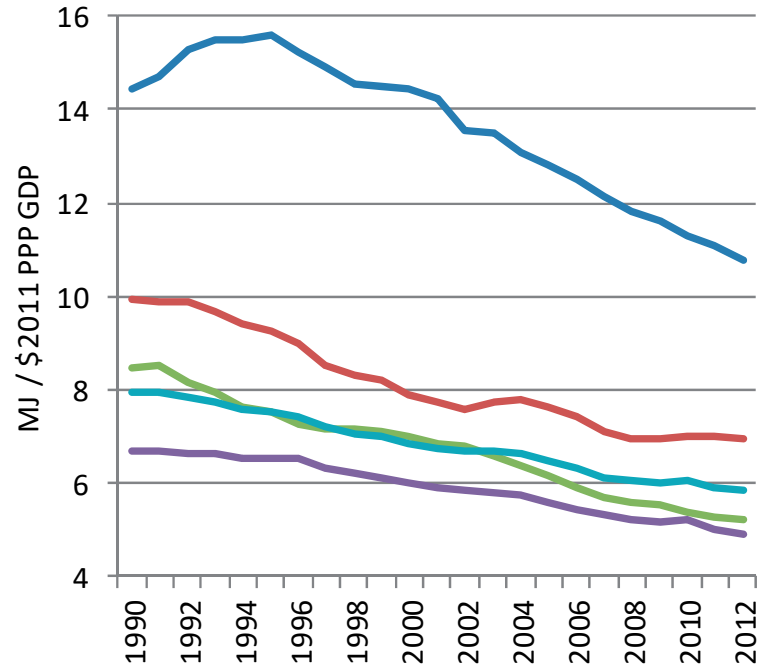

Low income

Upper middle income

Lower middle income

High income

World

Figure 1.4 Energy intensity by income group, 1990 - 2012

Source: World Development Indicators, the World Bank. 

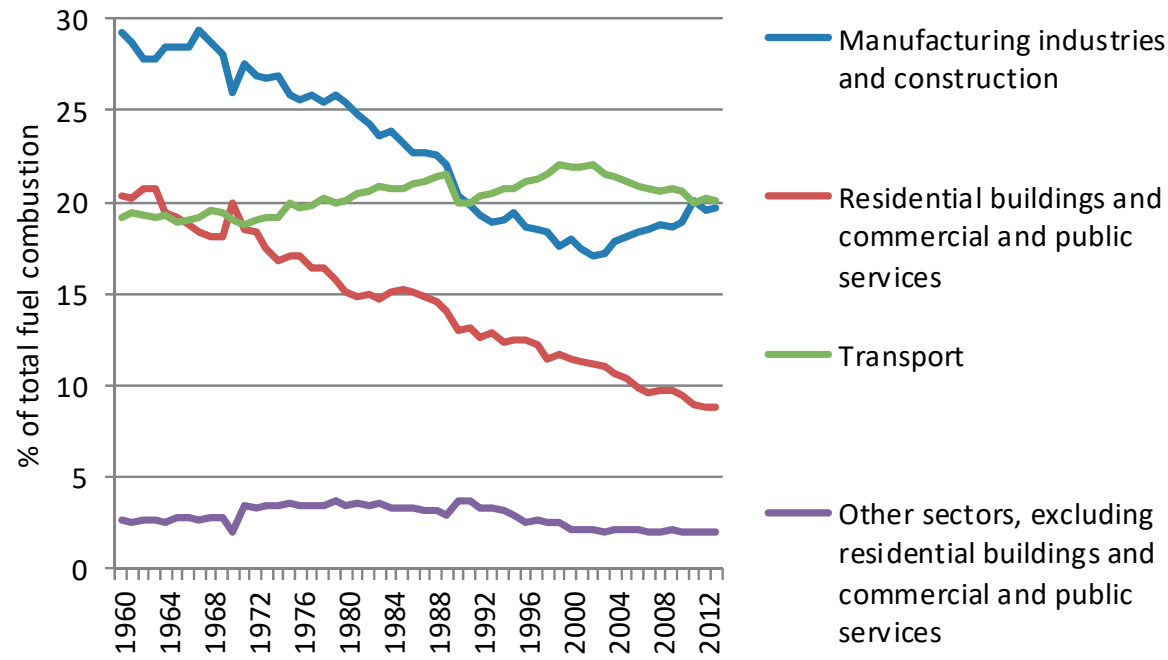

Figure 1.5 Selected sectors' shares of CO2 emissions, $1960-2013$

Source: World Development Indicators, the World Bank. Note that CO2 emissions from other sectors contain the emissions from commercial / institutional activities, residential, agriculture / forestry, fishing and other emissions not specified elsewhere that are included in the IPCC Source.

\subsection{ECONOMIC DEVELOPMENT AND ENVIRONMENTAL SUSTAINABILITY ${ }^{6}$}

The previous section has clearly outlined several stylized facts: hidden in the improvement of global energy efficiency, the performance in terms of energy efficiency significantly differs across sectors and income groups and the world still heavily relies on fossil fuels. Sustainable development not only means sustaining economic growth, but also achieving environmental sustainability. If the current stylized facts would persist in the future, the sustainable development targets would be fundamentally challenged and economic growth might be restricted under increasing resource constraints. The initial motivation of this thesis implies the basic relationship between economic development and environmental quality. Such a relationship has been heatedly debated in the literature. One of the most popular debates focuses on the link between income per capita and environmental quality at per capita level, i.e. the Environmental Kuznets Curve (EKC), an extension of Kuznets Curve. Dinda (2004) comprehensively reviews most influential theoretical developments and empirical studies concerning EKC. According to the EKC hypothesis, the environmental quality deteriorates in the early stage of development with the increase in income per capita, and then environmental quality starts

\footnotetext{
${ }^{6}$ This section is based on Chapter 2 "Energy Consumption, Energy Intensity and Economic Development between 1995 and 2009: A Structural Decomposition Approach". Part of Chapter 2 has been published in the UNIDO Inclusive and Sustainable Development Working Paper Series (see Zhong (2015)) and included in the UNIDO Industrial Development Report (2015).
} 
improving when income per capita reaches a certain level or a turning point. Intuitively, the EKC is an inverted U-shaped curve. One possible explanation of EKC is that people in less developed countries value material well-being (together with economic growth) over environmental quality, which leads to the consequence that environmental deterioration is regarded as an acceptable side effect in the early stage of economic development. When the living standard is sufficiently high (reflected by the increase in income per capita), people pay a greater attention to environmental amenities, which requires new regulations, policies and institutions for the protection of environment (Arrow et al., 1995). Dinda (2004) summarizes an alternative explanation that the progress of economic development leads to structural transformation: from agrarian economy to industrial economy to service economy (deindustrialization).

The pioneering work of Selden and Song (1994) substantiates the existence of the EKC and forecasts the increase in global emissions to study the link between four air pollutants and GDP per capita, based on the EKC hypothesis and a multi-national panel analysis. Grossman and Krueger (1995) empirically estimated the threshold per capita income of US dollars 8000 for several environmental indicators, demonstrating that economic growth would bring improvements in environmental quality once this threshold is met. A theoretical explanation for this is that in a static growth model in which a social planner chooses the technologies, the EKC makes sense as dirty technologies are used below the turning point while clean ones are applied once the threshold has been reached (Stokey, 1998). Also, this model suggests policies instruments such as a pollution tax and voucher system are useful to achieve the optimal utility of representative households in a single economy context. In addition, Copeland and Taylor (2004) present a model that can generate an EKC but under several strict assumptions such as neutral growth and a particular assumption on preferences.

One strand of literature has been questioning the existence of the EKC, typical examples including (Stern, 2004; Stern, Common, \& Barbier, 1996). Many studies find that the environment - development relationship is ambiguous, or that environmental quality is likely to continue to degrade. Copeland and Taylor (2004) review both theatrical and empirical work on the EKC and they are skeptical about the existence of a simple and predicable EKC. Holtzeakin and Selden (1995) focus on the global CO2 emissions and economic growth and find that the global emissions growth will continue because output and population will grow more rapidly in low income countries. De Bruyn, van den Bergh, and Opschoor (1998) discover that the time patterns of some emissions positively correlate with economic growth and that the reduction in emissions is a result of technological change. Stern and Common (2001) use a more globally representative dataset to explore the sulphur emissions-income per capita relationship and find that (1) the relationship is monotonic instead of inverted U-shaped, and (2) changes in emissions are time trend-related rather than income per capita-related. Moreover, many critics focus on the parametric econometric specifications employed by prior studies, 
which might be problematic for estimation (Millimet, List, \& Stengos, 2003), and develop semi-parametric or nonparametric approaches, for example, flexible semiparametric linear regression (Millimet et al., 2003), nonparametric kernel estimation with panel data (Azomahou, Laisney, \& Van, 2006) and the quantile fixed effect regression technique (Flores, Flores-Lagunes, \& Kapetanakis, 2014), pointing out that previous empirical findings about the EKC are extremely sensitive to parametric model specifications and that we are probably being too optimistic about the environmental quality improvements that can be achieved as income grows over time. More importantly, Andreoni and Levinson (2001) present a theoretical static model with microfoundations to study the environment - income relationship with a focus on technology. They ascertain that the reduction at per capita level of those pollutants following an inverted $U$-shaped relationship with income depends on increasing returns to scale in emission reduction technologies only. In other words, economic growth alone is not the solution to environmental deterioration. In fact, the environment-income relationship is not necessarily inverted $U$-shaped: it can assume an entirely different shape, depending on technology.

There might be a risk that policymakers erroneously interpret such an inverted Ushaped relationship as prioritizing economic growth over the environment, i.e., to "grow first, and then clean up" (Dasgupta, Laplante, Wang, \& Wheeler, 2002). If environmental deterioration is viewed as an acceptable side effect in the early stage of development, there is a risk that developing countries that use lax environmental regulations to attract FDI may end up with attracting less competitive firms (Dowell, Hart, \& Yeung, 2000). ${ }^{7}$ Modern industrial societies which heavily rely on fossil fuels are constantly generating new types of emissions, resulting in an increase of environmental risks. For example, the EKC hypothesis say nothing about the system-wide consequences that reductions in a certain pollutant in one country may be associated with increases in some other pollutants in the same country or even across countries (Arrow et al., 1995). Many influential theoretical or empirical studies on the EKC neglect the role of international trade (Copeland \& Taylor, 2004) and lots of institutional reforms and regulation concerning the environment ignore international and intergenerational consequences (Arrow et al., 1995). Moreover, according to growth theory, continuous improvements in technology, especially in those that increase input efficiency (e.g., energy) are likely to help the global economy overcome limitations to growth in the face of scarce and unrenewable resources (Grossman \& Helpman, 1994). More recently, Acemoglu et al. (2012) extend the notion of directed technological change (Acemoglu, 2002) into a growth model containing environmental constraints. They theoretically prove that sustainable development, a process in which directed technological change

\footnotetext{
${ }^{7}$ The developing countries that want to take advantage of lax environment regulations or standards are called "pollution havens". Eskeland and Harrison (2003) provide another related study on four developing countries showing that foreign firms in these four host countries are more energy efficient.
} 
towards clean inputs can play a crucial role, can be achieved if inputs are sufficiently substitutable. Further, their findings suggest that policy instruments (e.g., taxes and subsidies) should be intentionally designed (as soon as possible) to support innovations in clean inputs, because delay in invention would end up with a longer transition period and slow growth.

This section has reviewed the theoretical and empirical literature concerning the environment - development relationship and the related debates. In this thesis we empirically test this relationship. In Chapter 2, after obtaining the aggregate energy efficiency (both demand side and supply side) at the country level, we examine the relationship between economic development (as measured by GDP per capita) and energy efficiency by employing the Multilevel Mixed-Effect technique (MME) to estimate Grossman and Krueger (1995)'s classic specification. We therefore confirm a strictly decreasing relationship on both demand side and supply side. In Chapter 3 we are interested in the consumer market of energy-using durables. We test a wider range of socio-economic factors (e.g., household income and unemployment rate) that are associated with the distribution of vehicles, and the vehicles' staying or exiting decision.

\subsection{ENERGY EFFICIENCY PARADOX AND TECHNOLOGY}

The section above has reviewed the literature related to the environment - development relationship. It shows that both technology and policy play a crucial role. This section will focus on the technology aspect: the issues in technology diffusion and transition, the causes of energy efficiency gap and potential policy options. This work pays attention to the product life cycle of vehicles (Chapter 3). Instead of exploring the factors affecting technology diffusion, this thesis empirically assesses the contributions to the aggregate energy efficiency due to the introduction of new products (technologies) and the substitution of old ones. In Chapter 4, we manage to quantify the most important patents and their citation relations (technological trajectories) in three fields of interest: energy generation, vehicles and ICT in buildings.

Energy efficiency, in a narrow sense, can be viewed as a special productivity, since energy is one of the key inputs in economic activities. ${ }^{8}$ The most natural measure of energy efficiency is the ratio between useful (or desirable) output and energy input. Patterson (1996) provides a relatively well-rounded classification of energy efficiency, including: scientific indicator, economic-scientific indicator and pure economic indicator. Scientific indicator is usually described in the physical or thermodynamic sense:

\footnotetext{
${ }^{8}$ Roughly, energy used in the production and household can be distinguished as fossil fuels and renewable energy based on concerns of environmental sustainability, or can be disaggregated into primary energy (for example, oil, coal, natural gas, solar energy, wind power and so on), and secondary energy that is generated from primary energy, such as electricity.
} 
ratio between useful output (e.g., ton, enthalpy and kilometer) and input measured by thermodynamic unit. The economic - scientific indicator uses monetary value and sum of enthalpy to measure useful output and input respectively. The pure economic indicator applies monetary measures for both inputs and outputs. Energy efficiency, however, is a more generalized concept than productivity, because energy is not only used in the production process, but also consumed by non-production units such as vehicles, commercial and residential buildings. In describing the dynamics of energy efficiency, this work carefully takes into account the role of energy consumed by households in the entire economy system and pays a special attention to the energy efficiency of vehicles.

However, even though there are plenty of energy efficient technologies available in the market, they are not widely used by market agents like firms and consumers. In other words, the diffusion and adoption of energy efficient products are slow. For example, the market share of electric cars is very small (as shown in Chapter 3). More formally, this phenomenon is called energy efficiency gap or energy efficiency paradox which refers to the difference between the optimal level of energy efficiency and the actual level. ${ }^{9}$ Numerous academic studies have already documented this issue (Allcott \& Greenstone, 2012; Backlund, Thollander, Palm, \& Ottosson, 2012; Brown, 2001; DeCanio, 1998; Gillingham, Newell, \& Palmer, 2009; Gillingham \& Palmer, 2014; Jaffe, Newell, \& Stavins, 2005; Jaffe \& Stavins, 1994a, 1994b, 1994c). Then the question becomes how to define the optimal level. According to a most widely cited academic article by Jaffe and Stavins (1994a), there are five various dimensions of optimal level of energy efficiency: (1) narrow social optimum, which can be achieved under perfect market, (2) true social optimum, which can be obtained by justifying environmental externalities after reaching narrow social optimum, (3) economist's economic potential, which can be achieved by eliminating market failures for energy efficient technologies, (4) technologist's economic potential that is based on economist's economic potential, requires low discount rates and homogeneity of market agents, and (5) hypothetical potential which can be achieved by eliminating either market failures or market barriers. Furthermore, Backlund et al. (2012) propose a different optimal energy efficiency that includes energy management practice, and demonstrate that the energy efficiency potential is greater than if only the technological aspect is considered.

Of course, the diffusion of a new technology is generally gradual and the transition process is hindered by technical, economic and institutional barriers (Kemp \& Soete, 1992). It is of great importance to distinguish between incremental and radical innovations, because radical innovations are crucial for economic growth, especially for changes in trend growth (Fagerberg \& Verspagen, 2002), while decentralized market structure and difficulties in forecasting technological developments can restrict techno-

\footnotetext{
${ }^{9}$ For instance, according to UNIDO (2012), if current best practice technologies are adopted, energy efficiency gains can roughly yield US dollars 65 billion in developed countries and US dollars 165 billion in developing countries, which are approximately $23 \%$ of total annual industrial energy costs.
} 
logical advance (Bresnahan \& Trajtenberg, 1995). In a technological catching-up context, Triulzi (2015) summarizes three key general features that make technological change complex: uncertainty, interactions and path-dependence. In their focus on the choice between sticking current technology and switching to a better one, Jovanovic and Nyarko (1996) illustrate a theoretical model with micro-foundation, in which a switch of technologies would reduce the agent's expertise (the bigger the technological leap, the larger the loss in expertise). Consequently, the loss in expertise as well as the prospect of productivity drop prevents the agent from adopting a better but less familiar technology as quickly as he or she might (that is, "overtaking").

Table 1.1 Market and behavioral failures related to energy efficiency and potential policy responses

\begin{tabular}{|c|c|c|c|}
\hline \multicolumn{3}{|c|}{ Causes of energy efficiency gap } & \multirow{2}{*}{$\begin{array}{l}\text { Potential policy options } \\
\text { Emission pricing (tax, cap- } \\
\text { and-trade) }\end{array}$} \\
\hline Market failures & Energy market failures & Environmental externalities & \\
\hline & & Average-cost electricity pricing & $\begin{array}{l}\text { Real-time pricing; market } \\
\text { pricing }\end{array}$ \\
\hline & & Energy security & $\begin{array}{l}\text { Energy taxation; strategic } \\
\text { reserves }\end{array}$ \\
\hline & Capital market failures & Liquidity constraints & Financing; loan programs \\
\hline & $\begin{array}{l}\text { Innovation market } \\
\text { failures }^{10}\end{array}$ & R\&D spillovers & $\begin{array}{l}\text { R\&D tax credits; public } \\
\text { funding }\end{array}$ \\
\hline & & Learning-by-doing spillovers & $\begin{array}{l}\text { Incentives for early market } \\
\text { adoption }\end{array}$ \\
\hline & Information problems & $\begin{array}{l}\text { Lack of information; asymmetric } \\
\text { information }\end{array}$ & Information programs \\
\hline & & Principal-agent problems & \\
\hline & & Learning-by-using & \\
\hline \multirow[t]{2}{*}{$\begin{array}{l}\text { Behavioural } \\
\text { failures }\end{array}$} & \multicolumn{2}{|c|}{$\begin{array}{l}\text { Prospect theory, bounded rationality, Heuristic decision- } \\
\text { making }\end{array}$} & $\begin{array}{l}\text { Education; information; } \\
\text { product standards }\end{array}$ \\
\hline & \multicolumn{2}{|c|}{$\begin{array}{l}\text { Nonstandard preferences, nonstandard beliefs and } \\
\text { nonstandard decision-making }\end{array}$} & \\
\hline
\end{tabular}

Source: this table is cited and revised from Gillingham et al. (2009) and Gillingham and Palmer (2014).

Specially, in the field of energy efficiency, many articles focus on the reasons for energy efficiency gap. A classical explanation by Jaffe and Stavins (1994a) is that there are three kinds of influencing factors: market failure, market barriers and discount rates. ${ }^{11}$

\footnotetext{
${ }^{10}$ As summarized by Gillingham et al. (2009), R\&D spillovers and learning-by-doing spillovers may cause underinvestment in energy efficient technology. Since knowledge is a public good, both types of spillovers would lower the benefits of the firms that do R\&D and the costs for others that are not involved in R\&D activities without compensation. In addition, using a new energy efficient technology would produce knowledge about the technology (learning-by-using) and the knowledge may be accessible to others. Accordingly, the early users may have fewer incentives to adopt the new technology.

${ }^{11}$ Using data on both purchase and utilization of air conditioning equipment, Hausman (1979) demonstrates that consumers apply a relatively high implicit discount rate when doing trade off capital costs and expected
} 
DeCanio (1998) pays attention to the bureaucratic and organizational barriers, for example, the barriers to the access to capital. Kemp, Schot, and Hoogma (1998) provide a relatively well-rounded overview of relevant factors, such as technology limitation, government policy, cultural and psychological factors, demand factors (e.g., consumer preference, risk aversion and willingness to pay), supply side production factors (e.g., low incentives), infrastructure and maintenance (e.g., initial costs and sunk investment), and undesirable social and environmental effects of new technologies. Allcott and Greenstone (2012) state two types of market failures, which are, energy use externalities and investment inefficiencies (e.g., imperfect information). Two recent studies (Gillingham et al., 2009; Gillingham \& Palmer, 2014) comprehensively review extensive literature on energy efficiency gap and summarize the developments in this field, as shown in Table 1.1. In addition to market failures that are commonly addressed in prior studies, they provide a review of the causes of energy efficiency gap from a behavioral failure perspective, such as bounded rationality. Recently, using a novel identification strategy and high quality microdata on the U.S. secondhand vehicle market, Sallee, West, and Fan (2016) have provided some evidence that consumers fully recognize the value of the fuel economy. This finding is quite inspiring. Also, Table 1.1 presents several potential policy responses to the relevant causes of energy efficiency gap. In reality various causes might jointly lead to energy efficiency gap, depending on dynamic local circumstances, and accordingly the corresponding policy response might be a package mixed with different policy options. Table 1.1 reflects the complexity of the issue of energy efficiency gap. Though this work does not discuss any specific causes of energy efficiency gap or optimal policies, Table 1.1 provides a very useful guidance for further studies.

\subsection{POLICIES AND INITIATIVES ON ENERGY EFFICIENCY: AN OVERVIEW}

The focus of this section is on policy in a general sense that applies to a wide range of governments and organizations, including government policies, programs, funds, facilities and mechanisms. Unlike the previous section that shows general policy options corresponding to various causes of energy efficiency gap, this section provides an extensive review of recent policy efforts concerning energy efficiency that have been actually implemented (e.g., partners, regions or countries of implementation, timeframe, targets, cost and revenue, main services, etc.). Also, this section reviews some findings and debates in the literature relevant to specific policy implementation. Note that the policy may not necessarily lead to the desirable outcomes as expected. More importantly, in an evolutionary view, policy implementation is not the end of

operating costs (related to energy efficiency). The efficiency gap can be illustrated by the difference between the market discount rate and the consumer's implicit discount rate. 
policymaking. It is an ongoing and dynamic process: the effective policies that are currently implemented should also be updated to fit the changing circumstances (locally and globally). Though the design of specific optimal policy options is beyond the scope of this thesis, the methodological contributions and findings developed in this thesis can provide useful insights to assist policymakers in either designing or updating appropriate policies, for example, more precisely assessing the aggregate energy efficiency dynamics based on transactions across sectors and economies (demand side and supply side, Chapter 2), linking regional aggregate energy efficiency in the consumer market to technological characteristics, product life cycle and collective individual behaviors (Chapter 3) and quantifying technological trajectories and promising technological fields (Chapter 4). Moreover, the review of incumbent policies and literature is very useful for the policy implications of this thesis. In the literature the crucial role of government in technological change (in particular in the fields of environment and energy efficiency) has been extensively documented. Newell, Jaffe, and Stavins (1999) augment the Hicks's induced innovation hypothesis by introducing government regulations and find evidence that both energy prices and government regulations have affected the energy efficiency of energy-using durables such as air conditioners and gas water heaters and the direction of innovation. ${ }^{12}$ Jaffe et al. (2002) present an overview of the theoretical and empirical advances of the relations between policy and technological change. By generalizing the notion of directed technical change (Acemoglu, 2002), Acemoglu et al. (2012) show that directed innovation towards clean inputs requires optimal policy instruments such as carbon tax and research subsidy.

There is a very large literature investigating potential policy options concerning energy efficiency (Fischer \& Newell, 2008; Gillingham, Newell, \& Palmer, 2006; Gillingham et al., 2009; Gillingham \& Palmer, 2014; Hassett \& Metcalf, 1995; Jaffe \& Palmer, 1997; Jaffe, Peterson, Portney, \& Stavins, 1995; Jaffe \& Stavins, 1994b, 1995). As illustrated in Table 1.1, Gillingham et al. (2009) extensively review the literature in this field and summarize relevant tailored policy options. In fact, R\&D subsidy is the most widely used way of policy intervention (Allcott \& Mullainathan, 2010; Kemp et al., 1998) and governments have invested a lot in energy efficient technology related R\&D. Recent data on energy technology related R\&D provided by International Energy Agency (IEA) show that 29 IEA countries have spent about US dollars 200.9 billion on energy technology related R\&D over 2000 to 2013, which were mainly provided by governments. However, R\&D related policy intervention is the second-best approach (Allcott \& Greenstone, 2012) and there is something more that policy can do: (1) policymakers should pay more attention to those policies or programs which have higher potential impacts on market agents' behaviors; (2) governments should provide market incentives and information disclosure (Allcott \& Mullainathan, 2010).

\footnotetext{
${ }^{12}$ However, there is still a sizable portion of autonomous improvements in energy efficiency.
} 
The implementation of policy that aims to promote energy efficiency is costly. Jaffe et al. (1995) propose several critical aspects of measuring environmental regulation, mainly including the on-budget costs of administering (e.g., monitoring and enforcing) the policies and regulations, the costs associated with regulatory compliance, other direct costs (such as legal and transaction costs, the effect of refocused management attention and the risk of disrupted production) the transition costs of economies responding to regulatory changes, potential substantial social impacts on jobs and economic security, and potential "negative costs" (the additional benefits such as productivity gains and innovation-simulating effects). Arrow et al. (1996) emphasize the important role of benefit-cost analysis in the legislative and regulatory policymaking process related to the environment. Daily et al. (2000) suggest that ecosystems can be viewed as capital assets and the wisely designed valuation methods are useful for policymaking regarding the environment. Allcott and Greenstone (2012) show a series of policies, regulations or government programs that are actually implemented in the United States, as shown in Table 1.2. Also, they provide the information of cost and revenue of these policies. Some policies are very costly. For example, US dollars 10 billion annual incremental cost has been spent on the Corporate Average Fuel Economy Standards since $1978 .{ }^{13}$ Still, for some regulations (e.g., Residential and Commercial Building Codes), the actual cost is unknown, especially under the measurement framework suggested by Jaffe et al. (1995).

On the other hand, it is very difficult to precisely evaluate the actual benefits or impacts due to the implemented policies and programs. Variable credibility and unobserved factors like hidden costs and benefits make it too difficult to empirically access the magnitude of energy efficiency. Considering the facts that lots of resources have been invested while many previous studies have been done at aggregate level employing normal econometric techniques, new econometric methods such as randomized controlled trials and quasi-experimental techniques should be applied to investigate impacts of energy efficiency related policies or programs on heterogeneous types of consumers (Allcott \& Greenstone, 2012). Currently, relatively less is known at the micro level. A recent research project (Allcott, 2011) applies a method called randomized natural field experiments to collect a very large sample of data across the United States (in total 600000 households in the treatment and control group), investigate the consequences of a series of energy efficiency improving programs on households' energy consumption behaviors, and obtains some crucial findings: (1) on average such programs can only reduce $2 \%$ of the energy consumption; (2) non-price interventions can have similar effects with short-run increase in electricity price, changing consumers' behavior effectively, but require less program costs; and (3) heterogeneity of consumers (for example, consumers with different social norms) cannot be ignored because

\footnotetext{
${ }^{13}$ Due to the 1973 oil crisis, the U.S. established the Energy Policy and Conservation Act of 1975 and since then a series of crucial energy efficiency related policies have been implemented.
} 
they significantly respond to such programs. Similarly, Ayres, Raseman, and Shih (2013) conducted two field experiments on a sample of about 75000 households in the United States, to explore impacts of two energy saving related programs (the difference between them is information disclosure: whether the program provides a household energy consumption information of its nearby neighbors) and confirm the importance of information disclosure in terms of reducing energy usage. Unlike the studies using randomized experiments or quasi-experimental methods, this thesis approaches the heterogeneity issue by using large datasets.

Table 1.2 Selected U.S. energy efficiency related policies

\begin{tabular}{|c|c|c|}
\hline Policy & Period & Cost \& Revenue \\
\hline $\begin{array}{l}\text { Corporate Average Fuel Economy } \\
\text { Standards }\end{array}$ & 1978-Present & $\begin{array}{l}\text { US dollars } 10 \text { billion annual } \\
\text { incremental cost }\end{array}$ \\
\hline Federal Hybrid Vehicle Tax Credit & $2006-2010$ & US dollars 426 million annual credit \\
\hline Gas Guzzler Tax & 1980-Present & US dollars 200 million annual revenues \\
\hline $\begin{array}{l}\text { Federal Appliance energy Efficiency } \\
\text { Standards }\end{array}$ & 1990-Present & $\begin{array}{l}\text { US dollars } 2.9 \text { billion annual } \\
\text { incremental cost }\end{array}$ \\
\hline $\begin{array}{l}\text { Residential and Commercial Building } \\
\text { Codes }\end{array}$ & 1978-Present & Unknown \\
\hline $\begin{array}{l}\text { Electricity Demand-Side Management } \\
\text { Programs }\end{array}$ & t1978-Present & US dollars 3.6 billion annual cost \\
\hline Weatherization Assistance Program & 1976-Present & US dollars 250 million annual cost \\
\hline 2009 Economic Stimulus & $2009-2011$ & US dollars 17 billion in total \\
\hline
\end{tabular}

Source: own elaboration based on Allcott and Greenstone (2012).

In recent years, energy efficiency has gained great support and has been recognized as a key element in the design of development policies and strategies across governments and international organizations. UNDESA (2012) provides an overview of government policies or initiatives relevant to energy efficiency, as shown in Table 1.3. Specifically, in 2005 the Chinese government legislated on promoting renewable energy and later after the legislation, a series of policies were created (Wang, Yin, \& Li, 2010). For example, the Mid- and Long-Term Plan for Renewable Energy Development was established in 2007. According to these policy documents, the share of renewable energy consumption in total energy consumption should be increased by $20 \%$ by 2020 . When the Renewable Energy Law was established in 2005, renewable energy accounted for around $7.1 \%$ in energy consumption in China. The consequences of these policies are impressive. For instance, wind power capacity installation grew at the rate of over $200 \%$ every year over the period 2006 to 2008 without interruption. The European Union, as a whole institution, made its early step towards improving energy efficiency in 2006 through the "Energy Services Directive" (ESD), aiming at reducing energy usage at the rate of $9 \%$ by 2016 in EU's non-trading part (Backlund et al., 2012). Similarly, the European Commission (2010) announced energy efficiency as one of its policy priorities, 
and aimed at improving 20\% energy efficiency by 2020, also known as the "EU 20-20-20 Strategy". The expected benefits of the EU 20-20-20 Strategy are quite attractive: if it was well implemented, EU countries could spend EUR 60 billion less in importing fossil fuels such as oil and natural gas by 2020 , adding an additional $0.6 \%$ to $0.8 \%$ GDP gains, and create around 600000 to 1 million new jobs in the EU. At the international level, cooperation between governments and organizations on the environment and energy efficiency has made a great progress ${ }^{14}$, through the 1997 Kyoto Protocol and the 2016 Paris Agreement for example. Concerning technologies related to the environment and energy efficiency, the OECD has recently proposed a list of patents that contribute to environment protection, titled as "Search Strategies for the Identification of Selected Environment-Related Technologies" (ENV-TECH) (Haščič \& Migotto, 2015). Specifically, in this work, we successfully quantify the technological trajectories for the energy efficiency technologies listed in the OECD ENV-TECH list. Moreover, in the field of international trade, the OECD and APEC have proposed their lists of environmental goods (Steenblik, 2005; Sugathan, 2013). ${ }^{15}$ Under the WTO framework, however, the negotiation of a widely accepted list of environmental goods is still ongoing.

Table 1.3 Selected policy documents related to energy efficiency

\begin{tabular}{|c|c|}
\hline Organization / country & Name \\
\hline United Nations (2015) & Transforming our World: The 2030 Agenda for Sustainable Development \\
\hline $\begin{array}{l}\text { European Commission } \\
\text { (2010) }\end{array}$ & Europe 2020: A European strategy for smart, sustainable and inclusive growth \\
\hline Federal Democratic & Ethiopia's Climate - Resilient Green Economy \\
\hline \multicolumn{2}{|l|}{ Republic of Ethiopia (2011) } \\
\hline $\begin{array}{l}\text { The Government of UK } \\
\text { (2011) }\end{array}$ & $\begin{array}{l}\text { Enabling the Transition to a Green Economy: Government and business working } \\
\text { together }\end{array}$ \\
\hline French Republic (2010) & National Sustainable Development Strategy: Towards a Green \& Fair Economy \\
\hline Republic of Korea (2009) & Road to Our Future: Green Growth \\
\hline $\begin{array}{l}\text { Statistics Netherlands } \\
\text { (2009) }\end{array}$ & Green Growth in the Netherlands \\
\hline UNCTAD (2010) & $\begin{array}{l}\text { Promoting poles of clean growth to foster the transition to a more sustainable } \\
\text { economy }\end{array}$ \\
\hline $\begin{array}{l}\text { The State Council of the } \\
\text { People's Republic of China } \\
\text { (2011) }\end{array}$ & China's 12th five-year plan \\
\hline
\end{tabular}

Source: own elaboration based on UNDESA (2012).

\footnotetext{
${ }^{14}$ However, such an international cooperation may have negative impacts. Babiker (2005) finds evidence that due to the 1997 Kyoto Protocol, there is a significant relocation of energy-intensive industries away from OECD countries, which leads to higher actual global emissions. A careful evaluation of relevant policies and initiatives is needed.

15 These two lists contain different environmental goods. Steenblik (2005) and Sugathan (2013) provide a comparison between the two lists.
} 
In the United Nations system, energy efficiency has been given an increased level of attention, which indicates a change in development strategies. In the Millennium Development Goals (United Nations, 2000), energy efficiency was actually not declared as a goal, while in the newer Sustainable Development Goals (United Nations, 2015), energy efficiency is explicitly identified as a target in Goals 7, 8, 9, 11 and 12, as illustrated in Table 1.4 below. Note that energy efficiency is not only a target set in Goal 7 (affordable and clean energy), but also generalized into the goals about decent job, infrastructure, industrialization, cities and human settlements, and consumption and production. Likewise, across numerous international organizations, lots of resources and policy efforts have focused on energy efficiency. Table 1.5 lists some selected global programs, funds, facilities and mechanisms related to energy efficiency. Among these diverse programs, various international partners are involved and the common services are capacity building (e.g., advisory services and technical assistance) and finance. As stated above, however, the actual costs and the impacts (or benefits) of these programs may be very difficult to estimate. The international cooperation also plays a key role in these programs.

Table 1.4 Energy Efficiency in the United Nations Sustainable Development Goals (SDGs)

Sustainable Development Goal
Goal 7: Affordable and clean energy. Ensure
access to affordable, reliable, sustainable and
modern energy for all.

Target

\section{Target 7.3}

By 2030, double the global rate of improvement in energy efficiency.

Target 7.a

By 2030, enhance international cooperation to facilitate access to clean energy research and technology, including renewable energy, energy efficiency and advanced and cleaner fossil-fuel technology, and promote investment in energy infrastructure and clean energy technology.

Goal 8: Decent work and economic growth.

Target 8.4

Promote sustained, inclusive and sustainable economic growth, full and productive employment and decent work for all.

Improve progressively, through 2030, global resource efficiency in consumption and production and endeavor to decouple economic growth from environmental degradation.

Goal 9: Industry, innovation and infrastructure. Build resilient infrastructure, promote inclusive and sustainable industrialization and foster innovation.

Target 9.4

By 2030, upgrade infrastructure and retrofit industries to make them sustainable, with increased resource-use efficiency and greater adoption of clean and environmentally sound technologies and industrial processes, with all countries taking action in accordance with their respective capabilities.

Goal 11: Sustainable cities and communities. Make cities and human settlements inclusive, safe, resilient and sustainable.

\section{Target 11.b}

By 2020, substantially increase the number of cities and human settlements adopting and implementing integrated policies and plans towards inclusion, resource efficiency, mitigation and adaptation to climate change, resilience to disasters, and develop and implement. 


\begin{tabular}{ll}
\hline Sustainable Development Goal & Target \\
\hline Goal 12: Responsible consumption and & Target 12.2 \\
production. Ensure sustainable consumption & By 2030, achieve the sustainable management and efficient \\
and production patterns. & use of natural resources. \\
& Target 12.c \\
& Rationalize inefficient fossil-fuel subsidies that encourage \\
& wasteful consumption by removing market distortions. \\
\hline
\end{tabular}

Source: own elaboration based on United Nations $(2015)^{16}$.

Table 1.5 Selected global programs, funds, facilities and mechanisms related to energy efficiency

\begin{tabular}{|c|c|c|c|}
\hline Name & Main Partner & Service & Timeframe \\
\hline Green Economy Imitative & UNEP & $\begin{array}{l}\text { Capacity building (advisory } \\
\text { services and technical } \\
\text { assistance) and research }\end{array}$ & 2008 - ongoing \\
\hline $\begin{array}{l}\text { Green Economy Joint } \\
\text { Programme }\end{array}$ & $\begin{array}{l}\text { UNDP, UNEP, UNDESA, } \\
\text { the Government of } \\
\text { Netherlands }\end{array}$ & $\begin{array}{l}\text { Capacity building (technical } \\
\text { assistance), information } \\
\text { exchange / awareness raising } \\
\text { and research }\end{array}$ & $\begin{array}{l}\text { The first phase in } \\
2012 \text { and the second } \\
\text { phase for } 2013- \\
2014\end{array}$ \\
\hline $\begin{array}{l}\text { Low-Emission Capacity } \\
\text { Building Programme }\end{array}$ & $\begin{array}{l}\text { UNDP, European } \\
\text { Commission, the } \\
\text { Government of Germany } \\
\text { and the Government of } \\
\text { Australia }\end{array}$ & $\begin{array}{l}\text { Capacity building (advisory } \\
\text { services and technical } \\
\text { assistance), knowledge } \\
\text { management }\end{array}$ & $2011-2015$ \\
\hline Green Industry Initiative & UNIDO & $\begin{array}{l}\text { Capacity building, awareness } \\
\text { raising / knowledge } \\
\text { management and research }\end{array}$ & 2010 - ongoing \\
\hline $\begin{array}{l}\text { Green Jobs Initiative and } \\
\text { Green Jobs Programme }\end{array}$ & ILO, UNEP, ITUC and IOE & $\begin{array}{l}\text { Capacity building (advisory } \\
\text { services, technical assistance } \\
\text { and training), knowledge } \\
\text { management }\end{array}$ & $2012-2015$ \\
\hline $\begin{array}{l}\text { Joint Commitment to } \\
\text { Sustainable Transport }\end{array}$ & $\begin{array}{l}\text { Multilateral Development } \\
\text { Banks }\end{array}$ & Capacity building and finance & $2012-2022$ \\
\hline Clean Energy Programme & Asian Development Bank & $\begin{array}{l}\text { Finance, matching services and } \\
\text { technology transfer }\end{array}$ & 1995 - ongoing \\
\hline $\begin{array}{l}\text { Energy Sector } \\
\text { Management Assistance } \\
\text { Program }\end{array}$ & World Bank & $\begin{array}{l}\text { Capacity building (technical } \\
\text { assistance, toolkits and best } \\
\text { practice), information } \\
\text { exchange and research }\end{array}$ & 1983 - ongoing \\
\hline Sustainable Energy For All & UN & $\begin{array}{l}\text { Framework for action, } \\
\text { information exchange }\end{array}$ & 2011 - ongoing \\
\hline
\end{tabular}

\footnotetext{
${ }^{16}$ See also United Nations Sustainable Development Knowledge Platform. Available at https://sustainabledevelopment.un.org/sdgs
} 


\begin{tabular}{|c|c|c|c|}
\hline Name & Main Partner & Service & Timeframe \\
\hline $\begin{array}{l}\text { 10-Year Framework of } \\
\text { Programmes on } \\
\text { Sustainable Consumption } \\
\text { and Production }\end{array}$ & $\begin{array}{l}\text { UNEP and other UN } \\
\text { agencies }\end{array}$ & $\begin{array}{l}\text { Capacity building (technical } \\
\text { assistance, advisory services), } \\
\text { finance, technology transfer, } \\
\text { information services } \\
\text { (information exchange, } \\
\text { knowledge management) }\end{array}$ & 2012 - ongoing \\
\hline $\begin{array}{l}\text { OECD Green Growth } \\
\text { Programme }\end{array}$ & OECD & $\begin{array}{l}\text { Capacity building (technical } \\
\text { assistance, advisory services, } \\
\text { tools/best practice), research }\end{array}$ & 2011 - ongoing \\
\hline $\begin{array}{l}\text { Global Environment Facility } \\
\text { (GEF) }\end{array}$ & $\begin{array}{l}\text { GEF agencies: World Bank, } \\
\text { UNDP, UNEP, ADB, AfDB, } \\
\text { EBRD, FAO, IADB, IFAD, } \\
\text { UNIDO }\end{array}$ & Finance & 1991 - ongoing \\
\hline $\begin{array}{l}\text { Special Climate Change } \\
\text { Fund }\end{array}$ & UNFCCC and GEF agencies & Finance & 2006 - ongoing \\
\hline $\begin{array}{l}\text { Strategic Priority for } \\
\text { Adaptation }\end{array}$ & GEF agencies & Finance & $2004-2010$ \\
\hline $\begin{array}{l}\text { Clean Technology Fund } \\
\text { Strategic Climate Fund } \\
\text { The Pilot Program for } \\
\text { Climate Resilience } \\
\text { Program for Scaling-Up } \\
\text { Renewable Energy in Low } \\
\text { Income Countries }\end{array}$ & $\begin{array}{l}\text { World Bank and Multilateral } \\
\text { Development Banks }\end{array}$ & Finance and capacity building & 2008 - ongoing \\
\hline $\begin{array}{l}\text { Global Energy Efficiency } \\
\text { and Renewable Energy } \\
\text { Fund }\end{array}$ & EU & Finance & 2008 - ongoing \\
\hline
\end{tabular}

Source: own elaboration based on UNDESA (2013).

\subsection{THESIS OUTLINE}

Sustainable development is a process involving many important dimensions and its study requires efforts from researchers from all the disciplines of natural and social sciences. As economists, we believe that energy efficiency is a key element in the pursuit of sustainable development, while its dynamics is an evolutionary process that involves industries, technologies and institutions. Therefore, it requires a wide range of policies, aimed at both macro and micro levels. It is of primary importance to have a careful economic study of all the detailed processes that are involved in the policyrelevant areas. As shown in the sections above, numerous programs, funds, facilities related to energy efficiency have been implemented and are still ongoing. As an early step, we narrow down our research at micro and macro levels to energy in trade (sectoral and country levels), aggregate vehicle energy efficiency (regional level) and the 
technologies related to energy efficiency in the fields of power station, ICT in buildings and vehicles. We hope that our results can shed light on the relevant policies and studies in the future.

Using large datasets, this dissertation provides a comprehensive narrative of how energy efficiency and the technologies related to energy efficiency evolve. We develop a new analytical framework and several measures for crucial factors affecting energy consumption and energy efficiency in trade at sectoral and country levels. Based on big data, we design an empirical statistical approach to estimate regional aggregate vehicle energy efficiency that is formed by the technological characteristics and collective behaviors of micro-agents, and describe the life cycle and restructuring of the vehicle population. Also, we identify the technological trajectories of technologies related to energy efficiency, and develop some measures for whether a country can be classified as an incumbent country or a latecomer country, and for how much a country contributes to technological development. The approaches used in this dissertation that build aggregate or macro measures on the basis of detailed and micro large datasets are of great value for the study of economic, industrial and scientific evolution. The optimal path method in this dissertation based on the patent citation networks may inspire studies in any other technological fields, and enable policymakers as well as investors to monitor technological development and discover business opportunities. The precise empirical evidence provided by this dissertation can assist policymakers in finding tailored solutions to the real world problems. The outline of this thesis is as follows.

Chapter 2 reviews the decomposition techniques commonly used in energy and environmental economics, and proposes a new decomposition method in the input-output framework to identify crucial factors affecting the growth of energy consumption and energy efficiency. We take into account trade relations and intermediate inputs in production that are mostly neglected by traditional methods. Unlike prior studies, we develop two perspectives: energy directly used for production or household consumption purposes, and energy embodied in the products consumed by economies and households. We also apply the analysis to all the major economies and sectors in the world.

The methods used in Chapter 3 are developed based on firm productivity literature and convergence analysis in development economics. We particularly focus on vehicles, a typical durable product consuming energy. By tracking every vehicle, we estimate regional aggregate vehicle energy efficiency based on the usage and energy efficiency of every individual vehicle. By doing so, we do not have the issues of heterogeneity and representative agent. We also estimate the entry effect of new vehicles, the reallocation of energy efficiency vehicles and the Ergodic distribution of aggregate vehicle energy efficiency. The availability of the big data makes this paper one of first few papers estimating regional energy efficiency for vehicles. 
In Chapter 4, using up-to-date bibliographical and citation information of patents from the European Patent Office, we study the technological evolution of three fields on energy efficiency classified by the OECD ENV-TECH list: power station, ICT in buildings and vehicles. We construct patent citation datasets for these fields, and identify the optimal technological paths by maximizing total search pair count (SPC) weights in the citation networks. We also develop new measures to evaluate countries' role (incumbent or latecomer) and contribution in these fields. This paper is an early attempt of quantifying technological development of the OECD ENV-TECH list. The methods used in this chapter can be applied to any other fields. 
Chapter

Energy Consumption, Energy Intensity and Economic Development between 1995 and 2009: A Structural Decomposition Approach 
Abstract: Using over 68 million data points from the World Input-Output Database (WIOD) over 1995 to 2009 in both current prices and previous years' prices, this article (1) quantitatively assesses six influencing factors at economy level and five factors at sectoral level that cause dynamics of aggregate energy consumption and aggregate energy intensity across 35 sectors and 41 major economies in the world by employing structural decomposition techniques and chain mechanism for deflating; (2) analyzes the convergence of energy intensity at economy level, and (3) applies Multilevel MixedEffect model (MME) to investigate the relationship between energy intensity and economic development. At economy level the main findings both on supply side and demand side include (1) compensation effect in energy consumption caused by energy intensity change and final demand change; (2) small trade effect in intermediate inputs in energy consumption; (3) the crucial role of reducing energy intensity within sectors through energy efficiency related technological change in the pursuit of sustainable development; (4) convergence trend of energy intensity; and (5) strictly decreasing relationship between energy intensity and GDP per capita. At sectoral level, the compensation effect in energy consumption decompositions, the small trade effect in intermediate inputs, and the crucial role of intensity effect within sectors still hold. Policy implications and further studies are briefly discussed.

Keywords: Structural Decomposition Analysis, Energy Consumption, Energy Intensity, Convergence, Multilevel Mixed-Effect Model.

This study was supported by the United Nations Industrial Development Organization (UNIDO). Part of this paper has been published as UNIDO Inclusive and Sustainable Development Working Paper Series 11/2015. This paper was presented in the 2014 ISEO Summer School in Iseo, Italy (chaired by Sir James Mirrlees) and the $6^{\text {th }}$ Spanish Conference on Input-Output Analysis at the University of Barcelona, Spain. 


\subsection{INTRODUCTION}

The major part of global energy consumption is unrenewable fossil fuel. The continuously increasing global demand for energy, especially in developing countries, implies that the world at large faces challenges with respect to sustainable development. For instance, China's use of primary energy noticeably rose by over 109\% between 1995 and $2009^{17}$. The increasingly large amount of energy consumption has already brought environmental pressures on societies across the world. Energy efficiency, which is widely considered to be the solution to problems caused by growing energy consumption, has been generally promoted in policy documents (European Commission, 2010; UNIDO, 2012). Applying best practice technologies to industries can not only yield $23 \%$ energy savings from US dollars 1 trillion global annual industrial energy costs, but can also significantly reduce $\mathrm{CO}_{2}$ emissions and fossil fuel dependence, and lead to productivity gains, new employment, better health and working conditions (UN-Energy, 2009; UNIDO, 2012).

Some remarkable efforts have been made already. In 2005 the Chinese government introduced legislation on promoting renewable energy. In the same year the U.S. Energy Policy Act of 2005 was signed into law. The European Commission (2010) announced energy efficiency as one of its policy priorities, and aimed at improving by $20 \%$ energy efficiency by 2020. But such policies are not the end in themselves: they should be wisely implemented and updated in the long run. Two questions are therefore of great importance and interest in policy making and updating: (1) what are the influencing factors that drive the dynamics of energy consumption and energy efficiency differentials across various economies and sectors? (2) What are the relationships between energy intensity and economic development?

The latter of these questions poses a fundamental dilemma in development. The prospect of developing the less-developed economies in the world promises to provide access to material well-being to important parts of the global population, who have been denied decent living standards so far. The well-known examples include the United Nations Millennium Development Goals and Sustainable Development Goals (United Nations, 2000, 2015). However, if the basic relationship between energy consumption and material well-being that we observe in the world today would persist, developing the less-developed world also implies a trend in energy demand that is unsustainable, given the global energy supplies and the context of greenhouse gasses and climate change.

The current paper wants to contribute to analyzing this dilemma by outlining the salient trends, over the last decade and a half, in the interconnection between development (interpreted here in a narrow context, i.e., growth of average living standards in a coun-

\footnotetext{
${ }^{17}$ Source: the World Input-Output Database (WIOD).
} 
try) and energy consumption. The backward-looking perspective is not intended to be used for extrapolation, or prediction of future trends for any specific economy or sector. Instead, the analysis looks at past trends in order to identify which trend-breaks are necessary for policymakers to focus on. Thus, we ask what the main drivers in the trends of energy consumption are, and what they would imply for a scenario in which material well-being in the global economy would become more equally distributed.

In outlining trends in energy consumption (and energy efficiency), one may take two different perspectives about where energy use should be attributed. One perspective, which is easiest to apply given the way in which international statistics are collected, is to allocate energy use to production. In this view, energy use is attributed to the country where energy is actually used, either in the production of goods and services, or directly by end-users (consumers). The other perspective is to allocate energy use embedded in the products consumed by countries and households. This is a perspective that is taken in the calculation of so-called "energy footprints", which is similar to the concept of emissions embodied in trade (Hertwich \& Peters, 2009; Kanemoto, Lenzen, Peters, Moran, \& Geschke, 2012; Kanemoto, Moran, Lenzen, \& Geschke, 2014; Wiedmann, Lenzen, Turner, \& Barrett, 2007; Xu \& Dietzenbacher, 2014). Here, it does not matter where a good is produced, and hence where the energy is actually used, but instead it matters where the goods (or services) that use energy are consumed. A simple example illustrates the difference between these two perspectives: because China has become "the factory of the world", it seems likely that an important part of the energy that is used in manufacturing in China actually leaves a footprint in many other countries, to which China exports consumer goods. These two perspectives are similar to the production- and consumption-based accounting in $\mathrm{CO} 2$ emissions presented by Chang (2013). Figure 2.3 summarizes these two perspectives.

The distinction is captured here by distinguishing between supply side energy consumption and demand side energy consumption. Supply side energy consumption is defined as the energy used for production purposes and consumed directly by households (production-based accounting); and demand side energy consumption stands for the energy embodied in the products consumed by economies and households (consumptionbased accounting). An example of selected economies is shown in Figure 2.1. Although China's supply side energy consumption started to accelerate in 2001 and had already overtaken that of the EU and USA, China still consumed much less energy on the demand side. Accordingly, if any of the two sides was neglected, the findings might be adversely misleading to policy making. 

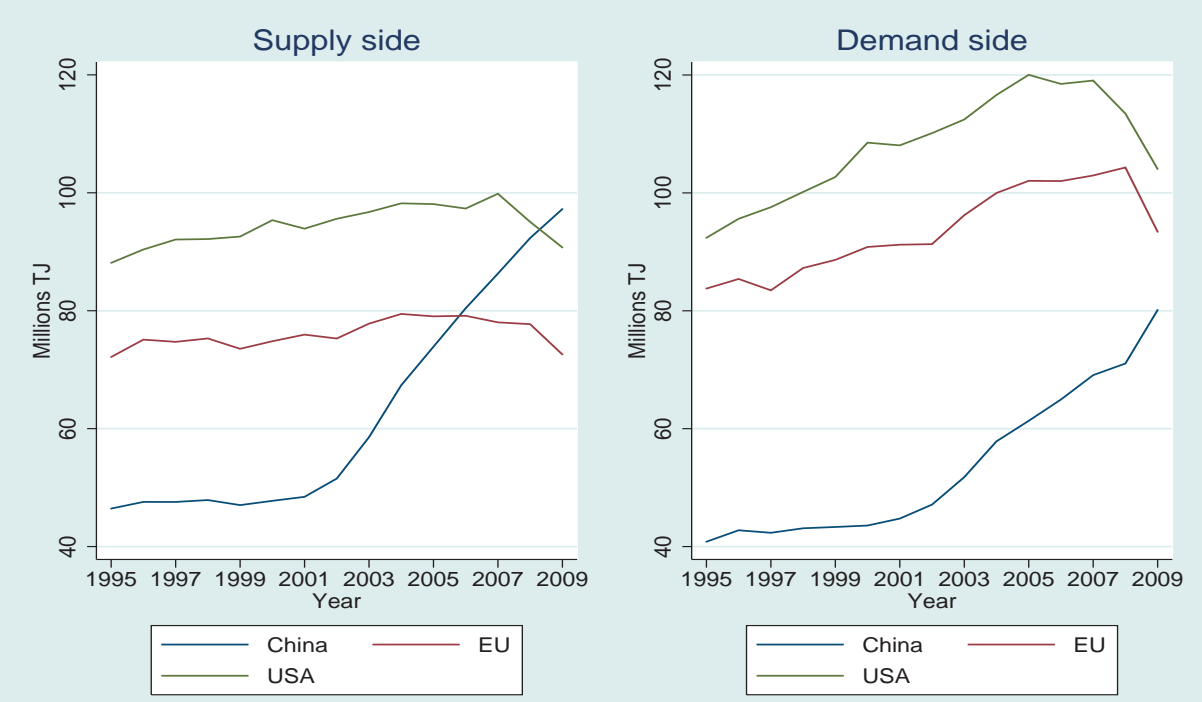

Source: Own elaboration using WIOD data

Figure 2.1 Supply side and demand side energy consumption for selected economies, 1995-2009

The approach chosen here to identify trends in energy consumption and energy efficiency is structural decomposition analysis (SDA). Numerous studies have been done, choosing decomposition methods to derivate several determinants of energy consumption or energy intensity through simple algebraic transformations, such as the 69 studies summarized by N. Liu and Ang (2007), but there are mainly four limitations in the research of this field. (1) Lots of studies employing Index Decomposition Analysis (IDA) are generally based on final gross outputs which means that they do not consider intermediate inputs in production. Trade relations between economies and sectors have been mostly neglected. (2) Structural decomposition methods are not unique, and decomposition results might vary significantly in different methods (Dietzenbacher \& Los, 1998). (3) Lots of structural decomposition studies on energy or emissions focus on a specific country, for example Australia (Wood \& Lenzen, 2009), Brazil (Machado, Schaeffer, \& Worrell, 2001), the UK (Wiedmann et al., 2010), China (Guan, Hubacek, Weber, Peters, \& Reiner, 2008) and the U.S. (Weber, 2009), while relatively less is known across economies and sectors and at the global level ${ }^{18}$, probably due to data constraint. (4) Relatively fewer studies are carried out to explore both supply side and demand side. Fortunately, the World Input-Output Database (WIOD) collecting a huge mass of cross-sector and cross-economy transaction data in both intermediate inputs and final demand has been opened to the public since 2012. More importantly, WIOD

\footnotetext{
${ }^{18}$ Recently, Xu and Dietzenbacher (2014) provide a structural decomposition study of emissions embodied in trade for 40 major economies in the world.
} 
covers energy consumption data across economies and sectors as well. That makes it possible to analyze big data in the input-output analysis framework.

Consequently, this article attempts to quantitatively explore the influencing factors which cause energy consumption and intensity differentials across economies and sectors in input-output analysis framework, and investigate the relationships between energy intensity and economic development, using the World Bank database and the WIOD data over the years 1995 - 2009. This article is structured as follows. The first section is an introduction. Then second section discusses some major studies on measurement issues, the Environmental Kuznets Curve and main decomposition techniques, and the third section presents the details about data source, decomposition approaches in input-output analysis framework and Multilevel Mixed-Effect models (MME). Decomposition results and econometric analysis results are shown in the fourth section. Lastly, a brief summary and some policy implications are discussed in the fifth section.

\subsection{LITERATURE REVIEW}

\subsubsection{Energy consumption and energy intensity}

Energy, in a general sense, is one of the key inputs of a production process. Specifically, it has various physical forms such as fossil fuels (including petroleum, coal, natural gas, et al.) and renewable energy (e.g., solar energy, wind power, biomass, hydropower, geothermal power and so on). Simply, similar to the concept of productivity, energy efficiency can be viewed as the relationship between output of production and energy input. A useful indicator of energy efficiency is called "energy intensity" (energy input per unit of gross outputs), which is generally used by international organizations such as UNIDO and the International Energy Agency (IEA) and administrative departments such as the U.S. Energy Information Administration (EIA). Upadhyaya (2010) applies a fixedyear index approach to calculate energy intensity indicators, combining UNIDO and IEA databases.

Due to the measurement consideration, there are some differences between physical and economic calculation methods (Jaffe \& Stavins, 1994a; Patterson, 1996). Based on the original concept of energy efficiency, Patterson (1996) provides a relatively wellrounded classification, disaggregating it into three dimensions: scientific indicator, economic-scientific indicator and pure economic indicator. The scientific indicator is usually described in the physical or thermodynamic sense: it is the ratio between useful output (e.g., ton, enthalpy and kilometer) and input measured by thermodynamic unit. The economic-scientific indicator uses market value and the sum of enthalpy to measure useful outputs and energy inputs respectively. The pure economic indicator uses market values to measure inputs and outputs. 
However, there are two limitations in both economic and scientific indicators. First, as addressed by Patterson (1996), the scientific indicator can provide more stable or objective measurement: the calculation of energy efficiency in terms of physical or thermodynamic unit can remain the same regardless of time and location while there are usually some problems such as currency comparison, consumer preference or pricing when using market value. Second, the scientific indicator views all forms of energy in the same way, no matter what it actually is (e.g., petroleum or electricity), while in an economic sense, they are different. Accordingly, it is quite likely that there is a problem of inconsistency when employing various indicators to do empirical analysis.

In this article, we have chosen the economic-scientific indicator, because (1) it might be the only feasible way to calculate the sum of different categories of energy as mentioned above, since energy inputs can be measured in the same stable physical unit; (2) it is too difficult and costly to collect monetary data of energy inputs across economies over time due to imperfect information (e.g., energy pricing); and (3) it can link the physical flows to the monetary flows. In fact, in many databases such as the WIOD and EIA databases, energy irrespective of sources is usually recorded in the physical unit.

\subsubsection{Environmental Kuznets Curve and the role of technology}

In academia the relationship between economic development and environmental quality has been heatedly discussed. One of the most influential debates focuses on the relationship between income per capita and the environmental quality at per capita level, which is the Environmental Kuznets Curve (EKC). In general, EKC assumes that at the early stage of development, the environmental quality degrades with the increase in income per capita, while the environmental quality starts getting enhanced when the income per capita reaches a certain level or a turning point. The important pioneering work was done by Selden and Song (1994) who confirmed the existence of the EKC and forecasted the growth of global emissions based on the EKC by using multi-national panel analysis to study the relationships between four air pollutants and GDP per capita. Later Grossman and Krueger (1995) show an inverted-U-shaped EKC and empirically estimate the threshold income per capita of US dollars 8000 for various environmental indicators which means that economic growth would subsequently bring improvements in environmental quality after reaching this threshold. A theoretical explanation is that in a static growth model where social planner chooses technologies, the EKC is reasonable, if only dirty technology can be used below the turning point and clean technology can be used when the threshold is reached (Stokey, 1998).

More recent studies question the existence of the EKC, however, which implies that the environmental quality is likely to continuously degrade. De Bruyn et al. (1998) argue that the time patterns of some emissions positively correlate with economic growth and that the reduction in emissions is a result of technological change. Stern and Common 
(2001) use a more globally representative dataset to explore the sulfur emissionsincome per capita relationship and find that (1) the relationship is monotonic instead of inverted-U-shaped, and (2) changes in emissions are time trend related rather than income per capita related. Many critiques focus on the parametric econometric specifications employed by prior studies which might be problematic in estimation (Millimet et al., 2003) and develop some semi-parametric or nonparametric approaches, for example, flexible semi-parametric linear regression (Millimet et al., 2003), the nonparametric kernel estimation with panel data (Azomahou et al., 2006) and the quantile fixed effect regression technique (Flores et al., 2014), pointing out that previous empirical findings about the EKC are significantly sensitive to parametric model specifications and we are probably too optimistic about the improvement in environmental quality as income grows over time.

More importantly, Andreoni and Levinson (2001) present a theoretical static model with micro-foundations to study the environment-income relationship with a focus on technology. They strictly prove that for those pollutants following the inverted-U-shaped relationship with income, its reduction at per capita level depends on the increasing returns to scale in the technologies reducing emissions only. In other words, economic growth alone is not the solution to environmental deterioration. In fact, the environment-income relationship does not necessarily need to be inverted-U-shaped: it can take a totally different form if the technology differs.

The main reason for reviewing the literature on the EKC is to show that the EKC probably does not globally exist even that it holds in some cases, and that the important matter behind the environment-income relationship is the technology. There might be a danger that such an inverted-U-shaped relationship would be wrongly interpreted as priority between economic growth and environment by some policymakers-"grow first, and then clean up" (Dasgupta et al., 2002). The modern industrial societies that heavily rely on fossil fuels are constantly generating new types of emissions which results in increasing environmental risks. Additionally, on the basis of growth theory, continuous improvements in technology, especially in the ones increasing input efficiency (e.g., energy) are the best chance for the global economy to overcome limits to growth in the face of scarce and unrenewable resources (Grossman \& Helpman, 1994). More recently, Acemoglu et al. (2012) theoretically point out the primary importance of directed technological change by developing a growth model with environmental constraints, and suggest that policy instruments (e.g., tax and subsidy) should be purposefully designed to support innovations toward clean inputs to achieve sustainable growth. All in all, it is necessary to promote new development initiatives with a special focus on technology and innovation.

The literature on the EKC suggests that technology needs to be seriously taken into account behind the environment-income relationship. This article in fact employs a 
backward-looking perspective that tries to empirically explore the historical dynamics of energy consumption and energy intensity. Specifically, the relative change of the variable of interest over a period is decomposed into several influencing factors with an attention to technology. The section below presents a brief literature review.

\subsubsection{Major decomposition techniques}

Economic (e.g., GDP growth, value added), environmental (e.g., energy use, energy intensity, gas emissions) and employment (e.g., labor productivity) variables are often broken down into several driving forces of causing the dynamics of these variables. There are basically three major decomposition techniques, that is, the production function based econometric method, Index Decomposition Analysis (IDA) and Structural Decomposition Analysis (SDA).

\subsubsection{Production function based econometric method}

The production function based econometric method describes the emissions (e.g., the total emissions of sulfur) by using a Cobb-Douglas function with various inputs and technology (Stern, 2002, 2006). By deriving the per capita version of the Cobb-Douglas function, the changes in the emissions can be decomposed into changes in input mix, output mix, scale, and the state of technological change. Such an econometric decomposition specification can be estimated by panel data techniques, taking into account the country and time effects simultaneously. The following emissions production function is developed by Stern (2002):

$$
S_{i, t}=f_{i}\left(y_{i, t}, x_{i, t}, A_{i, t}\right)
$$

Where $f(\cdot)$ is a Cobb-Douglas form function which imposes non-negativity on the dependent variable, $S$ is total emissions of sulfur, $y_{i, t}$ represents a vector of outputs (for example, agriculture, manufacturing and services) in Country $i$ in the year $t, x$ denotes inputs, and $A$ stands for the level of technology.

On the basis of the emissions production function above, emissions per capita can be decomposed into five components, i.e., gross outputs per capita, technology-effects of emissions specific technical progress, technology-effects of overall technical progress, output mix and input mix (Stern, 2002).

\subsubsection{Index Decomposition Analysis (IDA)}

IDA has been generally used by previous studies (Ang \& Lee, 1996; Farla, Blok, \& Schipper, 1997; Steenhof, 2006; Worrell, Price, Martin, Farla, \& Schaeffer, 1997; Zhang, 2003). Proposed by Boyd, Hanson, and Sterner (1988), Ang and Lee (1994) and Ang (2005), the basic equation of index decomposition can be obtained through simple algebraic identity transformation as follows (assuming there are $n$ sectors): 


$$
E=\sum_{i}^{n} E_{i}=\sum_{i}^{n} \frac{E_{i}}{Y_{i}} \frac{Y_{i}}{Y} Y
$$

Where $\mathrm{E}$ is the gross energy consumption and $\mathrm{Y}$ is the total value added.

Let $\mathrm{E}_{0}$ and $\mathrm{E}_{\mathrm{t}}$ denote gross energy consumption in the year 0 and $\mathrm{t}$, then $\Delta \mathrm{E}_{\text {tot }}=\mathrm{E}_{\mathrm{t}}-$ $\mathrm{E}_{0}$. Take the derivative with respect to the time. Equation (1) can be transformed to:

$$
\Delta E_{\text {tot }}=\Delta E_{\text {int }}+\Delta E_{\text {str }}+\Delta E_{\text {out }}+R
$$

Where $\Delta \mathrm{E}_{\text {int }}$ is change in energy consumption due to changes in energy intensities; $\Delta \mathrm{E}_{\text {str }}$ is the change in energy consumption due to structural changes; $\Delta \mathrm{E}_{\text {out }}$ is the change in energy consumption due to a change in aggregate production; $R$ is the residual term.

Plenty of index methods have been skillfully developed to describe the difference terms in Equation (2), such as Laspeyres approach of using base year weights, Paasche's approach of using terminal year weights, and Marshall-Edgeworth's approach of using mean value of base and terminal year weights (Hoekstra \& Van den Bergh, 2002). Specifically, Ang and Lee (1994) provide two general index decomposition formulas for energy consumption, i.e., parametric Divisia methods 1 and 2 (PDM 1 and PDM 2). By changing the parameters in PDM 1 and PDM 2, five various methods for estimating difference terms in Equation (2) are proposed: Laspeyres-based PDM 1 (LAS-PDM 1), simple average PDM 1 (AVE-PDM 1), Laspeyres-based PDM 2 (LAS-PDM 2), simple average PDM 2 (AVE-PDM 2), and adaptive weighting parametric Divisia method (AWTPDM).

As discussed above, the index decomposition methods are not unique. Most IDA studies follow the basic relationship of Equation (2), but it has an obvious disadvantage that there is an unexplained residual term. Zhang (2003) proposes a non-residual method by redefining of $\Delta E_{\text {str }}$ and $\Delta E_{\text {int }}$ in Equation (2) ${ }^{19}$ :

$$
\begin{aligned}
& \Delta E_{\text {str }}=\sum_{i}\left(Q_{t} S_{i, t} I_{i, 0}-Q_{t} S_{i, 0} I_{i, 0}\right)=Q_{t} \sum_{i}\left(S_{i, t}-S_{i, 0}\right) I_{i, 0} \\
& \Delta E_{\text {int }}=\sum_{i}\left(Q_{t} S_{i, t} I_{i, t}-Q_{t} S_{i, t} I_{i, 0}\right)=Q_{t} \sum_{i} S_{i, t}\left(I_{i, t}-I_{i, 0}\right)
\end{aligned}
$$

Where $Q_{0}$ and $Q_{t}$ represent aggregate production in the industrial sector in the year 0 and $\mathrm{t} ; \mathrm{S}_{\mathrm{i}, 0}$ and $\mathrm{S}_{\mathrm{i}, \mathrm{t}}$ are the $\mathrm{i}$-th sector's share of aggregate production in the year 0 and $\mathrm{t}$; $I_{i, 0}$ and $I_{i, t}$ are the $i$-th sector's energy intensity in the year 0 and $t$.

19 Adding Equation (3) and (4), we obtain: $\Delta E_{\text {int }}+\Delta E_{s t r}+\Delta E_{\text {out }}=\left(Q_{t}-\right.$
$\left.Q_{0}\right) \sum_{i} S_{i, 0} I_{i, 0}+Q_{t} \sum_{i}\left(S_{i, t}-S_{i, 0}\right) I_{i, 0}+Q_{t} \sum_{i} S_{i, t}\left(I_{i, t}-I_{i, 0}\right)=-Q_{0} \sum_{i} S_{i, 0} I_{i, 0}+$
$Q_{t} \sum_{i} S_{i, t} I_{i, t}=-E_{0}+E_{t}=\Delta E_{\text {tot }}$. Then the residual term is eliminated. 
Using 29 industrial sectors for China in the 1990s and the non-residual index decomposition method, Zhang (2003) points out that change in energy intensity is the only major reason for causing decline in industrial energy use. But China lowered its primary energy use by $4 \%$ in 2000 compared to 1996 while nearly doubled energy use from 2002 to 2009, making China the second-largest energy user and the largest greenhouse emitter. In both periods the role of structural change became more important (Kahrl, RolandHolst, \& Zilberman, 2013; Sinton \& Fridley, 2000), for example, with heavy industry growth (mainly construction and equipment investment) due to the country's investment-dominated growth model, and closing down of factories.

However, even when the non-residual method is applied, using only aggregate data at the sector level, intermediate inputs in production and consumption in final demand have been neglected in IDA: energy consumption embodied in trade cannot be assessed.

\subsubsection{Structural Decomposition Analysis (SDA)}

For SDA, the basic idea of performing decompositions is still the same. The key difference is that SDA performs the decompositions with a data intensive matrix form dataset. In this sense, SDA can be viewed as an extension of IDA in the context of linear algebra. In the input-output framework, the gross outputs of a sector are consumed in two ways: intermediate inputs and final demand. The input-output dataset is a matrix that contains trade transaction information between any pair of sectors within the same economy and across economies. The number of data points of input-output dataset can be extremely large. Supposing there are $\mathrm{m}$ economies in the world and each economy has $\mathrm{n}$ sectors and $\mathrm{k}$ final demands, the total number of data points for one period only is $\left(\mathrm{m}^{2} \mathrm{n}^{2}+\mathrm{mkn}\right)$.

Miller and Blair (1985) offer a rather well-rounded instruction about how to carry out energy related or environmental SDA. Specifically, Wiedmann et al. (2007) give a detailed review about six newly developed input-output models that use more sophisticated cross-sector and-economic data, to investigate environmental impacts embodied in trade activities.

There are some typical country-specific studies. Using the U.S. data for 1997 and 2002, Weber (2009) confirms the "compensation effect" in the U.S. energy usage and flows: energy demand driven by rising population and household consumption would be offset by structural change. Using Brazilian trade data for 1995 (inflows and outflows specified), Machado et al. (2001) employ SDA to calculate energy use and carbon embodied in the international trade and argue that (1) Brazil is a net exporter of energy and carbon; and (2) export is a more crucial contributor of energy use and carbon emissions. In the case of China, other researchers decompose carbon dioxide emissions instead of energy consumption, pointing out that (1) rapid carbon dioxide emissions 
result from economic growth and structural change and improvement in energy efficiency can offset them (Han \& Chatterjee, 1997), using nine selected countries' data from 1972 to 1990; but (2) specifically using data for China from 1982 to 2002, energy efficiency gains are not sufficient enough to stabilize future emissions from China, if energy consumption patterns converge on the current level of the U.S. (Guan et al., 2008). Unlike other SDA studies employing absolute change approach, Dietzenbacher, Hoen, and Los (2000) choose to decompose the relative change in the study of labor productivity dynamics in six Western European countries. Compared to absolute change approach, it would be more convenient to compare different economies or sectors that have large differences through calculating relative change.

Although both IDA and SDA usually need historical data for only two periods, the main difference between them might be the type of data they use (Hoekstra \& Van den Bergh, 2002). IDA only needs the aggregate data at the sector level, such as gross energy consumption and total outputs, while SDA requires the intensive data from InputOutput (IO) tables in the form of a matrix, which is a very high requirement. Statistical bureaus of many countries do not collect data for IO tables annually, or do not collect data in the form of IO tables, though SDA based on the Input-Output model has been proven to be a very useful tool for years (Rose \& Chen, 1991). In the vast literature of decomposition studies, consequently, it seems that IDA has been used more widely. Ang and Zhang (2000) conduct a survey and found out 109 studies applying IDA but only 15 studies applying SDA. Recently, Voigt, De Cian, Schymura, and Verdolini (2014) apply IDA techniques to input-output data. Specifically in the area of energy consumption and energy intensity decompositions, N. Liu and Ang (2007) summarize 69 IDA papers including 336 sets of decomposition results. Additionally, Hoekstra and Van den Bergh (2002) provide a brief table listing 27 SDA studies applied to physical flows.

The input-output framework can describe the global economy in a perfectly reasonable way catching the trade interactions between sectors, but it is extremely expensive and time-consuming to construct the datasets, and sometimes that is even impossible because of data unavailability. For quite a long time the input-output dataset modeling the whole world did not exist. In recent years, tremendous efforts have been achieved. The World Input-Output Database (WIOD) at the University of Groningen has been constructed for years, authorizing free access to extremely intensive input-output data and environmental data including monetary and physical flows. Other commonly used input-output tables include Eora and GTAP. Recently, Xu and Dietzenbacher (2014) performed a structural decomposition analysis of emissions embodied in trade for 40 economies in the World Input-Output Database (WIOD), decomposing the dynamics of emissions into 10 factors with a special attention to the effects at home country and abroad. 
This article employs the Structural Decomposition Analysis to approach the first research question. The reasons are the following. First, in the context of globalization, international fragmentation of production is increasingly expanding, so that sectors within the same economy and across various economies are closely connected to each other through trade networks which leads to many influencing impacts such as technological change, production substitution, and production specialization based on labor and income level (Timmer, Erumban, Los, Stehrer, \& de Vries, 2014). The growing international trade also stimulates the development of production offshoring resulting in shared gains for all the domestic factors (Grossman \& Rossi-Hansberg, 2008). Such trade activities can only be included in the input-output dataset and taken into account by using the structural decomposition approach. Second, the production function based econometric method requires a very strong assumption on the Cobb-Douglas form of production function. Accordingly, in order to have a comprehensive understanding of energy consumption dynamics for both supply side and demand side, integrating changes in productivity, trade structure in both intermediate inputs and final demand, efficiency, and economic development, the Structural Decomposition Analysis (SDA) seems to be a more suitable method. In fact, it has been proven as a useful tool and standard method in energy related studies (Hoekstra \& Van den Bergh, 2002; Rose \& Casler, 1996; Weber, 2009).

This article employs the Structural Decomposition Analysis (SDA) to approach the first research question and decomposes the dynamics of relative changes in energy consumption and energy intensity by economy (40 major economies in the world, the whole world, EU and EU Enalrgement countries) and by sector (35 sectors, primary industry, manufacturing, services, and in particular, manufacturing subgroups by technological level). The parametric approach on the basis of Grossman and Krueger (1995)'s model specification is used to answer the second research question.

\subsection{METHODOLOGY}

\subsubsection{Data}

This article employs the Structural Decomposition Analysis (SDA) that requires multiregional input-output (MRIO) tables. Currently three MRIO databases are commonly used: Eora (Lenzen, Kanemoto, Moran, \& Geschke, 2012; Lenzen, Moran, Kanemoto, \& Geschke, 2013), GTAP (Andrew \& Peters, 2013) and the World Input-Output Database (Dietzenbacher, Los, Stehrer, Timmer, \& de Vries, 2013). However, there is a lack of consistency between these MRIO databases because of the different approaches that are used to produce them, which would lead to different computing results when the same structural decomposition models are employed. Owen, Steen-Olsen, Barrett, 
Wiedmann, and Lenzen (2014) find that for most regions covered in the databases, GTAP and WIOD can produce similar results. Since WIOD also provides the previous years' prices version of the input-output tables that are needed for deflating monetary values, the data source used in this article is WIOD.

Funded by the European Commission, WIOD $^{20}$ is the first public input-output database that aims to provide researchers with a large-scale time-series information source to analyze the cross-industry and transnational trade relations, environment related changes and socio-economic development ${ }^{21}$ (Timmer, 2012). In order to describe the global economy, WIOD collects official input-output data for 40 economies across the world $^{22}$, including $27 \mathrm{EU}$ member states, 13 other major economies in the world and employs a model to simulate the rest of the world (Dietzenbacher et al., 2013). Each economy listed in WIOD has 35 sectors, though some of the sectors might have 0 output. These sectors can be aggregated into primary industry, manufacturing and services. Manufacturing sectors in particular can be grouped into three categories: low-tech manufacturing, medium/low-tech manufacturing and medium/high-tech manufacturing on the basis of their technological levels. Appendix 2.1 provides a full list of all the economies, sectors, industries and manufacturing subgroups covered in WIOD.

WIOD is more than a database containing input-output tables. It provides information about environmental and socio-economic development as well. The table below illustrates all the main components in WIOD.

\begin{tabular}{ll}
\hline The World Input-Output & The World Input-Output Tables (WIOT), including current prices version and \\
Database (WIOD) & previous years' prices version \\
& National Input-Output Tables \\
& Socio-Economic Accounts \\
& Environmental Accounts, including data for energy consumption, emissions, \\
& land use, water use and material use
\end{tabular}

Source: the World Input-Output Database (WIOD).

Specifically, this article uses: (1) cross-industry and transnational expenditure data (in current prices) from the World Input-Output Tables (WIOT) over the year 1995 to 2009, which have 35301000 data points in total ${ }^{23}$; and (2) the World Input-Output tables (in previous years' prices) over 1996 to 2009, containing 32947600 data points. Conse-

\footnotetext{
${ }^{20}$ The World Input-Output Database (WIOD): http://www.wiod.org/database/index.htm

${ }^{21}$ The updated version of the World Input-Output (IO) tables covers the year 2010 and 2011. However, the Socio-Economic Accounts and Environmental Accounts only cover years from 1995 to 2009.

${ }^{22}$ Note that the 41th economy is the rest of the world (RoW).

${ }^{23}$ For each year in WIOT, in intermediate inputs there are 41 economies and each of them has 35 sectors. Accordingly, there are $41 * 35 * 41 * 35=2059225$ data points; each economy's final demand is disaggregated into 5 categories, which means there are $41 * 35 * 41 * 5=294175$ data points. Then the world IO tables for a single year contain 2353400 data points.
} 
quently, 68248600 data points in the World Input-Output tables are used. The data structure of WIOT for a single year is shown in Figure 2.2 for illustration purpose.

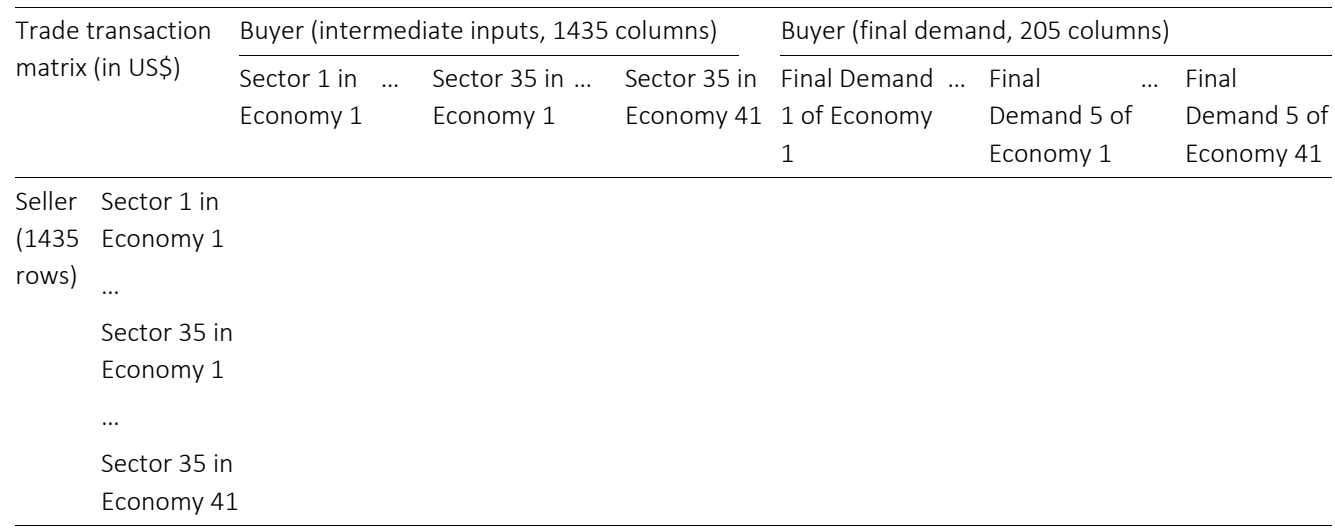

Figure 2.2 WIOT data structure for a single year

Correspondingly, the gross energy consumption data from 1995 to 2009 for each sector (35 economic sectors and 1 household sector) and economy are available in the WIOD Environmental Accounts, which contain 265680 data points ${ }^{24}$. In the WIOD Environmental Accounts, 27 categories $^{25}$ of energy by source including 12 kinds of primary energy and 15 kinds of secondary energy are listed. Since secondary energy is produced from primary energy, to avoid the problem of double counting, only the gross energy consumption which is the sum of all the categories of primary energy is used. Since every category of primary energy is measured in the same physical unit (TJ), they can be added up.

GDP and GDP per capita data (ppp, constant 2005 US dollar) for 39 economies $^{26}$ over 1995 and 2009 are available in the World Development Indicators of the World Bank.

\subsubsection{Supply side and demand side}

Following the concepts of supply side and demand side energy consumption, if the trade transaction matrix illustrated in Figure 2.2 can be transformed into an energy transaction matrix by using WIOD Environmental Accounts, intuitionally, supply side and demand side energy consumption can be viewed as the row sum and the column sum of such an energy transaction matrix respectively, as shown in Figure 2.3.

\footnotetext{
${ }^{24}$ For each economy in a single year, there are 12 kinds of primary energy, 35 economic sectors and 1 household sector, which means $36 * 12=432$ data points.

${ }^{25}$ Primary energy refers to HCOAL, BCOAL, CRUDE, NATGAS, HEATPROD, NUCLEAR, HYDRO, GEOTHERM, SOLAR, WIND, OTHRENEW, and OTHSOURC. Secondary energy contains COKE, DIESEL, GASOLINE, JETFUEL, LFO, HFO, NAPHTA, OTHPETRO, OTHGAS, WASTE, BIOGASOL, BIODIESEL, BIOGAS, ELECTR, and LOSS.

${ }^{26}$ Taiwan and RoW are not applicable in the World Development Indicators.
} 
Similarly, supply side and demand side energy intensity are defined as the ratio of supply energy consumption and gross outputs of an economy, and the ratio of demand side energy consumption and gross outputs consumed by the economy respectively.

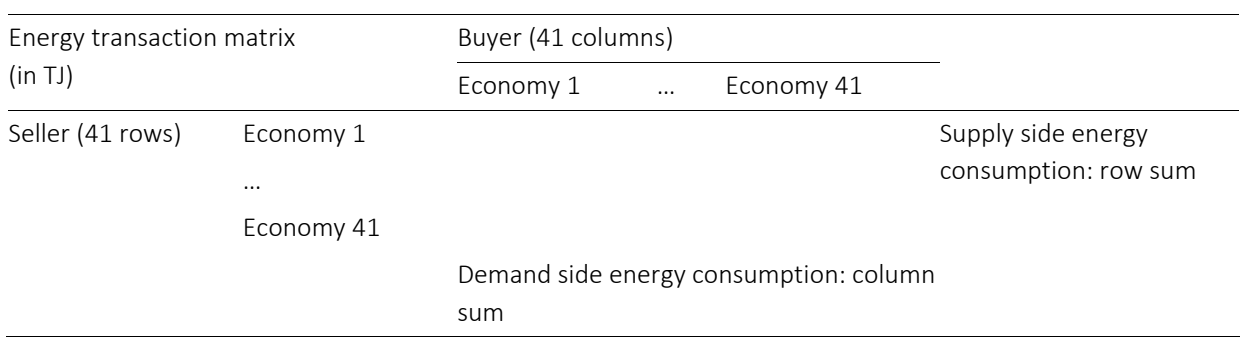

Figure 2.3 Energy transaction matrix structure for a single year

\subsubsection{Decomposition approaches}

\subsubsection{Structural decomposition of energy consumption at economy level}

Following the basic input-output equations and linear algebra notations (Miller \& Blair, $1985), E$, the scalar of energy consumption can be simply written as:

$$
E=e^{\prime} L f+i H
$$

Where:

$\mathrm{e}^{\prime}=\left[\mathrm{e}_{1}, \cdots, \mathrm{e}_{1435}\right]$, which is a vector of sectors' energy inputs (TJ) per US dollar of gross outputs or total emissions (tonnes) per US dollar of gross outputs. Note that WIOT contains 41 economies and each of them has 35 sectors.

$L$ is the Leontief inverse matrix (1435*1435 square matrix), defined as $L=(I-A)^{-1}$. $I$ is a $1435 * 1435$ identity matrix and $A$ denotes the matrix of intermediate inputs per unit of gross outputs (1435*1435 matrix), that is, the technical coefficient matrix, defined as $A=Z *(\hat{x})^{-1}$. Matrix $Z$ is the intermediate inputs matrix in WIOT (1435*1435 matrix). $\hat{\mathrm{x}}$ stands for the diagonal matrix of $x$, the vector of sectors' gross outputs, $\mathrm{x}^{\prime}=$ $\left[\mathrm{x}_{1}, \cdots, \mathrm{x}_{1435}\right]$.

$\mathrm{f}^{\prime}=\left[\mathrm{f}_{1}, \cdots, \mathrm{f}_{1435}\right]$, where $f_{i}$ indicates the total outputs of the $i-t h$ sector spent on final demand $(i=1,2, \cdots, 1435)$.

$\mathrm{H}^{\prime}=\left[\mathrm{H}_{1}, \cdots \mathrm{H}_{41},\right]$ where $H_{i}$ stands for the primary energy consumed by households in the $i-t h$ economy $(i=1,2, \cdots, 41)$.

$i$ is a $1^{*} 41$ column summation vector where every element is 1 .

Let 0 and 1 denote two consecutive years respectively. Then the relative change of energy consumption in the year 0 and 1 is: 


$$
\frac{E_{1}}{E_{0}}=\frac{e_{1}^{\prime} L_{1} f_{1}+i H_{1}}{e_{0}^{\prime} L_{0} f_{0}+i H_{0}}
$$

If one year is fixed and the other year is changed, Equation (6) could be decomposed into four various factors by using "Control Variable Method", in order to estimate the impacts of $e^{\prime}, L, f$ and $H$ on $\frac{E_{1}}{E_{0}}$, which is:

$$
\frac{E_{1}}{E_{0}}=\frac{e_{1}^{\prime} L_{1} f_{1}+i H_{1}}{e_{0}^{\prime} L_{1} f_{1}+i H_{1}} * \frac{e_{0}^{\prime} L_{1} f_{1}+i H_{1}}{e_{0}^{\prime} L_{0} f_{1}+i H_{1}} * \frac{e_{0}^{\prime} L_{0} f_{1}+i H_{1}}{e_{0}^{\prime} L_{0} f_{0}+i H_{1}} * \frac{e_{0}^{\prime} L_{0} f_{0}+i H_{1}}{e_{0}^{\prime} L_{0} f_{0}+i H_{0}}
$$

Where $\frac{E_{1}}{E_{0}}$ on the left means the scalar of relative change of energy consumption between the year 0 and 1 ; the first component on the right stands for the change of energy consumption due to change in energy intensity vector e; the second component represents the change of energy consumption due to change in Leontief inverse matrix, that is, the production structure; the third component shows the change of energy consumption due to change in final demand; and the last component is the change of energy consumption due to change in energy consumed in households.

The structural decompositions are not unique (Dietzenbacher \& Los, 1998; Miller \& Blair, 1985), Equation (7) shows the first decomposition method. The second decomposition method will be illustrated later.

On the basis of Dietzenbacher et al. (2000)'s approach to further decompose the matrix $A$, matrix $L$ becomes:

$$
L=\left(I-A^{* \circ} A^{T}\right)^{-1}
$$

Where:

$A^{*}$ indicates a $1435^{*} 1435$ matrix of aggregate intermediate inputs per unit of gross outputs by sector by economy, formally defined as $\forall \mathrm{r}:\left[\mathrm{A}^{*}\right]_{\mathrm{ij}}^{\mathrm{r} s}=\sum_{1}^{41} \mathrm{~A}_{\mathrm{ij}}^{\mathrm{r} s}$, for trade flows from Sector $i$ in Economy $r$ to Sector $j$ in Economy $s(i, j=1,2, \cdots, 35 ; r, s=$ $1,2, \cdots, 41)$. Mathematically, $\mathrm{A}^{*}=A^{\text {sum }} * \mathrm{~A}$. Here the matrix $A^{\text {sum }}$ is an aggregation

\begin{tabular}{|c|c|c|c|c|c|}
\hline & $\begin{array}{l}\text { Sector } 1 \text { of } \\
\text { Economy } 1\end{array}$ & $\begin{array}{l}\text { Sector } 2 \text { of } \\
\text { Economy } 1\end{array}$ & $\ldots \ldots$ & $\begin{array}{l}\text { Sector } 1 \text { of } \\
\text { Economy } 2\end{array}$ & $\ldots \ldots$ \\
\hline $\begin{array}{l}\text { Sector } 1 \text { of } \\
\text { Economy } 1\end{array}$ & 1 & 0 & $\ldots \ldots$ & 1 & $\ldots \ldots$ \\
\hline $\begin{array}{l}\text { Sector } 2 \text { of } \\
\text { Economy } 1\end{array}$ & 0 & 1 & $\ldots \ldots$ & 0 & $\ldots \ldots$ \\
\hline$\ldots \ldots$ & $\ldots \ldots$ & $\ldots \ldots$ & $\ldots \ldots$ & $\ldots \ldots$ & $\ldots \ldots$ \\
\hline
\end{tabular}
matrix (1435*1435 matrix) constructed as follows ${ }^{27}$ :

For the value in Row $n$ Column $m(n, m=1,2, \cdots, 1435)$, 


$$
A_{n, m}^{\text {sum }}=\left\{\begin{array}{l}
1, \text { if the trade flow's sector of origin and destination sector are identical; } \\
0, \text { otherwise. }
\end{array}\right.
$$

Note that here $n$ denotes the sector in Economy $r(r=1,2, \cdots, 41)$.

$\mathrm{A}^{\mathrm{T}}$ is a $1435^{*} 1435$ matrix of trade coefficients in intermediate inputs, which is formally defined as $\left[\mathrm{A}^{\mathrm{T}}\right]_{\mathrm{i} j}^{\mathrm{r} s}=\mathrm{A}_{\mathrm{i} j}^{\mathrm{r} s} /\left[\mathrm{A}^{*}\right]_{\mathrm{i} j}^{\mathrm{r} s}$. Then $\mathrm{A}=\mathrm{A}^{* \circ} \mathrm{A}^{\mathrm{T}}{ }^{\circ}{ }^{\circ}$ denotes the Hadamard product.

Moreover, $f$ can be further decomposed into:

$$
f=s C
$$

Where:

$s$ is the structural coefficient matrix in final demand (1435*41 matrix), where $s_{n, m}$ denotes the share of Sector $\mathrm{n}$ in the total final demand of Economy $\mathrm{m}$ ( $\mathrm{n}=1,2, \cdots, 1435 ; \mathrm{m}=1,2, \cdots, 41)$.

$\mathrm{C}$ is a vector of economies' total final demand ( $41 * 1$ vector).

Substituting Equation (8) and Equation (9) into Equation (7) yields:

$$
\begin{gathered}
\frac{E_{1}}{E_{0}}=\frac{e_{1}^{\prime} L_{1} f_{1}+i H_{1}}{e_{0}^{\prime} L_{1} f_{1}+i H_{1}} * \frac{e_{0}^{\prime}\left(I-A_{1}^{* \circ} A_{1}^{T}\right)^{-1} f_{1}+i H_{1}}{e_{0}^{\prime}\left(I-A_{0}^{* \circ} A_{1}^{T}\right)^{-1} f_{1}+i H_{1}} * \frac{e_{0}^{\prime}\left(I-A_{0}^{* \circ} A_{1}^{T}\right)^{-1} f_{1}+i H_{1}}{e_{0}^{\prime}\left(I-A_{0}^{* \circ} A_{0}^{T}\right)^{-1} f_{1}+i H_{1}} * \frac{e_{0}^{\prime} L_{0} S_{1} C_{1}+i H_{1}}{e_{0}^{\prime} L_{0} S_{0} C_{1}+i H_{1}} * \frac{e_{0}^{\prime} L_{0} S_{0} C_{1}+i H_{1}}{e_{0}^{\prime} L_{0} S_{0} C_{0}+i H_{1}} * \\
\frac{e_{0}^{\prime} L_{0} f_{0}+i H_{1}}{e_{0}^{\prime} L_{0} f_{0}+i H_{0}}
\end{gathered}
$$

The structural decomposition equations are not unique. Equation (10) only shows one of the possibilities. In fact, if the subscripts are reversed simultaneously for components which are identical in both numerator and denominator, Equation (10) still definitely holds, as shown below:

$$
\begin{gathered}
\frac{E_{1}}{E_{0}}=\frac{e_{1}^{\prime} L_{0} f_{0}+i H_{0}}{e_{0}^{\prime} L_{0} f_{0}+i H_{0}} * \frac{e_{1}^{\prime}\left(I-A_{1}^{* \circ} A_{0}^{T}\right)^{-1} f_{0}+i H_{0}}{e_{1}^{\prime}\left(I-A_{0}^{* \circ} A_{0}^{T}\right)^{-1} f_{0}+i H_{0}} * \frac{e_{1}^{\prime}\left(I-A_{1}^{*}{ }^{\circ} A_{1}^{T}\right)^{-1} f_{0}+i H_{0}}{e_{1}^{\prime}\left(I-A_{1}^{* \circ} A_{0}^{T}\right)^{-1} f_{0}+i H_{0}} * \frac{e_{1}^{\prime} L_{1} s_{1} C_{0}+i H_{0}}{e_{1}^{\prime} L_{1} s_{0} C_{0}+i H_{0}} * \frac{e_{1}^{\prime} L_{1} s_{1} C_{1}+i H_{0}}{e_{1}^{\prime} L_{1} s_{1} C_{0}+i H_{0}} * \\
\frac{e_{1}^{\prime} L_{1} f_{1}+i H_{1}}{e_{1}^{\prime} L_{1} f_{1}+i H_{0}}
\end{gathered}
$$

For simplicity Equation (10) and Equation (11) are viewed as products of six factors which are expressed as follows respectively:

$$
\frac{E_{1}}{E_{0}}=\prod_{i=1}^{6}\left(\text { Factor } i_{0 \rightarrow 1}^{1}\right)
$$

and

$$
\frac{E_{1}}{E_{0}}=\prod_{i=1}^{6}\left(\text { Factor } i_{0 \rightarrow 1}^{2}\right)
$$

Where Factor $i_{0 \rightarrow 1}^{1}$ and Factor $i_{0 \rightarrow 1}^{2}$ indicate factor $i$ between the year 0 and 1 obtained by using the first and the second decomposition method respectively $(i=$ $1,2,3,4,5$ and 6$)$, which are shown in the table below: 
Structural decomposition of energy consumption at economy level

\begin{tabular}{ll}
\hline The first decomposition method & The second decomposition method \\
\hline Factor $1_{0 \rightarrow 1}^{1}=\frac{e_{1}^{\prime} L_{1} f_{1}+i H_{1}}{e_{0}^{\prime} L_{1} f_{1}+i H_{1}}$ & Factor $1_{0 \rightarrow 1}^{2}=\frac{e_{1}^{\prime} L_{0} f_{0}+i H_{0}}{e_{0}^{\prime} L_{0} f_{0}+i H_{0}}$ \\
Factor $2_{0 \rightarrow 1}^{1}=\frac{e_{0}^{\prime}\left(I-A_{1}^{* \circ} A_{1}^{T}\right)^{-1} f_{1}+i H_{1}}{e_{0}^{\prime}\left(I-A_{0}^{* \circ} A_{1}^{T}\right)^{-1} f_{1}+i H_{1}}$ & Factor $2_{0 \rightarrow 1}^{2}=\frac{e_{1}^{\prime}\left(I-A_{1}^{* \circ} A_{0}^{T}\right)^{-1} f_{0}+i H_{0}}{e_{1}^{\prime}\left(I-A_{0}^{* \circ} A_{0}^{T}\right)^{-1} f_{0}+i H_{0}}$ \\
Factor $3_{0 \rightarrow 1}^{1}=\frac{e_{0}^{\prime}\left(I-A_{0}^{* \circ} A_{1}^{T}\right)^{-1} f_{1}+i H_{1}}{e_{0}^{\prime}\left(I-A_{0}^{* \circ} A_{0}^{T}\right)^{-1} f_{1}+i H_{1}}$ & Factor $3_{0 \rightarrow 1}^{2}=\frac{e_{1}^{\prime}\left(I-A_{1}^{* \circ} A_{1}^{T}\right)^{-1} f_{0}+i H_{0}}{e_{1}^{\prime}\left(I-A_{1}^{* \circ} A_{0}^{T}\right)^{-1} f_{0}+i H_{0}}$ \\
Factor $4_{0 \rightarrow 1}^{1}=\frac{e_{0}^{\prime} L_{0} S_{1} C_{1}+i H_{1}}{e_{0}^{\prime} L_{0} S_{0} C_{1}+i H_{1}}$ & Factor $4_{0 \rightarrow 1}^{2}=\frac{e_{1}^{\prime} L_{1} s_{1} C_{0}+i H_{0}}{e_{1}^{\prime} L_{1} s_{0} C_{0}+i H_{0}}$ \\
Factor $5_{0 \rightarrow 1}^{1}=\frac{e_{0}^{\prime} L_{0} S_{0} C_{1}+i H_{1}}{e_{0}^{\prime} L_{0} S_{0} C_{0}+i H_{1}}$ & Factor $5_{0 \rightarrow 1}^{2}=\frac{e_{1}^{\prime} L_{1} s_{1} C_{1}+i H_{0}}{e_{1}^{\prime} L_{1} s_{1} C_{0}+i H_{0}}$ \\
Factor $6_{0 \rightarrow 1}^{1}=\frac{e_{0}^{\prime} L_{0} f_{0}+i H_{1}}{e_{0}^{\prime} L_{0} f_{0}+i H_{0}}$ & Factor $6_{0 \rightarrow 1}^{2}=\frac{e_{1}^{\prime} L_{1} f_{1}+i H_{1}}{e_{1}^{\prime} L_{1} f_{1}+i H_{0}}$
\end{tabular}

\subsubsection{Structural decomposition of energy intensity at economy level}

Following the same notations, the relative change of aggregate energy intensity between the year 0 and 1 is:

$$
\frac{\frac{E_{1}}{t x_{1}}}{\frac{E_{0}}{t x_{0}}}=\frac{E_{1}}{E_{0}} * \frac{t x_{0}}{t x_{1}}
$$

Where $t$ is a $1 * 1435$ column summation vector where every element is 1 , so that $t x$ becomes a scalar.

Note that the gross outputs $x=L f$. Then Equation (14) becomes:

$$
\frac{\frac{E_{1}}{t x_{1}}}{\frac{E_{0}}{t x_{0}}}=\left(\frac{e_{1}^{\prime} L_{1} f_{1}+i H_{1}}{e_{0}^{\prime} L_{1} f_{1}+i H_{1}}\right) *\left(\frac{e_{0}^{\prime} L_{1} f_{1}+i H_{1}}{e_{0}^{\prime} L_{0} f_{1}+i H_{1}} * \frac{t L_{0} f_{1}}{t L_{1} f_{1}}\right) *\left(\frac{e_{0}^{\prime} L_{0} f_{1}+i H_{1}}{e_{0}^{\prime} L_{0} f_{0}+i H_{1}} * \frac{t L_{0} f_{0}}{t L_{0} f_{1}}\right) * \frac{e_{0}^{\prime} L_{0} f_{0}+i H_{1}}{e_{0}^{\prime} L_{0} f_{0}+i H_{0}}
$$

Where the component on the left is the scalar of relative change of energy intensity between the year 0 and 1 ; on the right side, the first component in brackets indicates the change of energy intensity due to change in energy intensity within the sectors; the second component in brackets suggests the change of energy intensity due to change in Leontief inverse matrix (production structure); the third component in brackets implies the change of energy intensity due to change in final demand, and the last component is the change of energy intensity due to change in energy consumed in households.

Equation (15) shows the first decomposition method. By introducing $A^{*}, A^{T}, s$ and $C$, and rearranging polynomial components, two versions of decomposition equations can be obtained:

$$
\frac{\frac{E_{1}}{t x_{1}}}{\frac{E_{0}}{t x_{0}}}=\prod_{i=1}^{6}\left(\text { factor } i_{0 \rightarrow 1}^{1}\right)=\prod_{i=1}^{6}\left(\text { factor } i_{0 \rightarrow 1}^{2}\right)
$$


Note that: factor $i_{0 \rightarrow 1}^{1}$ and factor $i_{0 \rightarrow 1}^{2}$ denote factor $i$ between the year 0 and 1 based on the first and the second decomposition method ( $i=1,2,3,4,5$ and 6$)$. Specifically, they are:

Structural decomposition of energy intensity at economy level

\begin{tabular}{|c|c|}
\hline The first decomposition method & The second decomposition method \\
\hline factor $1_{0 \rightarrow 1}^{1}=\frac{e_{1}^{\prime} L_{1} f_{1}+i H_{1}}{e_{0}^{\prime} L_{1} f_{1}+i H_{1}}$ & factor $1_{0 \rightarrow 1}^{2}=\frac{e_{1}^{\prime} L_{0} f_{0}+i H_{0}}{e_{0}^{\prime} L_{0} f_{0}+i H_{0}}$ \\
\hline factor $2_{0 \rightarrow 1}^{1}=\frac{e_{0}^{\prime}\left(I-A_{1}^{* \circ} A_{1}^{T}\right)^{-1} f_{1}+i H_{1}}{e_{0}^{\prime}\left(I-A_{0}^{* \circ} A_{1}^{T}\right)^{-1} f_{1}+i H_{1}} * \frac{t\left(I-A_{0}^{* \circ} A_{1}^{T}\right)^{-1} f_{1}}{t\left(I-A_{1}^{* \circ} A_{1}^{T}\right)^{-1} f_{1}}$ & factor $2_{0 \rightarrow 1}^{2}=\frac{e_{1}^{\prime}\left(I-A_{1}^{* \circ} A_{0}^{T}\right)^{-1} f_{0}+i H_{0}}{e_{1}^{\prime}\left(I-A_{0}^{* \circ} A_{0}^{T}\right)^{-1} f_{0}+i H_{0}} * \frac{t\left(I-A_{0}^{* \circ} A_{0}^{T}\right)^{-1} f_{0}}{t\left(I-A_{1}^{*} A_{0}^{T}\right)^{-1} f_{0}}$ \\
\hline factor $3_{0 \rightarrow 1}^{1}=\frac{e_{0}^{\prime}\left(I-A_{0}^{* \circ} A_{1}^{T}\right)^{-1} f_{1}+i H_{1}}{e_{0}^{\prime}\left(I-A_{0}^{* \circ} A_{0}^{T}\right)^{-1} f_{1}+i H_{1}} * \frac{t\left(I-A_{0}^{* \circ} A_{0}^{T}\right)^{-1} f_{1}}{t\left(I-A_{0}^{* \circ} A_{1}^{T}\right)^{-1} f_{1}}$ & factor $3_{0 \rightarrow 1}^{2}=\frac{e_{1}^{\prime}\left(I-A_{1}^{* \circ} A_{1}^{T}\right)^{-1} f_{0}+i H_{0}}{e_{1}^{\prime}\left(I-A_{1}^{*} A_{0}^{T}\right)^{-1} f_{0}+i H_{0}} * \frac{t\left(I-A_{1}^{*}{ }^{\circ} A_{0}^{T}\right)^{-1} f_{0}}{t\left(I-A_{1}^{*} A_{1}^{T}\right)^{-1} f_{0}}$ \\
\hline factor $4_{0 \rightarrow 1}^{1}=\frac{e_{0}^{\prime} L_{0} s_{1} C_{1}+i H_{1}}{e_{0}^{\prime} L_{0} s_{0} C_{1}+i H_{1}} * \frac{t L_{0} s_{0} C_{1}}{t L_{0} s_{1} C_{1}}$ & factor $4_{0 \rightarrow 1}^{2}=\frac{e_{1}^{\prime} L_{1} s_{1} C_{0}+i H_{0}}{e_{1}^{\prime} L_{1} s_{0} C_{0}+i H_{0}} * \frac{t L_{1} s_{0} C_{0}}{t L_{1} s_{1} C_{0}}$ \\
\hline factor $5_{0 \rightarrow 1}^{1}=\frac{e_{0}^{\prime} L_{0} S_{0} C_{1}+i H_{1}}{e_{0}^{\prime} L_{0} S_{0} C_{0}+i H_{1}} * \frac{t L_{0} S_{0} C_{0}}{t L_{0} S_{0} C_{1}}$ & factor $5_{0 \rightarrow 1}^{2}=\frac{e_{1}^{\prime} L_{1} s_{1} C_{1}+i H_{0}}{e_{1}^{\prime} L_{1} s_{1} C_{0}+i H_{0}} * \frac{t L_{1} s_{1} C_{0}}{t L_{1} s_{1} C_{1}}$ \\
\hline factor $6_{0 \rightarrow 1}^{1}=\frac{e_{0}^{\prime} L_{0} f_{0}+i H_{1}}{e_{0}^{\prime} L_{0} f_{0}+i H_{0}}$ & factor $6_{0 \rightarrow 1}^{2}=\frac{e_{1}^{\prime} L_{1} f_{1}+i H_{1}}{e_{1}^{\prime} L_{1} f_{1}+i H_{0}}$ \\
\hline
\end{tabular}

\subsubsection{Supply side and demand side at economy level}

In order to obtain supply side and demand side decomposition results for each economy, the transposed matrix $\mathrm{e}^{\prime}$ in Equation (5) would be replaced to the diagonal matrix $\hat{\mathrm{e}}$, and then Equation (5) would be pre-multiplied the economy aggregation matrix $C^{\text {sum }}$ and the column summation vector $k$ respectively. Then the new expressions for supply side and demand side energy consumption go as follows:

$$
E_{S}=C^{\text {sum }} \hat{e}\left(I-A^{* \circ} A^{T}\right)^{-1} s C+H
$$

and

$$
E_{d}=k \hat{e}\left(I-A^{* \circ} A^{T}\right)^{-1} s \hat{C}+H^{\prime}
$$

Where $E_{s}$ is a vector of economies' supply side energy consumption (41*1 vector), $E_{d}$ denotes a vector of economies' demand side energy consumption ( $1 * 41$ vector), and $k$ is a column summation vector ( $1 * 1435$ vector) where every element is 1 . Matrix $C^{\text {sum }}$ is constructed as follows ${ }^{28}$ :

For the value in Row $n$ Column $m(n=1,2, \cdots, 41 ; m=1,2, \cdots, 1435)$,

\begin{tabular}{llllll}
\hline${ }^{28}$ The formation of matrix $C^{\text {sum }}$ is: & & & \\
\hline & $\begin{array}{l}\text { Sector } 1 \text { of } \\
\text { Economy } 1\end{array}$ & Sector 2 of & $\ldots \ldots$ & Sector 1 of & $\ldots \ldots$ \\
Economy 1 & 1 & 1 & & Economy 1 & \\
Economy 2 & 0 & 0 & $\ldots \ldots$ & 0 & $\ldots \ldots$ \\
$\ldots \ldots$ & $\ldots \ldots$ & $\ldots \ldots$ & $\ldots \ldots$ & 1 & $\ldots \ldots$ \\
\hline
\end{tabular}




$$
\begin{aligned}
& C_{n, m}^{s u m} \\
& =\left\{\begin{array}{l}
1, \text { if the trade flow's economy of origin and destination economy are identical } ; \\
0, \text { otherwise. }
\end{array}\right.
\end{aligned}
$$

Note that here $n$ denotes the economy.

By using Equation (17) and Equation (18), supply side and demand side decomposition results can be obtained. To calculate the decompositions for the whole world, a $1 * 1435$ summation vector could be applied to replace the country aggregation matrix $C^{\text {sum }}$. Note that for the whole world, the supply side and the demand side energy consumption and energy intensity are the same. The decompositions for two other specific groups of economies, that is, the EU and countries joining the EU after 2004 (EU Enlargement) are calculated as well. For supply side in Equation (17), a 1*1435 aggregation vector ${ }^{29}$ would be employed to replace the economy aggregation matrix $C^{\text {sum }}$ and the vector $H$ would be changed to energy consumed in households in the EU or EU Enlargement. For demand side in Equation (18), the economies' total final demand matrix $\hat{C}$ would multiply a $41^{*} 1$ aggregation vector ${ }^{30}$ and the vector $H^{\prime}$ would be changed to energy consumed in households in the EU or EU Enlargement as well.

\subsubsection{Structural decomposition of energy consumption and energy intensity at sectoral level}

Section 2.3.3.1 and Section 2.3.3.2 shows the structural decomposition approaches at economy. Following the same logic of decomposition at economy level, the sectoral level structural decomposition of energy consumption and energy intensity can be directly obtained by neglecting matrix $H$ in Equation (5), the energy expenditure in households, which yields the following equations and five decomposition factors:

The energy consumption at sectoral level (35*1 vector), $E_{\text {sectoral }}$, can be described below:

$$
E_{\text {sectoral }}=S^{\text {sum }} \hat{e}\left(I-A^{* \circ} A^{T}\right)^{-1} S C
$$

Where $S^{\text {sum }}$ is the sectoral aggregation matrix which can be constructed as follows ${ }^{31}$ :

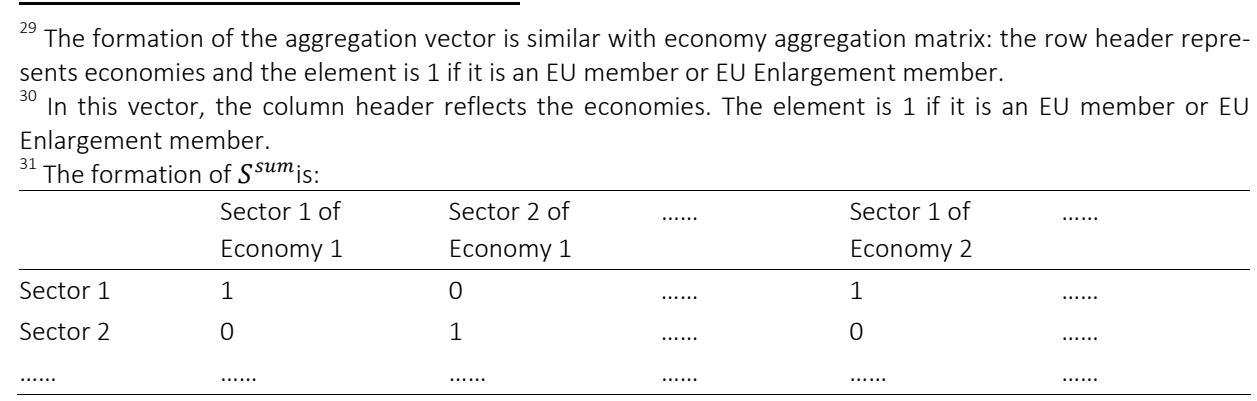


For the value in Row $n$ and Column $m(n=1,2, \cdots, 35 ; m=1,2, \cdots, 1435)$,

$S_{n, m}^{\text {sum }}=\left\{\begin{array}{l}1, \text { if the trade flow'ssector of origin and destination sector are identical; } \\ 0, \text { otherwise. }\end{array}\right.$

Note that here the $n$ represents the sector of the world. Following the similar logic, the aggregation matrices for calculating the results for industrial groups and manufacturing subgroups can be constructed.

$$
\frac{E_{1}}{E_{0}}=\frac{e_{1}^{\prime} L_{1} f_{1}}{e_{0}^{\prime} L_{0} f_{0}}
$$

Structural decomposition of energy consumption at sectoral level

\begin{tabular}{|c|c|}
\hline The first decomposition method & The second decomposition method \\
\hline Factor $1_{0 \rightarrow 1}^{1}=\frac{e_{1}^{\prime} L_{1} f_{1}}{e_{0}^{\prime} L_{1} f_{1}}$ & Factor $1_{0 \rightarrow 1}^{2}=\frac{e_{1}^{\prime} L_{0} f_{0}}{e_{0}^{\prime} L_{0} f_{0}}$ \\
\hline Factor $2_{0 \rightarrow 1}^{1}=\frac{e_{0}^{\prime}\left(I-A_{1}^{* \circ} A_{1}^{T}\right)^{-1} f_{1}}{e_{0}^{\prime}\left(I-A_{0}^{* \circ} A_{1}^{T}\right)^{-1} f_{1}}$ & Factor $2_{0 \rightarrow 1}^{2}=\frac{e_{1}^{\prime}\left(I-A_{1}^{* \circ} A_{0}^{T}\right)^{-1} f_{0}}{e_{1}^{\prime}\left(I-A_{0}^{* \circ} A_{0}^{T}\right)^{-1} f_{0}}$ \\
\hline Factor $3_{0 \rightarrow 1}^{1}=\frac{e_{0}^{\prime}\left(I-A_{0}^{* \circ} A_{1}^{T}\right)^{-1} f_{1}}{e_{0}^{\prime}\left(I-A_{0}^{* \circ} A_{0}^{T}\right)^{-1} f_{1}}$ & Factor $3_{0 \rightarrow 1}^{2}=\frac{e_{1}^{\prime}\left(I-A_{1}^{* \circ} A_{1}^{T}\right)^{-1} f_{0}}{e_{1}^{\prime}\left(I-A_{1}^{* \circ} A_{0}^{T}\right)^{-1} f_{0}}$ \\
\hline Factor $4_{0 \rightarrow 1}^{1}=\frac{e_{0}^{\prime} L_{0} S_{1} C_{1}}{e_{0}^{\prime} L_{0} S_{0} C_{1}}$ & Factor $4_{0 \rightarrow 1}^{2}=\frac{e_{1}^{\prime} L_{1} s_{1} C_{0}}{e_{1}^{\prime} L_{1} S_{0} C_{0}}$ \\
\hline Factor $5_{0 \rightarrow 1}^{1}=\frac{e_{0}^{\prime} L_{0} S_{0} C_{1}}{e_{0}^{\prime} L_{0} S_{0} C_{0}}$ & Factor $5_{0 \rightarrow 1}^{2}=\frac{e_{1}^{\prime} L_{1} s_{1} C_{1}}{e_{1}^{\prime} L_{1} s_{1} C_{0}}$ \\
\hline
\end{tabular}

and

$$
\frac{\frac{E_{1}}{t L_{1} f_{1}}}{\frac{E_{0}}{t L_{0} f_{0}}}=\frac{E_{1}}{E_{0}} * \frac{t L_{0} f_{0}}{t L_{1} f_{1}}
$$

\begin{tabular}{|c|c|}
\hline The first decomposition method & The second decomposition method \\
\hline factor $1_{0 \rightarrow 1}^{1}=\frac{e_{1}^{\prime} L_{1} f_{1}}{e_{0}^{\prime} L_{1} f_{1}}$ & factor $1_{0 \rightarrow 1}^{2}=\frac{e_{1}^{\prime} L_{0} f_{0}}{e_{0}^{\prime} L_{0} f_{0}}$ \\
\hline factor $2_{0 \rightarrow 1}^{1}=\frac{e_{0}^{\prime}\left(I-A_{1}^{* \circ} A_{1}^{T}\right)^{-1} f_{1}}{e_{0}^{\prime}\left(I-A_{0}^{* \circ} A_{1}^{T}\right)^{-1} f_{1}} * \frac{t\left(I-A_{0}^{* \circ} A_{1}^{T}\right)^{-1} f_{1}}{t\left(I-A_{1}^{* *} A_{1}^{T}\right)^{-1} f_{1}}$ & factor $2_{0 \rightarrow 1}^{2}=\frac{e_{1}^{\prime}\left(I-A_{1}^{* \circ} A_{0}^{T}\right)^{-1} f_{0}}{e_{1}^{\prime}\left(I-A_{0}^{*} \circ A_{0}^{T}\right)^{-1} f_{0}} * \frac{t\left(I-A_{0}^{* \circ} A_{0}^{T}\right)^{-1} f_{0}}{t\left(I-A_{1}^{*} A_{0}^{T}\right)^{-1} f_{0}}$ \\
\hline factor $3_{0 \rightarrow 1}^{1}=\frac{e_{0}^{\prime}\left(I-A_{0}^{*} \circ A_{1}^{T}\right)^{-1} f_{1}}{e_{0}^{\prime}\left(I-A_{0}^{* \circ} A_{0}^{T}\right)^{-1} f_{1}} * \frac{t\left(I-A_{0}^{*} \circ A_{0}^{T}\right)^{-1} f_{1}}{t\left(I-A_{0}^{* \circ} A_{1}^{T}\right)^{-1} f_{1}}$ & factor $3_{0 \rightarrow 1}^{2}=\frac{e_{1}^{\prime}\left(I-A_{1}^{*} \circ A_{1}^{T}\right)^{-1} f_{0}}{e_{1}^{\prime}\left(I-A_{1}^{*} A_{0}^{T}\right)^{-1} f_{0}} * \frac{t\left(I-A_{1}^{* \circ} A_{0}^{T}\right)^{-1} f_{0}}{t\left(I-A_{1}^{*} A_{1}^{T}\right)^{-1} f_{0}}$ \\
\hline factor $4_{0 \rightarrow 1}^{1}=\frac{e_{0}^{\prime} L_{0} S_{1} C_{1}}{e_{0}^{\prime} L_{0} S_{0} C_{1}} * \frac{t L_{0} S_{0} C_{1}}{t L_{0} S_{1} C_{1}}$ & factor $4_{0 \rightarrow 1}^{2}=\frac{e_{1}^{\prime} L_{1} s_{1} C_{0}}{e_{1}^{\prime} L_{1} s_{0} C_{0}} * \frac{t L_{1} s_{0} C_{0}}{t L_{1} s_{1} C_{0}}$ \\
\hline factor $5_{0 \rightarrow 1}^{1}=\frac{e_{0}^{\prime} L_{0} s_{0} C_{1}}{e_{0}^{\prime} L_{0} s_{0} C_{0}} * \frac{t L_{0} S_{0} C_{0}}{t L_{0} s_{0} C_{1}}$ & factor $5_{0 \rightarrow 1}^{2}=\frac{e_{1}^{\prime} L_{1} s_{1} C_{1}}{e_{1}^{\prime} L_{1} s_{1} C_{0}} * \frac{t L_{1} s_{1} C_{0}}{t L_{1} s_{1} C_{1}}$ \\
\hline
\end{tabular}

Structural decomposition of energy intensity at sectoral level 


\subsubsection{Computing procedures}

\subsubsection{The deflating strategy: chain mechanism}

To eliminate the impacts of inconsistent monetary measurement, ideally, all the timeseries monetary data need to be comparable. The availability of World Input-Output Tables in both current prices and previous years' prices over 1996 to 2009 makes it possible by constructing a "chain", as shown in Equation (22) and Equation (23). The basic idea is that for any pair of consecutive years (e.g., the year $t$ and the year $t+1$ ), current prices version of monetary data for the year $t$ and the previous years' prices version of monetary data for the year $t+1$ are used in the decompositions.

Accordingly, applying the "chain mechanism" described above to the structural decomposition equations, the relative change between 1995 and 2009 can be obtained. Take the structural decomposition at economy level as example.

The structural decomposition of energy consumption at economy level:

$$
\frac{E_{2009}}{E_{1995}}=\prod_{t=1995}^{2008} \frac{E_{t+1}}{E_{t}}=\prod_{i=1}^{6} \prod_{t=1995}^{2008} \text { Factor } i_{t \rightarrow t+1}^{1}=\prod_{i=1}^{6} \prod_{t=1995}^{2008} \text { Factor } i_{t \rightarrow t+1}^{2}
$$

Where the components $\prod_{t=1995}^{2008}$ Factor $i_{t \rightarrow t+1}^{1}$ and $\prod_{t=1995}^{2008}$ Factor $i_{t \rightarrow t+1}^{2}$ indicate the decomposition factor $i$ between 1995 and 2009 calculated by using the first and the second decomposition method respectively $(i=1,2,3,4,5$ and 6$)$.

For the structural decompositions of energy intensity at economy level, applying the similar computing procedure yields:

$$
\begin{gathered}
\frac{\frac{E_{2009}}{t x_{2009}^{*}}}{\frac{E_{1995}}{t x_{1995}^{c u r r e n t}}}=\prod_{t=1995}^{2008} \frac{\frac{E_{t+1}}{t x_{t+1}^{\text {pyp }}}}{\frac{E_{t}}{t x_{t}^{\text {current }}}}=\prod_{i=1}^{6} \prod_{t=1995}^{2008} \text { factor } i_{t \rightarrow t+1}^{1}= \\
\prod_{i=1}^{6} \prod_{t=1995}^{2008} \text { factor } i_{t \rightarrow t+1}^{2}
\end{gathered}
$$

Where $\mathrm{x}_{2009}^{*}$ denotes the 2009 gross outputs measured by 1995 US\$ and price level; $\mathrm{x}_{\mathrm{t}}^{\text {current }}$ is the current prices version of gross output in the year $\mathrm{t} ; \mathrm{x}_{\mathrm{t}+1}^{\text {pyp }}$ means the previous years' prices version of gross output in the year $t+1$; the components $\prod_{\mathrm{t}=1995}^{2008}$ factor $\mathrm{i}_{\mathrm{t} \rightarrow \mathrm{t}+1}^{1}$ and $\prod_{\mathrm{t}=1995}^{2008}$ factor $\mathrm{i}_{\mathrm{t} \rightarrow \mathrm{t}+1}^{2}$ stand for decomposition factor $\mathrm{i}$ between 1995 and 2009 from the first and the second decomposition method respectively (i $=1,2,3,4,5$ and 6$)$.

For the structural decomposition at sectoral level, the chain mechanism still holds. The only difference is that at sectoral level, five decomposition factors are obtained instead of six factors.

\subsubsection{Taking into account results from two methods}

To take into account results from different methods, the average approach is commonly used. Since this article chooses the multiplicative form of decomposition equations, the 
mean value of the log points of factors is employed, as shown below taking the structural decomposition at economy level as example.

$$
\log \left(\frac{E_{2009}}{E_{1995}}\right)=\frac{1}{2} \sum_{i=1}^{6}\left[\log \left(\prod_{t=1995}^{2008} \text { Factor } i_{t \rightarrow t+1}^{1}\right)+\log \left(\prod_{t=1995}^{2008} \text { Factor } i_{t \rightarrow t+1}^{2}\right)\right]
$$

and

$\log \left(\frac{\frac{E_{2009}}{t x_{2009}^{*}}}{\frac{E_{1995}}{t x_{1995}^{\text {current }}}}\right)=\frac{1}{2} \sum_{i=1}^{6}\left[\log \left(\prod_{t=1995}^{2008}\right.\right.$ factor $\left.i_{t \rightarrow t+1}^{1}\right)+\log \left(\prod_{t=1995}^{2008}\right.$ factor $\left.\left.i_{t \rightarrow t+1}^{2}\right)\right]$

On the basis of Equation (24) and Equation (25), results would be aggregated by economy, the whole world, EU and EU Enlargement group. Likewise, the five-factor structural decomposition at sectoral level follows the same logic described in Equation (24) and Equation (25). The sectoral level results would be aggregated into three industrial groups: primary industry, manufacturing and services as well. Specifically, the global manufacturing would be aggregated into three technological groups: low-tech manufacturing, medium/low-tech manufacturing and medium/high-tech manufacturing.

\subsubsection{Understanding the decomposition factors}

After having done all the tedious identical algebraic transformations illustrated above, six factors for structural decompositions at economy level and five factors for structural decompositions at sectoral level are finally obtained. More importantly, a comprehensive understanding of the economic meanings behind all the decomposition factors is needed.

Since the multiplicative form of the decompositions is used, both left-hand side components $\frac{E_{2009}}{E_{1995}}$ and $\frac{\frac{E_{2009}}{t_{x}^{*} x_{2009}}}{\frac{E_{1995}}{t_{1} x_{1995}^{c u r r e n t}}}$ in Equation (24) and Equation (25) are compared to 1, which can be illustrated in the following cases:

$\frac{E_{2009}}{E_{1995}}:\left\{\begin{array}{l}\text { if }>1: \text { more energy consumption in the economy / sector in } 2009 \text { than in } 1995 ; \\ \text { if }=1: \text { no changes in energy consumption between } 1995 \text { and } 2009 ;\end{array}\right.$ and

$\frac{\frac{E_{2009}}{t x_{2009}^{*}}}{\frac{E_{1995}}{t x_{1995}^{c c r r e n t}}}:\left\{\begin{array}{l}\text { if }>1: \text { more energy intensive in the economy / sector in } 2009 \text { than in 1995; } \\ \text { if }=1: \text { no changes in energy intensity between } 2009 \text { and } 1995 ; \\ \text { if }<1: \text { less energy intensive in the economy / sector in } 2009 \text { than in } 1995 .\end{array}\right.$

Applying these criteria the performance in terms of total primary energy consumption, energy intensity by economy, by sector, by industry and by manufacturing technological level can be precisely assessed and compared. 
In both Equation (24) and Equation (25) the right-hand side six decomposition factors are similar. The first factor, which is the impact due to changes in the intensity matrix $\mathrm{e}$ if all the other factors have no variations, is closely related to the energy efficient technology. The second factor is the impact of the change in $A^{*}$, which means the interindustry structure (i.e., the change in intermediate inputs within the sectors). The third factor illustrates the impact of the change in $\mathrm{A}^{\mathrm{T}}$, which measures the trade structure in intermediate inputs. The forth factor stands for the impact of the change in $\mathbf{s}$, which is the structural change in economies' total final demand. The fifth factor reflects the impact of change in $\mathrm{C}$, which is the economies' total final demand and designed to assess the impact of economic development. The last factor is the impact of change in $\mathrm{H}$, which is the energy directly consumed in households.

For each of the five decomposition factors listed above, similarly, a value larger than 1 stands for a positive effect of the factor on the right-hand side outcome. The factor with a value less than 1 would lower the increases of the outcomes. The closer the value is to 1 , the weaker impact the factor has. By employing such criteria, the influencing factor or factors can be clearly identified.

\subsubsection{Convergence analysis of energy intensity at economy level}

On the basis of econometric approaches creatively designed by Barro and SalaiMartin (1991) and SalaiMartin (1996), a simple OLS is employed to check the relationship between relative energy intensity and growth of relative energy intensity for 39 major economies in the world, using energy consumption data from WIOD Environmental Accounts and GDP data from the World Development Indicators ${ }^{32}$. The purpose of such an empirical examination is to investigate the trends of energy efficiency at economy level whether the global economy is becoming increasingly energy efficient or not. Although there are some critiques that the standard approach only focuses on the representative economies rather than the whole distribution and collapses dynamic characteristics into a series of statistic values, that is, a relative value or growth rate (Quah, 1993a, 1997), I would like to start from the standard approach and have a general picture of the trend of energy intensity at economy level.

Formally, energy intensity, relative energy intensity (REI) and growth of relative energy intensity are:

$$
\text { Energy intensity }(E I)=\frac{\text { Total primary energy consumpion of the economy }}{\text { GDP of the economy (ppp,constant } 2005 \text { US } \$)}
$$

\footnotetext{
${ }^{32}$ Taiwan and RoW are not included in the regression, due to data availability in the World Development Indicators.

${ }^{33}$ The total primary energy consumption of the economy includes the primary energy used in economic sectors and that consumed in households' final consumption in the economy.
} 
Relative energy intensity $(R E I)=\frac{\text { Energy intensity of the economy }}{\text { Energy intensity of the world }}$

Growth of relative energy intensity $(G R E I)=\frac{\text { REI in 2009-REI in } 1995}{\text { REI in } 1995}$

Note that the energy intensity of the world is a ratio between total primary energy consumption of the world and the GDP of the world. Then each economy is compared to the world in the same year (the world's level is 1). Using relative energy intensity as the independent variable and its growth as the dependent variable, a significant and negative slope in the simple OLS would imply a trend of convergence of energy intensity between economies.

\subsubsection{Environmental Kuznets Curve: multilevel mixed-effect model}

Inspired by the Environmental Kuznets Curve, this article explores the relationship between energy intensity and GDP per capita as well. Following the same definition of energy intensity in Section 2.3.6, a panel dataset for 39 economies $^{34}$ in WIOD over 1995 and 2009 is constructed using energy consumption data from WIOD Environmental Accounts and GDP and GDP per capita data from the World Development Indicators.

The Multilevel Mixed-Effect model (MME) is employed because there is an economyspecific trend in energy intensity over time. On the basis of the econometric specification developed by Grossman and Krueger (1995), the quadratic term of GDP per capita is included in Equation (29) and Equation (30). As illustrated in the literature review, EKC is very sensitive to the environmental indicator, parametric technique and model specification, but I would like to start the analysis using the standard approach. The econometric specifications go as follows:

For supply side, the MME contains a random slope and a random intercept,

$$
\begin{gathered}
\log \left(E I_{t, j}^{\text {Supply }}\right)=\beta_{0}+\beta_{1} \log \left(G D P_{-} P C_{t, j}\right)+\beta_{2}\left[\log \left(G D P_{-} P C_{t, j}\right)\right]^{2}+\mu_{0, j}+ \\
\mu_{1, j} \log \left(G D P_{-} P C_{t, j}\right)+\varepsilon_{t, j}
\end{gathered}
$$

and for the demand side, the MME contains a random slope only,

$\log \left(E I_{t, j}^{\text {Demand }}\right)=\beta_{0}^{\prime}+\beta_{1}^{\prime} \log \left(G D P_{-} P C_{t, j}\right)+\beta_{2}^{\prime}\left[\log \left(G D P_{-} P C_{t, j}\right)\right]^{2}+\mu_{0, j}^{\prime}+\varepsilon_{t, j}^{\prime}$

Where $E I_{t, j}^{\text {Supply }}$ and $E I_{t, j}^{\text {Demand }}$ mean supply side and demand side energy intensity of Economy $j$ in the year $t$ respectively; $G D P_{-} P C_{t, j}$ stands for the GDP per capita (ppp, constant 2005 US\$) for Economy $j$ in the year $t ; \mu_{0, j}$ and $\mu_{0, j}^{\prime}$ are Economy $j$ 's economyspecific random intercepts for supply side and demand side respectively; $\mu_{1, j}$ is the economy-specific random slope for Economy $j ; \varepsilon_{t, j}$ and $\varepsilon_{t, j}^{\prime}$ are error terms for Economy $j$ in the year $t$ for supply side and demand side respectively.

\footnotetext{
${ }^{34}$ Taiwan and RoW are not included.
} 
The model selection is an important issue. Different model specifications can lead to different results. The econometric specifications above are selected by using the likelihood ratio test on a group of models that have the "nested" structure. For instance, if specification $A$ is nested in specification $B$, it means that specification $B$ includes all the components in specification $A$ and some additional terms. In this sense, specification $A$ is one of the "subsets" of specification $B$, as shown in the example below:

$$
\begin{gathered}
\text { Specification } A: y=\alpha x+c \\
\text { Specification } B: y=\alpha x+\beta x^{2}+c
\end{gathered}
$$

The basic idea of the model selection is in line with the Occam's razor: a simpler model would be selected if the additional random term has a low explanatory power. For supply side and demand side, the MME model with random intercept only is compared to the MME model with random slope and random intercept. Grossman and Krueger (1995)' model specification has an additional cubic term. However, the likelihood ratio test did not favor the models with the additional cubic term. All in all, Equation (29) and Equation (30) are the optimal specifications for supply side and demand side respectively chosen by likelihood ratio tests.

\subsection{RESULTS}

Equation (17), (18) and (24) are employed to calculate structural decomposition results of energy consumption for supply side and demand side. Likewise, Equation (17), (18) and (25) are used to calculate structural decomposition results of energy intensity for supply side and demand side. Moreover, the aggregation of the whole world, EU and EU Enlargement countries are calculated as well. The decomposition results of the EU cover $27 \mathrm{EU}$ members ${ }^{35}$, and the EU Enlargement countries contain $12 \mathrm{EU}$ states joining the EU after 2004 EU Enlargement ${ }^{36}$.

\subsubsection{Structural decomposition results of energy consumption at economy level}

\subsubsection{Supply side}

Table 2.1 illustrates the decomposition results of relative change of supply side energy consumption of selected major economies in the world. EU members are aggregated into "EU" or "EU Enlargement" for comparison purpose. Table 2.9 in Appendix 2.2 provides full decomposition results including every single EU state.

\footnotetext{
${ }^{35} \mathrm{EU}$ members covered in decompositions: AUT, BEL, BGR, CYP, CZE, DNK, EST, FIN, FRA, DEU, GBR, GRC, HUN, IRL, ITA, LVA, LTU, LUX, MLT, NLD, POL, PRT, ROM, SVK, SVN, ESP, and SWE.

${ }^{36}$ EU Enlargement members covered in decompositions: CYP, EST, LVA, LTU, POL, CZE, SVK, HUN, MLT, SVN, ROM, and BGR.
} 
In table 2.1, Factor 1, the impact of change in energy intensity, is lower than 1 in most economies except in Australia, Brazil, Japan, Mexico and Turkey, which implies that due to energy efficiency related technological change, most economies have improved their energy efficiencies in production significantly. At the world level, the value of Factor 1 is 0.7898. The four largest improvements can be found in Taiwan (about 65.25\%), Mainland China (about 46.55\%), RoW (about 34.85\%), and EU Enlargement economies (about 31.34\%), while in some more developed economies, the improvements are much smaller or there is even a decrease in energy efficiency, for example, around $3.33 \%$ in the U.S., $19.07 \%$ in the EU, and $-14.54 \%$ in Japan. The explanation is that in developing and transition economies, the starting levels of energy efficiency are very low, while through technological change (for example, learning and applying energy efficient technologies from developed economies), they might achieve leap frog developments in energy efficiency.

Factor 2, the impact of change in inter-industry structure, indicates the changing shares of outputs within the sectors. At the world level, as well as in six other economies, the value of Factor 2 is larger than 1, which means that in those economies, due to production related technological change, sectors consume more intermediate inputs and expand their production levels, which leads to a positive effect in aggregate energy consumption. The largest improvement is observed in Taiwan (about 54.97\%). In some developed economies such as Australia, Canada, Japan, and USA, however, Factor 2 restricts the growth of aggregate energy consumption, but not heavily.

Factor 3, the impact of change in trade structure in intermediate inputs, is quite dynamic: it is larger than 1 in seven economies and smaller than 1 in the others. This effect is quite neutral at the world level. The three largest positive impacts on aggregate energy consumption can be found in Taiwan (1.6074), Mainland China (1.1567) and South Korea (1.1268) which are major players in international trade.

Factor 4, the impact of change structural coefficient, is larger than 1 in Mainland China, India, Indonesia, South Korea, Taiwan and RoW, which implies that the economic sectors from these economies have an increasing share in global economy. In some developed economies such as Japan, USA and the EU, Factor 4 is smaller than 1, probably due to outsourcing.

Factor 5, the impact of change total final demand, is larger than 1 in all the economies, which implies that all the economies consume an increasing number of commodities, driving the aggregate energy consumption to increase significantly (that is, using more energy in production). At the world level, the value of Factor 5 is 1.5504. The strongest effect is observed in China (2.3642) while the smallest effect is in Japan (1.0753).

Factor 6, the impact of change energy consumed in households, is quite dynamic as well. In all the economies, the values of Factor 6 are quite close to 1, which means that this factor for all the economies is very small or even neutral. 
Table 2.1 Structural decomposition of supply side energy consumption of selected economies

\begin{tabular}{|c|c|c|c|c|c|c|c|}
\hline Econom & $\begin{array}{l}\text { y Relative change } \\
\text { of supply side } \\
\text { energy use } \\
\text { between } 2009 \\
\text { and } 1995\end{array}$ & $\begin{array}{l}\text { Factor 1: } \\
\text { change in e: } \\
\text { intensity effect }\end{array}$ & $\begin{array}{l}\text { Factor } 2 \text { : } \\
\text { change in } A^{*} \text { : } \\
\text { inter-industry } \\
\text { structural effect }\end{array}$ & $\begin{array}{l}\text { Factor 3: } \\
\text { change in } A^{\top} \text { : } \\
\text { trade effect in } \\
\text { tintermediate } \\
\text { inputs }\end{array}$ & $\begin{array}{l}\text { Factor } 4 \text { : } \\
\text { change in s: } \\
\text { structural } \\
\text { change effect in } \\
\text { final demand }\end{array}$ & $\begin{array}{l}\text { Factor 5: } \\
\text { change in C: } \\
\text { total final } \\
\text { demand effect }\end{array}$ & $\begin{array}{l}\text { Factor 6: } \\
\text { change in } \mathrm{H} \text { : } \\
\text { household } \\
\text { consumption } \\
\text { effect }\end{array}$ \\
\hline AUS & 1.2054 & 1.0590 & 0.9868 & 0.7835 & 0.8825 & 1.6639 & 1.0026 \\
\hline BRA & 1.5439 & 1.0735 & 1.1074 & 0.9659 & 0.9298 & 1.4317 & 1.0099 \\
\hline CAN & 1.0937 & 0.7160 & 0.9795 & 1.0573 & 0.9563 & 1.5366 & 1.0038 \\
\hline $\mathrm{CHN}$ & 2.0936 & 0.5343 & 1.2143 & 1.1567 & 1.1935 & 2.3642 & 0.9888 \\
\hline IDN & 1.4098 & 0.9417 & 1.0802 & 0.9157 & 1.0099 & 1.4228 & 1.0533 \\
\hline IND & 1.9318 & 0.9088 & 0.9628 & 1.0363 & 1.0766 & 1.9086 & 1.0369 \\
\hline JPN & 0.9943 & 1.1454 & 0.9303 & 0.9264 & 0.9370 & 1.0753 & 0.9998 \\
\hline KOR & 1.8218 & 0.9631 & 0.9840 & 1.1268 & 1.0290 & 1.6094 & 1.0301 \\
\hline MEX & 1.2317 & 1.0603 & 0.9786 & 0.9359 & 0.8099 & 1.5683 & 0.9986 \\
\hline RUS & 1.0144 & 0.8887 & 0.9638 & 0.9073 & 0.8510 & 1.6005 & 0.9583 \\
\hline TUR & 1.4681 & 1.0101 & 0.8593 & 0.9846 & 0.9736 & 1.6456 & 1.0722 \\
\hline TWN & 1.7825 & 0.3475 & 1.5497 & 1.6074 & 1.2549 & 1.6365 & 1.0028 \\
\hline USA & 1.0296 & 0.9667 & 0.9061 & 0.9223 & 0.9067 & 1.4095 & 0.9972 \\
\hline RoW & 1.3804 & 0.6515 & 1.1917 & 1.0938 & 1.0653 & 1.4360 & 1.0625 \\
\hline World & 1.2901 & 0.7898 & 1.0470 & 1.0063 & 0.9870 & 1.5504 & 1.0131 \\
\hline EU & 1.0060 & 0.8093 & 1.0408 & 0.9431 & 0.9230 & 1.3644 & 1.0056 \\
\hline EU & 0.9110 & 0.6866 & 0.9521 & 0.9325 & 0.9753 & 1.5515 & 0.9875 \\
\hline \multicolumn{8}{|c|}{$\begin{array}{l}\text { Enlarge- } \\
\text { ment }\end{array}$} \\
\hline
\end{tabular}

Change of supply side energy use in Table 2.1 indicates the ratio of gross energy consumption between the year 1995 and 2009. If the value is larger than 1, it implies that the economy consumed more energy in 2009, compared to the year 1995. Most economies in Table 2.1 have a value larger than 1, except Japan and EU Enlargement economies. Among all the economies in Table 2.1, the largest decrease in energy consumption is observed in EU Enlargement economies, around 8.9\%, while in Japan, energy consumption drops to approximately $0.57 \%$. In the case of EU Enlargement economies, values of all the factors except Factor 5 are smaller than 1.

\subsubsection{Demand side}

Table 2.2 shows demand side energy decomposition results of selected economies. Table 2.10 in Appendix 2.2 provides full results including every single EU state. 
Table 2.2 Structural decomposition of demand side energy consumption of selected economies

\begin{tabular}{|c|c|c|c|c|c|c|c|}
\hline Economy & $\begin{array}{l}\text { Relative } \\
\text { change of } \\
\text { demand side } \\
\text { energy use } \\
\text { between } \\
2009 \text { and } \\
1995\end{array}$ & $\begin{array}{l}\text { Factor 1: } \\
\text { change in } \\
\text { e e: intensity } \\
\text { effect }\end{array}$ & $\begin{array}{l}\text { Factor 2: } \\
\text { change in A } \\
\text { inter- } \\
\text { industry } \\
\text { structural } \\
\text { effect }\end{array}$ & $\begin{array}{l}\text { Factor } 3: \\
\text { * : change in } A^{\top}: \\
\text { trade effect in } \\
\text { intermediate } \\
\text { inputs }\end{array}$ & $\begin{array}{l}\text { Factor 4: } \\
\text { change in s: } \\
\text { structural } \\
\text { change } \\
\text { effect in } \\
\text { final } \\
\text { demand }\end{array}$ & $\begin{array}{l}\text { Factor 5: } \\
\text { change in } \\
\text { C: total } \\
\text { final } \\
\text { demand } \\
\text { effect }\end{array}$ & $\begin{array}{l}\text { Factor } 6 \text { : } \\
\text { change in } \mathrm{H} \text { : } \\
\text { household } \\
\text { consumption } \\
\text { effect }\end{array}$ \\
\hline AUS & 1.7234 & 0.9014 & 0.9994 & 1.0690 & 1.0511 & 1.6982 & 1.0026 \\
\hline BRA & 1.5164 & 0.9983 & 1.1255 & 1.0102 & 0.9500 & 1.3930 & 1.0096 \\
\hline CAN & 1.2957 & 0.7422 & 1.0550 & 1.0234 & 0.9979 & 1.6133 & 1.0044 \\
\hline $\mathrm{CHN}$ & 1.9632 & 0.5692 & 1.2544 & 0.9635 & 1.0282 & 2.8076 & 0.9885 \\
\hline IDN & 1.6823 & 0.7959 & 1.2762 & 1.0263 & 1.1218 & 1.3516 & 1.0643 \\
\hline IND & 1.8699 & 0.8729 & 1.0078 & 0.9721 & 1.0389 & 2.0302 & 1.0367 \\
\hline JPN & 0.9507 & 0.9464 & 0.9580 & 1.0547 & 1.0034 & 0.9910 & 0.9998 \\
\hline KOR & 1.4585 & 0.8717 & 1.0388 & 1.0714 & 0.9552 & 1.5253 & 1.0319 \\
\hline MEX & 1.4251 & 0.9461 & 0.9962 & 1.0344 & 0.9136 & 1.6016 & 0.9990 \\
\hline RUS & 1.0076 & 0.8952 & 0.8645 & 0.9821 & 0.8316 & 1.6906 & 0.9431 \\
\hline TUR & 1.7035 & 0.8776 & 0.9674 & 1.0817 & 1.0288 & 1.7168 & 1.0503 \\
\hline TWN & 1.1615 & 0.5083 & 1.3985 & 0.9745 & 1.1664 & 1.4338 & 1.0027 \\
\hline USA & 1.1263 & 0.8914 & 0.9305 & 1.0255 & 0.9554 & 1.3893 & 0.9975 \\
\hline RoW & 1.3142 & 0.6825 & 1.1118 & 0.9865 & 1.0137 & 1.6057 & 1.0787 \\
\hline World & 1.2901 & 0.7898 & 1.0470 & 1.0063 & 0.9870 & 1.5504 & 1.0131 \\
\hline EU & 1.1148 & 0.7831 & 1.0802 & 1.0043 & 0.9992 & 1.3071 & 1.0047 \\
\hline \multicolumn{2}{|c|}{ EU Enlargement 1.0865} & 0.7517 & 1.0368 & 0.9228 & 0.9354 & 1.6340 & 0.9884 \\
\hline
\end{tabular}

Factor 1 , the impact of change in energy intensity, is much lower than 1 in all the economies, which means that all the economies consume more energy efficient products, probably due to energy efficiency related technological change of the producers. Accordingly, Factor 1 would cause a strong negative impact on aggregate energy consumption by sector. Specifically, the Factor 1 of Taiwan (0.5083) and Mainland China (0.5692) is much lower than the world level (0.7898).

At the world level, Factor 2 (impact of change inter-industry structure), Factor 3 (impact of change trade structure in intermediate inputs) and Factor 4 (impact of change structure coefficient) have a small fluctuation around 1, which implies a neutral effect. In other economies, these three factors are quite dynamic. Interestingly, for major international trade players such as Mainland China, Taiwan and South Korea, Factor 3 is smaller on demand side than on supply side, and specifically the Factor 3 of Mainland China and Taiwan would cause a negative impact on demand side energy consumption. The reason is that these economies are export-oriented. 
The value of Factor 5 (impact of change in total final demand) is much higher than 1 in all the economies except in Japan, which implies that with the development of society and the economy, an increasing number of commodities would be consumed. To satisfy the increasing demand, more energy would be used in expanding production. Factor 5 of China (2.8076) and India (2.0302) is much higher than the world level (1.5504). Similarly, Factor 6, the impact of change in energy consumed in households, is still very weak in all the economies.

\subsubsection{Basic conclusions}

Interestingly, manufacturing-based developing economies consume more energy on supply side than on demand side, as in China and Mexico for example. This is probably due to manufacturing outsourcing. The same phenomenon can be observed in some manufacturing-based developed economies such as Japan and South Korea. Figure 2.4 and Figure 2.5 provide a more intuitional illustration of the six factors that affect aggregate energy consumption. After taking log points, all six factors are illustrated in the bar chart.

\section{Compensation Effect}

In both Figure 2.4 and Figure 2.5, Factor 1 and Factor 5 cause two very strong effects on aggregate energy consumption in most economies, but in opposite directions: the negative impact is caused by Factor 1, while Factor 5 significantly and positively contributes to the increase in aggregate energy consumption. Officially, this phenomenon is called "compensation effect" in this article, which means that the energy conservation due to energy efficiency related technological change would be roughly (or partly) offset by the energy consumption increase by change in total final demand. A similar finding can be found in Weber (2009)'s SDA study of the U.S. energy use ${ }^{37}$. In other words, as a result of socio-economic development, people consume more commodities, which should have greatly stimulated the demand for energy in production. But thanks to energy efficiency related technological change, the energy consumption does not increase that sharply. This demonstrates the importance of improving energy efficiency for sustainable development.

\footnotetext{
${ }^{37}$ However, in Weber (2009)'s study, the compensation effect is formed by rising population and household consumption that drive up energy demand, and structural change within the economy which is related to a quickly increasing trade deficit in manufacturing goods. The energy intensity effect is smaller.
} 


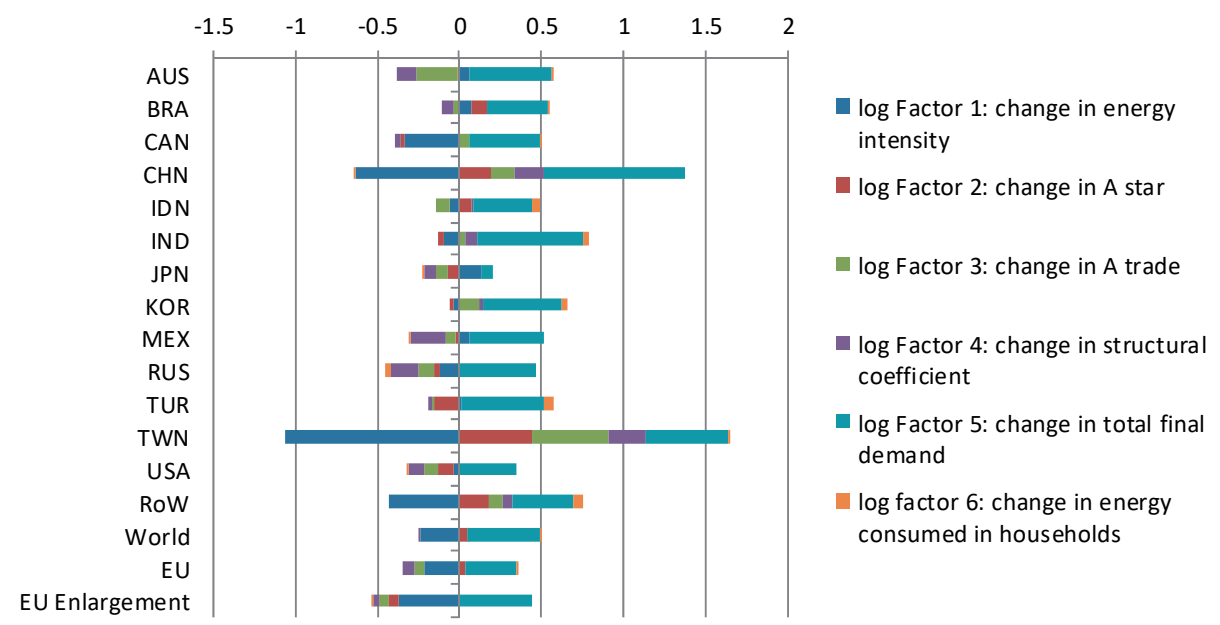

Figure 2.4 Structural decomposition of supply side energy consumption of selected economies (log points)

\section{Small Trade Effect}

In Figure 2.4 and Figure 2.5, the effect of change in trade structure in intermediate inputs (Factor 3 ) is found to be relatively much smaller (except in some economies such as Australia and Taiwan on supply side). A similar finding can be found in the research on labor productivity conducted by Dietzenbacher et al. (2000) as well, but the finding is contrary to Weber (2009)'s study on the U.S. indicating that structural change caused by a quickly increasing trade deficit in manufacturing good can be explained more in the drop of energy demand. In economies such as Australia, Mainland China, South Korea, and Taiwan on supply side, the trade effect seems to be much stronger than in other economies, while in some other major players in international trade like the U.S. and the EU, the trade effect tends to be neutral. At the whole world level, the small trade effect is confirmed as well. A possible explanation might be that the demand for those energy intensive commodities in intermediate inputs can be satisfied in the domestic market, rather than through trade on the international market.

As shown in both figures, it seems that in relatively more developed economies, the aggregate impact of the six factors is weaker than that in developing economies: intuitionally, the bar representing the developed economy is significantly "shorter" than the one indicating the developing economy (for example, the EU and EU Enlargement, Mainland China, Japan, South Korea, and the U.S.) ${ }^{38}$. Such a phenomenon is reasonable: considering the fact that Factor 1 and Factor 5 are the two major factors in most economies, the starting levels of energy efficiency and socio-economic development in developed economies are much higher than those in developing economies. Consequently, the improvements of energy efficiency and final demand in developed economies would be

\footnotetext{
${ }^{38}$ There are several exceptions, such as Brazil and India.
} 
relatively limited in the scalar sense. This might suggest the catching-up development of developing economies in energy efficiency and final demand consumption.

Additionally, as illustrated in Table 2.9, Table 2.10,Figure 2.16 and Figure 2.17 in Appendix 2.2, for every single EU member, the catching-up development of relatively less developed EU economies (e.g., countries joining the EU after 2004 Enlargement) is found as well. Factor 5 is still the main driving force of increasing energy consumption, while Factor 1 becomes weaker. A compensation effect can be found in 10 out of $27 \mathrm{EU}$ members on supply side and in 21 out of $27 \mathrm{EU}$ members on demand side.

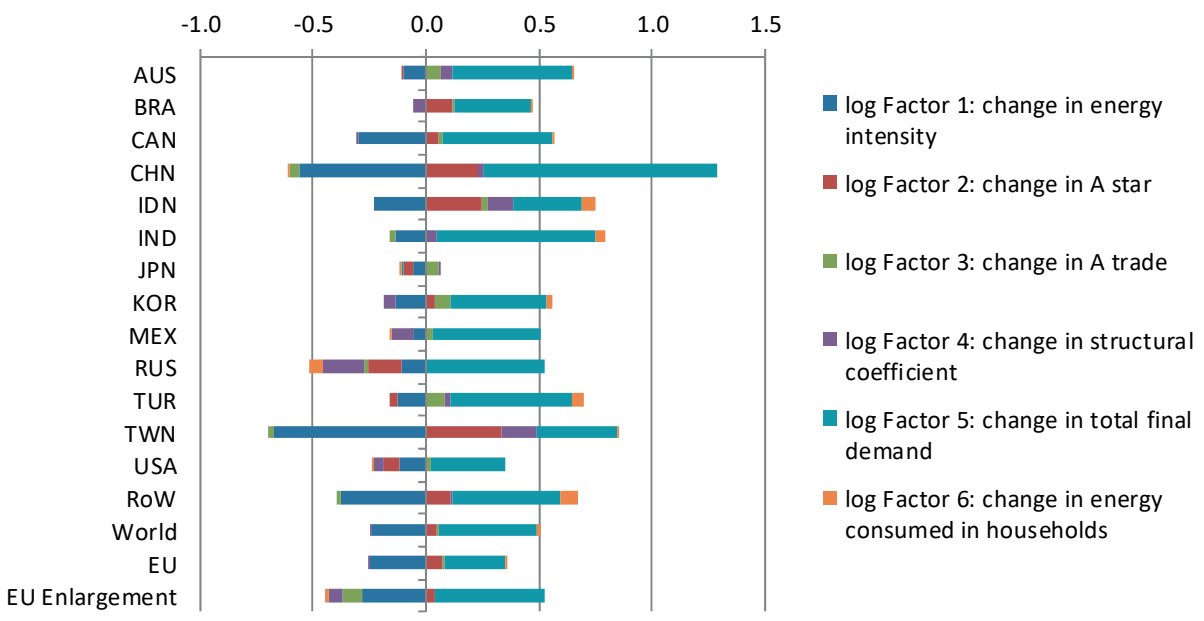

Figure 2.5 Structural decomposition of demand side energy consumption of selected economies (log points)

\subsubsection{Structural decomposition results of energy intensity at economy level}

\subsubsection{Supply side}

Table 2.3 shows the supply side energy intensity decomposition results and Figure 2.6 illustrates a bar chart of six factors (in log points). Aggregation results for the world, EU and EU Enlargement are listed for comparison purpose. The relative change of supply side aggregate energy intensity is lower than 1 in almost all the economies except in Brazil where the total supply side energy intensity increased by about $3.71 \%$ between 1995 and 2009. In all the other economies, the catching-up development of energy efficiency only exists in a part of developing economies (e.g., Mainland China) and transition economies (e.g., Russia and EU Enlargement economies). Developed economies such as Australia, Canada, USA and EU perform better than the world level (0.8130).

Factor 1 , the impact of change in energy intensity within sectors is smaller than 1 in 12 out of 17 economies, and is the strongest negative in 7 out of 17 economies. Due to energy efficiency related technological change, energy intensity within sectors has been 
greatly improved and become the most crucial factor: one unit of energy can be used to produce more outputs. A key finding is that the catching-up development in supply side energy intensity exists in some developing and transition economies. For example, economies such as Taiwan (0.3475), Mainland China (0.5343), RoW (0.6515) and EU Enlargement economies (0.6866) have a considerably strong Factor 1 , which is much stronger in major developed economies such as the U.S. (0.9667), EU (0.8093), Japan (1.1454) and the world level (0.7898).

Factor 2, the impact of change in inter-industry structure, affects the aggregate energy intensity negatively in most economies except in Brazil, China, Indonesia, Taiwan, and RoW. At the world level, this factor is very weak (0.9920). The explanation might be that responding to the great growth of commodities consumption in final demand, the direct effect of production related technological change is to expand the scale of production where most products are produced, which might lead to a faster growth of energy demand in production in products' home countries. This factor is much stronger in economies such as Russia, Turkey and Taiwan.

Table 2.3: Structural decomposition of supply side energy intensity of selected economies

\begin{tabular}{|c|c|c|c|c|c|c|c|}
\hline Econom & $\begin{array}{l}\text { Relative change } \\
\text { of supply side } \\
\text { energy intensity } \\
\text { between } 2009 \\
\text { and } 1995\end{array}$ & $\begin{array}{l}\text { Factor 1: } \\
\text { change in e: } \\
\text { yintensity effect }\end{array}$ & $\begin{array}{l}\text { Factor } 2 \text { : } \\
\text { change in } A^{*}: \\
\text { inter-industry } \\
\text { structural effect }\end{array}$ & $\begin{array}{l}\text { Factor 3: } \\
\text { change in } A^{\top} \text { : } \\
\text { trade effect in } \\
\text { tintermediate } \\
\text { inputs }\end{array}$ & $\begin{array}{l}\text { Factor 4: } \\
\text { change in s: } \\
\text { structural } \\
\text { change effect ir } \\
\text { final demand }\end{array}$ & $\begin{array}{l}\text { Factor 5: } \\
\text { change in C: } \\
\text { total final } \\
\text { n demand effect }\end{array}$ & $\begin{array}{l}\text { Factor } 6 \text { : } \\
\text { change in } \mathrm{H} \text { : } \\
\text { household } \\
\text { consumption } \\
\text { effect }\end{array}$ \\
\hline AUS & 0.7627 & 1.0590 & 0.9172 & 0.8525 & 0.9426 & 0.9747 & 1.0026 \\
\hline BRA & 1.0371 & 1.0735 & 1.0190 & 0.9905 & 0.9499 & 0.9976 & 1.0099 \\
\hline CAN & 0.6668 & 0.7160 & 0.9528 & 1.0203 & 0.9978 & 0.9566 & 1.0038 \\
\hline $\mathrm{CHN}$ & 0.4199 & 0.5343 & 1.0748 & 0.9621 & 0.9440 & 0.8144 & 0.9888 \\
\hline IDN & 0.8671 & 0.9417 & 1.0328 & 0.9032 & 1.0026 & 0.9347 & 1.0533 \\
\hline IND & 0.7600 & 0.9088 & 0.9617 & 1.0183 & 1.0271 & 0.8019 & 1.0369 \\
\hline JPN & 0.9861 & 1.1454 & 0.9172 & 0.9666 & 0.9767 & 0.9945 & 0.9998 \\
\hline KOR & 0.8740 & 0.9631 & 0.9450 & 0.9773 & 0.9514 & 1.0025 & 1.0301 \\
\hline MEX & 0.7675 & 1.0603 & 0.9688 & 0.9289 & 0.8192 & 0.9832 & 0.9986 \\
\hline RUS & 0.6006 & 0.8887 & 0.8419 & 0.9797 & 0.9523 & 0.8978 & 0.9583 \\
\hline TUR & 0.6285 & 1.0101 & 0.7819 & 0.8842 & 0.9138 & 0.9186 & 1.0722 \\
\hline TWN & 0.9161 & 0.3475 & 1.4487 & 1.3884 & 1.2665 & 1.0321 & 1.0028 \\
\hline USA & 0.7467 & 0.9667 & 0.8852 & 0.9555 & 0.9299 & 0.9849 & 0.9972 \\
\hline RoW & 0.7001 & 0.6515 & 1.0677 & 1.0597 & 1.0613 & 0.8422 & 1.0625 \\
\hline World & 0.8130 & 0.7898 & 0.9920 & 1.0040 & 0.9903 & 1.0302 & 1.0131 \\
\hline EU & 0.7328 & 0.8093 & 0.9808 & 0.9634 & 0.9521 & 1.0009 & 1.0056 \\
\hline EU & 0.4919 & 0.6866 & 0.9001 & 0.9041 & 0.9501 & 0.9384 & 0.9875 \\
\hline \multicolumn{8}{|l|}{$\begin{array}{l}\text { Enlarge- } \\
\text { ment }\end{array}$} \\
\hline
\end{tabular}


In regard to the other four factors, generally they have much weaker impacts on total supply side energy intensity. At the world level, they have a tiny fluctuation around the value 1 (Factor 3: 1.0040, Factor 4: 0.9903, Factor 5: 1.0302, and Factor 6: 1.0131). Similar findings can be found in developed economies such as Japan, USA and EU.

In Table 2.11 and Figure 2.18 in Appendix 2.2, full structural decomposition results of energy intensity for every single EU member state are illustrated. In the EU, the total supply side energy intensity was lowered in all the EU states except in Italy where it slightly increased by $0.19 \%$ in 2009. In 18 EU states Factor 1 contributes to a decline in total supply side energy intensity, and in $13 \mathrm{EU}$ states Factor 1 is the strongest negative factor.

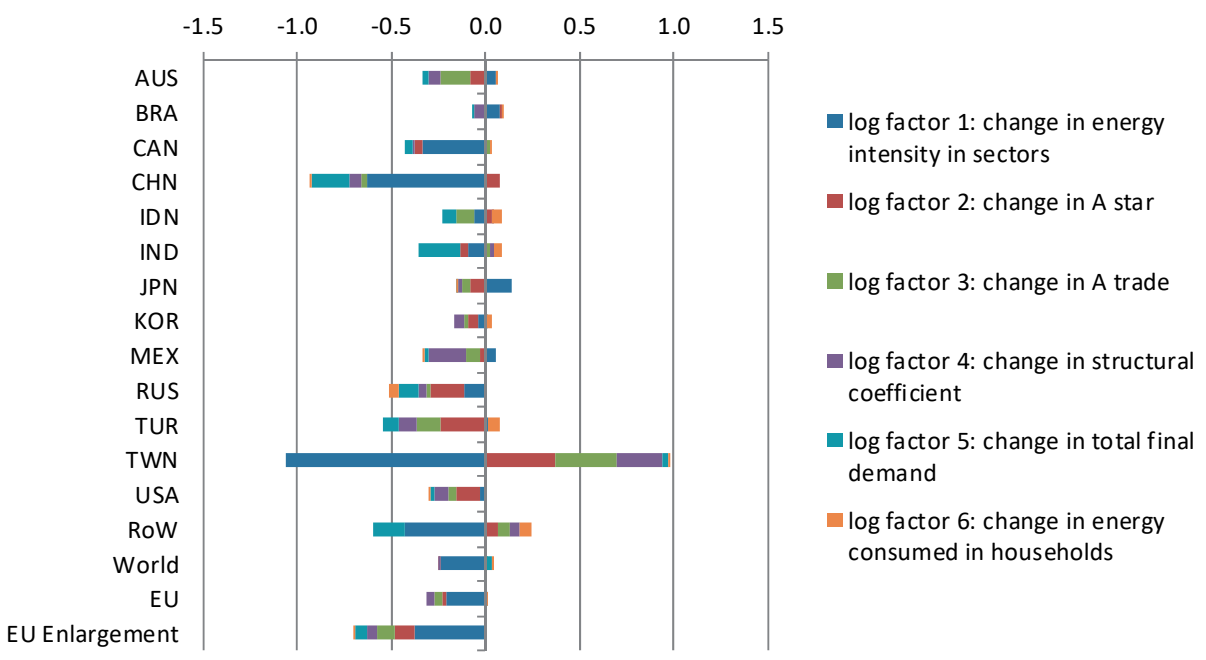

Figure 2.6 Structural decomposition of supply side energy intensity of selected economies (log points)

\subsubsection{Demand side}

Table 2.4 and Figure 2.7 show the decomposition results for demand side energy intensity. Likewise, the aggregation results for the world, EU and EU Enlargement are provided. Generally, the total demand side energy intensity declined in 2009 in almost all the listed economies except in Indonesia where a small increase $(0.53 \%)$ is observed. At the world level, it decreased by $17.3 \%$ in 2009 compared to the 1995 level. Both developed and developing economies perform better than the world level (e.g., Mainland China: 56.71\%, USA: 21.32\%, EU: 19.71\%). The EU Enlargement economies perform much better than the EU level. The result implies that less energy intensive products are consumed.

Factor 1, the impact of change in energy intensity within sectors is lower than 1 in all the economies, and it is the strongest negative factor in 11 out 17 economies. At the 
world level, the value of Factor 1 is 0.7898 , and two economies with strong Factor 1 are found in Taiwan (0.5083) and Mainland China (0.5692).

Factor 2, the impact of change in inter-industry structure, tends to be quite strong in some economies such as Indonesia, Russia, Taiwan and USA, while it is relatively weaker in the other economies. Similarly, Factor 3, Factor 4, Factor 5 and Factor 6 seem to cause a small fluctuation in total demand side energy intensity in general. At the world level, these five factors are very close to 1 . However, there are some exceptions. For instance, Factor 4 is quite strong in Russia and Taiwan and Factor 5 has a powerful negative impact in Mainland China and India.

Table 2.4 Structural decomposition of demand side energy intensity of selected economies

\begin{tabular}{|c|c|c|c|c|c|c|c|}
\hline Economy & $\begin{array}{l}\text { Relative change } \\
\text { of demand side } \\
\text { energy intensity } \\
\text { between } 2009 \\
\text { and } 1995\end{array}$ & $\begin{array}{l}\text { Factor 1: } \\
\text { change in e: } \\
\text { intensity } \\
\text { effect }\end{array}$ & $\begin{array}{l}\text { Factor } 2 \text { : } \\
\text { change in } A^{*}: \\
\text { inter-industry } \\
\text { structural } \\
\text { effect }\end{array}$ & $\begin{array}{l}\text { Factor } 3 \text { : } \\
\text { change in } A^{\top} \text { : } \\
\text { trade effect in } \\
\text { intermediate } \\
\text { inputs }\end{array}$ & $\begin{array}{l}\text { Factor } 4 \text { : } \\
\text { change in s: } \\
\text { structural } \\
\text { change effect in } \\
\text { final demand }\end{array}$ & $\begin{array}{l}\text { Factor 5: } \\
\text { change in C: } \\
\text { total final } \\
\text { demand } \\
\text { effect }\end{array}$ & $\begin{array}{l}\text { Factor } 6 \text { : } \\
\text { change in } \mathrm{H} \text { : } \\
\text { household } \\
\text { consumption } \\
\text { effect }\end{array}$ \\
\hline AUS & 0.9578 & 0.9014 & 0.9637 & 1.0647 & 1.0532 & 0.9807 & 1.0026 \\
\hline BRA & 0.9816 & 0.9983 & 1.0335 & 1.0080 & 0.9473 & 0.9870 & 1.0096 \\
\hline CAN & 0.7092 & 0.7422 & 0.9897 & 1.0210 & 0.9746 & 0.9660 & 1.0044 \\
\hline $\mathrm{CHN}$ & 0.4329 & 0.5692 & 1.0545 & 0.9763 & 0.9812 & 0.7616 & 0.9885 \\
\hline IDN & 1.0053 & 0.7959 & 1.1383 & 1.0248 & 1.1084 & 0.9179 & 1.0643 \\
\hline IND & 0.6938 & 0.8729 & 0.9795 & 0.9698 & 1.0190 & 0.7920 & 1.0367 \\
\hline JPN & 0.9694 & 0.9464 & 0.9420 & 1.0540 & 1.0317 & 1.0001 & 0.9998 \\
\hline KOR & 0.8966 & 0.8717 & 0.9630 & 1.0643 & 0.9900 & 0.9823 & 1.0319 \\
\hline MEX & 0.8090 & 0.9461 & 0.9625 & 1.0252 & 0.8872 & 0.9778 & 0.9990 \\
\hline RUS & 0.4782 & 0.8952 & 0.7987 & 0.9790 & 0.8333 & 0.8693 & 0.9431 \\
\hline TUR & 0.7794 & 0.8776 & 0.8329 & 1.0773 & 1.0160 & 0.9276 & 1.0503 \\
\hline TWN & 0.8578 & 0.5083 & 1.3798 & 0.9720 & 1.2586 & 0.9972 & 1.0027 \\
\hline USA & 0.7868 & 0.8914 & 0.9104 & 1.0223 & 0.9677 & 0.9825 & 0.9975 \\
\hline RoW & 0.6496 & 0.6825 & 1.0323 & 0.9796 & 1.0064 & 0.8670 & 1.0787 \\
\hline World & 0.8130 & 0.7898 & 0.9920 & 1.0040 & 0.9903 & 1.0302 & 1.0131 \\
\hline EU & 0.8029 & 0.7831 & 1.0167 & 1.0022 & 1.0015 & 0.9999 & 1.0047 \\
\hline $\begin{array}{l}\text { EU } \\
\text { Enlarge- } \\
\text { ment }\end{array}$ & 0.5486 & 0.7517 & 0.9239 & 0.9254 & 0.9255 & 0.9330 & 0.9884 \\
\hline
\end{tabular}




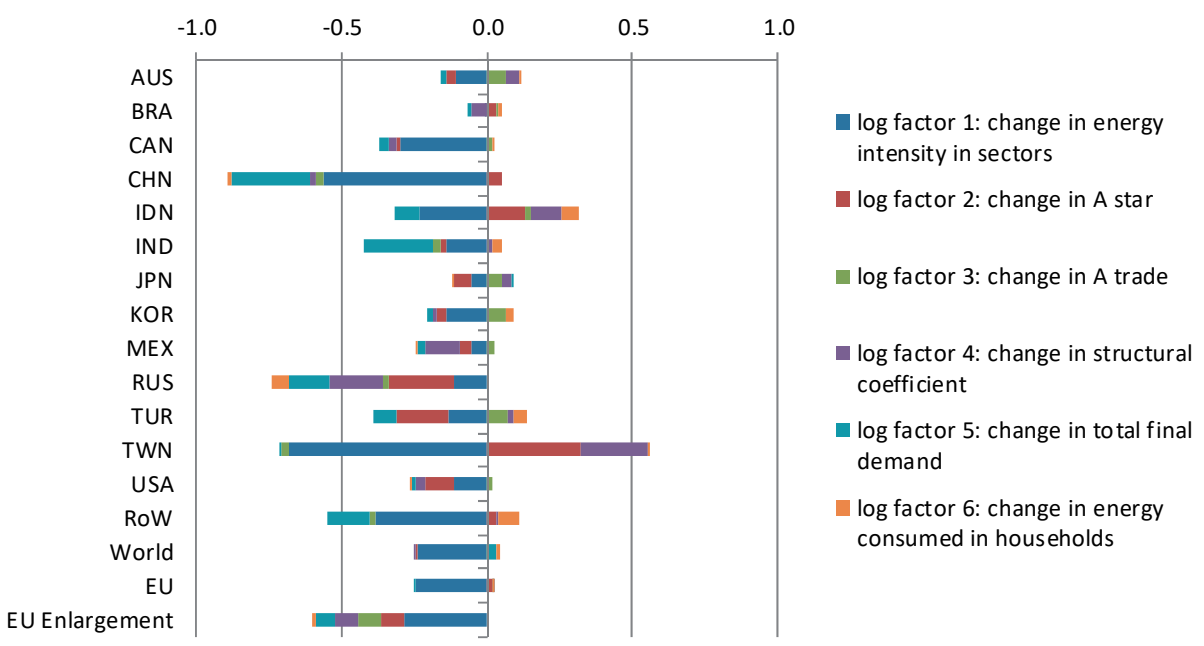

Figure 2.7 Structural decomposition of demand side energy intensity of selected economies (log points)

Table 2.12 and Figure 2.19 in Appendix 2.2 show decomposition results for every single EU member. The total demand side energy intensity declined in all the EU countries in 2009 compared to the 1995 level. Factor 1 causes a negative impact in all the EU countries except in Hungary. Specifically, Factor 1 is the most powerful negative factor in 20 EU countries. Factor 2, Factor 3 and Factor 4 seem to be much stronger in EU countries.

\subsubsection{Convergence analysis}

Following the definitions shown in Equation (26), (27) and (28), simple OLS is employed to check whether economies would converge on the world level ${ }^{39}$ for supply side and demand side using initial relative energy intensity as the independent variable and the growth of relative energy intensity as the dependent variable. Table 2.15 and Table 2.16 in Appendix 2.3 show full regression results. Both slopes in OLS are negative and significant at $1 \%$ level.

For supply side,

$$
G R E I=-0.2109 * R E I_{1995}+0.1563+e ; \quad R^{2}=0.4029
$$

For demand side,

$$
G R E I=-0.3057 * R E I_{1995}+0.3391+e^{\prime} ; \quad R^{2}=0.5260
$$

\footnotetext{
${ }^{39}$ The world level is 1.
} 


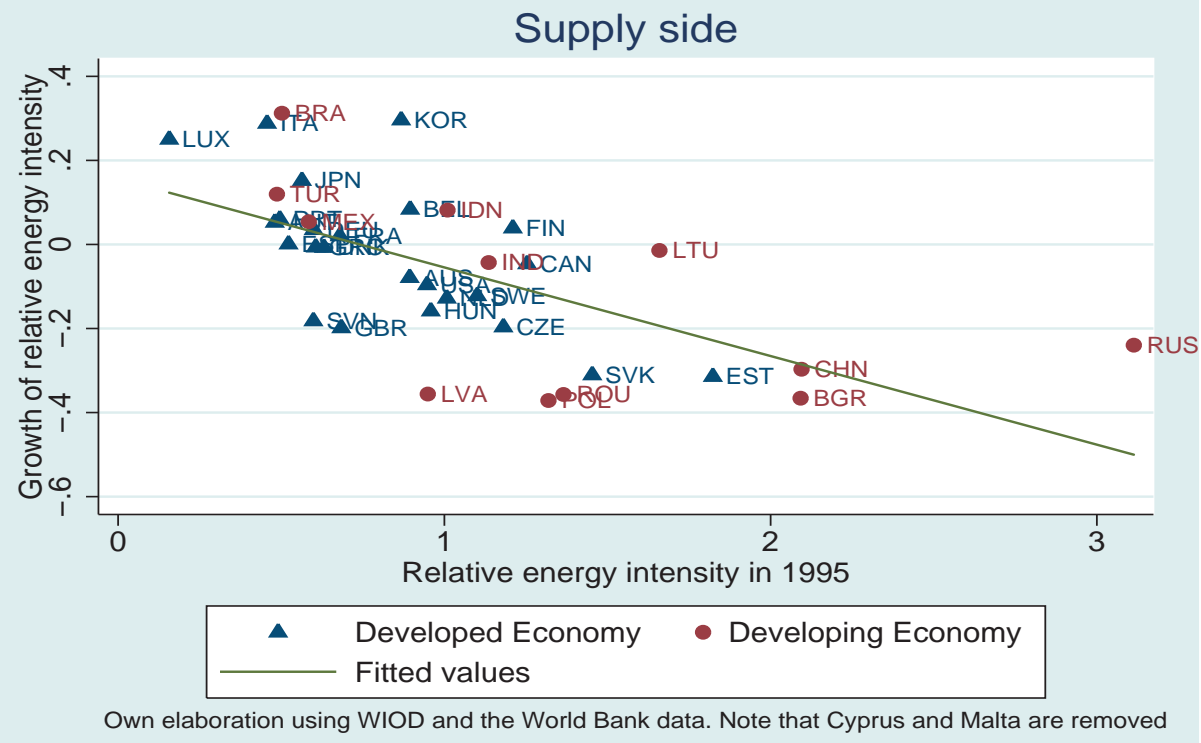

Figure 2.8 Convergence analysis for supply side relative energy intensity

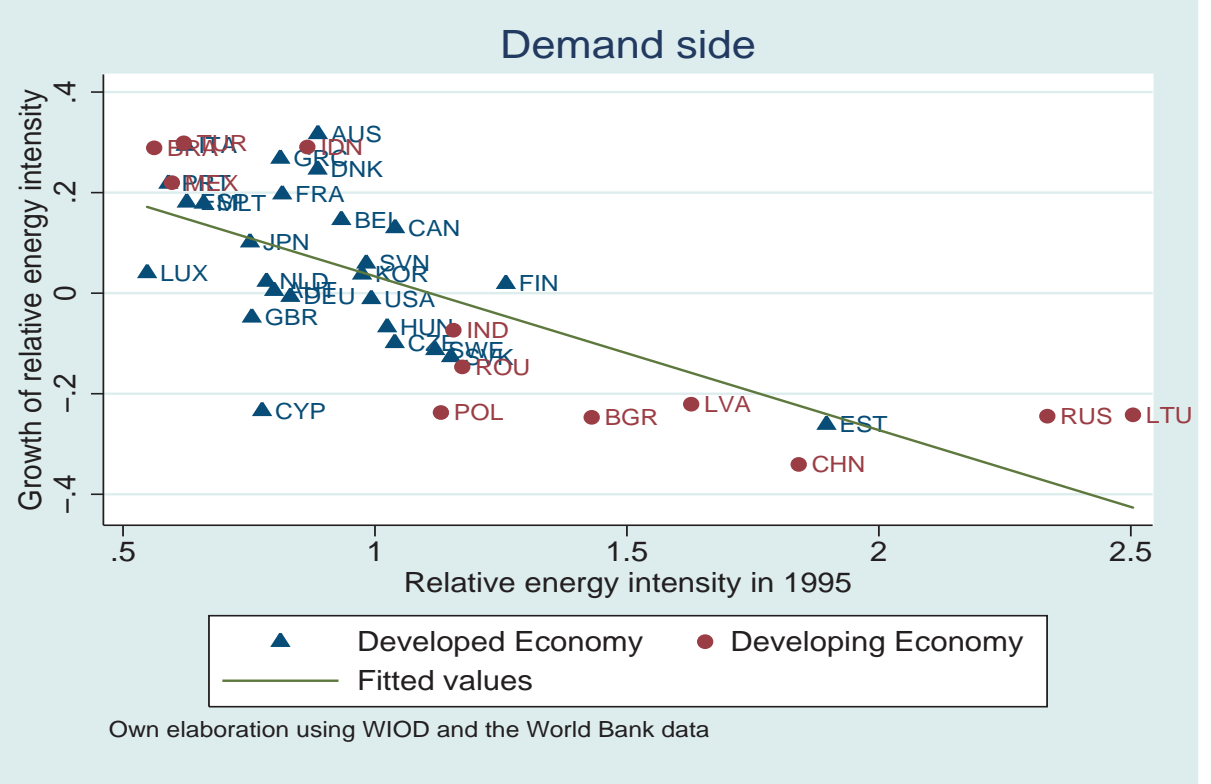

Figure 2.9 Convergence analysis for demand side relative energy intensity

As shown in Figure 2.8 and Figure 2.9, developed economies perform much better in energy efficiency. The significant negative slope implies that there is a tendency for 
developed and developing economies' energy intensities to converge on a certain level. Probably the reason is the energy efficient technology transfer and diffusion from developed economies to developing economies through international trade, so that the energy intensity gap between developed and developing economies can be narrowed.

\subsubsection{Structural decomposition results at sectoral level}

Equation (20) aims to decompose the relative changes of energy consumption over 1995 to 2009. Equation (21) is used for the decompositions of energy intensity from 1995 to 2009. Table 2.5 below is a collective illustration of decomposition results of energy consumption and energy intensity by aggregated industry and by manufacturing technological level. In Table 2.5, the product of five decomposition factors in principle should be equal to the relative change between 1995 and 2009, but there is a very small error in computing. Appendix 2.2 shows a more detailed version of decomposition results by sector listed in WIOD.

Table 2.5 Structural decomposition results of energy consumption and energy intensity, $1995-2009$

\begin{tabular}{|c|c|c|c|c|c|c|c|}
\hline & & $\begin{array}{l}\text { Relative } \\
\text { change } \\
\text { between } \\
2009 \text { and } \\
1995\end{array}$ & $\begin{array}{l}\text { Factor } 1: \\
\text { change in } \\
e \text { : intensity } \\
\text { effect }\end{array}$ & $\begin{array}{l}\text { Factor } 2 \text { : } \\
\text { change in } \\
y A^{*} \text { : inter- } \\
\text { industry } \\
\text { structural } \\
\text { effect }\end{array}$ & $\begin{array}{l}\text { Factor 3: } \\
\text { change in } A^{T} \text { : } \\
\text { trade effect in } \\
\text { intermediate } \\
\text { inputs }\end{array}$ & $\begin{array}{l}\text { Factor 4: } \\
\text { change in } \\
S \text { : } \\
\text { structural } \\
\text { change } \\
\text { effect in } \\
\text { final } \\
\text { demand }\end{array}$ & $\begin{array}{l}\text { Factor } 5 \text { : } \\
\text { change in } \\
C \text { : total } \\
\text { final } \\
\text { demand } \\
\text { effect }\end{array}$ \\
\hline \multirow{6}{*}{$\begin{array}{l}\text { Energy } \\
\text { consumption } \\
\text { decomposition }\end{array}$} & $\begin{array}{l}\text { Total } \\
\text { manufacturing }\end{array}$ & 1.2209 & 0.7733 & 0.9953 & 1.0093 & 0.9744 & 1.6129 \\
\hline & $\begin{array}{l}\text { Low-tech } \\
\text { manufacturing }\end{array}$ & 1.1431 & 0.7691 & 0.9424 & 1.0145 & 0.9215 & 1.6870 \\
\hline & $\begin{array}{l}\text { Medium/low-tech } \\
\text { manufacturing }\end{array}$ & 1.2242 & 0.7809 & 0.9954 & 1.0083 & 0.9748 & 1.6024 \\
\hline & $\begin{array}{l}\text { Medium/high-tech } \\
\text { manufacturing }\end{array}$ & 1.2471 & 0.7027 & 1.0353 & 1.0173 & 1.0109 & 1.6668 \\
\hline & Primary industry & 1.3682 & 0.8385 & 1.1705 & 0.8751 & 0.9372 & 1.6996 \\
\hline & Services & 1.4619 & 0.7472 & 1.1375 & 1.0150 & 1.0052 & 1.6859 \\
\hline \multirow[t]{6}{*}{$\begin{array}{l}\text { Energy intensity } \\
\text { decomposition }\end{array}$} & $\begin{array}{l}\text { Total } \\
\text { manufacturing }\end{array}$ & 0.7641 & 0.7733 & 0.9688 & 0.9969 & 0.9990 & 1.0242 \\
\hline & $\begin{array}{l}\text { Low-tech } \\
\text { manufacturing }\end{array}$ & 0.8572 & 0.7691 & 0.9790 & 1.0072 & 1.0440 & 1.0827 \\
\hline & $\begin{array}{l}\text { Medium/low-tech } \\
\text { manufacturing }\end{array}$ & 0.8103 & 0.7809 & 1.0149 & 0.9967 & 1.0200 & 1.0056 \\
\hline & $\begin{array}{l}\text { Medium/high-tech } \\
\text { manufacturing }\end{array}$ & 0.6596 & 0.7027 & 0.9341 & 1.0007 & 0.9495 & 1.0575 \\
\hline & Primary industry & 0.8051 & 0.8385 & 1.0532 & 0.8601 & 1.0627 & 0.9974 \\
\hline & Services & 0.9296 & 0.7472 & 1.0691 & 1.0186 & 0.9872 & 1.1573 \\
\hline
\end{tabular}


Instead of going into too much detail of some specific sectors, however, this article pays more attention to results at aggregated industry level, because such aggregated results can provide important information about some common patterns shared by those sectors with similar characteristics. More crucially, this article specially focuses on the technological level of the manufacturing sectors, due to the key role that technology plays in development.

\subsubsection{Performance: energy consumption and energy intensity at sectoral level}

This section summarizes the performance in terms of energy consumption and energy intensity by aggregated industry and by manufacturing technological level between 1995 and 2009, on the basis of the decomposition results presented in Table 2.5. Figure 2.10 below compares the performance results in a more intuitional way.

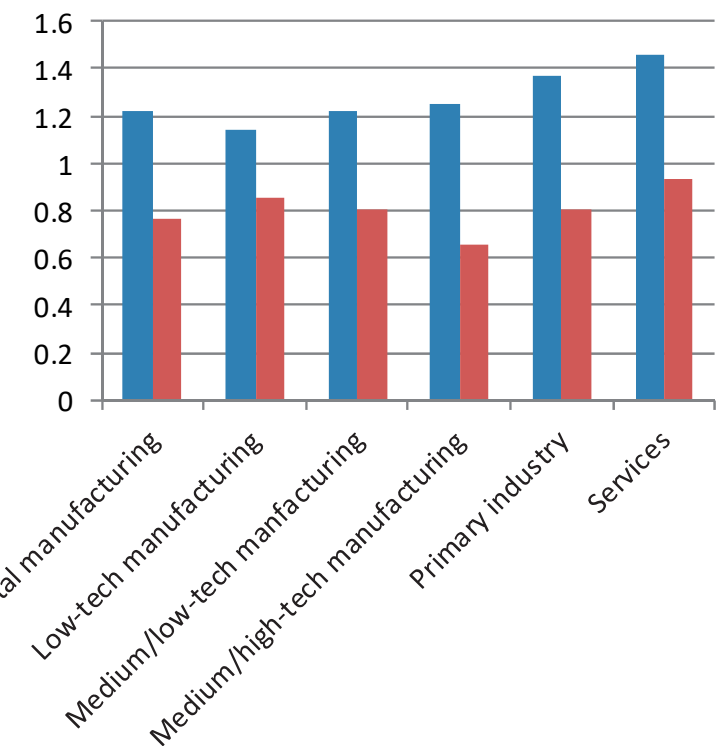

Change of energy consumption between 2009 and 1995

Change of energy intensity between 2009 and 1995

Figure 2.10 Performance in energy consumption and energy intensity from 1995 to 2009

As shown in Figure 2.10, the largest increase in energy consumption is found in services, that is, by $46.19 \%$ compared to 1995 . While the smallest increase in energy consumption is in manufacturing, by $22.09 \%$ in 2009 compared to 1995 . In primary industry, the energy consumption grew by $36.83 \%$ in 2009 , which is between the levels of manufacturing and services. For the performance in energy intensity, the changes in all the industries were below 1 in 2009, which means that the energy efficiency had improved. Interestingly, the same pattern still holds: the best improvement in energy efficiency has been achieved in manufacturing, which corresponds to a $23.59 \%$ decrease in energy intensity. Relatively, the least improved industry is services, which shows a $7.04 \%$ de- 
crease in energy intensity. The explanation for such phenomena is the following. On the one hand, due to structural changes caused by economic development, economic resources have been continuously shifted to services from the other industries, leading to an increasingly large economic scale in services which requires a growing amount of energy. On the other hand, relatively, manufacturing is more technologically intensive, and technological change and innovation play a more crucial role in manufacturing. For example, energy efficient technologies are much easier to be applied in manufacturing.

Specifically, Figure 2.10 presents the performance of three subgroups of manufacturing classified on the basis of technological level, that is, low-tech manufacturing, medium/low-tech manufacturing and medium/high-tech manufacturing. Interestingly, the change of energy consumption in the low-tech manufacturing is the smallest: a $14.13 \%$ increase in energy consumption. The largest increase in energy consumption is found in the medium/high-tech manufacturing (24.71\%), and the medium/low-tech manufacturing has a very high level of energy consumption growth $(22.42 \%)$ as well. Without surprise, the medium/high-tech manufacturing has the largest improvement in energy efficiency. A possible explanation is the industrial upgrading, which leads to resources shifting to technologically superior subgroups from low-tech manufacturing.

\subsubsection{Structural decomposition of energy consumption at sectoral level}

Based on the structural decomposition results in Table 2.5, this section provides a more straightforward way of visualization to illustrate all the factors' effects by transferring them into log points, as shown in Figure 2.11. In this section, the outcome variable is energy consumption.

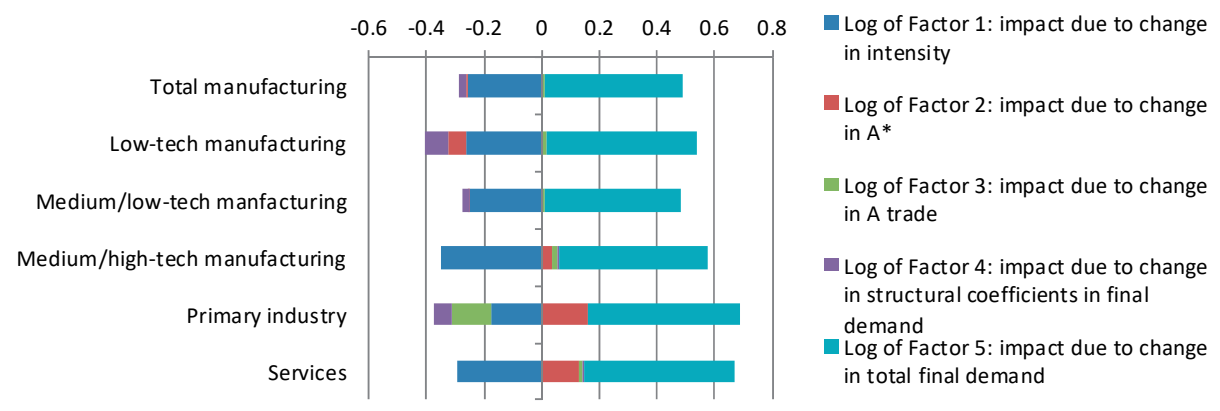

Figure 2.11 Structural decomposition of energy consumption at sectoral level from 1995 to 2009

\section{Common pattern}

There are several crucial findings which are consistent with the findings at economy level. First, for every aggregated industry and for every manufacturing subgroups classified by technological level, the most influencing decomposition factor contributing positively to increasing energy consumption, is factor 5 , the impact due to changes in 
economies' total final demand. A persuasive explanation is that with the improvement in living standard as well as the increasing number of global population, the demand for agricultural, manufacturing products and services has been greatly stimulated, resulting in increasing economic scales in the sectors. Reasonably, more energy inputs need to be consumed in the production process. For energy decompositions, the strongest factor 5 is found in primary industry (1.6996) and low-tech manufacturing among manufacturing subgroups (1.6870).

Second, for aggregated industry and manufacturing subgroups, the overwhelmingly factor that contributes to the reduction in energy consumption is factor 1 , the impact caused by changes in energy intensity. This factor is closely related to energy efficient technologies. Due to the innovation, diffusion and application of such types of technologies, the energy inputs consumed to obtain one unit of gross outputs have been significantly lowered, thus slowing down the growth of energy consumption. Specifically, the strongest factor 1 in energy consumption decomposition for aggregated industry is the services (0.7472), and for manufacturing subgroups is medium/high-tech (0.7027). Clearly, technology plays a significant role in lowering the increases in energy consumption, especially in technologically intensive sectors.

Third, the other decomposition factors seem to have a less influencing or even a neutral effect in shaping the dynamics of energy consumption. For aggregated industries, factor 2 , the impact due to changes in inter-industry structure, is relatively stronger in primary industry and services, causing increase in energy consumption. Probably it means that driven by increasing market demand, market agents in both of the industries have significantly improved their productivity which leads to expansions in energy related production or businesses. Specifically, for primary industry, both of factor 3 (the impact due to changes in trade structure in intermediate inputs) and factor 4 (the impact due to structural changes in economies' total final demand) are detrimental to the growth of energy consumption, which probably implies that less energy intensive inputs have been consumed through trade in the production process of primary industry, and in the final demand the market shares of this industry have shifted to the other industries. For manufacturing subgroups, perhaps due to industrial upgrading, market shares of lowtech manufacturing have shrunk, as shown by the factor 4 in decompositions of energy consumption.

More interestingly, in every aggregated industry and manufacturing subgroups, factor 1 and factor 5 affect the dynamics of energy consumption in the opposite direction-factor 1 is always the factor leading to the declines of outcome variables and factor 5 is the contrary one. Accordingly, the energy consumption caused by factor 5 can be partially or largely offset by factor 1 . Consequently, though the energy consumption had increased, they could have increased by a much greater percentage. Empirically, the compensation effect persuasively illustrates how it is possible to achieve sustainable 
development - reducing energy intensity. This section shows that the compensation effect still holds at sectoral level in the decompositions of energy consumption.

\subsubsection{Structural decomposition of energy intensity at sectoral level}

We can zoom in on the dynamics of energy intensity by decomposing the relative changes during the period under research, to have a deeper understanding about crucial factors affecting the dynamics, since we are especially interested in technological factors related to energy efficiency. Table 2.5 also provides decomposition results of energy intensity from 1995 to 2009 by employing Equation (21). In this section, the outcome variable is energy intensity or total emission intensity. Similarly, the log point version of both bar charts is illustrated in Figure 2.12 below.

The most important finding is that in structural decompositions of energy intensity the overwhelmingly factor is factor 1 , that is, the impact due to changes in intensity within economic sectors, which means that energy efficiency improving technological change happening within sectors is the driving factor of reducing energy intensity. Specifically, the factor 1 of medium/high-tech manufacturing is the strongest one compared to the other manufacturing subgroups and aggregated industries in terms of magnitude.

Factor 3, the trade effect in intermediate inputs, still plays a role in reducing the energy intensity of primary industry. Such a finding is consistent with what we discussed in Section 2.4.3.2, namely that because of changes in consumers' preference and product substitution, less energy intensive inputs are consumed through trade for production purpose in primary industry.

Factor 5, the economies' total final demand effect, causes an increase in energy intensity for almost all the categories except for primary industry. But the impact of the factor 5 in primary industry is very weak (about 0.9974), which only causes a small fluctuation on the outcomes.

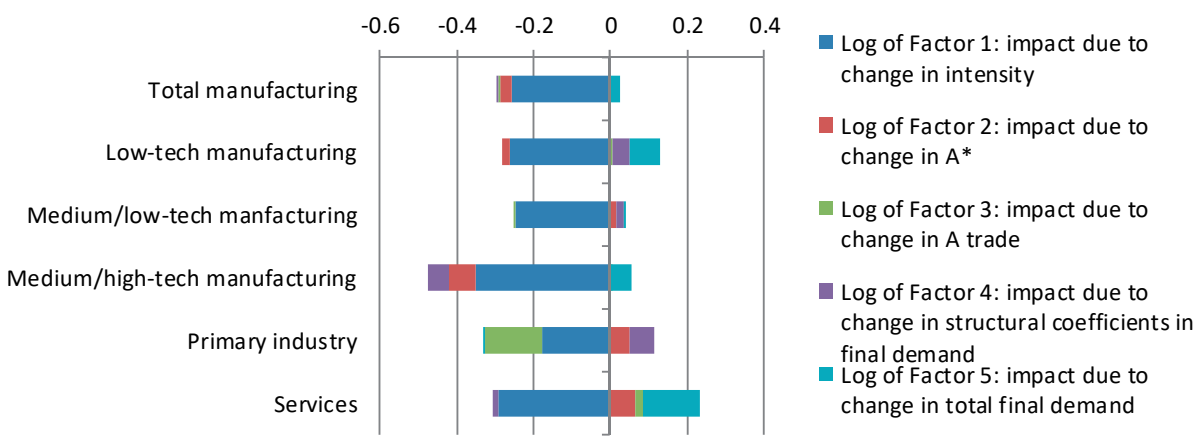

Figure 2.12 Structural decomposition of energy intensity at sectoral level from 1995 to 2009 


\subsubsection{Multilevel Mixed-Effect Model}

Multilevel Mixed-Effect regression results on energy intensity and GDP per capita for supply side and demand side are shown in Table 2.5. The predictions of the regression models for supply side and demand side are illustrated in Figure 2.13. The coefficients of all the independent variables are significant while the signs are contrary to each other for supply side and demand side. Figure 2.13 shows that the model predictions can fit the original data quite well and there seems to be a decreasing relationship between energy intensity and GDP per capita.

Figure 2.14 and Figure 2.15 provide further information about the fixed portions of the two models. For supply side, the prediction of the fixed portion of the model is a downward sloping curve ${ }^{40}$ with the GDP per capita ranging between US dollar 1416.986 and US dollar 74021.45 over 1995 to 2009. For demand side, fixed portion of the model is predicted to a strictly decreasing curve until it reaches its minimum at the stationary point 35600999.24. Since this number is not a reasonable value for GDP per capita, the strictly decreasing relationship is confirmed. The explanation would be that with economic development, a growing number of resources can be invested in energy efficiency related R\&D and energy efficient technology adoption.

Table 2.6 Multilevel mixed-effect model results for supply side and demand side

\begin{tabular}{|c|c|c|c|}
\hline & & Supply Side & Demand Side \\
\hline \multicolumn{2}{|l|}{ Number of observations } & 574 & 580 \\
\hline \multicolumn{2}{|c|}{ Number of groups (group variable: economy) } & 39 & 39 \\
\hline \multicolumn{2}{|l|}{ Dependent variable } & $\log E I_{t, j}^{\text {Supply }}$ & $\log E I_{t, j}^{\text {Demand }}$ \\
\hline \multirow[t]{2}{*}{ Independent variable } & $\log G D P_{-} P C_{t, j}$ & $\begin{array}{l}2.2247^{* *} \\
(0.8196)\end{array}$ & $\begin{array}{l}-0.8890^{* * *} \\
(0.2329)\end{array}$ \\
\hline & $\left(\log G D P_{-} P C_{t, j}\right)^{2}$ & $\begin{array}{l}-0.1634^{* * *} \\
(0.0444)\end{array}$ & $\begin{array}{l}0.0256^{* *} \\
(0.0125)\end{array}$ \\
\hline \multicolumn{2}{|l|}{ Constant } & $\begin{array}{l}-18.1273^{* * *} \\
(3.7706)\end{array}$ & $\begin{array}{l}-5.435859^{* * *} \\
(1.0824)\end{array}$ \\
\hline \multirow[t]{3}{*}{$\begin{array}{l}\text { Random-effects } \\
\text { parameters }\end{array}$} & $\mathrm{Sd}\left(\log G D P_{-} P C_{t, j}\right)$ & $\begin{array}{l}0.1315 \\
(0.0150)\end{array}$ & \\
\hline & Sd(constant) & $\begin{array}{l}4.66 \mathrm{e}-11 \\
(1.49 \mathrm{e}-07)\end{array}$ & $\begin{array}{l}0.3293 \\
(0.0383)\end{array}$ \\
\hline & Sd(residual) & $\begin{array}{l}0.2715 \\
(0.0083)\end{array}$ & $\begin{array}{l}0.0751 \\
(0.0022)\end{array}$ \\
\hline \multicolumn{2}{|l|}{ Log likelihood } & -178.9815 & 568.5664 \\
\hline \multicolumn{2}{|l|}{ Wald chi2 } & $143.73^{* * *}$ & $476.37^{* * *}$ \\
\hline \multicolumn{2}{|l|}{ Chibar2 } & $1358.33^{* * *}$ & $1290.69^{* * *}$ \\
\hline
\end{tabular}

\footnotetext{
${ }^{40}$ In fact, on the whole positive horizontal axis, the curve is a skew inverted-U-shaped curve with a peak at the stationary point 902. This cannot be confirmed, since no energy consumption data at this level of GDP per capita are available.
} 
Note that: (1)*,** and $* * *$ denote for significance level at $10 \%, 5 \%$ and $1 \%$ respectively; (2) Std. Err. is in the brackets; (3) In panel regression, the coefficient of $\left(\log G D P_{-} P C_{t, j}\right)^{2}$ is -0.1366 and 0.0246 for supply side and demand side, respectively. The coefficient of $\log G D P \_P C_{t, j}$ is 1.7274 and -0.8631 for supply side and demand side, respectively. The conclusion still holds.
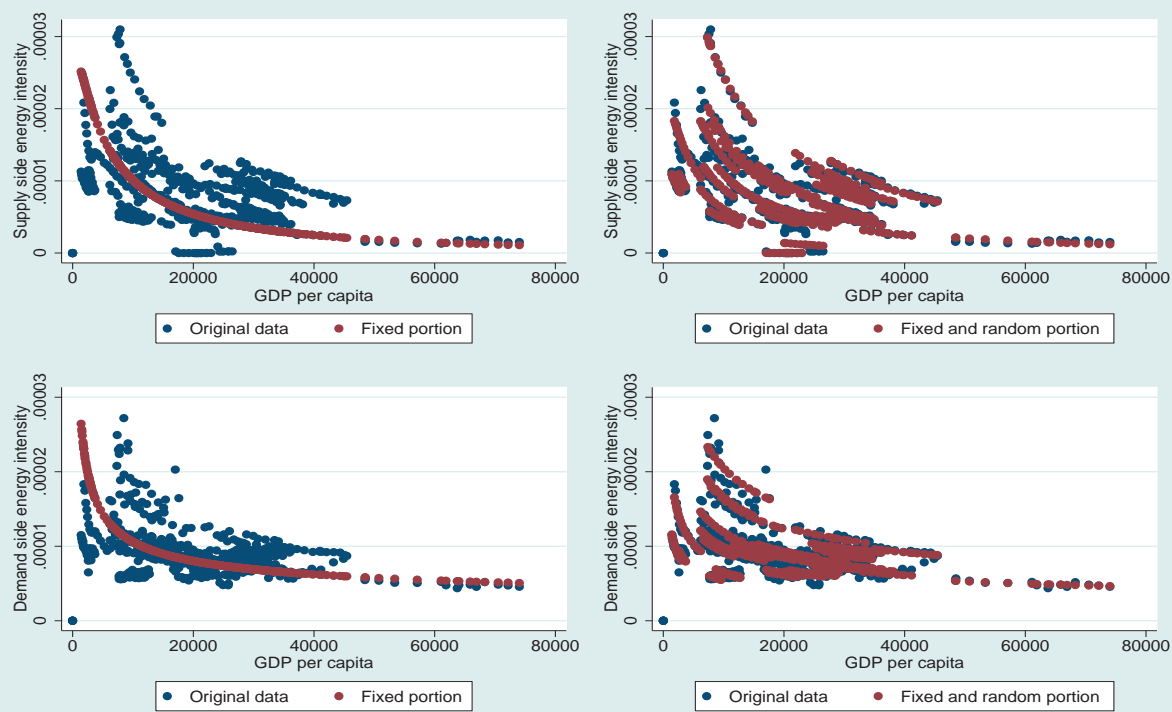

Source: Own elaboration

Figure 2.13 Predictions of multilevel mixed-effect model for supply side and demand side energy intensity

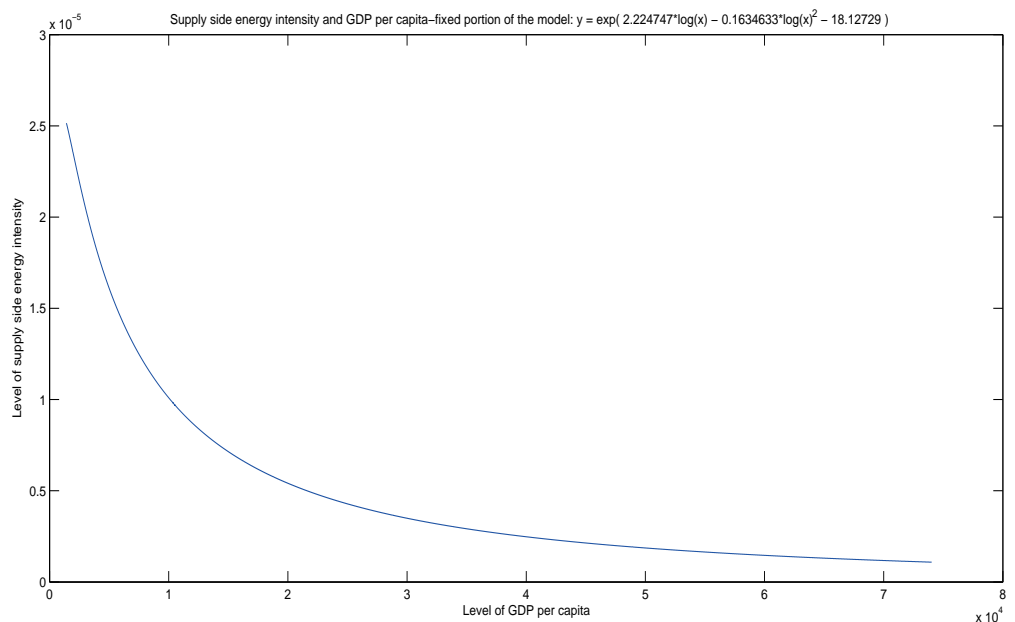

Figure 2.14 Supply side energy intensity and GDP per capita-prediction of fixed portion 


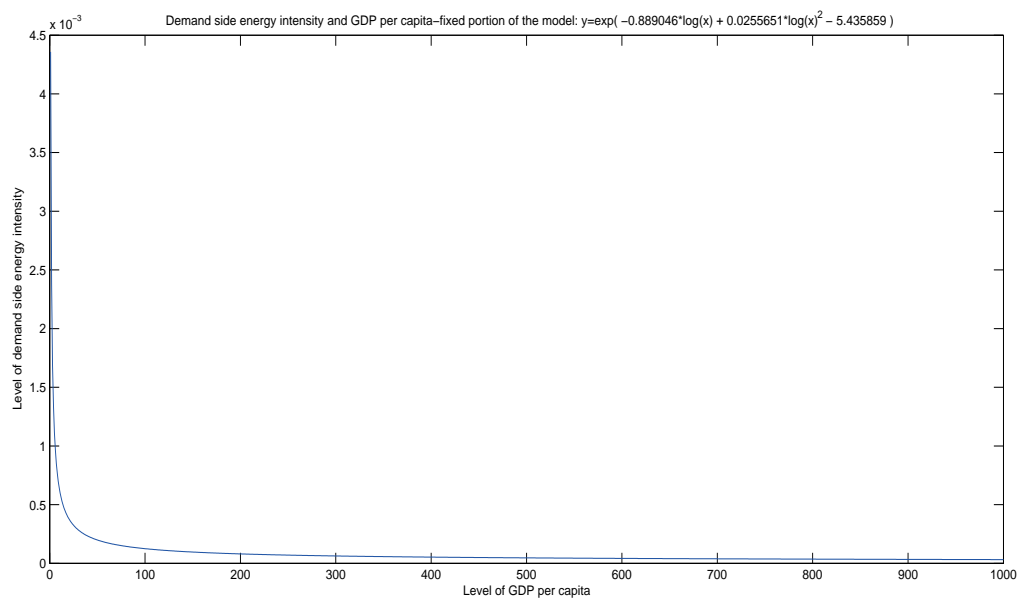

Figure 2.15 Demand side energy intensity and GDP per capita-prediction of fixed portion

In Figure 2.13, a similar downward pattern can be found among different economies on both supply side and demand side. When energy inefficient economies reach the same economic development stage as energy efficient economies, although the difference in energy intensity between the two types of economies still exists, the magnitude of the difference decreases, which is consistent with the results of convergence analysis. Specifically, energy inefficient economies (usually developing economies) contribute more to improving the energy efficiency of the world.

Both Figure 2.14 and Figure 2.15 clearly reflect two crucial findings. (1) With economic development, energy intensity declines on both supply side and demand side, which implies that not only production but also consumption becomes more energy efficient. The direct reason probably is energy efficiency related technological change. (2) However, the improvement of energy efficiency considerably varies along different economic development stages. Mathematically, the tangent slopes of both curves become increasingly smaller in magnitude. At the early stage of economic development, the improvement of energy efficiency is bigger than that at the later stages, which is in line with the findings from energy intensity decompositions. This accordingly implies that economic policy should match the country's economic development stage.

\subsection{CONCLUSIONS}

This article has not only demonstrated that structural decomposition analysis is a very useful and powerful analytical tool to be applied to complex and extremely data intensive research of integrating energy issues and economic systems, but also has illustrated 
an alternative relative change decomposition approach benefiting from the recent availability of the World Input-Output Database (WIOD). Additionally, as a complement to current research, this method is not only a recent application of the input-output model, but also can be viewed as a data mining technique discovering new knowledge in special matrix form dataset. The method in this article can be applied to further studies relating to gas emissions as well.

For the constantly discussed issue of development, more importantly, this article has provided some positive outcomes. It has been widely argued that developing countries cannot reach the stage of development that is comparable to that of developed countries. The logic behind this pessimistic assertion is that given the larger population in developing countries and the greatly higher energy consumption per capita in developed countries, there is no enough energy on the earth to support the highly developed stage of development of developing countries. A world where people in developing countries would live at the American or the European living standard is beyond imagination, given the serious environmental problems we are currently facing. However, this article argues that (1) due to the compensation effect, the growth in energy consumption on both supply side and demand side has been greatly slowed down, and (2) supply side and demand side energy intensity empirically decline with the growth of GDP per capita. The solution might be to: reduce energy intensity, especially the energy intensity within sectors, and to achieve improvement of energy efficiency through technology diffusion.

More comprehensively, using mass data from WIOD from the year 1995 to 2009 covering 35 economic sectors and 41 major economies across the world, this article decomposed the relative changes of the aggregate energy consumption and aggregate energy intensity at economy level into six influencing factors: energy intensity effect, interindustry structure effect, inter-industry trade effect, structural change effect, total final demand effect and household expenditure effect. At sectoral level, the first five decomposition factors are obtained. At economy level several crucial findings on both supply side and demand side were mined and acquired from data: (1) Compensation effect in aggregate energy consumption change, illustrating the phenomenon that energy consumption driven by changing total final demand was roughly (or partly) offset by negative energy intensity effect. A similar finding is confirmed in the study of the U.S. economy (Weber, 2009). (2) The trade structure effect in intermediate inputs was relatively small in shaping changes of energy consumption, similar to the finding of Dietzenbacher et al. (2000). (3) "Catching-up" features can be found among some economies in energy consumption and energy intensity decompositions. (4) For the energy intensity decomposition, lowering energy intensity within sectors is the overwhelming factor contributing to the decline in aggregate energy intensity in most economies. (5) Economies' energy intensities tend to converge on the world level. (6) A strictly decreasing relationship between energy intensity and GDP per capita was confirmed. At sectoral level, the 
compensation effect in energy consumption decompositions, small trade effect in intermediate inputs and the overwhelming role of intensity effect in energy intensity decompositions still hold.

As regards some additional policy implications, since the energy intensity effect is the major influencing factor that lowers both aggregate energy consumption and aggregate energy intensity, policymakers, especially those in developing countries, would find it beneficial to implement energy efficiency related technological change through policy efforts, in order to obtain sustainable socio-economic development. Policies aiming at promoting energy efficiency technologies and matching the stage of economic development should be preferred. It is necessary to clarify that designing and implementing such policies does not necessarily mean to fully allay the concern or worry about development. It might be the most reasonable and practical solution, since the world would consume much more energy without such policies. Moreover, as suggested by the structural decomposition results at sectoral level, the performance in energy consumption and energy intensity can shed some light on the design of industrial policy. Compared to primary industry and services, the increase in energy consumption in manufacturing is the smallest, probably due to the relatively larger decline in energy intensity. This finding implies a paradigm for development that can inspire new industrial development initiatives: in the context of structural change dynamics, the key for achieving economic sustainability is to slow down the growth of manufacturing energy consumption through technological change, given the fact that the manufacturing industry contributes the most to global energy consumption. For manufacturing subgroups, the medium/low-tech manufacturing industry should be given more attention when designing industrial policies, because it has the second largest growth in energy consumption compared to the other manufacturing subgroups, higher than the level of total manufacturing, but shows less improvements in energy efficiency than the level of total manufacturing. Accordingly, policies in favor of technological change toward higher efficiency in medium/low-tech manufacturing would be preferable.

The decompositions in this paper are based on the period 1995 - 2009. It would be useful to extend the decomposition analysis to several different periods because some other crucial factors (e.g., financial incentives) can influence the dynamics of energy efficiency. For example, during the period 1995 - 2002 the global oil price remained relatively stable, while during the period 2002 - 2009 the oil price rose gradually to a much higher level. The rapid increases in energy prices may lead to faster changes in the energy efficiency within sectors. The relationship between trade and energy efficiency is probably more complex than the decomposition factor shown in this paper. New energy efficiency technologies may affect the other factors in the decomposition (e.g., the impact of trade). It is possible that the direct effect of trade is small, but the indirect effect is large. Further research is needed. Moreover, the energy efficiency gap, meaning the difference between cost-minimizing level of energy efficiency and the 
actual level (Allcott \& Greenstone, 2012), still generally exists. Current evidence from empirical studies suggests market or non-market reasons such as hidden benefits, technological uncertainty, slow returns to investment, market barriers, bureaucratic barriers, search and transition cost, and imperfect information to explain it (Allcott \& Greenstone, 2012; DeCanio \& Watkins, 1998; Jaffe \& Stavins, 1994a; Kemp et al., 1998). That implies that such energy efficiency improving policies should be carefully designed into a combination of various policy instruments to overcome these obstacles; and stricter econometric analyses paying a special attention to causal relationship instead of normal statistical correlation should be more widely performed to evaluate policy impacts. 
Chapter 2

\section{APPENDIX 2.1 DEFINITIONS OF ECONOMIES AND SECTORS IN WIOD}

Table 2.7 List of economies in WIOD

\begin{tabular}{|c|c|c|c|}
\hline Abbreviation of the Economy & Economy & Abbreviation of the Economy & Economy \\
\hline AUS & Australia & KOR & Korea \\
\hline AUT & Austria & LVA & Latvia \\
\hline BEL & Belgium & LTU & Lithuania \\
\hline BRA & Brazil & LUX & Luxembourg \\
\hline$B G R$ & Bulgaria & MLT & Malta \\
\hline CAN & Canada & MEX & Mexico \\
\hline $\mathrm{CHN}$ & China & NLD & Netherlands \\
\hline CYP & Cyprus & POL & Poland \\
\hline CZE & Czech Republic & PRT & Portugal \\
\hline DNK & Denmark & ROU & Romania \\
\hline EST & Estonia & RUS & Russia \\
\hline FIN & Finland & SVK & Slovak Republic \\
\hline FRA & France & SVN & Slovenia \\
\hline DEU & Germany & ESP & Spain \\
\hline GRC & Greece & SWE & Sweden \\
\hline HUN & Hungary & TWN & Taiwan \\
\hline IND & India & TUR & Turkey \\
\hline IDN & Indonesia & GBR & United Kingdom \\
\hline IRL & Ireland & USA & United States \\
\hline ITA & Italy & RoW & Rest of the World \\
\hline$J P N$ & Japan & & \\
\hline
\end{tabular}


Table 2.8 List of sectors in WIOD; industry and manufacturing technological level classifications

\begin{tabular}{|c|c|c|c|}
\hline Sector & Industry & & Description \\
\hline 1 & \multirow{2}{*}{\multicolumn{2}{|c|}{ Primary industry }} & Agriculture, Hunting, Forestry and Fishing \\
\hline 2 & & & Mining and Quarrying \\
\hline 3 & \multirow[t]{14}{*}{ Manufacturing } & Low-tech & Food, Beverages and Tobacco \\
\hline 4 & & Low-tech & Textiles and Textile Products \\
\hline 5 & & Low-tech & Leather, Leather and Footwear \\
\hline 6 & & Low-tech & Wood and Products of Wood and Cork \\
\hline 7 & & Low-tech & Pulp, Paper, Paper Printing and Publishing \\
\hline 8 & & $\begin{array}{l}\text { Medium/ } \\
\text { low-tech }\end{array}$ & Coke, Refined Petroleum and Nuclear Fuel \\
\hline 9 & & $\begin{array}{l}\text { Medium/ } \\
\text { high-tech }\end{array}$ & Chemicals and Chemical Products \\
\hline 10 & & $\begin{array}{l}\text { Medium/ } \\
\text { low-tech }\end{array}$ & Rubber and Plastics \\
\hline 11 & & $\begin{array}{l}\text { Medium/ } \\
\text { low-tech }\end{array}$ & Other Non-Metallic Mineral \\
\hline 12 & & $\begin{array}{l}\text { Medium/ } \\
\text { low-tech }\end{array}$ & Basic Metals and Fabricated Metal \\
\hline 13 & & $\begin{array}{l}\text { Medium/ } \\
\text { high-tech }\end{array}$ & Machinery, Nec \\
\hline 14 & & $\begin{array}{l}\text { Medium/ } \\
\text { high-tech }\end{array}$ & Electrical and Optical Equipment \\
\hline 15 & & $\begin{array}{l}\text { Medium/ } \\
\text { high-tech }\end{array}$ & Transport Equipment \\
\hline 16 & & Low-tech & Manufacturing, Nec; Recycling \\
\hline 17 & \multirow[t]{13}{*}{ Services } & & Electricity, Gas and Water Supply \\
\hline 18 & & & Construction \\
\hline 19 & & & $\begin{array}{l}\text { Sale, Maintenance and Repair of Motor Vehicles and Motorcycles; Retail } \\
\text { Sale of Fuel }\end{array}$ \\
\hline 20 & & & $\begin{array}{l}\text { Wholesale Trade and Commission Trade, Except of Motor Vehicles and } \\
\text { Motorcycles }\end{array}$ \\
\hline 21 & & & $\begin{array}{l}\text { Retail Trade, Except of Motor Vehicles and Motorcycles; Repair of } \\
\text { Household Goods }\end{array}$ \\
\hline 22 & & & Hotels and Restaurants \\
\hline 23 & & & Inland Transport \\
\hline 24 & & & Water Transport \\
\hline 25 & & & Air Transport \\
\hline 26 & & & $\begin{array}{l}\text { Other Supporting and Auxiliary Transport Activities; Activities of Travel } \\
\text { Agencies }\end{array}$ \\
\hline 27 & & & Post and Telecommunications \\
\hline 28 & & & Financial Intermediation \\
\hline 29 & & & Real Estate Activities \\
\hline
\end{tabular}




\section{Chapter 2}

\begin{tabular}{ll}
\hline Sector Industry & Description \\
\hline 30 & Renting of M\&Eq and Other Business Activities \\
31 & Public Admin and Defence; Compulsory Social Security \\
32 & Education \\
33 & Health and Social Work \\
34 & Other Community, Social and Personal Services \\
35 & Private Households with Employed Persons \\
\hline
\end{tabular}




\section{APPENDIX 2.2 FULL DECOMPOSITION RESULTS}

Table 2.9 Full structural decomposition results of supply side energy consumption in the EU

\begin{tabular}{|c|c|c|c|c|c|c|c|}
\hline Economy & $\begin{array}{l}\text { Relative } \\
\text { change of } \\
\text { supply side } \\
\text { energy use } \\
\text { between } \\
2009 \text { and } \\
1995\end{array}$ & $\begin{array}{l}\text { Factor 1: } \\
\text { change in e: } \\
\text { intensity } \\
\text { effect }\end{array}$ & $\begin{array}{l}\text { Factor } 2 \text { : } \\
\text { change in } A^{*} \text { : } \\
\text { inter-industry } \\
\text { structural } \\
\text { effect }\end{array}$ & $\begin{array}{l}\text { Factor } 3 \text { : } \\
\text { change in } A^{\top} \text { : } \\
\text { trade effect in } \\
\text { intermediate } \\
\text { inputs }\end{array}$ & $\begin{array}{l}\text { Factor } 4 \text { : } \\
\text { change in s: } \\
\text { sstructural } \\
\text { change effect } \\
\text { in final } \\
\text { demand }\end{array}$ & $\begin{array}{l}\text { Factor 5: } \\
\text { change in C: } \\
\text { total final } \\
\text { demand } \\
\text { effect }\end{array}$ & $\begin{array}{l}\text { Factor } 6 \text { : } \\
\text { change in } \mathrm{H} \text { : } \\
\text { household } \\
\text { consumption } \\
\text { effect }\end{array}$ \\
\hline AUT & 1.1251 & 0.7691 & 1.1448 & 1.0402 & 0.9650 & 1.2643 & 1.0068 \\
\hline BEL & 1.1240 & 0.8867 & 1.1125 & 0.8375 & 0.9903 & 1.3700 & 1.0028 \\
\hline BGR & 0.7651 & 0.2438 & 1.9278 & 0.9808 & 1.1117 & 1.4958 & 0.9981 \\
\hline CYP & 0.1130 & 0.2678 & 1.0714 & 0.3084 & 0.4967 & 1.4861 & 1.7299 \\
\hline CZE & 0.9621 & 0.8985 & 0.8409 & 0.8909 & 0.9881 & 1.4433 & 1.0023 \\
\hline DEU & 0.9642 & 0.7325 & 1.1182 & 0.9907 & 0.9731 & 1.2220 & 0.9993 \\
\hline DNK & 0.9600 & 0.9978 & 1.1258 & 0.8045 & 0.7786 & 1.3220 & 1.0321 \\
\hline ESP & 1.2057 & 0.6247 & 1.2973 & 0.9964 & 0.9795 & 1.4944 & 1.0201 \\
\hline EST & 1.0479 & 1.1727 & 0.7106 & 1.0195 & 0.7776 & 1.5932 & 0.9957 \\
\hline FIN & 1.2116 & 1.0026 & 0.9455 & 0.9715 & 0.9229 & 1.3990 & 1.0190 \\
\hline FRA & 1.0289 & 0.6501 & 1.0648 & 1.0928 & 0.9924 & 1.3427 & 1.0208 \\
\hline GBR & 0.8949 & 0.9431 & 0.9908 & 0.8686 & 0.7990 & 1.3853 & 0.9962 \\
\hline GRC & 1.2165 & 0.8173 & 0.9043 & 0.9305 & 1.0888 & 1.6106 & 1.0086 \\
\hline HUN & 0.9371 & 1.2495 & 0.9074 & 0.8010 & 0.7704 & 1.3530 & 0.9899 \\
\hline IRL & 1.2739 & 0.4501 & 1.2814 & 1.2017 & 1.1714 & 1.5496 & 1.0124 \\
\hline ITA & 1.1587 & 1.4607 & 0.8991 & 0.8439 & 0.8034 & 1.2682 & 1.0261 \\
\hline LTU & 1.4880 & 1.2118 & 0.8727 & 0.9594 & 0.9131 & 1.6510 & 0.9729 \\
\hline LUX & 1.6891 & 1.1216 & 1.0496 & 1.0153 & 1.0304 & 1.3531 & 1.0136 \\
\hline LVA & 0.9795 & 1.5948 & 0.9716 & 0.9424 & 0.4858 & 1.4453 & 0.9548 \\
\hline \multicolumn{8}{|l|}{ MLT } \\
\hline NLD & 0.9605 & 0.8419 & 1.1191 & 0.8723 & 0.8775 & 1.3444 & 0.9907 \\
\hline POL & 0.9267 & 0.5614 & 0.9547 & 1.0596 & 1.0642 & 1.6009 & 0.9578 \\
\hline PRT & 1.1008 & 1.0840 & 1.1792 & 0.7738 & 0.8390 & 1.3094 & 1.0130 \\
\hline ROM & 0.7371 & 0.6214 & 0.8991 & 0.7732 & 0.9905 & 1.6940 & 1.0169 \\
\hline SVK & 1.0007 & 0.9653 & 0.7100 & 0.9213 & 0.9548 & 1.6364 & 1.0144 \\
\hline SVN & 1.0459 & 0.8651 & 0.9913 & 0.9498 & 0.8506 & 1.4469 & 1.0434 \\
\hline SWE & 0.9733 & 0.7965 & 1.0067 & 0.9512 & 0.9312 & 1.3556 & 1.0109 \\
\hline
\end{tabular}

Note that results for Malta are missing due to data availability. 
Chapter 2

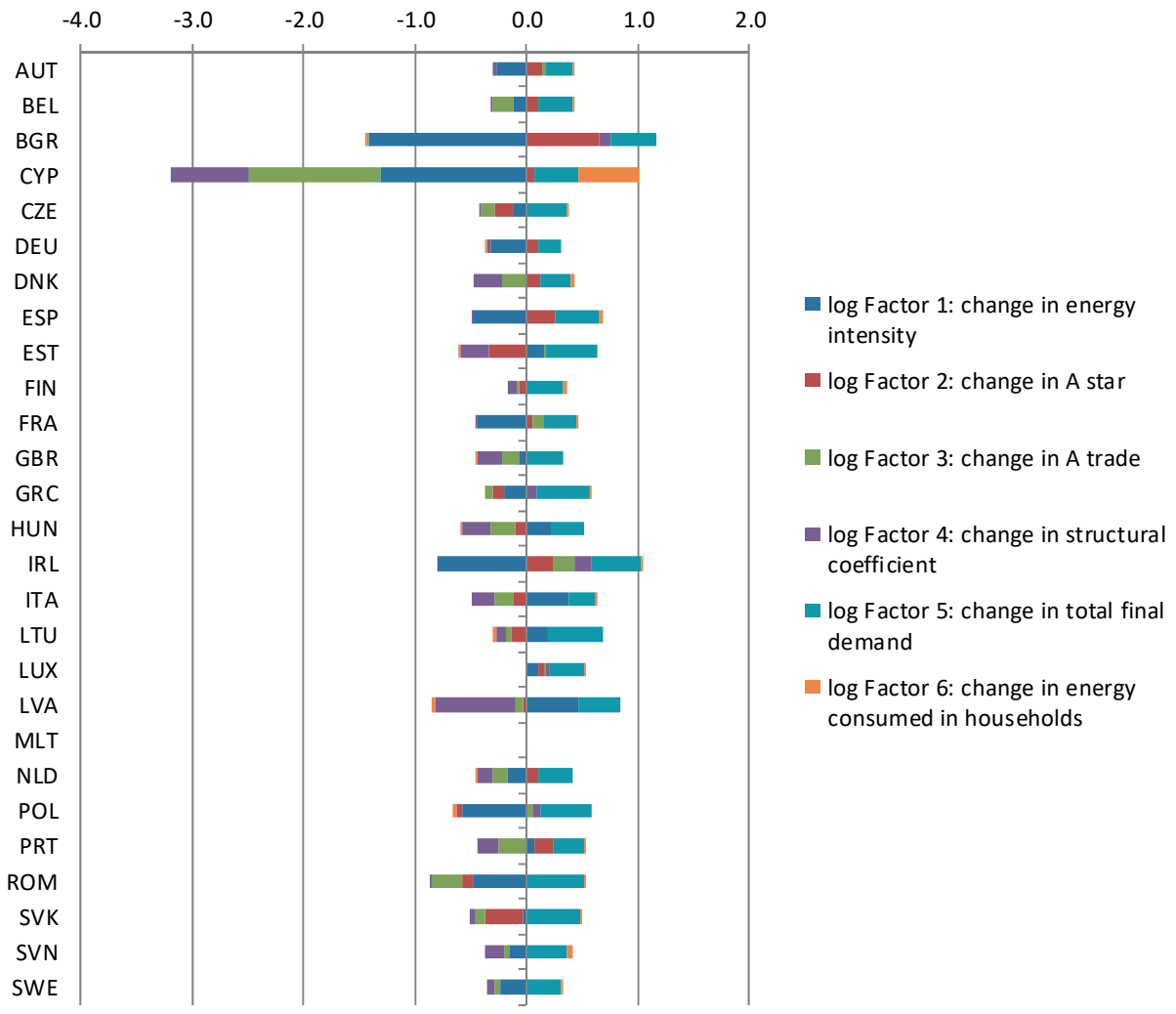

Figure 2.16 Structural decomposition of supply side energy consumption in the EU (log points) 
Table 2.10 Full structural decomposition results of demand side energy consumption in the EU

\begin{tabular}{|c|c|c|c|c|c|c|c|}
\hline Economy & $\begin{array}{l}\text { Relative } \\
\text { change of } \\
\text { demand side } \\
\text { energy use } \\
\text { between } \\
2009 \text { and } \\
1995\end{array}$ & $\begin{array}{l}\text { Factor 1: } \\
\text { change in e: } \\
\text { intensity } \\
\text { effect }\end{array}$ & $\begin{array}{l}\text { Factor } 2: \\
\text { change in } A^{*} \text { : } \\
\text { inter-industry } \\
\text { structural } \\
\text { effect }\end{array}$ & $\begin{array}{l}\text { Factor } 3 \text { : } \\
\text { change in } A^{\top} \text { : } \\
\text { y trade effect in } \\
\text { intermediate } \\
\text { inputs }\end{array}$ & $\begin{array}{l}\text { Factor 4: } \\
\text { change in s: } \\
\text { nstructural } \\
\text { change effect } \\
\text { in final } \\
\text { demand }\end{array}$ & $\begin{array}{l}\text { Factor 5: } \\
\text { change in C: } \\
\text { total final } \\
\text { temand } \\
\text { effect }\end{array}$ & $\begin{array}{l}\text { Factor } 6 \text { : } \\
\text { change in } \mathrm{H} \text { : } \\
\text { household } \\
\text { consumption } \\
\text { effect }\end{array}$ \\
\hline AUT & 1.0743 & 0.7487 & 1.1573 & 0.9854 & 1.0515 & 1.1910 & 1.0046 \\
\hline BEL & 1.1888 & 0.7884 & 1.1579 & 1.0461 & 0.9704 & 1.2789 & 1.0031 \\
\hline$B G R$ & 0.9087 & 0.4047 & 2.1342 & 0.7570 & 0.9512 & 1.4627 & 0.9990 \\
\hline CYP & 0.9701 & 0.7460 & 1.1476 & 0.8683 & 0.7896 & 1.6109 & 1.0260 \\
\hline CZE & 1.0792 & 0.8673 & 0.9226 & 0.9248 & 0.9809 & 1.4817 & 1.0034 \\
\hline DEU & 0.9250 & 0.7282 & 1.0898 & 1.0140 & 1.0440 & 1.1020 & 0.9993 \\
\hline DNK & 1.2054 & 0.7688 & 1.1794 & 1.0424 & 1.0384 & 1.2036 & 1.0204 \\
\hline ESP & 1.4224 & 0.6812 & 1.2627 & 1.0227 & 1.0608 & 1.5006 & 1.0158 \\
\hline EST & 1.1288 & 0.9995 & 0.9042 & 0.8930 & 0.8112 & 1.7270 & 0.9984 \\
\hline FIN & 1.1883 & 0.8769 & 1.0646 & 0.9858 & 0.9317 & 1.3604 & 1.0187 \\
\hline FRA & 1.2070 & 0.7667 & 1.1397 & 0.9718 & 1.0673 & 1.3099 & 1.0167 \\
\hline GBR & 1.0631 & 0.7898 & 0.9644 & 1.0709 & 0.9627 & 1.3542 & 0.9996 \\
\hline GRC & 1.5524 & 0.7785 & 1.0210 & 1.0653 & 1.1299 & 1.6133 & 1.0057 \\
\hline HUN & 1.0386 & 1.0362 & 1.0428 & 0.9323 & 0.7932 & 1.3119 & 0.9909 \\
\hline IRL & 1.8493 & 0.7029 & 1.2322 & 1.0448 & 1.1742 & 1.7308 & 1.0055 \\
\hline ITA & 1.1638 & 1.0256 & 1.0280 & 1.0178 & 0.9042 & 1.1775 & 1.0186 \\
\hline LTU & 1.1445 & 0.8730 & 0.8979 & 0.9587 & 0.8307 & 1.8670 & 0.9818 \\
\hline LUX & 1.4057 & 0.7984 & 1.1572 & 1.0313 & 0.9543 & 1.5350 & 1.0071 \\
\hline LVA & 1.1850 & 1.1568 & 1.1667 & 0.9068 & 0.5854 & 1.6990 & 0.9734 \\
\hline MLT & 1.3756 & 0.8100 & 1.2816 & 0.9384 & 1.0668 & 1.3237 & 1.0000 \\
\hline NLD & 1.1272 & 0.7919 & 1.0981 & 1.0220 & 0.9845 & 1.3045 & 0.9876 \\
\hline POL & 1.1241 & 0.6555 & 1.0527 & 0.9605 & 1.0308 & 1.7215 & 0.9558 \\
\hline PRT & 1.2651 & 0.8472 & 1.2935 & 0.9200 & 0.9812 & 1.2669 & 1.0094 \\
\hline ROM & 0.9781 & 0.6706 & 0.9313 & 0.8665 & 0.9760 & 1.8141 & 1.0206 \\
\hline SVK & 1.2676 & 0.9428 & 0.8551 & 0.9372 & 0.8606 & 1.9133 & 1.0187 \\
\hline SVN & 1.3547 & 0.8442 & 1.0846 & 1.0030 & 0.9731 & 1.4822 & 1.0227 \\
\hline SWE & 0.9839 & 0.7738 & 1.0127 & 1.0438 & 0.9572 & 1.2436 & 1.0105 \\
\hline
\end{tabular}


Chapter 2

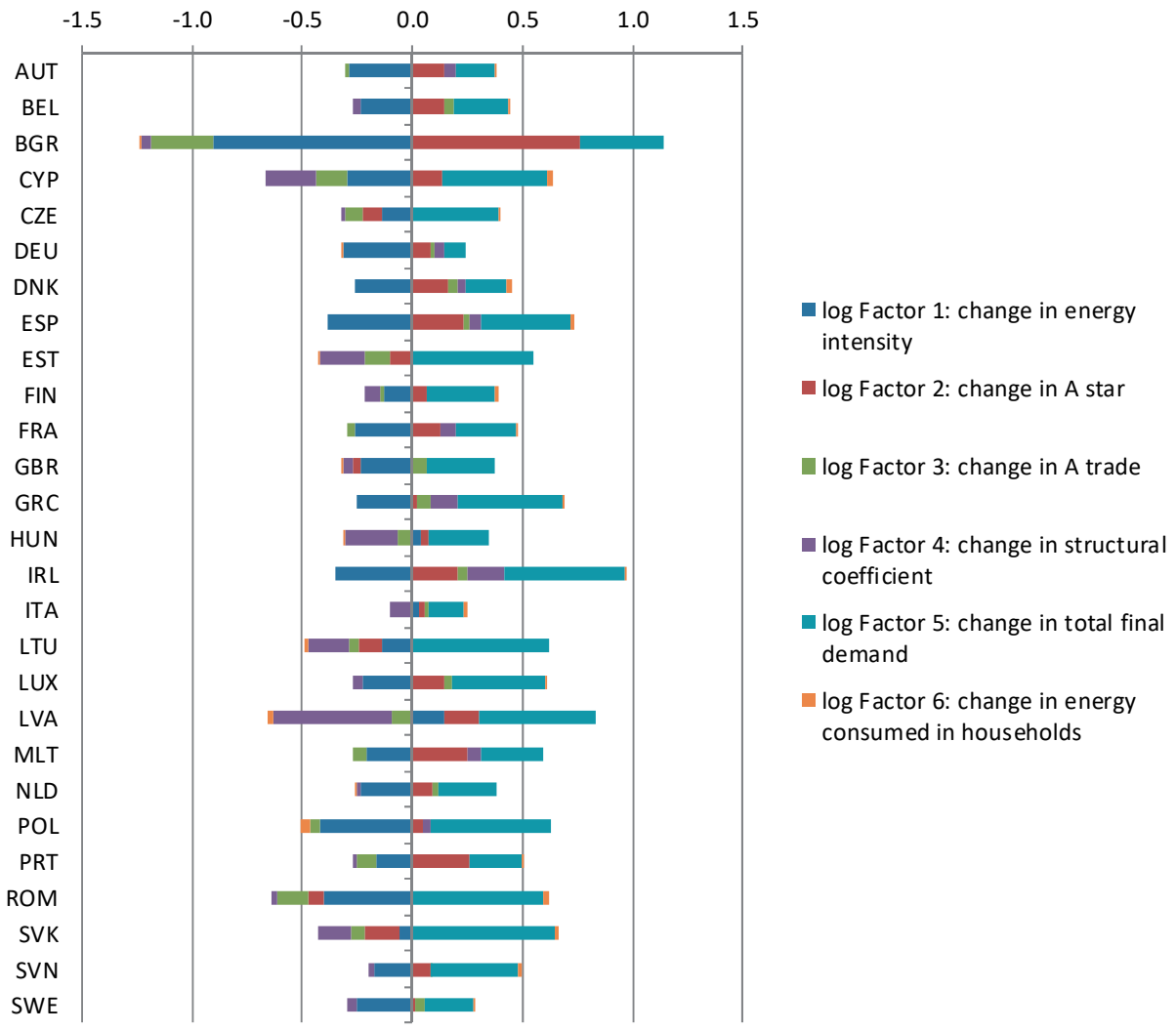

Figure 2.17 Structural decomposition of demand side energy consumption in the EU (log points) 
Table 2.11 Full structural decomposition results of supply side energy intensity in the EU

\begin{tabular}{|c|c|c|c|c|c|c|c|}
\hline Economy & $\begin{array}{l}\text { Relative } \\
\text { change of } \\
\text { supply side } \\
\text { energy } \\
\text { intensity } \\
\text { between } \\
2009 \text { and } \\
1995\end{array}$ & $\begin{array}{l}\text { Factor 1: } \\
\text { change in e: } \\
\text { intensity } \\
\text { effect }\end{array}$ & $\begin{array}{l}\text { Factor } 2: \\
\text { change in } A^{*} \text { : } \\
\text { inter-industry } \\
\text { structural } \\
\text { effect }\end{array}$ & $\begin{array}{l}\text { Factor } 3 \text { : } \\
\text { change in } A^{\top} \text { : } \\
\text { y trade effect in } \\
\text { intermediate } \\
\text { inputs }\end{array}$ & $\begin{array}{l}\text { Factor 4: } \\
\text { change in s: } \\
\text { nstructural } \\
\text { change effect } \\
\text { in final } \\
\text { demand }\end{array}$ & $\begin{array}{l}\text { Factor 5: } \\
\text { change in C: } \\
\text { total final } \\
\text { t demand } \\
\text { effect }\end{array}$ & $\begin{array}{l}\text { Factor } 6 \text { : } \\
\text { change in } \mathrm{H} \text { : } \\
\text { household } \\
\text { consumption } \\
\text { effect }\end{array}$ \\
\hline AUT & 0.7736 & 0.7691 & 1.0571 & 1.0030 & 0.9675 & 0.9740 & 1.0068 \\
\hline BEL & 0.8390 & 0.8867 & 1.0450 & 0.8903 & 1.0224 & 0.9920 & 1.0028 \\
\hline BGR & 0.4772 & 0.2438 & 1.3691 & 1.1287 & 1.2868 & 0.9861 & 0.9981 \\
\hline CYP & 0.0591 & 0.2678 & 0.9156 & 0.2883 & 0.5217 & 0.9262 & 1.7299 \\
\hline CZE & 0.5441 & 0.8985 & 0.7662 & 0.8754 & 0.9422 & 0.9559 & 1.0023 \\
\hline DEU & 0.7873 & 0.7325 & 1.0707 & 1.0118 & 1.0073 & 0.9856 & 0.9993 \\
\hline DNK & 0.7192 & 0.9978 & 1.0175 & 0.8410 & 0.8235 & 0.9912 & 1.0321 \\
\hline ESP & 0.7755 & 0.6247 & 1.1669 & 1.0250 & 1.0228 & 0.9948 & 1.0201 \\
\hline EST & 0.5467 & 1.1727 & 0.6360 & 0.9640 & 0.8148 & 0.9373 & 0.9957 \\
\hline FIN & 0.7822 & 1.0026 & 0.8889 & 0.9470 & 0.9388 & 0.9687 & 1.0190 \\
\hline FRA & 0.7168 & 0.6501 & 1.0352 & 1.0708 & 0.9961 & 0.9782 & 1.0208 \\
\hline GBR & 0.6394 & 0.9431 & 0.9209 & 0.9182 & 0.8289 & 0.9711 & 0.9962 \\
\hline GRC & 0.8143 & 0.8173 & 0.9241 & 0.9424 & 1.1531 & 0.9837 & 1.0086 \\
\hline HUN & 0.5813 & 1.2495 & 0.8237 & 0.8082 & 0.7537 & 0.9366 & 0.9899 \\
\hline IRL & 0.5568 & 0.4501 & 1.1637 & 0.9925 & 1.1141 & 0.9496 & 1.0124 \\
\hline ITA & 1.0019 & 1.4607 & 0.8339 & 0.9143 & 0.8770 & 0.9997 & 1.0261 \\
\hline LTU & 0.8606 & 1.2118 & 0.8669 & 0.9443 & 0.9826 & 0.9075 & 0.9729 \\
\hline LUX & 0.6784 & 1.1216 & 0.9340 & 0.8731 & 0.9377 & 0.7803 & 1.0136 \\
\hline LVA & 0.5342 & 1.5941 & 0.8307 & 0.9567 & 0.5510 & 0.8007 & 0.9548 \\
\hline \multicolumn{8}{|l|}{ MLT } \\
\hline NLD & 0.6928 & 0.8419 & 1.0459 & 0.9145 & 0.8947 & 0.9706 & 0.9907 \\
\hline POL & 0.4505 & 0.5614 & 0.9499 & 0.9700 & 1.0051 & 0.9046 & 0.9578 \\
\hline PRT & 0.8368 & 1.0840 & 1.0776 & 0.7703 & 0.9282 & 0.9892 & 1.0130 \\
\hline ROM & 0.4267 & 0.6214 & 0.8645 & 0.8242 & 1.0462 & 0.9058 & 1.0169 \\
\hline SVK & 0.4969 & 0.9653 & 0.7337 & 0.8712 & 0.8489 & 0.9352 & 1.0144 \\
\hline SVN & 0.6572 & 0.8651 & 0.9447 & 0.9437 & 0.8475 & 0.9637 & 1.0434 \\
\hline SWE & 0.7201 & 0.7965 & 0.9694 & 0.9685 & 0.9603 & 0.9919 & 1.0109 \\
\hline
\end{tabular}

Note that results for Malta are missing due to data availability. 
Chapter 2

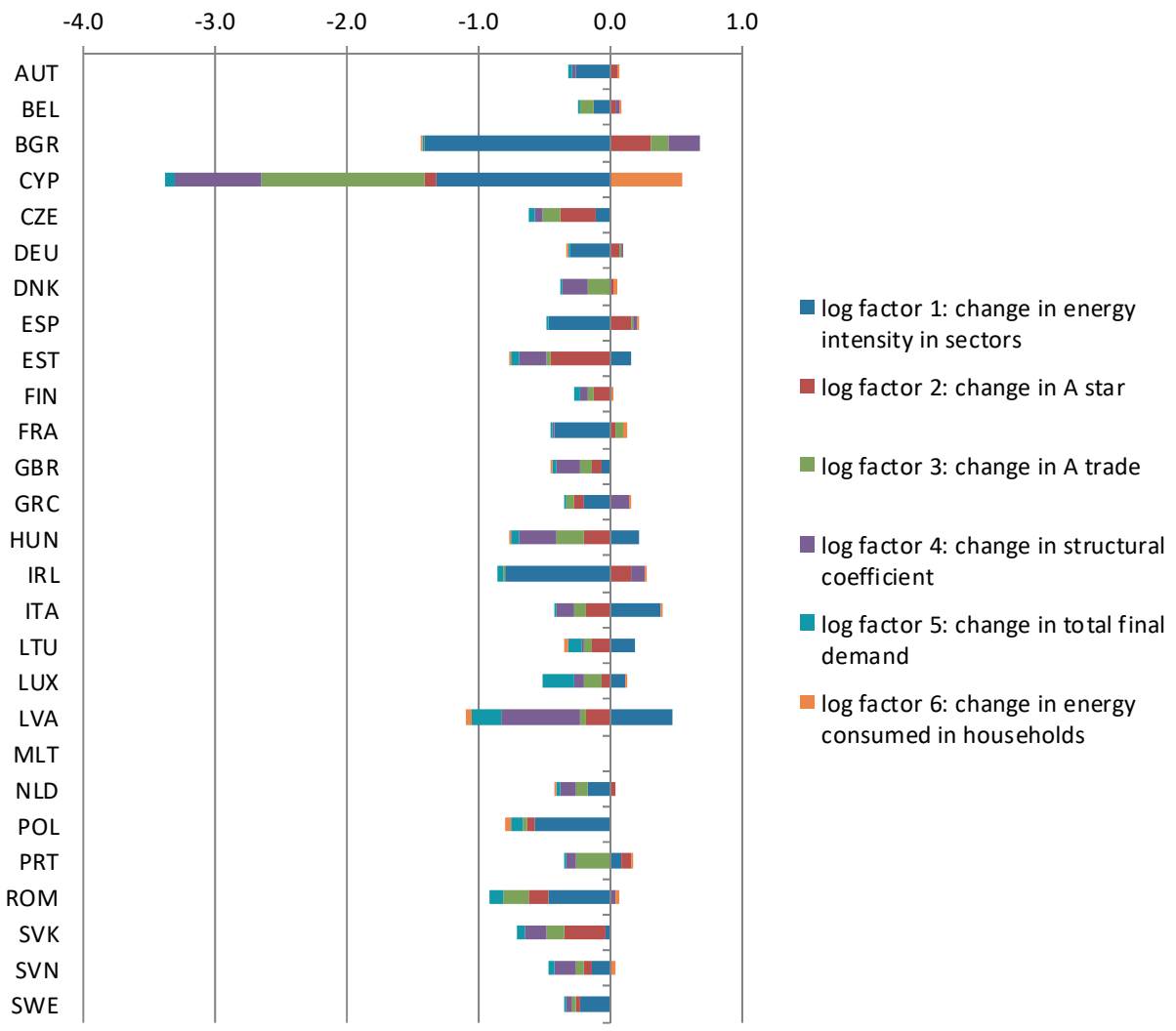

Figure 2.18 Structural decomposition of supply side energy intensity in the EU (log points) 
Table 2.12 Full structural decomposition results of demand side energy intensity in the EU

\begin{tabular}{|c|c|c|c|c|c|c|c|}
\hline Economy & $\begin{array}{l}\text { Relative } \\
\text { of dema } \\
\text { energy ir } \\
\text { between } \\
\text { and } 199\end{array}$ & $\begin{array}{l}\text { e Factor } 1 \text { : } \\
\text { change in e: } \\
\text { yintensity effect }\end{array}$ & $\begin{array}{l}\text { Factor 2: } \\
\text { change in } A^{*}: \\
\text { inter-industry } \\
\text { structural effec }\end{array}$ & $\begin{array}{l}\text { Factor } 3 \text { : } \\
\text { change in } \mathrm{A}^{\top} \text { : } \\
\text { trade effect in } \\
\text { ctintermediate } \\
\text { inputs }\end{array}$ & $\begin{array}{l}\text { Factor 4: } \\
\text { change in s: } \\
\text { structural } \\
\text { change effect i } \\
\text { final demand }\end{array}$ & $\begin{array}{l}\text { Factor 5: } \\
\text { change in C: } \\
\text { total final } \\
\text { indemand effect }\end{array}$ & $\begin{array}{l}\text { Factor 6: } \\
\text { change in } \mathrm{H} \text { : } \\
\text { household } \\
\text { consumption } \\
\text { effect }\end{array}$ \\
\hline AUT & 0.8141 & 0.7487 & 1.0649 & 0.9819 & 1.0518 & 0.9843 & 1.0046 \\
\hline BEL & 0.8566 & 0.7884 & 1.0835 & 1.0447 & 0.9713 & 0.9852 & 1.0031 \\
\hline$B G R$ & 0.4067 & 0.4047 & 1.4120 & 0.7667 & 0.9607 & 0.9673 & 0.9990 \\
\hline CYP & 0.5313 & 0.7460 & 0.9665 & 0.8724 & 0.8251 & 0.9979 & 1.0260 \\
\hline CZE & 0.6156 & 0.8673 & 0.8109 & 0.9301 & 0.9851 & 0.9521 & 1.0034 \\
\hline DEU & 0.8162 & 0.7282 & 1.0649 & 1.0093 & 1.0513 & 0.9927 & 0.9993 \\
\hline DNK & 0.8986 & 0.7688 & 1.0645 & 1.0412 & 1.0504 & 0.9840 & 1.0204 \\
\hline ESP & 0.8499 & 0.6812 & 1.1317 & 1.0218 & 1.0745 & 0.9885 & 1.0158 \\
\hline EST & 0.5181 & 0.9995 & 0.7824 & 0.8871 & 0.8223 & 0.9095 & 0.9984 \\
\hline FIN & 0.7616 & 0.8769 & 0.9645 & 0.9805 & 0.9209 & 0.9789 & 1.0187 \\
\hline FRA & 0.8539 & 0.7667 & 1.0969 & 0.9702 & 1.0470 & 0.9830 & 1.0167 \\
\hline GBR & 0.7185 & 0.7898 & 0.9156 & 1.0665 & 0.9647 & 0.9660 & 0.9996 \\
\hline GRC & 0.9309 & 0.7785 & 1.0167 & 1.0620 & 1.1116 & 0.9904 & 1.0057 \\
\hline HUN & 0.6671 & 1.0362 & 0.8973 & 0.9380 & 0.8111 & 0.9518 & 0.9909 \\
\hline IRL & 0.8787 & 0.7029 & 1.0563 & 1.0468 & 1.1641 & 0.9657 & 1.0055 \\
\hline ITA & 0.9030 & 1.0256 & 0.9411 & 1.0186 & 0.9128 & 0.9879 & 1.0186 \\
\hline LTU & 0.5145 & 0.8730 & 0.8148 & 0.9562 & 0.8076 & 0.9538 & 0.9818 \\
\hline LUX & 0.7923 & 0.7984 & 1.0318 & 1.0286 & 0.9598 & 0.9675 & 1.0071 \\
\hline LVA & 0.4764 & 1.1568 & 0.9335 & 0.9056 & 0.5824 & 0.8593 & 0.9734 \\
\hline MLT & 0.9302 & 0.8100 & 1.1141 & 0.9368 & 1.1003 & 1.0000 & 1.0000 \\
\hline NLD & 0.7953 & 0.7919 & 1.0289 & 1.0203 & 0.9974 & 0.9712 & 0.9876 \\
\hline POL & 0.5246 & 0.6555 & 0.9722 & 0.9591 & 0.9987 & 0.8991 & 0.9558 \\
\hline PRT & 0.9048 & 0.8472 & 1.1378 & 0.9231 & 1.0177 & 0.9898 & 1.0094 \\
\hline ROM & 0.4299 & 0.6706 & 0.8556 & 0.8711 & 0.9429 & 0.8937 & 1.0206 \\
\hline SVK & 0.5779 & 0.9428 & 0.8024 & 0.9469 & 0.8558 & 0.9253 & 1.0187 \\
\hline SVN & 0.8358 & 0.8442 & 1.0076 & 1.0040 & 0.9782 & 0.9781 & 1.0227 \\
\hline SWE & 0.7526 & 0.7738 & 0.9769 & 1.0392 & 0.9584 & 0.9893 & 1.0105 \\
\hline
\end{tabular}


Chapter 2

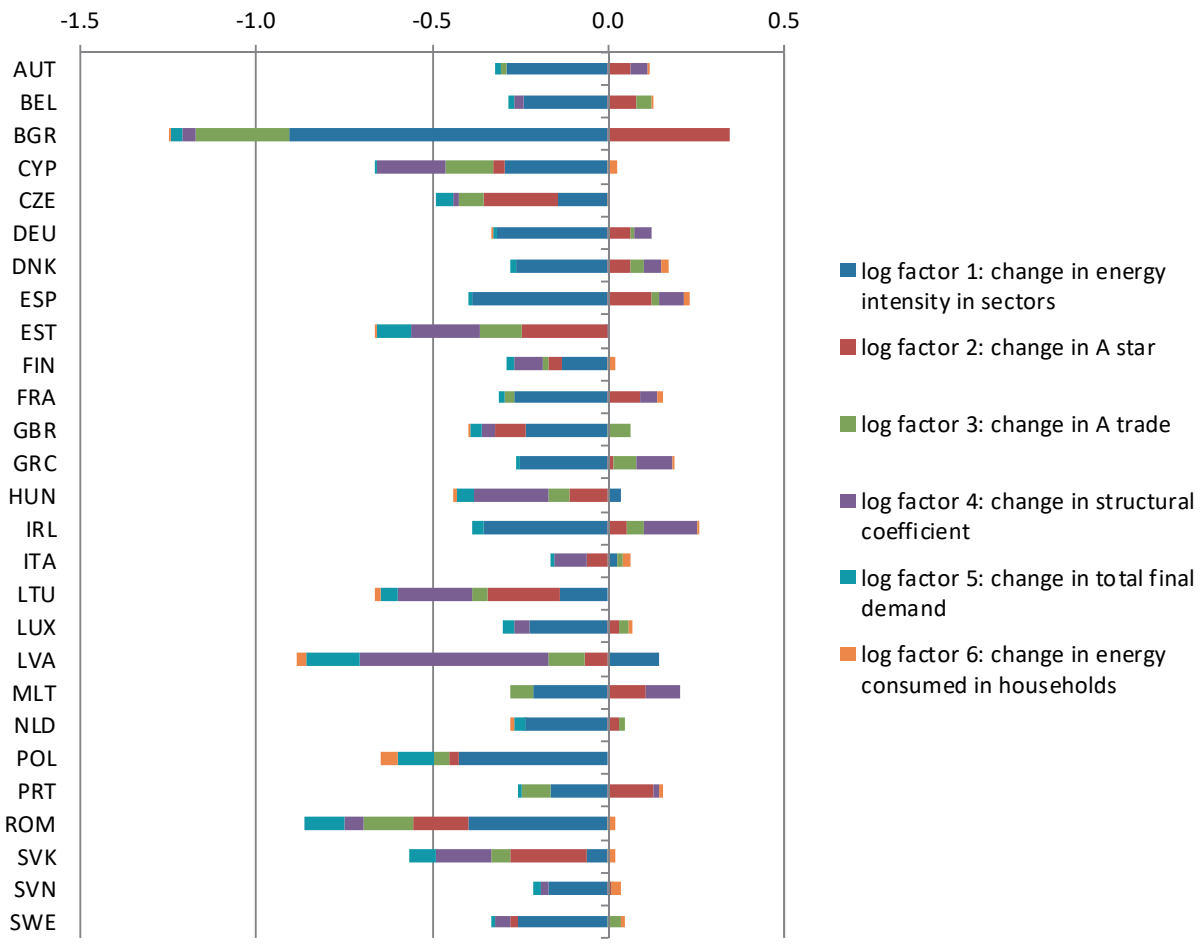

Figure 2.19 Structural decomposition of demand side energy intensity in the EU (log points) 
Table 2.13 Full structural decomposition results of energy consumption at sectoral level, 1995 to 2009

\begin{tabular}{|c|c|c|c|c|c|c|}
\hline Sector & $\begin{array}{l}\text { Relative change } \\
\text { between } 2009 \\
\text { and } 1995\end{array}$ & $\begin{array}{l}\text { Factor 1: change } \\
\text { in } e \text { : intensity } \\
\text { effect }\end{array}$ & $\begin{array}{l}\text { Factor } 2 \text { : change } \\
\text { in } A^{*} \text { : inter- } \\
\text { industry } \\
\text { structural effect }\end{array}$ & $\begin{array}{l}\text { Factor } 3 \text { : change } \\
\text { in } A^{T}: \text { trade } \\
\text { effect in } \\
\text { intermediate } \\
\text { inputs }\end{array}$ & $\begin{array}{l}\text { e Factor } 4 \text { : change } \\
\text { in } s \text { : structural } \\
\text { change effect in } \\
\text { final demand }\end{array}$ & $\begin{array}{l}\text { Factor 5: change } \\
\text { in } C \text { : total final } \\
\text { demand effect }\end{array}$ \\
\hline 1 & 0.8180 & 0.5871 & 0.9267 & 0.9895 & 0.8262 & 1.8388 \\
\hline 2 & 1.5070 & 0.9011 & 1.2170 & 0.8549 & 0.9584 & 1.6772 \\
\hline 3 & 1.2887 & 0.7638 & 1.0573 & 1.0028 & 0.8745 & 1.8196 \\
\hline 4 & 0.9725 & 0.5216 & 0.9610 & 1.0513 & 1.0247 & 1.8010 \\
\hline 5 & 0.8380 & 0.5390 & 0.9753 & 0.9994 & 0.8789 & 1.8147 \\
\hline 6 & 0.8495 & 0.6703 & 0.9034 & 0.9869 & 0.8734 & 1.6277 \\
\hline 7 & 1.2824 & 1.0255 & 0.8386 & 0.9938 & 0.9449 & 1.5880 \\
\hline 8 & 1.1931 & 0.8018 & 0.9922 & 1.0015 & 0.9655 & 1.5510 \\
\hline 9 & 1.2686 & 0.7343 & 1.0156 & 1.0216 & 1.0065 & 1.6543 \\
\hline 10 & 1.3480 & 0.7960 & 1.1411 & 0.9480 & 0.9230 & 1.6961 \\
\hline 11 & 1.5028 & 0.7473 & 0.8741 & 1.0399 & 1.0238 & 2.1610 \\
\hline 12 & 1.3853 & 0.5936 & 1.0549 & 1.0787 & 1.0740 & 1.9096 \\
\hline 13 & 0.7824 & 0.3641 & 1.0975 & 1.0483 & 1.0117 & 1.8463 \\
\hline 14 & 1.1985 & 0.5202 & 1.3896 & 0.8778 & 1.1449 & 1.6497 \\
\hline 15 & 1.5450 & 0.7353 & 1.1054 & 1.0405 & 1.0176 & 1.7952 \\
\hline 16 & 0.8899 & 0.5485 & 0.9555 & 1.1103 & 0.9683 & 1.5791 \\
\hline 17 & 1.5239 & 0.7632 & 1.1489 & 1.0171 & 1.0108 & 1.6905 \\
\hline 18 & 0.9800 & 0.4469 & 1.0292 & 0.9953 & 1.0804 & 1.9812 \\
\hline 19 & 1.1599 & 0.8194 & 1.0268 & 0.9915 & 0.9591 & 1.4497 \\
\hline 20 & 1.2144 & 0.6551 & 1.0834 & 1.0009 & 1.0456 & 1.6351 \\
\hline 21 & 1.2308 & 0.9042 & 1.0002 & 0.9916 & 0.9411 & 1.4584 \\
\hline 22 & 1.5505 & 0.7943 & 1.0619 & 1.0450 & 0.9843 & 1.7872 \\
\hline 23 & 1.1600 & 0.7921 & 0.9956 & 0.9575 & 0.9080 & 1.6918 \\
\hline 24 & 1.1012 & 1.5007 & 0.9858 & 0.6861 & 0.6185 & 1.7543 \\
\hline 25 & 1.5463 & 1.0021 & 0.9598 & 1.0539 & 1.0855 & 1.4054 \\
\hline 26 & 0.7876 & 0.4472 & 1.1394 & 0.9982 & 0.9559 & 1.6199 \\
\hline 27 & 0.9476 & 0.3797 & 1.2560 & 0.9870 & 1.2889 & 1.5618 \\
\hline 28 & 1.2040 & 0.6832 & 1.0803 & 0.9765 & 1.0582 & 1.5788 \\
\hline 29 & 0.8905 & 0.4663 & 1.0671 & 0.9999 & 1.0405 & 1.7202 \\
\hline 30 & 1.9396 & 0.8609 & 1.3430 & 1.0088 & 1.0539 & 1.5779 \\
\hline 31 & 0.7252 & 0.5031 & 0.9930 & 0.9988 & 0.9345 & 1.5551 \\
\hline 32 & 1.1136 & 0.6551 & 1.0512 & 1.0012 & 0.9237 & 1.7487 \\
\hline 33 & 1.5742 & 0.8933 & 1.0305 & 1.0025 & 1.0977 & 1.5539 \\
\hline 34 & 1.1125 & 0.7994 & 1.0096 & 1.0062 & 0.8319 & 1.6469 \\
\hline
\end{tabular}

Note that results for Sector 35 are not available due to missing data problem. 
Table 2.14 Full structural decomposition results of energy intensity at sectoral level, 1995 to 2009

\begin{tabular}{|c|c|c|c|c|c|c|}
\hline Sector & $\begin{array}{l}\text { Relative } \\
\text { change } \\
\text { between } 2009 \\
\text { and } 1995\end{array}$ & $\begin{array}{l}\text { Factor } 1 \text { : } \\
\text { change in } e \text { : } \\
\text { intensity effect }\end{array}$ & $\begin{array}{l}\text { Factor } 2 \text { : } \\
\text { change in } A^{*} \text { : } \\
\text { t inter-industry } \\
\text { structural } \\
\text { effect }\end{array}$ & $\begin{array}{l}\text { Factor } 3 \text { : change } \\
\text { in } A^{T}: \text { trade } \\
\text { effect in } \\
\text { intermediate } \\
\text { inputs }\end{array}$ & $\begin{array}{l}\text { Factor } 4 \text { : } \\
\text { change in } s \text { : } \\
\text { structural } \\
\text { change effect } \\
\text { in final demand }\end{array}$ & $\begin{array}{l}\text { Factor 5: } \\
\text { change in } C \text { : } \\
\text { total final } \\
\text { demand effect } \\
\text { d }\end{array}$ \\
\hline 1 & 0.5810 & 0.5871 & 0.9731 & 0.9777 & 1.0124 & 1.0274 \\
\hline 2 & 0.6879 & 0.9011 & 0.8882 & 0.8355 & 0.9858 & 1.0435 \\
\hline 3 & 0.9236 & 0.7638 & 1.0291 & 0.9994 & 1.0112 & 1.1627 \\
\hline 4 & 0.6930 & 0.5216 & 1.0195 & 1.0231 & 1.1546 & 1.1033 \\
\hline 5 & 0.6243 & 0.5390 & 1.0347 & 0.9797 & 1.0442 & 1.0942 \\
\hline 6 & 0.6704 & 0.6703 & 0.9575 & 0.9753 & 1.0219 & 1.0482 \\
\hline 7 & 1.0766 & 1.0255 & 1.0051 & 0.9894 & 1.0077 & 1.0477 \\
\hline 8 & 0.7666 & 0.8018 & 0.9638 & 0.9910 & 0.9758 & 1.0258 \\
\hline 9 & 0.7913 & 0.7343 & 1.0218 & 1.0038 & 0.9961 & 1.0546 \\
\hline 10 & 0.8453 & 0.7960 & 1.1079 & 0.9289 & 0.9576 & 1.0775 \\
\hline 11 & 1.0458 & 0.7473 & 0.9977 & 1.0302 & 1.0915 & 1.2474 \\
\hline 12 & 0.9375 & 0.5936 & 1.0889 & 1.0675 & 1.1417 & 1.1900 \\
\hline 13 & 0.5011 & 0.3641 & 1.0765 & 1.0366 & 1.0752 & 1.1470 \\
\hline 14 & 0.4167 & 0.5202 & 1.0407 & 0.8492 & 0.8755 & 1.0353 \\
\hline 15 & 0.9982 & 0.7353 & 1.0555 & 1.0393 & 1.0643 & 1.1627 \\
\hline 16 & 0.6927 & 0.5485 & 0.9551 & 1.1165 & 1.1041 & 1.0725 \\
\hline 17 & 0.9331 & 0.7632 & 1.0644 & 1.0087 & 1.0359 & 1.0993 \\
\hline 18 & 0.7076 & 0.4469 & 1.0161 & 0.9975 & 1.2176 & 1.2827 \\
\hline 19 & 0.8773 & 0.8194 & 1.0120 & 1.0041 & 0.9963 & 1.0576 \\
\hline 20 & 0.7614 & 0.6551 & 1.0456 & 1.0054 & 1.0082 & 1.0967 \\
\hline 21 & 0.8848 & 0.9042 & 1.0127 & 0.9941 & 0.9665 & 1.0058 \\
\hline 22 & 1.1216 & 0.7943 & 1.0593 & 1.0447 & 1.0312 & 1.2374 \\
\hline 23 & 0.7829 & 0.7921 & 1.0003 & 0.9590 & 0.9486 & 1.0861 \\
\hline 24 & 0.4615 & 1.5007 & 0.7642 & 0.6921 & 0.5736 & 1.0136 \\
\hline 25 & 1.0986 & 1.0021 & 0.9972 & 1.0572 & 1.0994 & 0.9459 \\
\hline 26 & 0.4888 & 0.4472 & 1.0186 & 1.0060 & 0.9782 & 1.0904 \\
\hline 27 & 0.3590 & 0.3797 & 0.9511 & 0.9909 & 0.9514 & 1.0544 \\
\hline 28 & 0.6572 & 0.6832 & 0.9439 & 0.9816 & 0.9495 & 1.0936 \\
\hline 29 & 0.6245 & 0.4663 & 1.0679 & 1.0030 & 1.0123 & 1.2352 \\
\hline 30 & 0.9967 & 0.8609 & 1.0397 & 1.0218 & 0.9858 & 1.1056 \\
\hline 31 & 0.5067 & 0.5031 & 1.0036 & 0.9997 & 0.9261 & 1.0839 \\
\hline 32 & 0.8032 & 0.6551 & 1.0243 & 1.0012 & 1.0136 & 1.1794 \\
\hline 33 & 0.9770 & 0.8933 & 1.0131 & 1.0021 & 0.9606 & 1.1215 \\
\hline 34 & 0.7757 & 0.7994 & 0.9740 & 1.0094 & 0.8466 & 1.1659 \\
\hline 35 & & & & & & \\
\hline
\end{tabular}

Note that results for Sector 35 are not available due to missing data problem. 


\section{APPENDIX 2.3 ECONOMETRIC ANALYSIS RESULTS}

Table 2.15 Convergence analysis for supply side relative energy intensity

\begin{tabular}{r|crc} 
Source & SS & df & \multicolumn{1}{c}{ MS } \\
\hline $\begin{array}{r}\text { Model } \\
\text { Residual }\end{array}$ & $\begin{array}{r}.536703108 \\
.79538545\end{array}$ & $\begin{array}{r}1 \\
.536703108\end{array}$ & .02339369 \\
\hline Total & 1.33208856 & 35 & .038059673
\end{tabular}

Number of obs $=36$ $F(1,34)=22.94$

Prob $>\mathrm{F}=0.0000$

R-squared $\quad=0.4029$

Adj R-squared $=0.3853$

Root MSE $=.15295$

\begin{tabular}{r|rrrrrr}
\hline growth & Coef. & Std. Err. & $t$ & P $>|t|$ & [95\% Conf. Interval] \\
\hline rei1995 & -.2108643 & .0440236 & -4.79 & 0.000 & -.300331 & -.1213976 \\
_cons & .1562715 & .0512687 & 3.05 & 0.004 & .0520809 & .2604621 \\
\hline
\end{tabular}

Table 2.16 Convergence analysis for demand side relative energy intensity

\begin{tabular}{r|crc} 
Source & SS & df & MS \\
\hline Model & .74119425 & 1 & .74119425 \\
Residual & .66790219 & 36 & .018552839 \\
\hline Total & 1.40909644 & 37 & .038083688
\end{tabular}

Number of obs $=38$

$F(1, \quad 36)=39.95$

Prob $>\mathrm{F} \quad=0.0000$

$\mathrm{R}$-squared $\quad=0.5260$

Adj R-squared $=0.5128$

Root MSE $=.13621$

\begin{tabular}{r|rrrrrr}
\hline growth & Coef. & Std. Err. & $t$ & P > t $\mid$ & [95\% Conf. Interval] \\
\hline rei1995 & -.3056989 & .0483652 & -6.32 & 0.000 & -.403788 & -.2076097 \\
_cons & .3391131 & .0548048 & 6.19 & 0.000 & .2279639 & .4502624 \\
\hline
\end{tabular}




\section{Chapter 2}

Table 2.17 Multilevel mixed-effect model for supply side energy intensity

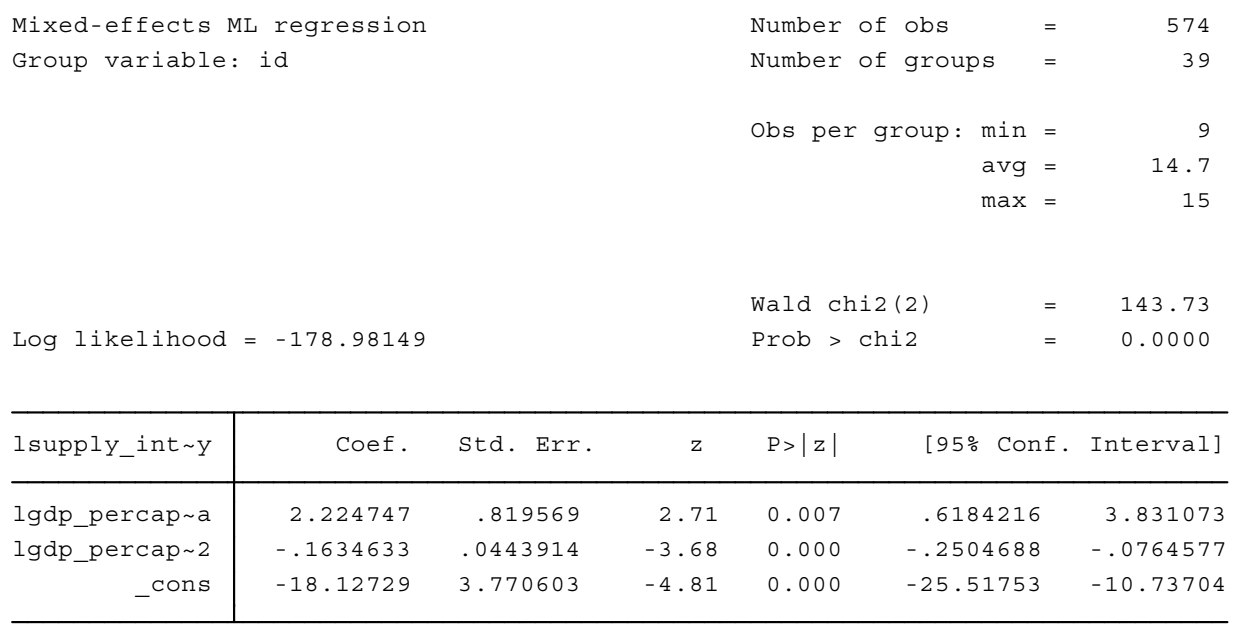

\begin{tabular}{|c|c|c|c|c|}
\hline Random-effects Parameters & Estimate & Std. Err. & [95\% Conf. & Interval] \\
\hline \multicolumn{5}{|l|}{ id: Independent } \\
\hline sd (lgdp_p a) & .1315333 & .0150239 & .1051503 & .1645359 \\
\hline sd(_cons) & $4.66 e-11$ & $1.49 e-07$ & 0 & . \\
\hline sd(Residual) & .2714683 & .0083024 & .2556739 & .2882384 \\
\hline
\end{tabular}

LR test vs. linear regression:

$\operatorname{chi2}(2)=1358.33 \quad$ Prob $>$ chi2 $=0.0000$

Note: LR test is conservative and provided only for reference. 
Table 2.18 Multilevel mixed-effect model for demand side energy intensity

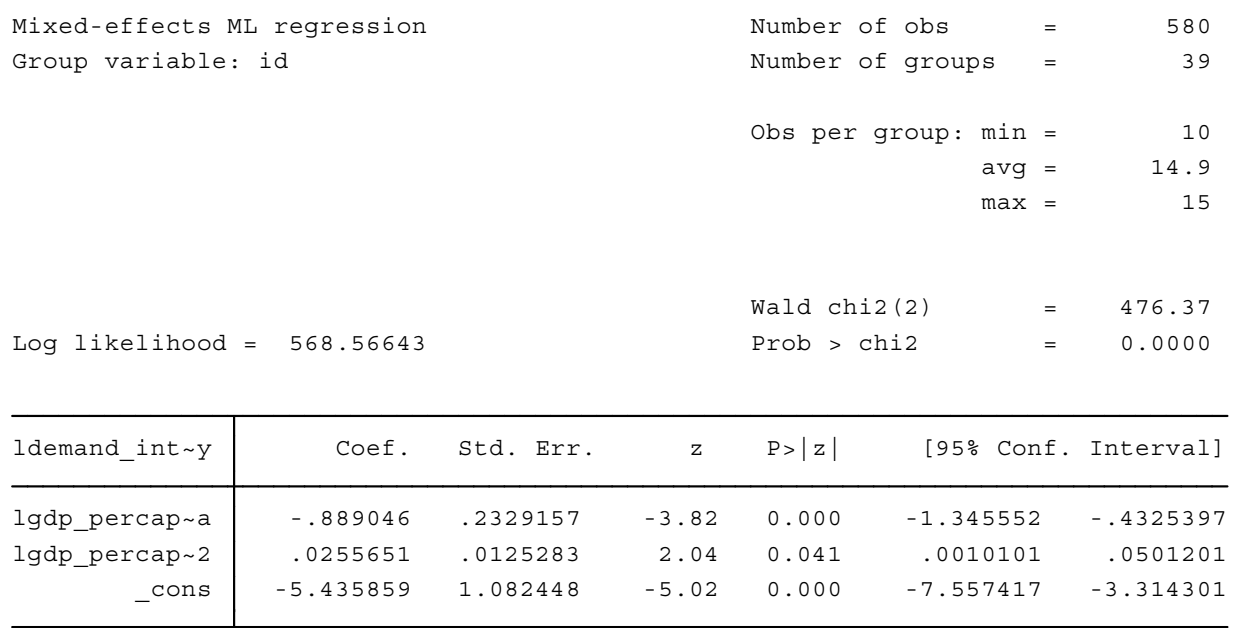

\begin{tabular}{|c|c|c|c|c|}
\hline Random-effects Parameters & Estimate & std. Err. & [95\% Conf. & Interval] \\
\hline \multicolumn{5}{|l|}{ id: Identity } \\
\hline sd(_cons) & .3292811 & .0383193 & .262126 & .4136408 \\
\hline sd(Residual) & .0750602 & .0022859 & .070711 & .0796769 \\
\hline
\end{tabular}

LR test vs. linear regression: $\operatorname{chibar2}(01)=1290.69$ Prob $>=$ chibar2 $=0.0000$ 

Chapter

The dynamics of vehicle energy efficiency:

Evidence from the

Massachusetts Vehicle Census 
Abstract: Using a rich quarterly panel dataset containing about 3.9 million vehicles in the state of Massachusetts, USA, over the period 2008q1 - 2011q4, this paper is an attempt to improve the micro level empirical basis of the study of population-level vehicle energy efficiency, and to provide some evidence that supports policy making related to sustainable development with regard to road vehicles. It (1) presents an aggregate vehicle energy efficiency indicator (at state and municipality level) by taking into account vehicle heterogeneity, (2) investigates the contribution of changes in the structure of the vehicle population that affect aggregate vehicle energy efficiency and its growth, with a particular attention to vehicles' entry and exit, (3) explores the convergence and the Ergodic distribution of aggregate vehicle energy efficiency between municipalities, and (4) checks the socio-economic factors affecting the distribution of vehicles over locations, and vehicle exit event. The results confirm the importance of structural change in the vehicle population, the convergence of aggregate vehicle energy efficiency between municipalities and the crucial role of socio-economic factors in shaping vehicle distribution.

Keywords: vehicle level micro data, vehicle energy efficiency dynamics, decomposition, reallocation, convergence, socio-economic factors

This study was supported by the United Nations Industrial Development Organization (UNIDO). This paper has been published as UNIDO Inclusive and Sustainable Development Working Paper Series 7/2016. This paper was presented in the 2016 Chinese Economic Association (Europe / UK) annual conference in Duisburg, Germany. 


\subsection{INTRODUCTION}

Sustainable development is a process involving many dimensions (e.g., efficient use of resources and raw materials, energy efficiency increase, CO2 emission reductions, etc.). Therefore, it also requires a wide range of policies, covering all those dimensions, e.g., the EU 2020 Strategy (European Commission, 2010). This, in turn, requires a careful study of the detailed processes that are taking place in in the policy-relevant areas. One of those areas is energy efficiency of road vehicles. The energy use of road vehicles (broadly speaking, cars and trucks) is substantial. Due to technological change, new vehicle models that are more energy efficient are entering the market. But the diffusion of new vehicles is a long term process, which involves not only the acquisition of new and efficient vehicles, but also vehicle substitution (new vehicles displacing existing vehicles) and vehicle migration (inflow or outflow of vehicles from a particular location). ${ }^{41}$ The displaced vehicles, however, do not necessarily exit the vehicle population immediately, they may be traded through the second-hand market, and possibly migrate to other places. If this is the case, the increase in energy efficiency at the level of the entire vehicle population becomes a function of which vehicles are replaced, and what is the energy efficiency of new vehicles. The analysis in this paper aims to contribute to a better understanding of the nature and timing of vehicle energy efficiency dynamics at the vehicle population level, and to find out how this is affected by the life cycle of vehicles, including the introduction of new vehicles and the replacement of old ones. This will provide policymakers as well as entrepreneurs with a better insight into how energy efficiency of road vehicles will change over time.

The analysis will describe the dynamics of vehicle energy efficiency in the state of Massachusetts, USA, over the period from 2008 to 2011. By linking vehicle level micro data to macro level municipal units, the analysis tries to answer the following questions with respect to the evolution of aggregate vehicle energy efficiency (municipality level and state level): (i) Does aggregate vehicle energy efficiency in Massachusetts improve as time progresses? (ii) What are the driving forces that cause the dynamics of vehicle energy efficiency? (iii) Is there a tendency of convergence (or divergence) in vehicle energy efficiency for municipalities in Massachusetts? What are the socio-economic factors that affect these dynamics?

These questions reflect several fundamental issues that are relevant for aggregate energy efficiency of the road vehicle population. First, there is a lack of suitable energy performance measurement indicators that are specific for a field in which policy can usefully be designed. For example, aggregate energy use per unit of GDP gives a general impression of how serious the sustainability pressure is, but it does not provide concrete guidance for policies. Indicators specifically designed for (for example) vehicles fill

\footnotetext{
${ }^{41}$ Upsizing of vehicle population would be observed if there is a net inflow of vehicles.
} 
this gap. Second, as a durable consumer product, there is an extremely large number of vehicles present in the market (commercial use as well as in households), and changes in the composition of this vehicle population can be expected to be slow. Moreover, the major fuel source used in the current global vehicle population is still fossil fuels such as gasoline and diesel, which bring lots of environmental pressures. Third, and related to the previous point, there are important differentials in the levels of energy efficiency across vehicles related to vehicle characteristics (e.g., model year, vehicle make, type of vehicle, fuel used by the vehicle, etc.) and the way in which the vehicle is used and maintained. When new vehicles are diffused through a population, these differences will determine aggregate energy efficiency in a complicated way. In particular, when different vehicle populations interact, for example through the existence of secondhand markets, the introduction of new vehicles in one population will also have (indirect) effects on the vehicle energy efficiency in other populations. These dynamics can be analyzed by looking at a set of such interacting populations (in our case municipalities) within a larger context (in our case, the state), and analyze how the overall dynamics of energy efficiency evolves (convergence or divergence). Fourth, the dynamics within and between subpopulations of vehicles will be influenced by socio-economic (and other) conditions (e.g., income, population, unemployment, etc.), and these factors provide an important avenue for policy.

The data used in the analysis come from the Massachusetts Vehicle Census, a rich vehicle level panel dataset developed by the Metropolitan Area Planning Council of Massachusetts, which makes this paper depart from branch of literature on energy efficiency or productivity growth using aggregate data on sectoral or country level. ${ }^{42}$ The advantages of using micro data are that (1) it allows to track the location and status of almost every vehicle over time in Massachusetts, (2) some interesting questions related to heterogeneity can be addressed effectively with micro data only (Bartelsman \& Doms, 2000), and (3) micro data based methods can produce more plausible estimates (Olley \& Pakes, 1996).

Figure 3.1 shows the total number of vehicles in Massachusetts over time. The total number of vehicles increased by around $8.18 \%$ between $2008 q 4$ and $2011 q 4$, rising from about 3.6 million to 3.9 million. ${ }^{43}$ However, the rapid growth of total vehicles between 2008q1 and 2008q4 may be the result of the completion of the census dataset, and hence may not reflect a real trend. Nevertheless, it is clear that Massachusetts underwent significant entry and exit of vehicles. From 2008q4 to 2010q4, there was only a $0.58 \%$ increase in the total number of vehicles, but as illustrated in Table 3.1 , the entry and exit of vehicles account for $13.79 \%$ and $13.29 \%$ of total vehicles in $2010 q 4$

\footnotetext{
${ }^{42}$ The data in this paper are probably subject to the issues of misreporting of true vehicle efficiency, the socalled Volkswagen scandal. There is currently no way to avoid this.

${ }^{43}$ The last quarter of both years is selected. According to Figure 3.1, there was a rapid growth of total vehicles between 2008q1 and 2008q4, which may be explained by the process of completing the census dataset.
} 
respectively. This implies that the restructuring and reallocation of the vehicle population probably plays an important role.

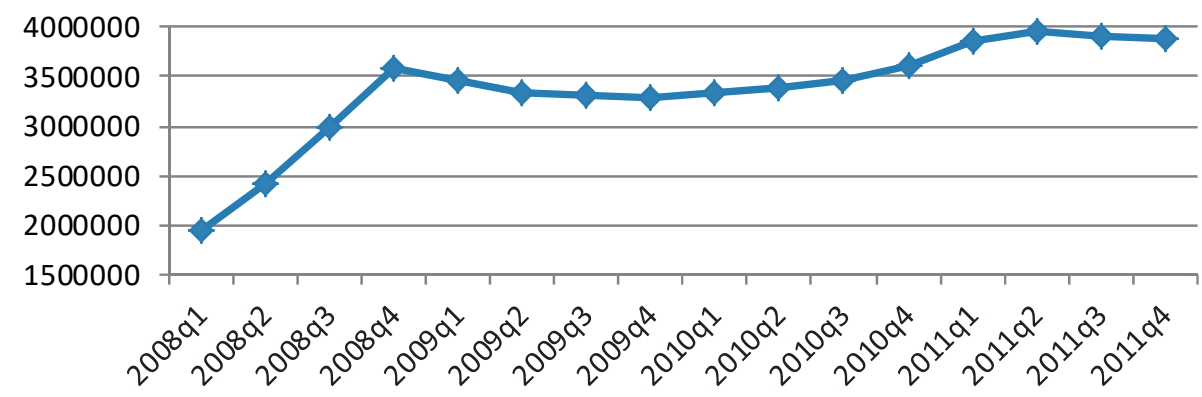

Figure 3.1 Total number of vehicles in Massachusetts; 2008q1 - 2011q4

Table 3.1 Summary statistics of vehicles in Massachusetts between 2008q4 and 2010q4

\begin{tabular}{lcc}
\hline Category & Number of vehicles & Share in the total vehicles \\
\hline $\begin{array}{l}\text { Entering vehicles: newly brought vehicles or vehicles coming } \\
\text { from other states }\end{array}$ & 574987 & $13.79 \%$ \\
$\begin{array}{l}\text { Exiting vehicles: out-of-service vehicles or vehicles moving to } \\
\text { other states or other countries }\end{array}$ & 554117 & $13.29 \%$ \\
Continuing vehicles: vehicles staying in Massachusetts & 3041663 & $72.93 \%$ \\
\hline
\end{tabular}

Source: own elaboration.

As will be shown below, the diversity among vehicles and municipalities is impressive. There are high energy efficiency entrants and low energy efficiency exiting vehicles (causing net efficiency gains), but also low energy efficiency entrants and high energy efficiency exiting vehicles (causing net efficiency losses), municipalities with rapid growth of vehicle energy efficiency and municipalities that have small vehicle energy efficiency growth or even undergo deterioration in vehicle energy efficiency.

In order to deal with the diversity of issues and data trends, this paper applies a number of empirical methods. First, it applies methods from the study of productivity dynamics in firm level micro data to the field of energy efficiency dynamics. ${ }^{44}$ This will look at Miles per Gallon (MPG) at the population level, and how its evolution can be explained by changes in the structure of vehicle (sub)population(s). The purpose of this part of the analysis is to find an appropriate model that can link micro data to aggregate energy efficiency (municipality level and state level), paying particular attention to the heterogeneity of vehicles. Two different decomposition approaches are introduced. The first decomposes the state level vehicle energy efficiency in each quarter from 2008q1 to

\footnotetext{
${ }^{44}$ Typical examples include: (Aw, Chen, \& Roberts, 2001; Baily, Bartelsman, \& Haltiwanger, 2001; Baily, Hulten, \& Campbell, 1992; Bartelsman \& Doms, 2000; Foster, Haltiwanger, \& Krizan, 1998, 2006; Olley \& Pakes, 1996).
} 
2011q4 into an unweighted average of vehicle level energy efficiency and a covariance between vehicle energy efficiency and the share of miles per day. The second looks at a between effect, a within effect, an entry effect and an exit effect that contribute to the growth of vehicle energy efficiency at municipal level between 2008q4 and 2010q4.

A second group of methods used below explores the tendency of movement of the aggregate vehicle energy efficiency, i.e., at the municipality level. Here we look at the relationship between initial relative vehicle energy efficiency at municipal level and its growth rate by performing OLS, nonparametric regression and bootstrapping quantile regression, and at a Markov-transition approach that maps the evolution of aggregate vehicle energy efficiency distribution. Lastly the socio-economic factors affecting the distribution of vehicles and the initially existing vehicle's staying or exiting decision are investigated.

\subsection{LITERATURE REVIEW}

One of the challenges faced in this paper is that there is little literature on the dynamics of vehicle energy efficiency in economics or in related areas. In fact, there seems to be no suitable indicator that can properly reflect the vehicle energy efficiency at population level, while such an aggregate indicator is greatly useful for policymaking regarding vehicles, given the extremely large number of vehicles in modern industrial societies and their large amount of fossil fuels consumption. A commonly used vehicle level technical indicator of a vehicle's energy efficiency is miles per gallon (MPG). It is also a commonly used indicator for producers' marketing activities. But it turns out to be extremely difficult to obtain a suitable aggregate indicator of vehicle energy efficiency at the population level. The reasons are mainly twofold.

First, the data availability issue. The classical definition of energy efficiency proposed by Patterson (1996) is simply a ratio:

\section{Useful output of a process \\ $\overline{\text { Energy input into a process }}$}

As a non-production unit, a vehicle does not generate any useful physical output, but provides useful services measured by the miles it travels. Generating an aggregate indicator of vehicle energy efficiency for an administrative unit, say, a municipality, requires full information about miles and vehicle's energy consumption in that municipality. Such aggregate information is often not available.

Second, the heterogeneity issue. The aggregation approach mentioned above might not be a suitable one even if aggregate information is available, since it does not take into account the heterogeneity of vehicles. Following insightful views by Bartelsman and Doms (2000) and Basu and Fernald (1997) in firm productivity studies, the complexity of 
the interactions between the factors correlated with aggregate energy efficiency growth, such as consumer behaviors regarding the usage of vehicles, vehicle level MPG, and vehicle movement (staying, entering or exiting), calls for a better aggregation method and a simple aggregation over all the heterogeneous units works. The preferred aggregation method taking into account heterogeneity is a weighted average of vehicle level MPG, where the weights are related to the importance of the vehicle, as suggested by several crucial studies in the area of productivity (Baily et al., 1992; Bartelsman \& Doms, 2000; Olley \& Pakes, 1996).

However, applying such an aggregation approach has an even higher requirement for the data: it needs big data that cover every vehicle over time. For a long time this has not been feasible: given the extremely large number of vehicles, the data collection would be greatly expensive and time-consuming and the processing of the data would be restricted by the computing ability of the computer. Fortunately, the Massachusetts Vehicle Census, one of the few public used databases providing vehicle level micro data, has recently been become available. Benefiting from this dataset, this paper aims to fill the existing research gap on energy efficiency dynamics based on micro data.

The methods used here heavily rely on the studies on productivity that use longitudinal micro data (LMD), following large numbers of firms over time. As summarized by Foster et al. (1998), many studies in this field pay great attention to the reallocation and restructuring of inputs and outputs, especially the reallocation due to entry and exit of firms, for example, in the U.S. retail trade sector (Foster et al., 2006), in the U.S. manufacturing sector (Baily, Bartelsman, \& Haltiwanger, 1996; Baily et al., 2001; Baily et al., 1992; Y. Lee \& Mukoyama, 2015; Olley \& Pakes, 1996), in the Taiwanese manufacturing sector (Aw et al., 2001) and in the Israeli industry (Griliches \& Regev, 1995). Moreover, using plant level micro data on manufacturing establishments in China, India and the U.S., Hsieh and Klenow (2009) estimate the loss of aggregate productivity due to the misallocation of resources.

To some extent energy efficiency can be viewed as a special productivity measure. But the nature of vehicles is less complex as compared to the nature of a firm. For example, as a production unit, a firm's productivity growth can be a consequence of complex interactions between factors such as worker skills, technological usage, management techniques and quality of output (Bartelsman \& Doms, 2000). In this respect, the most important distinction between a vehicle and a firm is that plant level productivity can be estimated following a typical production function incorporating all the key factors and using plant level micro data, while this is not the case for a vehicle. The simple nonproduction nature of a vehicle restricts the application of many well-established theoretical or empirical approaches from productivity studies in this paper. In fact, this paper mostly synthesizes and extends the empirical methods in productivity studies re- 
garding the decomposition of aggregate productivity and its growth. The methodological details will be discussed in the next section.

In addition, there are several crucial studies on the product substitution in the vehicle market. Brownstone and Train (1999) generalize the basic choice model to mixed logit model that can approximate any product substitution pattern among gas, electric, methanol and CNG vehicles with various attributes. Berry, Levinsohn, and Pakes (2004) utilize rich micro data on consumers' choice of vehicles to precisely estimate the demand for differentiated vehicles. Both studies show that micro data are very useful in understanding the process of product substitution. These studies require micro data on consumers but the data available in the Massachusetts Vehicle Census can only provide information on vehicles, not the owner of the vehicle. This implies that the product substitution cannot be directly observed and assessed in this dataset ${ }^{45}$, although it actually happens.

\subsection{DATA AND METHODOLOGY}

\subsubsection{Data description}

The main data source is the Massachusetts Vehicle Census, constructed by the Metropolitan Area Planning Council of Massachusetts. The census covers the period 2008q1 2011q4 and has a large and statistically representative sample of the heterogeneous vehicle population. For the computation of aggregate vehicle energy efficiency at both state and municipality levels and its decomposition, the entire dataset is used. For the decomposition of the growth of aggregate vehicle energy efficiency, the data for the period 2008q4 through 2010q4 are used. The reason is the data quality: in the first three quarters in 2008 there is a sharp increase in the vehicle population in the dataset (see Figure 3.1), probably due to a catch-up in data collection, while in 2011 a large quantity of vehicles' data on miles per day are missing in the dataset.

Vehicle energy efficiency is measured by miles per gallon (MPG), a commonly used vehicle level technical indicator measuring how many miles a vehicle can travel by consuming one gallon of fuel. In the Massachusetts Vehicle Census, two versions of MPG indicators are reported: the first is MPG2008 that is based on 2008 EPA ratings, and the second one is adjusted MPG that is adjusted to account for deterioration of energy efficiency over time and due to usage. In this study adjusted MPG is used as the only

\footnotetext{
${ }^{45}$ For example, when a new vehicle enters the state (it appears in the dataset), it is unknown whether the new vehicle is used to substitute the old one or not. The vehicle entry might be caused by migration of the owner.
} 
indicator for vehicle energy efficiency ${ }^{46}$, allowing us to track the performance of individual vehicles in energy efficiency over time. In the census the odometer of every individual vehicle during the quarter under investigation is recorded twice, so that the average miles per day that the vehicle travels can be obtained. Certainly there are some measurement errors in the dataset. For example, some vehicles' miles per day are more than 1 million. Another issue is related to the number of days covered by two inspections. For some vehicles the number of days between by two inspections of odometer is small but during this short period of time the vehicle is frequently used, which leads to a very high average miles per day, say, more than 1000. The high miles per day of some vehicles based on a short measurement period may not represent the usage of the vehicles in the whole quarter. To reduce the impact of these kinds of problems, the study employs a data cleaning strategy in which in each quarter the vehicles are excluded in the analysis if their miles per day are above the $99 \%$ quantile of the state.

Additionally, the dataset contains information about the municipality where every individual vehicle is located in each quarter, which permits us to generate aggregate vehicle energy efficiency at municipality level. In addition, some socio-economic data at municipality level are used in this study, so that the results related to vehicle energy efficiency can be linked to socio-economic factors. The mean household income and median household income at municipality level in Massachusetts over the period 2008 to 2011 are extracted from American Community Survey (ACS). Municipality level data for population, labor force and unemployment are available from Department of Revenue of Massachusetts.

\subsubsection{Aggregate vehicle energy efficiency and its decomposition over the period} $2008 q 1-2011 q 4$

On the basis of previous studies (Aw et al., 2001; Baily et al., 1992; Olley \& Pakes, 1996), the relationship between micro level vehicle energy efficiency and aggregate vehicle energy efficiency can be described as follows (take municipality level aggregate vehicle energy efficiency as example):

$$
\ln M P G_{t}=\sum_{i} \theta_{i, t} \ln M P G_{i, t}
$$

Where $M P G_{t}$ is a certain municipality's aggregate vehicle energy efficiency in time $t$; $M P G_{i, t}$ is the energy efficiency of vehicle $i$ at time $t$, measured by the vehicle's adjusted MPG; $\theta_{i, t}$ is vehicle $i$ 's share of miles per day in the municipality at time $t$, defined as $\theta_{i, t}=\frac{m_{i, t}}{\sum_{i} m_{i, t}} ; m_{i, t}$ is the vehicle i's miles per day at time $t$.

\footnotetext{
${ }^{46}$ The adjusted MPG is estimated by employing a formula that includes vehicle age and mileage. See Daly and Ó Gallachóir (2011).
} 
In this approach, the aggregate vehicle energy efficiency is viewed as a relative shareweighted average of individual vehicle energy efficiency. Shifts in the shares of miles per day from low energy efficiency vehicles to high energy efficiency vehicles will contribute positively to the growth of aggregate vehicle energy efficiency. The basic idea behind this formulation is to describe two aspects revolving around cross-sectional distribution of vehicle energy efficiency: innovation generates new vehicle models and market competition determines the diffusion and adoption of these new vehicle models. On the other hand, the market share in terms of sales of a certain vehicle model does not provide useful information about its usage, while usage of a the vehicle is an indicator as important as its technical energy efficiency in shaping the dynamics of aggregate vehicle energy efficiency.

Following the methods by Olley and Pakes (1996) and Aw et al. (2001), the deviation between an individual vehicle and the unweighted mean over all the vehicles is derived from Equation (1), as shown in the equation below:

$$
\ln M P G_{t}=\sum_{i=1}^{N_{t}} \theta_{i, t} \ln M P G_{i, t}=\sum_{i=1}^{N_{t}}\left(\overline{\theta_{t}}+\Delta \theta_{i, t}\right)\left(\overline{\ln M P G_{t}}+\Delta \ln M P G_{i, t}\right)
$$

where $\Delta \theta_{i, t}=\theta_{i, t}-\bar{\theta}_{t}, \Delta \ln M P G_{i, t}=\ln M P G_{i, t}-\overline{\ln M P G_{t}}$, and a bar over the variable indicates the unweighted mean of the variable at time $t$.

Then aggregate adjusted MPG (in log) can be written as a sum of an unweighted average MPG (in log) and a simple covariance term between individual vehicles' MPG and its share of miles per day. The following equation can be obtained ${ }^{47}$ :

$$
\ln M P G_{t}=\overline{\ln M P G_{t}}+\sum_{i=1}^{N_{t}} \Delta \theta_{i, t} \Delta \ln M P G_{i, t}
$$

This equation is very useful, because it provides insight into the effects of structural change in the vehicle population by separating out micro level indicators from an aggregate one in the time series. The larger the covariance term, the larger the share of miles per day that is contributed by higher energy efficiency vehicles and the more energy efficient is the vehicle. By employing Equation (3), state level aggregate vehicle energy efficiency over the period 2008q1 and 2011q4 is decomposed, in order to gain a general picture of the restructuring of vehicles and learn whether the cross-sectional reallocation is energy efficiency enhancing over time or not.

\footnotetext{
${ }^{47}$ This is because $\ln M P G_{t}$

$=\sum_{i=1}^{N_{t}} \overline{\theta_{t}} \overline{\ln M P G_{t}}+\sum_{i=1}^{N_{t}} \overline{\theta_{t}}\left(\ln M P G_{i, t}-\overline{\ln M P G_{t}}\right)+\sum_{i=1}^{N_{t}} \overline{\ln M P G_{t}}\left(\theta_{i, t}-\overline{\theta_{t}}\right)+\sum_{i=1}^{N_{t}} \Delta \theta_{i, t} \Delta \ln M P G_{i, t}$

$=N_{t} \bar{\theta}_{t} \overline{\ln M P G_{t}}+\bar{\theta}_{t}\left(\sum_{i=1}^{N_{t}} \ln M P G_{i, t}-N_{t} \overline{\ln M P G_{t}}\right)+\overline{\ln M P G_{t}}\left(\sum_{i=1}^{N_{t}} \theta_{i, t}-N_{t} \bar{\theta}_{t}\right)+\sum_{i=1}^{N_{t}} \Delta \theta_{i, t} \Delta \ln M P G_{i, t}$

$=N_{t} \overline{\theta_{t}} \overline{\ln M P G_{t}}+\sum_{i=1}^{N_{t}} \Delta \theta_{i, t} \Delta \ln M P G_{i, t}=\overline{\ln M P G_{t}}+\sum_{i=1}^{N_{t}} \Delta \theta_{i, t} \Delta \ln M P G_{i, t}$
} 


\subsubsection{Decomposition of growth of aggregate vehicle energy efficiency between $2008 q 4$ and 2010q4}

One limitation of Equation (3) is that entry and exit of vehicles across municipalities during a period of time are not reflected. According to Table 3.1, however, there is a large entry and exit movement between 2008q4 and 2010q4, which motivates an attempt to quantify the important role of the reallocation dynamics in aggregate vehicle energy efficiency dynamics.

In the group of entrants to a certain municipality during a period of time, one may roughly find two different sources depending on the status of the vehicle's initial location. One group corresponds to the vehicles that initially exist in other municipalities within the same state, including immigration of vehicles from other municipalities (the owner moves and takes the vehicle), and vehicles coming from other municipalities through the second-hand market. The other source is formed by the vehicles that come from outside Massachusetts, either through migration or trade (including the buying of brand-new vehicles and second-hand vehicles). Similarly, exiting vehicles from a certain municipality can be grouped into two categories, depending on their final locations. If the vehicle in end period still stays in Massachusetts, it might migrate or be sold to another municipality in Massachusetts. Otherwise the vehicle leaves Massachusetts through migration, trade in the second-hand market, or goes out of service. Table 3.2 below summarizes all the scenarios related to a vehicle's entry and exit in a certain municipality.

Table 3.2 Entry and exit of vehicles in a certain municipality

\begin{tabular}{|c|c|c|}
\hline $\begin{array}{l}\text { Movement of } \\
\text { vehicle }\end{array}$ & $\begin{array}{l}\text { Initially existing in } \\
\text { Massachusetts }\end{array}$ & Source \\
\hline \multirow[t]{2}{*}{ Entry } & Yes & $\begin{array}{l}\text { Immigration from other municipalities and vehicles brought from } \\
\text { other municipalities through second-hand market }\end{array}$ \\
\hline & No & $\begin{array}{l}\text { Immigration from other states and vehicles brought from other } \\
\text { states (including brand-new and second-hand vehicles) }\end{array}$ \\
\hline $\begin{array}{l}\text { Movement of } \\
\text { vehicle }\end{array}$ & $\begin{array}{l}\text { Final location in } \\
\text { Massachusetts }\end{array}$ & Direction \\
\hline \multirow[t]{2}{*}{ Exit } & Yes & $\begin{array}{l}\text { Migration to other municipalities and vehicles sold to other } \\
\text { municipality through second-hand market }\end{array}$ \\
\hline & No & $\begin{array}{l}\text { Out of service, migration to other states and vehicles sold to } \\
\text { other states through second-hand market }\end{array}$ \\
\hline
\end{tabular}

Source: own elaboration 
The growth of aggregate vehicle energy efficiency between two quarters is approximated by using the difference term of a logarithm function. ${ }^{48}$ Taking the first order difference on both sides of Equation (1) yields the growth of aggregate vehicle energy efficiency between time $t$ and $t-1$ :

$$
\Delta \ln M P G_{t}=\sum_{i} \theta_{i, t} \ln M P G_{i, t}-\sum_{i} \theta_{i, t-1} \ln M P G_{i, t-1}
$$

Taking into account all the possible scenarios related to a vehicle's entry and exit illustrated in Table 3.2, the following sets of vehicles are introduced:

Stayer: vehicles that stay in the municipality from start to end period (quarter);

Entry: vehicles that move to the municipality between the start and end quarter. This set consists of two subsets: $E 1$, the subset of vehicles that move to the municipality from other municipalities in the state, and $E 2$, the subset of vehicles that directly move to the municipality from outside the state;

Exit: a set of vehicles that leave the municipality between the start and end quarter; this set can be disaggregated into two subsets: $X 1$, the subsets of vehicles that move to other municipalities in the state, and $X 2$, the subset of vehicles that go out of service or move to other states (or countries).

The basic decomposition equation that is used was proposed by Baily et al. (1992), as shown below:

$$
\begin{gathered}
\Delta \ln M P G_{t} \\
=\sum_{i \in \text { Stayer }}\left(\theta_{i, t} \ln M P G_{i, t}-\theta_{i, t-1} \ln M P G_{i, t-1}\right)+\sum_{i \in \text { Entry }} \theta_{i, t} \ln M P G_{i, t} \\
-\sum_{i \in E x i t} \theta_{i, t-1} \ln M P G_{i, t-1} \\
=\sum_{i \in \text { Stayer }}\left(\theta_{i, t} \ln M P G_{i, t}-\theta_{i, t-1} \ln M P G_{i, t}+\theta_{i, t-1} \ln M P G_{i, t}-\theta_{i, t-1} \ln M P G_{i, t-1}\right) \\
+\sum_{i \in \text { Entry }} \theta_{i, t} \ln M P G_{i, t}-\sum_{i \in E x i t} \theta_{i, t-1} \ln M P G_{i, t-1}
\end{gathered}
$$

${ }^{48}$ According to the definition of derivative, $f(x)^{\prime}=\lim _{\Delta x \rightarrow 0} \frac{\Delta f(x)}{\Delta x}$. When $\Delta x$ is very small, approximately, $f(x)^{\prime} \approx \frac{\Delta f(x)}{\Delta x}$. Let $f(x)=\ln x$. Then $f(x)^{\prime}=(\ln x)^{\prime}=\frac{1}{x} \approx \frac{\Delta f(x)}{\Delta x}$, that is, $\Delta(\ln x) \approx \frac{\Delta x}{x}$. The growth of $x$ can be approximated by the difference of its logarithm function. 


$$
\begin{gathered}
=\sum_{i \in \text { Stayer }}\left(\theta_{i, t}-\theta_{i, t-1}\right) \ln M P G_{i, t}+\sum_{i \in \text { Stayer }} \theta_{i, t-1}\left(\ln M P G_{i, t}-\ln M P G_{i, t-1}\right) \\
+\sum_{i \in \text { Entry }} \theta_{i, t} \ln M P G_{i, t}-\sum_{i \in \text { Exit }} \theta_{i, t-1} \ln M P G_{i, t-1}
\end{gathered}
$$

The growth of aggregate vehicle energy efficiency in a certain municipality can be decomposed into the contributions of the stayers, entrants and exiting vehicles. The sets Entry and Exit can be further broken down into subsets E1 and E2, X1 and X2, respectively, that is,

$$
\begin{aligned}
& \Delta \ln M P G_{t} \\
&=\sum_{i \in \text { Stayer }}\left(\theta_{i, t}-\theta_{i, t-1}\right) \ln M P G_{i, t}+\sum_{i \in \text { Stayer }} \theta_{i, t-1}\left(\ln M P G_{i, t}-\ln M P G_{i, t-1}\right) \\
&+\sum_{i \in E 1} \theta_{i, t} \ln M P G_{i, t}+\sum_{i \in E 2} \theta_{i, t} \ln M P G_{i, t}-\sum_{i \in X 1} \theta_{i, t-1} \ln M P G_{i, t-1} \\
&-\sum_{i \in X 2} \theta_{i, t-1} \ln M P G_{i, t-1}
\end{aligned}
$$

The contribution of the stayers consists of two elements: the effect due to changes in individual vehicles' shares of miles per day, holding vehicle level MPG constant (or the "between effect", the first term) and the effect due to changes in MPG in each vehicle separately (or the "within effect", the second term). Unlike firm productivity, however, the deterioration of a vehicle's energy efficiency is irreversible, which implies that the within effect in the basic decomposition equation is negative. The third term and the forth term summarize the contribution of two kinds of entrants. The last two terms represent the effects of exiting vehicles. The net entry effect is then defined as the sum of the last four terms, all the effects of entering and exiting vehicles, reflecting any differences in the shares of miles per day between entering and exiting vehicles and any differences in levels of individual vehicles' MPG.

One disadvantage of this basic decomposition method is that the weights used in the between effect and within effect represent different time periods: the between effect uses ending-level vehicle-level MPG as the weight while the within effect uses the starting-level share of a vehicle's miles per day. As addressed by Foster et al. (1998), the between effect used in the basic decomposition method actually captures a covariance term as well, which might lead to a bias towards a positive between term and a negative net entry term in the analysis of firm productivity. They develop a modified version compared to Baily et al. (1992) and Baily et al. (1996), by separating out the covariance term from the between effect and using the deviations from initial aggregate MPG in 
the decomposition. This method is extended to the field of vehicle energy efficiency dynamics and labeled as Method 2, as shown in Table 3.3.

In Method 2, the growth of aggregate vehicle energy efficiency is decomposed into seven parts. The first three add up to the contribution of stayers to the growth of aggregate vehicle energy efficiency. Compared to the basic decomposition method, the components of Method 2 are distinguished as follows. The within term does not change: it is weighted by initial shares of miles per day. The between term is weighted by the deviation of initial vehicle level MPG (in log points) and initial aggregate MPG (in log points). The newly introduced covariance term is measured as a sum of vehicle level MPG growth and the vehicle's share change. The entry and exit effects are weighted by end period shares and initial shares, respectively, and revised by using the deviation terms between initial vehicle level MPG (in log points) and initial aggregate MPG (in log points).

Some other studies (Aw et al., 2001; Baily et al., 2001; Bartelsman \& Wolf, 2014; Griliches \& Regev, 1995) employ a more elegant decomposition approach that contains deviations from average aggregate MPG between start and end periods, instead of deviations from initial aggregate MPG. This method is labeled as Method 3, and illustrated in Table 3.3. Method 3 is the preferred decomposition approach used in this paper. The reasons are the following. First, conceptually Method 2 is more reasonable since it separates out the covariance term from between effect, but this method focuses on measurement errors (Baily et al., 2001). In fact, as shown later in the state level growth decomposition results in this paper, Method 2 generates results that are very similar to those from Method 3. Second, using mean values between start and end period in Method 3, there is no need to specify initial or ending level weights.

In Method 3, the growth of aggregate vehicle energy efficiency is decomposed into six components, distinguished as follows. The first term is a within effect, that is, the changes in stayer's MPG weighted by the average share of miles per day between start and end periods. The second term is a between effect reflecting changes in stayer's share of miles per day, weighted by the deviation of vehicle level average MPG (in log points) from average aggregate MPG (in log points). This implies that an increase in the share of miles per day can only have a positive impact on the growth of aggregate MPG if the vehicle's average MPG is higher than the average aggregate MPG. In other words, increasing usage of high energy efficiency vehicles can positively contribute to the growth of aggregate vehicle energy efficiency. Similarly, the entry and exit effects are broken down into their subsets of entrants and exiting vehicles, weighted by end period and initial period shares respectively. But both entry and exit effects are revised by using deviations between vehicle level MPG and average aggregate MPG. The basic idea behind such a formulation is that the exit of low energy efficiency vehicles is equivalent to the entry of high energy efficiency vehicles in improving aggregate MPG. 
Method 3 is applied to the decomposition of aggregate vehicle energy efficiency growth at municipality level between 2008q4 and 2010q4. For the growth decomposition at the whole state level, results are obtained by employing all three methods, as shown in the result section.

Table 3.3 Two alternative methods of decomposition of aggregate vehicle energy efficiency growth

\begin{tabular}{lll}
\hline & $\begin{array}{l}\text { Method 2: equation containing } \\
\text { deviation from initial aggregate MPG }\end{array}$ & $\begin{array}{l}\text { Method 3: equation containing deviation from average } \\
\text { aggregate MPG between two quarters }\end{array}$ \\
\hline Main references & (Baily et al., 1996; Bartelsman \& Doms, (Aw et al., 2001; Baily et al., 2001; Bartelsman \& Wolf, \\
& 2000; Foster et al., 1998, 2006) & $\begin{array}{l}\text { 2014; Christensen, Cummings, \& Jorgenson, 1981; } \\
\text { Griliches \& Regev, 1995; Olley \& Pakes, 1996) }\end{array}$
\end{tabular}

Growth of vehicle

$\Delta \ln M P G_{t}$

$\Delta \ln M P G_{t}$

energy efficiency

Factor 1: within effect

$$
\sum_{i \in \text { stayer }} \theta_{i, t-1}\left(\ln M P G_{i, t}-\ln M P G_{i, t-1}\right)
$$$$
\sum_{i \in \text { stayer }}\left(\frac{\theta_{i, t}+\theta_{i, t-1}}{2}\right)\left(\ln M P G_{i, t}-\ln M P G_{i, t-1}\right)
$$

Factor 2: between effect

$$
\begin{aligned}
\sum_{i \in \text { stayer }}\left(\theta_{i, t}-\theta_{i, t-1}\right) & \left(\ln M P G_{i, t-1}\right. \\
& \left.-\ln M P G_{t-1}\right)
\end{aligned}
$$

$$
\begin{aligned}
\sum_{i \in \text { stayer }}\left(\theta_{i, t}-\theta_{i, t-1}\right) & \frac{\ln M P G_{i, t}+\ln M P G_{i, t-1}}{2} \\
& \left.-\frac{\ln M P G_{t}+\ln M P G_{t-1}}{2}\right)
\end{aligned}
$$

Factor 3: covariance term

$$
\begin{aligned}
\sum_{i \in \text { stayer }}\left(\theta_{i, t}-\theta_{i, t-1}\right) & \left(\ln M P G_{i, t}\right. \\
& \left.-\ln M P G_{i, t-1}\right)
\end{aligned}
$$

Factor 4: entry effect vehicles coming from other municipalities

$$
\sum_{i \in E 1} \theta_{i, t}\left(\ln M P G_{i, t}-\ln M P G_{t-1}\right)
$$$$
\sum_{i \in E 1} \theta_{i, t}\left(\ln M P G_{i, t}-\frac{\ln M P G_{t}+\ln M P G_{t-1}}{2}\right)
$$

Factor 5: entry effect due to new vehicles or

$$
\sum_{i \in E 2} \theta_{i, t}\left(\ln M P G_{i, t}-\ln M P G_{t-1}\right)
$$$$
\sum_{i \in E 2} \theta_{i, t}\left(\ln M P G_{i, t}-\frac{\ln M P G_{t}+\ln M P G_{t-1}}{2}\right)
$$
vehicles coming from other states

Factor 6: exit effect due to vehicles moving to other

$$
-\sum_{i \in X 1} \theta_{i, t-1}\left(\ln M P G_{i, t-1}-\ln M P G_{t-1}\right) \quad-\sum_{i \in X 1} \theta_{i, t-1}\left(\ln M P G_{i, t-1}-\frac{\ln M P G_{t}+\ln M P G_{t-1}}{2}\right)
$$
municipalities

Factor 7: exit effect due to vehicles moving to other states

$$
-\sum_{i \in X 2} \theta_{i, t-1}\left(\ln M P G_{i, t-1}-\ln M P G_{t-1}\right) \quad-\sum_{i \in X 2} \theta_{i, t-1}\left(\ln M P G_{i, t-1}-\frac{\ln M P G_{t}+\ln M P G_{t-1}}{2}\right)
$$
or out of service

Source: Own elaboration

\subsubsection{Convergence and transition of aggregate vehicle energy efficiency}

Decompositions break down an effect observed in the entire population, in this case the state vehicle population, into different parts, as explained above. But they do not provide insight into what happens at the subpopulation level, i.e., within municipalities, or 
what are the underlying factors leading to the observed effects. In order to investigate these issues, we apply two other methods. For example, we would like to know whether the observed trends in energy efficiency, e.g., a rise or decline at the state level, are shared among all subpopulations (municipalities), or not, and why. This is what the methods introduced below will address.

\subsubsection{Econometric approach}

The primary focus of the analysis in this section is on the dynamic evolution of aggregate vehicle energy efficiency, investigating important features of convergence or divergence in particular, by extending well-established empirical approaches used in growth theory, to energy efficiency dynamics. There has been a debate about the advantages and disadvantages of various empirical methods and recent research effort on growth and convergence has been made more towards the laws that generate growth distribution rather than on the realizations of growth convergence (Maasoumi, Racine, \& Stengos, 2007). The purpose of the analysis in this section is to shed light on the features or stylized facts about the distribution of aggregate vehicle energy efficiency, instead of testing any specific theory. Traditional empirical methods can serve this purpose properly.

The first empirical specification used in this section is motivated by a series of works on examining the relationship between per capita growth rates of countries and starting level income per capita (Barro, 1991; Barro \& SalaiMartin, 1991, 1992; SalaiMartin, 1996). Using municipality level aggregate vehicle energy efficiency indicators based on vehicle level micro data, a similar empirical strategy is employed to investigate the relationship between the growth of relative aggregate vehicle energy efficiency and initial relative aggregate vehicle energy efficiency ${ }^{49}$ in a cross section of municipalities in Massachusetts. Specifically, all the relevant variables are defined as follows:

$$
\text { Relative aggregate } M P G=\frac{\text { Municipality level aggre gate } M P G}{\text { State level aggregate state MPG }}
$$

\section{Growth of relative aggregate $M P G$$$
=\frac{\text { Difference of relative aggregate } M P G \text { between } 2011 q 4 \text { and } 2008 q 1}{\text { Relative aggregate MPG in } 2008 q 1}
$$

The question behind this analysis is whether municipalities with low aggregate vehicle energy efficiency tend to improve faster than municipalities with high aggregate vehicle energy efficiency, i.e., whether a convergence tendency exists. The relationship between the growth of relative aggregate vehicle energy efficiency and initial relative aggregate vehicle energy efficiency is estimated by using three methods in a cross section of municipalities in Massachusetts. The first is the standard ordinary least squares

\footnotetext{
${ }^{49}$ Relative to the state level aggregate vehicle energy efficiency, measured as MPG.
} 
regression (OLS) that estimates the average effect of the independent variable. However, the average effect estimated by OLS might not be robust or even be misleading, because not all the municipalities' effects of initial relative aggregate vehicle energy efficiency are on the average level and there are some outliers. In this paper the quantile regression technique for cross-sectional data developed by Koenker and Bassett (1978) is employed. ${ }^{50}$ According to Verardi and Croux (2009) and Bartelsman et al. (2014), quantile regression can provide two advantages: first, the method is robust to certain types of outliers (e.g., the vertical outliers that have outlying values for the corresponding error term) and heavy-tailed distributions (see the example of the US wage structure provided by Buchinsky (1994)), and second, quantile regression relaxes Gaussian hypotheses on the error terms, compared to classical methods based on least squares residuals (Koenker \& Bassett, 1982). Note that three types of outliers can influence the OLS result: vertical outliers, bad leverage points and good leverage points. Although Verardi and Croux (2009) present some more effective robust estimators such as MM-estimators, this paper chooses quantile regression to look at the effects across the conditional distribution. Specifically, this paper follows the idea of the birth weight model example provided by Koenker and Hallock (2001): the quantile regression is applied at various quantiles of the growth of relative aggregate vehicle energy efficiency (ranging from 0 to 1 ), conditional on initial relative aggregate vehicle energy efficiency. Standard errors are estimated by using a bootstrapping technique.

In contrast to the first two estimation methods, as another robustness check, the empirical relationship between the two variables of interest is estimated by using a nonparametric approach. The main advantage of a nonparametric approach compared to parametric methods is that there is no need to assume any a priori parametric specification (misspecification of parametric models can lead to misleading results). Recent development of nonparametric estimation has extended the analysis to multivariate data (Li \& Racine, 2007) and recent research on growth has applied nonparametric estimation to convergence analysis (Maasoumi et al., 2007). Specifically, this paper chooses kernel regression (using Epanechnikov kernel as the weight function) to investigate the relationship between the two variables of interest for a cross section of municipalities. ${ }^{51}$

\subsubsection{Distribution approach}

Standard econometric approaches as outlined above collapse the dynamics of aggregate vehicle energy efficiency into growth rates over the period in a cross-sectional structure. In other words, information on the dynamic characteristics is lost. To make full use of the whole distribution of the variable of interest and its dynamic behavior

\footnotetext{
${ }^{50}$ The analysis in this section only uses cross-sectional data. The quantile regression has been extended to panel data analysis. See Bartelsman, Dobbelaere, and Peters (2014) for a discussion.

51 The kernel regression is estimated by using "kernreg1" package in Stata, based on a series works by (Salgado-Ugarte, Shimizu, \& Taniuchi, 1994, 1996a, 1996b).
} 
over time, the transition matrix has been proven to be a very useful tool and has been used in the area of productivity distributions (Baily et al., 1992; Bartelsman \& Dhrymes, 1998). Specifically, this paper extends the well-established distribution approach to aggregate vehicle energy efficiency distributions based on important works about income distribution literature (Quah, 1993a, 1996, 1997), as shown below.

The basic data are relative aggregate MPG over the period 2008q1 - 2010q4. All the municipalities in Massachusetts are divided into 10 groups on the basis of their relative aggregate MPG. The classification bounds are based on the decile of initial relative aggregate MPG, so that all the municipalities in the initial period can be divided into 10 equal-sized groups (ranging from the lowest aggregate vehicle energy efficiency to the highest aggregate vehicle energy efficiency). Let $F_{t}$ be the distribution of relative aggregate MPG across municipalities at time $t$. Then the distribution at time $t+1$ can be viewed as a standard first-order autoregression and can be described by the equation as follows:

$$
F_{t+1}=M * F_{t}
$$

Where $M$ is a $10 * 10$ Markov chain transition matrix mapping the distribution at time $t$ to the distribution at time $t+1$. The value in cell $(i, j)$ of matrix $M$ represents the probability that a municipality in Group $i$ moves to Group $j$ after one quarter, $1 \leq i, j \leq 10, i, j \in N^{*}$.

Then the future distribution at time $t+s$ can be obtained through iteration:

$$
F_{t+s}=M^{s} F_{t}
$$

Letting the time difference $s \rightarrow+\infty$ yields a likely long run distribution of relative aggregate MPG across municipalities, or the Ergodic distribution. The gap in aggregate MPG between municipalities narrows down if lots of municipalities tend to move to the group that contains the state level relative aggregate MPG, that is, 1 . Polarization would occur if lots of municipalities move to distant groups in the Ergodic distribution, for example, municipalities distributed in groups with very low and very high relative aggregate MPG.

\subsection{RESULTS}

This section presents results for the decomposition of aggregate vehicle energy efficiency at state level over the period 2008q1 to 2011q4, the decomposition of the growth of aggregate vehicle energy efficiency between 2008q4 and 2010q4, and the empirical exploration of distribution dynamics and mobility of aggregate vehicle energy efficiency. In addition, the relationship between a municipality's vehicle population and 
socio-economic factors, and the socio-economic factors that affect initially existing vehicles staying or exiting decision are investigated.

\subsubsection{Decomposition of aggregate vehicle energy efficiency over the period $2008 q 1-2011 q 4$}

On the basis of Equation (3) the state level aggregate vehicle energy efficiency (in log points, measured as aggregate MPG) is decomposed into a sum of an unweighted average state level aggregate MPG and a covariance term for the period 2008q1 - 2011q4, as illustrated in Table 3.4 and Figure 3.2 below.

Overall, the shapes of state level aggregate MPG and unweighted average aggregate MPG are somehow similar: both of them have a sharp increase in 2008 and a significant drop in 2011. One possible explanation is that because of data collection many existing vehicles were not included in the dataset in early 2008 as shown by the sharp increase in vehicle population in 2008 in Figure 3.1, and the data quality in 2011 is not very good; lots of vehicles' miles per day data are missing. Accordingly there might be some measurement errors in early 2008 and in 2011.

For the period $2008 q 4-2010 q 4$, with more reliable data, the state level aggregate MPG and the unweighted average aggregate MPG show slightly different dynamic patterns. Compared to $2008 q 4$, there is a small increase in the state level aggregate MPG in 2010q4, growing from 2.7227 to a peak of 2.7450, while a decline can be observed in between the two quarters. This indicates that the state is becoming more efficient in terms of vehicle energy efficiency during 2008q4 - 2010q4, but only to a small extent. On the other hand, the unweighted average aggregate MPG generally shows a downward trend: reducing to 2.6577 in 2010q4 after reaching its peak in 2009q1. This difference is certainly caused by the covariance term.

In general, the covariance term exhibits a cyclical dynamics and it is positive in all the quarters. The covariance term consists of two important components: one is the deviation of individual vehicles' MPG from the unweighted average aggregate MPG and the other is the deviation of individual vehicles' miles per day from the state level average. The positive covariance term clearly indicates the reallocation of high energy efficiency vehicles: the larger the covariance term, the larger share of miles per day contributed by high energy efficiency vehicles and the more energy efficient is the vehicle. The covariance term reaches its peak (0.0999) in 2008q2 and sharply decreases to its minimum level (0.0761) in 2009q1. The explanation for this significant decline might be the 2008 financial crisis that might lower the purchase and usage of high energy efficiency vehicles. Between 2008q4 and 2010q4, the unweighted average aggregate MPG shows a downward trend, which generally implies the ageing of the vehicle population in Massachusetts: vehicle energy efficiency is decreasing over time. The state level aggregate 
MPG increases by about $2.23 \%$ during this period due to the reallocation of high energy efficiency vehicles. The reallocation effect can be caused by increasing usage of existing or entering high energy efficiency vehicles, and equivalently by decreasing usage of existing or exiting low energy efficiency vehicles. However, the decomposition of state level aggregate MPG cannot provide more detailed information about the reallocation effect. Several crucial factors contributing to the growth of aggregate MPG are explored in the next section.

Table 3.4 Decomposition of state level aggregate MPG over the period 2008q1 - 2011q4

\begin{tabular}{|c|c|c|c|}
\hline Quarter & $\begin{array}{l}\ln M P G_{t}: \text { Log of state level } \\
\text { aggregate MPG }\end{array}$ & $\begin{array}{l}\overline{\ln M P G_{t}}: \text { Log of unweighted average } \\
\text { state level aggregate MPG }\end{array}$ & $\begin{array}{l}\sum_{i=1}^{N_{t}} \Delta \theta_{i, t} \Delta \ln M P G_{i, t} \\
\text { covariance term }\end{array}$ \\
\hline $2008 q 1$ & 2.6838 & 2.5921 & 0.0916 \\
\hline $2008 q 2$ & 2.7082 & 2.6083 & 0.0999 \\
\hline $2008 q^{3}$ & 2.7009 & 2.6174 & 0.0835 \\
\hline $2008 q 4$ & 2.7227 & 2.6387 & 0.0840 \\
\hline $2009 q 1$ & 2.7428 & 2.6667 & 0.0761 \\
\hline $2009 q 2$ & 2.7384 & 2.6586 & 0.0798 \\
\hline $2009 q 3$ & 2.7383 & 2.6581 & 0.0802 \\
\hline $2009 q 4$ & 2.7376 & 2.6539 & 0.0837 \\
\hline 2010q1 & 2.7389 & 2.6573 & 0.0817 \\
\hline $2010 q 2$ & 2.7423 & 2.6554 & 0.0869 \\
\hline $2010 q 3$ & 2.7416 & 2.6527 & 0.0889 \\
\hline $2010 q 4$ & 2.7450 & 2.6577 & 0.0874 \\
\hline 2011q1 & 2.7136 & 2.6322 & 0.0814 \\
\hline $2011 q 2$ & 2.7163 & 2.6323 & 0.0840 \\
\hline $2011 q 3$ & 2.7232 & 2.6328 & 0.0904 \\
\hline $2011 q 4$ & 2.7144 & 2.6318 & 0.0826 \\
\hline
\end{tabular}




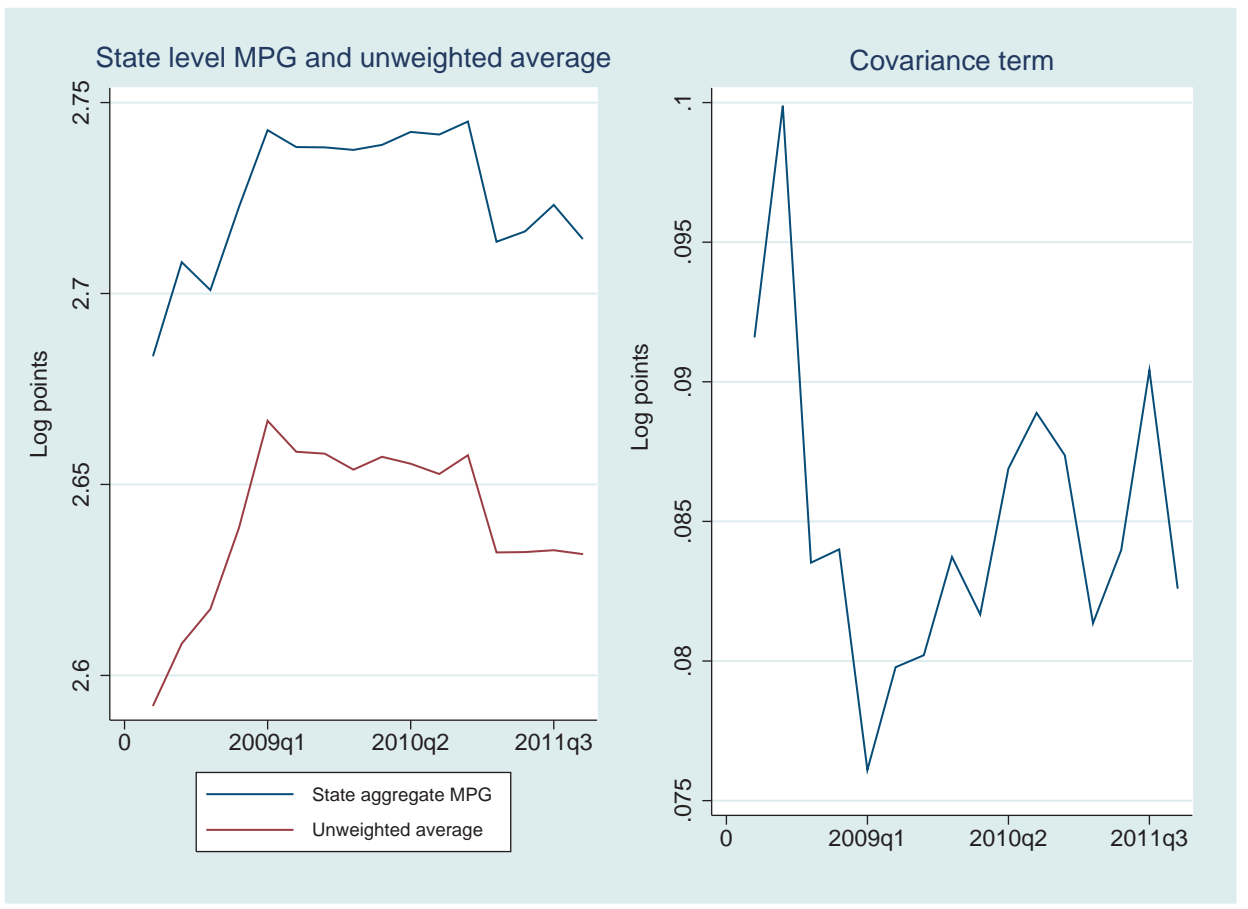

Figure 3.2 Decomposition of state level aggregate MPG over the period 2008q1 - 2011q4 Source: Own elaboration.

\subsubsection{Decomposition of growth of aggregate vehicle energy efficiency between $2008 q 4$ and $2010 q 4$}

In this section the results for decomposition of growth of aggregate MPG between 2008q4 and 2010q4 are presented. Table 3.5 below shows the decomposition results at state level. Method 3 is the preferred decomposition method, but the state level results based on the other two methods are included in this table for comparison purposes.

At the state level the subsets $E 1$ and $E 2$ are combined in calculating an aggregate entry effect and the subsets $X 1$ and $X 2$ are combined in calculating an aggregate exit effect. As shown in Table 3.5, the growth rates of aggregate MPG using three different methods are the same, and they are very close to the actual growth, $2.26 \%{ }^{52}$ Method 2 and Method 3 generate quite similar results, but they greatly differ from the results calculated using Method 1, except for the within effect. According to Method 1's results, the state level aggregate MPG is lowered by $8.41 \%$ due to decreasing energy efficiency of all vehicles, by $3.19 \%$ due to the ageing of the vehicle population and by $32.14 \%$ due to efficiency drain by the exiting of vehicles. But the entry of vehicles contributes to a

\footnotetext{
52 There is a very small difference between the growth of aggregate MPG calculated from decomposition and the actual growth, since the difference of log points is used as an approximation of the actual growth.
} 
much higher efficiency gain, $45.97 \%$, so that overall the aggregate MPG increases by $2.24 \%$ in the end quarter. The reason of such a big difference in the magnitude between factors is that weights for different quarters are used. Method 1 does not explicitly distinguish effects between high energy efficiency vehicles and low energy efficiency vehicles. Logically, lower usage or the exit of low energy efficiency vehicles should improve the aggregate MPG, but in Method 1 they are viewed as equivalent as detrimental effects caused by less usage or the exiting of high energy efficiency vehicles.

Accordingly, Method 2 and Method 3 provide more reasonable revised results that take into account different effects due to high and low energy efficiency vehicles. The high energy efficiency vehicle in Method 2 is the one whose MPG is higher than the initial level aggregate MPG, while in Method 3 the comparison threshold is the average of aggregate MPG between initial and ending levels. The conclusion changes between Method 2 and Method 3. Method 2 has an additional positive covariance term (0.0020), which means that the reallocation effect among staying vehicles contributes only $0.02 \%$ to the growth of aggregate MPG. The between effect becomes positive: $1.5 \%$ in Method 2 and $1.64 \%$ in Method 3, which refers to the increasing usage of high energy efficiency vehicles or decreasing usage of low energy efficiency vehicles among the staying vehicles. The within effect reflecting the ageing of the vehicle population is still negative, $3.19 \%$ in Method 2 and $3.09 \%$ in Method 3. The positive entry effect, $2.51 \%$ in Method 2 and $2.33 \%$ in Method 3, indicates that on average the entering vehicles have high energy efficiency, leading to an efficiency gain. Interestingly, compared to Method 1, the exit effect becomes positive, 1.22\% in Method 2 and $1.35 \%$ in Method 3. This finding shows that the exiting vehicles have low energy efficiency.

Table 3.5 Decomposition of aggregate vehicle energy efficiency at state level between 2008q4 and 2010q4

\begin{tabular}{|c|c|c|c|c|c|c|}
\hline & $\begin{array}{l}\text { Growth of } \\
\text { aggregate } \\
\text { MPG }\end{array}$ & $\begin{array}{l}\text { Between } \\
\text { effect: } \\
\text { change in the } \\
\text { share of } \\
\text { miles per day }\end{array}$ & $\begin{array}{l}\text { Within effect: } \\
\text { change in the } \\
\text { vehicles' } \\
\text { adjusted MPG }\end{array}$ & $\begin{array}{l}\text { Covariance } \\
\text { term }\end{array}$ & $\begin{array}{l}\text { Entry effect due to } \\
\text { vehicles coming } \\
\text { from other states or } \\
\text { newly brought } \\
\text { vehicles }\end{array}$ & $\begin{array}{l}\text { Exit effect due to } \\
\text { out of service or } \\
\text { vehicles moving } \\
\text { to other states }\end{array}$ \\
\hline Method 1 & 0.0224 & -0.0841 & -0.0319 & & 0.4597 & -0.3214 \\
\hline Method 2 & 0.0224 & 0.0150 & -0.0319 & 0.0020 & 0.0251 & 0.0122 \\
\hline Method 3 & 0.0224 & 0.0164 & -0.0309 & & 0.0233 & 0.0135 \\
\hline
\end{tabular}

Source: Own elaboration.

Note that Method 2 has a between term weighted by deviation from initial aggregate MPG and a covariance term. Method 3 has a between term weighted by deviation from average over all the vehicles' MPG between two quarters.

Another finding based on Method 2 and Method 3 is that the within effect is much stronger than the between effect (Method 3) or the between effect and covariance term combined (Method 2). This seems somehow pessimistic, because it means that among the large number of staying vehicles the deterioration of aggregate vehicle effi- 
ciency caused by the ageing effect is more influential than the improvement due to increase of the usage of high energy efficiency vehicles, or reducing the usage of low energy efficiency vehicles. Because of efficiency gains provided by both entry effect and exit effects, however, the deterioration of aggregate vehicle energy efficiency has been offset. In other words, the net entry effect (the sum of entry effect and exit effect) is the main driving force of the growth of aggregate MPG. This finding has important policy implication related to innovation and technological change.

To have a deeper and more comprehensive understanding of the vehicle energy efficiency dynamics, Method 3 is employed to decompose the growth of aggregate MPG between 2008q4 and 2010q4 for 350 municipalities in Massachusetts. ${ }^{53}$ A summary of the decomposition results is shown in Table 3.6 and relevant histograms are shown in Figure 3.3.

Generally the findings at municipality level are consistent with the decomposition at state level. The average growth of aggregate MPG over all the 350 municipalities is about $2.38 \%$ and most municipalities have improved their aggregate MPG during the period under research. But there are certainly some outliers in the growth of aggregate MPG: the best performing municipality has a surprisingly high growth of aggregate MPG (37.65\%), but the poorest performing municipality has a $15.63 \%$ decline. The standard deviation of the growth is $5.01 \%$, much larger than its mean, $2.38 \%$, which means that there is a very big difference in the growth across municipalities. This might be indicative of a large regional imbalance of vehicle energy efficiency. The same conclusion can be found in the between effect: most municipalities have a positive between effect but a large gap exists between the best performing and the poorest performing municipalities (29.37\% and $-11.09 \%$, respectively). The ageing of the vehicle population leads to a significant decline in aggregate MPG in all the municipalities. For most municipalities this decline caused by ageing of vehicle population is between $-3 \%$ and $-2 \%$, and stronger than the growth contributed by the between effect. On the other hand, most municipalities also have a larger net entry effect that can compensate the energy efficiency reduction, which means that the net entry effect is the main contributor of the growth of aggregate MPG. Specifically, it is evident that most municipalities actually benefit from the efficiency gain brought by vehicles entering due to purchase of new vehicles or migration of vehicles (from other municipalities or other states). Interesting$l y$, for most municipalities the strongest factor causing efficiency drain is the exit effect due to vehicle's moving to other municipalities within the state, probably through trade or migration. This implies that those vehicles belonging to this category are of high energy efficiency. If the vehicle is no longer in Massachusetts (for example, the vehicle moves to other states through trade or migration, or the vehicle goes out of service),

\footnotetext{
53 There are 351 official municipalities in Massachusetts. But for the municipality Gosnold there are no data for calculating the growth of aggregate MPG during the period under research.
} 
the exit effect then exhibits an efficiency gain, which implies the exiting of low energy efficiency vehicles.

Table 3.6 Summary of decomposition of growth of aggregate vehicle energy efficiency on municipal level using Method 3, 2008q4 - 2010q4

\begin{tabular}{|c|c|c|c|c|c|c|c|}
\hline & $\begin{array}{l}25 \% \\
\text { quantile }\end{array}$ & $\begin{array}{l}50 \% \\
\text { quantile }\end{array}$ & $\begin{array}{l}75 \% \\
\text { quantile }\end{array}$ & Mean & Std.dev. & Min. & Max. \\
\hline Growth of aggregate MPG & -0.0013 & 0.0175 & 0.0427 & 0.0238 & 0.0501 & -0.1563 & 0.3765 \\
\hline Between effect & -0.0003 & 0.0104 & 0.0266 & 0.0145 & 0.0317 & -0.1109 & 0.2937 \\
\hline Within effect & -0.0269 & -0.0260 & -0.0253 & -0.0258 & 0.0021 & -0.0321 & 0.0000 \\
\hline Net entry effect & 0.0200 & 0.0331 & 0.0460 & 0.0352 & 0.0332 & -0.1063 & 0.3648 \\
\hline Entry effect: from other municipalities & 0.0069 & 0.0119 & 0.0173 & 0.0125 & 0.0115 & -0.0422 & 0.0747 \\
\hline $\begin{array}{l}\text { Entry effect: from other states or newly } \\
\text { brought vehicles }\end{array}$ & 0.0172 & 0.0248 & 0.0300 & 0.0235 & 0.0179 & -0.1077 & 0.0901 \\
\hline Exit effect: to other municipalities & -0.0211 & -0.0149 & -0.0104 & -0.0162 & 0.0150 & -0.0801 & 0.1116 \\
\hline $\begin{array}{l}\text { Exit effect: to other states or out of } \\
\text { service }\end{array}$ & 0.0067 & 0.0123 & 0.0201 & 0.0153 & 0.0225 & -0.0334 & 0.3333 \\
\hline
\end{tabular}

The regional distribution of the growth of aggregate MPG at municipality level between 2008q4 and 2010q4 is visualized in the map in Figure 3.4. The darker (lighter) the color, the higher (lower) is the growth of aggregate MPG. The best performing municipalities seem to be distributed across the whole state and the urban areas (for example, the greater Boston area and municipalities close to Boston) seem to have an average level or below average level growth of aggregate MPG. Thus, Figure 3.4 gives an impression of a regional imbalance of vehicle energy efficiency, as previously shown in Table 3.6. It is additionally evident that poor performing municipalities (areas with a light color) are distributed in most parts of the state and there is a big discrepancy in the growth among neighboring municipalities. For example, the best performing and the poorest performing municipalities are close to each other in the northwestern part of the state. 

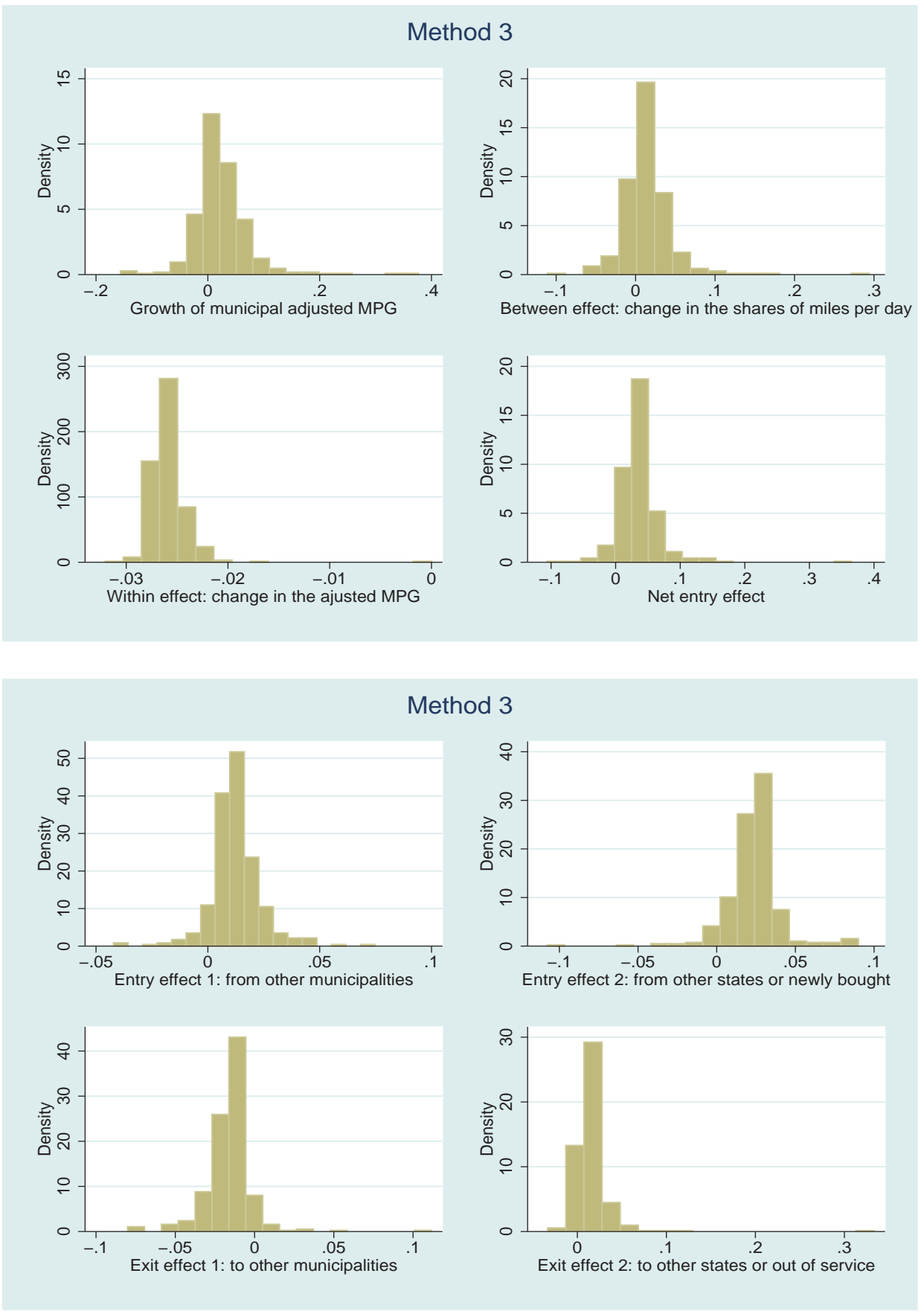

Figure 3.3 Histogram graphs of decomposition of growth of aggregate vehicle energy efficiency at municipality level using Method 3, 2008q4 - 2010q4 


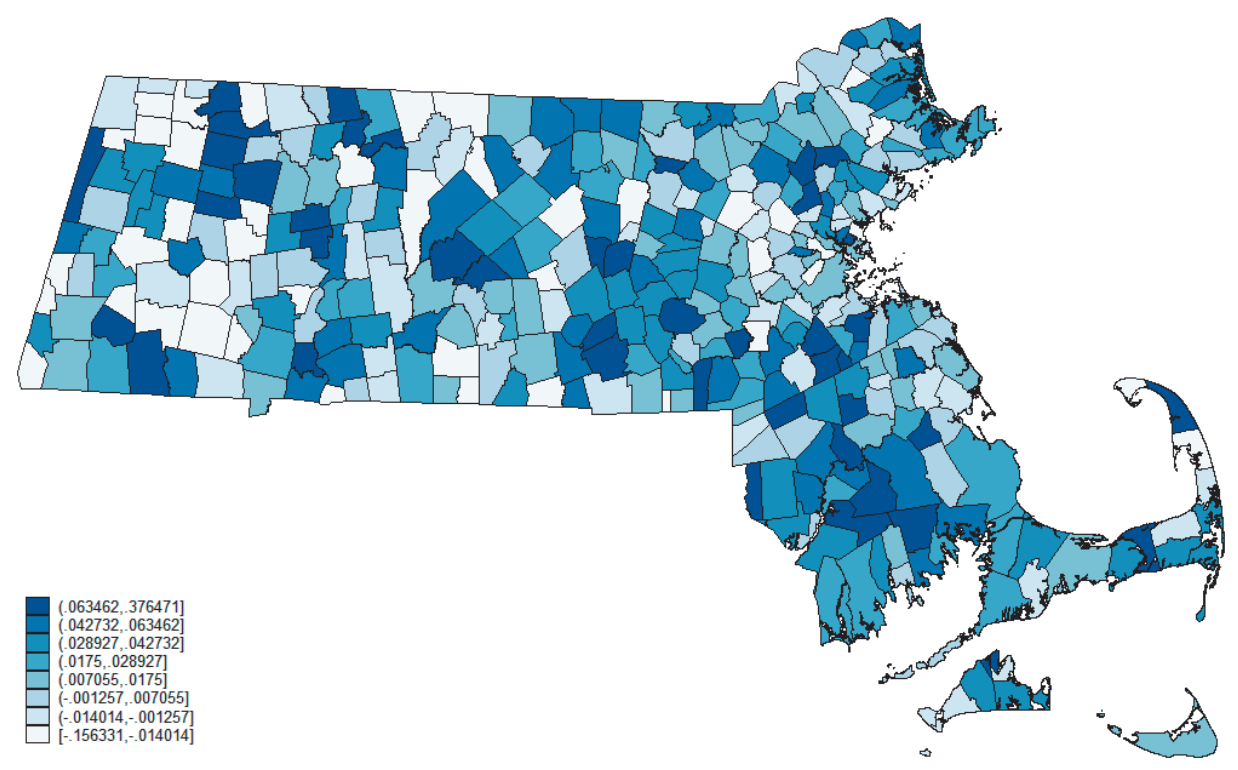

Figure 3.4 Massachusetts, growth of aggregate vehicle energy efficiency at municipality level between 2008q4 and 2010q4

Source: Own elaboration.

In order to get a better understanding of the variety of experiences at the municipality level, the 350 municipalities in Massachusetts are clustered into a much smaller number of groups on the basis of the results of the decomposition analysis, and a number of socio-economic characteristics of the municipalities. Municipalities that are similar to each other, in terms of these variables, are put in the same cluster. By analyzing the properties of the clusters, a better understanding of the extent and nature of variety between municipalities is obtained.

Five variables are taken into account in the clustering method: the net entry effect ${ }^{54}$, the between effect, the within effect, the average unemployment rate between 2008 and 2010, and the average of mean household income between 2008 and $2010^{55}$. The introduction of the last two variables is intended to reflect job market characteristics and the living standard in the municipality, respectively. The average of the two variables between the initial and ending years is used in the analysis. The commonly used Ward linkage is chosen to measure the dissimilarity between municipalities in clustering method. Then all the 350 municipalities are grouped into three clusters. ${ }^{56}$

\footnotetext{
${ }^{54}$ The net entry effect is the sum of two entry effects and two exit effects.

55 The municipality level unemployment data for 2008 and 2010 are available at the Massachusetts Department of Revenue. The municipality's mean household income data for 2008 and 2010 are taken from American Community Survey (ACS).

${ }^{56}$ The dendrogram of the hierarchical clustering analysis shows it is reasonable to group all the municipalities in to three clusters.
} 
The mean values of the standardized variables used in cluster analysis are presented by cluster in Table 3.7 below. The related Table 3.8 summarizes the mean values of the non-standardized version of all the five variables. Figure 3.5 is a visualization of the cluster analysis results, where municipalities that belong to the same cluster are labeled in the same color and all the three clusters are graphed onto a map of Massachusetts by using three colors (orange, green and purple).

There are several interesting findings that can be gathered from Table 3.8. The average within effect, or the ageing of vehicle population, does not significantly vary between the three clusters, and hence appears as a general tendency. Municipalities in Cluster 3 (in orange) have the highest average household income (132206.3 US dollars), the lowest average unemployment rate $(5.47 \%)$, the smallest average within effect $(-2.72 \%)$ as well as the lowest average net entry effect (2.72\%). This is probably because well-off municipalities have fewer incentives to use energy efficient vehicles. Municipalities in Cluster 2 (in purple) have a medium level of average household income (83739.51 US dollars), but show a high level of average net entry effect (5.5\%) and average between effect (4.38\%), which means a large effect from restructuring of the vehicle population and high usage of energy efficient vehicles. Municipalities with the lowest average household income (Cluster 1 , in green) have the lowest average between effect (only $0.12 \%$ ), indicating a low usage of high energy efficiency vehicles, but the average net entry effect in Cluster 1 is not so different from that in Cluster 3 (2.85\% for Cluster 1 and $2.72 \%$ for Cluster 3 ). Low income and high unemployment rate probably restrict the adoption and usage of (new) energy efficient vehicles.

In Figure 3.5 a clear geographical pattern is that the eastern part of Massachusetts is mainly dominated by municipalities belonging to Cluster 1 and Cluster 3. For example, the Boston area belongs to Cluster 1 and it is surrounded by rich municipalities belonging to Cluster 3. This may be explained by counter-urbanization. On the whole, municipalities in Cluster 3 with lower average net entry effect and average between effect are found more often in the eastern part of the state. As a result, the eastern part of the state generally has a lower growth rate of aggregate vehicle energy efficiency. This finding is consistent with Figure 3.4 where the eastern part of the map is lighter.

Table 3.7 Mean value of the five variables used in cluster analysis

\begin{tabular}{|c|c|c|c|c|c|}
\hline Cluster & $\begin{array}{l}\text { Standardized net } \\
\text { entry effect }\end{array}$ & $\begin{array}{l}\text { Standardized } \\
\text { between effect }\end{array}$ & $\begin{array}{l}\text { Standardized within } \\
\text { effect }\end{array}$ & $\begin{array}{l}\text { Standardized average } \\
\text { unemployment rate } \\
\text { between } 2008 \text { and } \\
2010\end{array}$ & $\begin{array}{l}\text { Standardized } \\
\text { average of the mean } \\
\text { household income } \\
\text { between } 2008 \text { and } \\
2010\end{array}$ \\
\hline 1 & -0.2017 & -0.4197 & 0.1701 & 0.1629 & -0.4205 \\
\hline 2 & 0.5974 & 0.9240 & 0.3114 & 0.3829 & -0.3146 \\
\hline 3 & -0.2421 & -0.1628 & -0.6672 & -0.7295 & 1.1628 \\
\hline
\end{tabular}




\section{Chapter 3}

Table 3.8 Mean value of the five variables by cluster

\begin{tabular}{|c|c|c|c|c|c|}
\hline Cluster & $\begin{array}{l}\text { Average net entry } \\
\text { effect (\%) }\end{array}$ & $\begin{array}{l}\text { Average between } \\
\text { effect (\%) }\end{array}$ & $\begin{array}{l}\text { Average within effect } \\
\text { (\%) }\end{array}$ & $\begin{array}{l}\text { Average } \\
\text { unemployment rate } \\
\text { between } 2008 \text { and } \\
2010(\%)\end{array}$ & $\begin{array}{l}\text { Average of the mean } \\
\text { household income } \\
\text { between } 2008 \text { and } \\
2010 \text { (US\$) }\end{array}$ \\
\hline 1 & 0.0285 & 0.0012 & -0.0255 & 0.0742 & 80263.5500 \\
\hline 2 & 0.0550 & 0.0438 & -0.0252 & 0.0791 & 83739.5100 \\
\hline 3 & 0.0272 & 0.0093 & -0.0272 & 0.0547 & 132206.3000 \\
\hline
\end{tabular}

Source: Own elaboration.

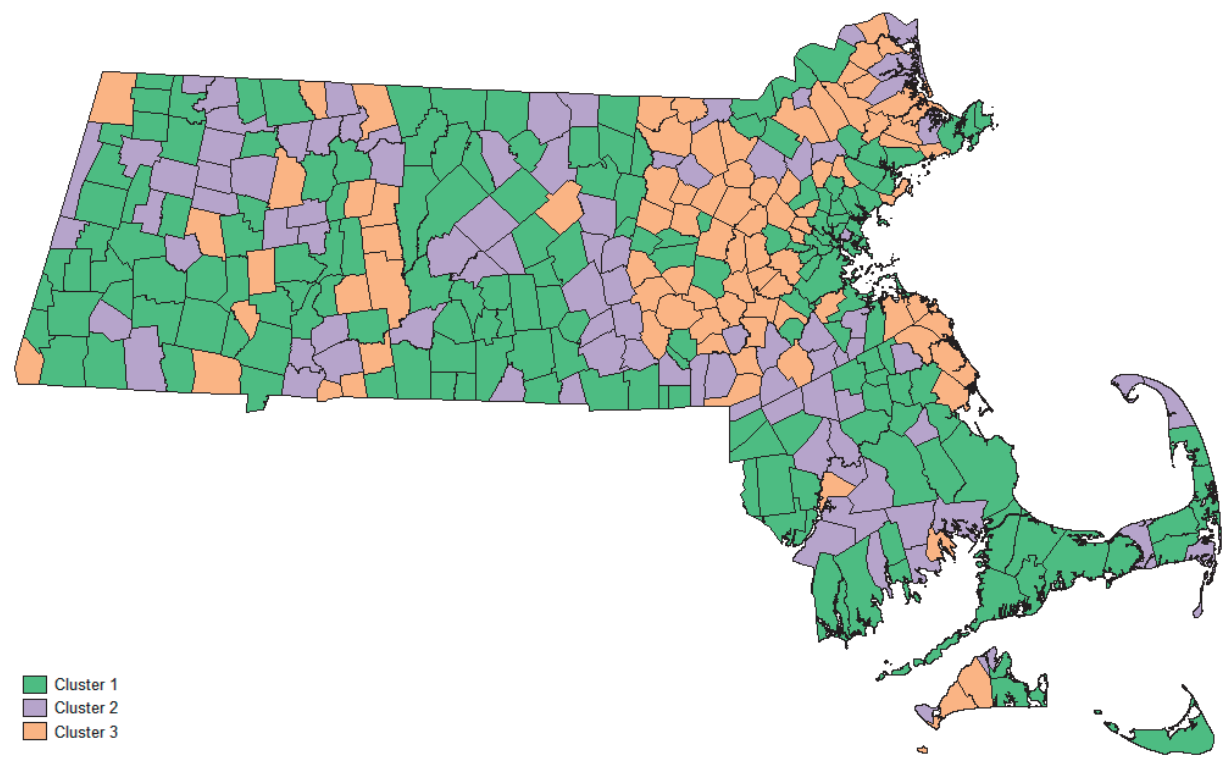

Figure 3.5 Massachusetts, municipality clusters based on five factors between 2008 and 2010

Source: Own elaboration.

Thus, the hierarchical clustering analysis in this section clearly shows that there are certain distributional patterns associated with municipal socio-economic characteristics hidden behind the growth decomposition results: reallocation effect and usage of energy efficient vehicles generally tend to be lower in both very rich and very poor municipalities. The growth decomposition results focused on the contributions of micro level vehicle related variables, but they cannot tell us whether and how these decomposition results differentiate across municipalities with various socio-economic characteristics. In fact, the socio-economic characteristics might affect people's behaviors regarding the movement and usage of vehicles, leading to significant differentials in decomposition factors across municipalities and then in the growth rates of aggregate MPG. 


\subsubsection{Convergence and transition of aggregate vehicle energy efficiency}

The focus of the analysis now shifts to the mobility and distributional dynamics of municipality level aggregate vehicle energy efficiency, in order to obtain further insights into the variety of experiences in subpopulations of vehicles. Table 3.6 and Figure 3.4 show results for the period 2008q4 - 2010q4, during which an imbalanced development of aggregate vehicle energy efficiency is found. But the results obtained so far do not illustrate how this trend is shared or differs between municipalities. In particular, do the effects related to vehicle mobility (between municipalities), as well as the other effects, lead to a convergence between municipalities in terms of vehicle energy efficiency, or not?

First, we collapse the dynamic characteristics of MPG at municipality level into a single summary statistic, that is, the growth of relative aggregate MPG between the initial and end quarter, and then regress this relative growth on the initial level of relative aggregate MPG. The basic idea underlying here is that a tendency for narrowing down the gap of MPG between municipalities results if municipalities that have low aggregate MPG at the beginning, improve their vehicle energy efficiency faster than the municipalities that are initially energy efficient. Second, once municipalities have been ranked by their aggregate MPG relative to the state level, in each quarter, they can be classified into quantile groups that have fixed bounds, and a transition matrix can be obtained that provides useful information about the long-run dynamics of the distribution. As emphasized by Quah (1993a), however, such a steady-state distribution should not be interpreted as a precise forecast, since random shocks (for example, sudden change in government policy) are not taken into account.

Table 3.9 shows the results regarding the relationship between the initial level of relative aggregate MPG and the growth of relative aggregate MPG. The OLS regression in Column 1 is the basic estimation of this relationship. Since the average effect of the initial level of relative aggregate MPG estimated by OLS is not robust when there are outliers in the dataset, quantile regression is employed as a robustness check. Specifically, the median regression is considered as the counterpart to the OLS. Columns $2-4$ in Table 3.9 show the results of quantile regression at 25\%, 50\% (median) and $75 \%$ quantiles of the dependent variable. Table 3.9 clearly gives some evidence that supports the convergence of relative aggregate MPG: the coefficients of the initial level relative aggregate MPG are negative and significant at 5\% significance level in OLS and all three quantile regressions, which implies that municipalities with lower initial level relative aggregate MPG tend to have a higher growth of relative aggregate MPG. Interestingly, when the quantile used in the quantile regression (25\%,50\% and $75 \%$ quantile) increases, the coefficient of interest keeps decreasing $(-0.3,-0.4653$, and -0.6648 , respectively). 
The graphical evidence obtained by using OLS and the nonparametric approach for the convergence of relative aggregate MPG is illustrated in Figure 3.6. As in Table 3.9, the fitted line estimated by OLS shows a downward sloping trend. As another robustness check, the curve estimated by using nonparametric approach (kernel regression) is illustrated in Figure 3.6 as well. In general, the curve is downward sloping which indicates that municipalities with a higher initial level of relative aggregate energy efficient vehicles have a lower growth rate. In the interval where the relative aggregate MPG is below 0.8 , there is a big discrepancy in the growth of relative aggregate MPG across municipalities, so that the kernel regression curve significantly fluctuates. Among the municipalities whose relative aggregate MPG is higher than 0.8 , the gap in the growth is much smaller and accordingly the kernel regression curve is smoothly downward sloping. To conclude, the finding from the nonparametric approach is consistent with the one from OLS, and convergence between municipalities in terms of the energy efficiency of their vehicle populations is observed.

Table 3.9 The relationship between relative aggregate MPG in 2008q1 and growth of relative aggregate MPG; OLS and quantile regression at $25 \%, 50 \%$ and $75 \%$ quantile

\begin{tabular}{|c|c|c|c|c|}
\hline Variable & OLS & $\begin{array}{l}\text { Quantile } \\
\text { regression 25\% }\end{array}$ & $\begin{array}{l}\text { Quantile } \\
\text { regression 50\% }\end{array}$ & $\begin{array}{l}\text { Quantile } \\
\text { regression 75\% }\end{array}$ \\
\hline Relative aggregate MPG in 2008q1 & $\begin{array}{l}-0.7442 * * * \\
(0.0505)\end{array}$ & $\begin{array}{l}-0.3000 * * * \\
(0.0437)\end{array}$ & $\begin{array}{l}-0.4653^{* * *} \\
(0.0344)\end{array}$ & $\begin{array}{l}-0.6648 * * * \\
(0.0498)\end{array}$ \\
\hline Constant & $\begin{array}{l}0.7565 * * * \\
(0.0494)\end{array}$ & $\begin{array}{l}0.2773 * * * \\
(0.0427)\end{array}$ & $\begin{array}{l}0.4781^{* * *} \\
(0.0337)\end{array}$ & $\begin{array}{l}0.7151^{* * *} \\
(0.0488)\end{array}$ \\
\hline Number of observations & 350 & 350 & 350 & 350 \\
\hline
\end{tabular}

Source: Own elaboration. 


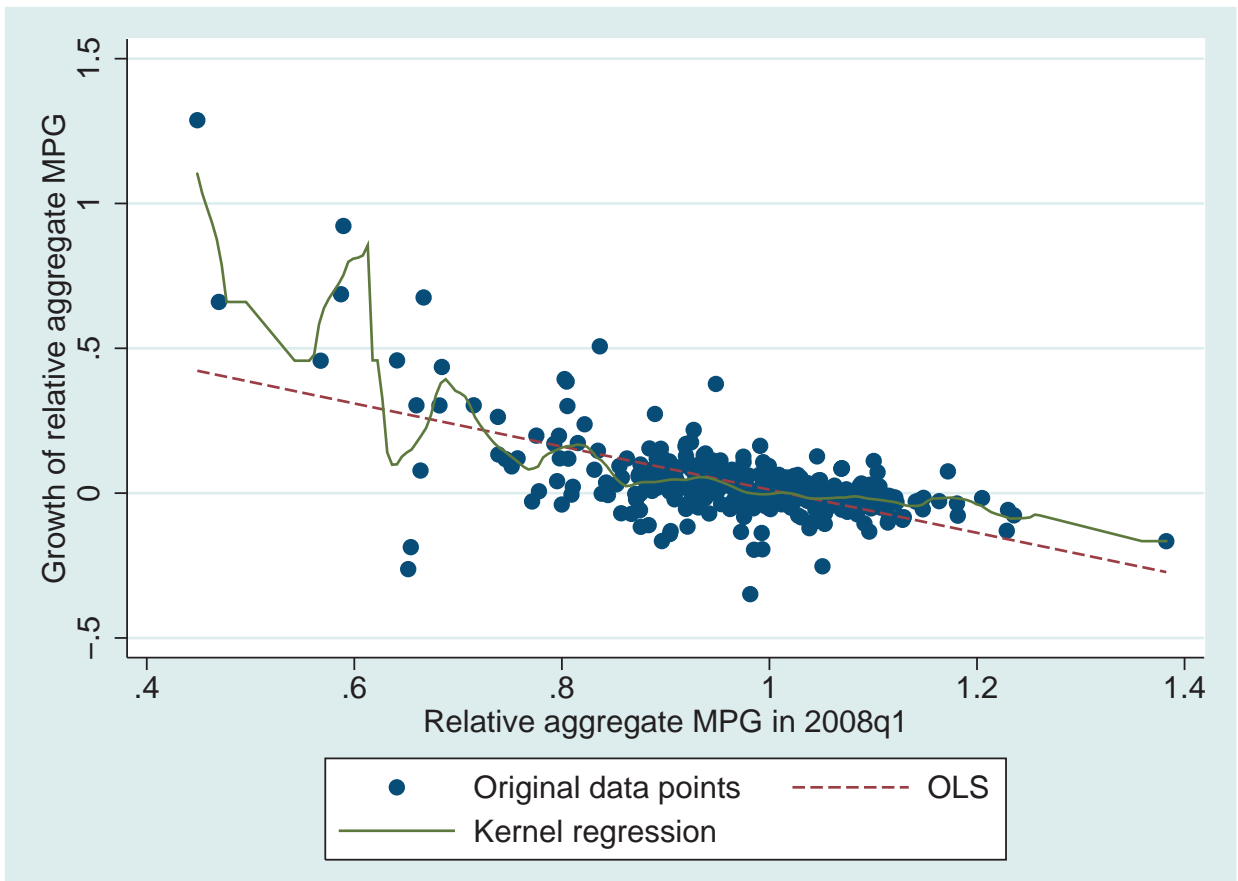

Figure 3.6 The relationship between relative aggregate MPG in 2008q1 and growth of relative aggregate MPG; OLS and nonparametric approach

Source: Own elaboration.

Table 3.9 provides the quantile regression results at three representative quantiles only. A more comprehensive and robust examination of the empirical relationship is provided by applying bootstrapping quantile regression at various quantile from 0 to 1 . Figure 3.7 below illustrates the graphic results of bootstrapping quantile regression and the OLS as a comparison. The horizontal axis represents the quantile of the dependent variable and the vertical axis stands for the coefficient of the initial level relative aggregate MPG estimated by quantile regression at a given quantile. It is evident that the coefficient estimated by quantile regression at any quantile is negative and with the increase in quantile used in quantile regression, the coefficient of interest is constantly decreasing (i.e., the convergence effect is getting stronger). These findings are consistent with Table 3.9 as well. When regressing at low and high quantiles (below 0.2 and above 0.8 , respectively), there is a sharp decline in the coefficient. The coefficient estimated by OLS is roughly similar to the one obtained by quantile regression at $80 \%$ quantile. The bootstrapping quantile regression results are very robust and provide strong support for the convergence hypothesis. Municipalities with low initial aggregate MPG actually improve much faster, while those initially energy efficient municipalities experience a smaller growth, as compared with the OLS result. 


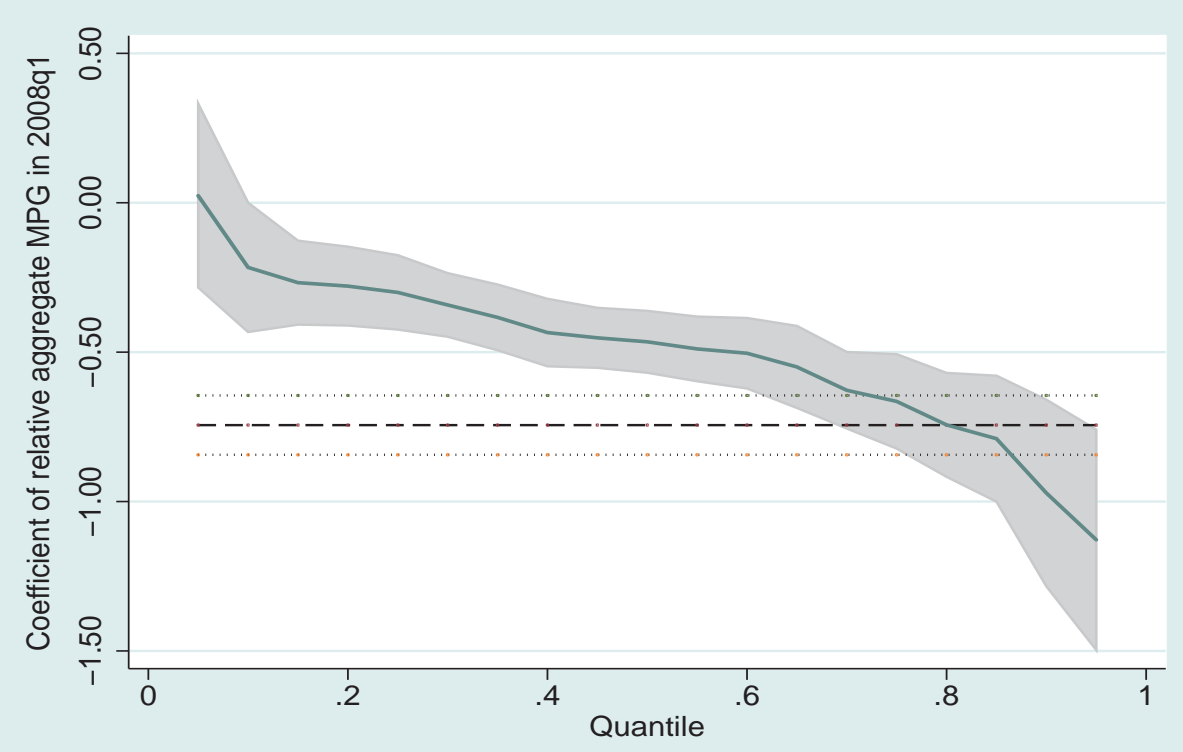

Figure 3.7 The relationship between relative aggregate MPG in 2008q1 and growth of relative aggregate MPG; OLS and bootstrapping quantile regression

Source: Own elaboration.

Notes: The shadow area indicates the $95 \%$ confidence intervals of quantile regression; the solid line presents coefficients of quantile regression; "---" stands for coefficient estimated by using OLS and "..." marks the 95\% confidence interval of OLS. The number of bootstrapping replications is 500 .

Turning to the Markov analysis, the municipalities, in each quarter, are grouped into 10 groups and the group bounds are based on the initial level relative aggregate MPG, as shown in Table 3.10 below. Group 1 contains the municipalities whose relative aggregate MPG are smaller than (or equal to) $10 \%$ quantile of initial level relative aggregate MPG (0.8228), indicating the lowest vehicle energy efficiency group. Group 2 then consists of the municipalities that have a relative aggregate MPG between $10 \%$ and $20 \%$ quantile of the initial level, and so on and so forth. Group 10 is the highest vehicle energy efficiency group. All 10 groups are then sorted according to the lowest to the highest vehicle energy efficiency. Note that only in the initial period, the groups will be equal in terms of the number of municipalities.

Table 3.10 Group bounds based on municipality level relative aggregate vehicle energy efficiency in 2008q1, relative to the state level

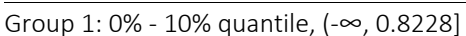

Group 2: $10 \%$ - 20\% quantile, $(0.8228,0.8944]$

Group 3: 20\% - 30\% quantile, $(0.8944,0.9314]$

Group 4: 30\% - 40\% quantile, $(0.9314,0.9622]$

Group 5: 40\% - 50\% quantile, (0.9622, 0.9795]
Group 6: 50\% - 60\% quantile, $(0.9795,1.0011]$

Group 7: 60\% - 70\% quantile, $(1.0011,1.0363]$

Group 8: 70\% - 80\% quantile, $(1.0363,1.0625]$

Group 9: $80 \%$ - 90\% quantile, $(1.0625,1.1057]$

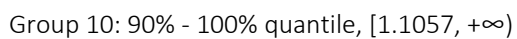

Source: Own elaboration. 
Table 3.11 provides the estimated one-period transition matrix of relative aggregate MPG over the period 2008q1 - 2011q4. The row header indicates the group of relative aggregate MPG in time $t$ and the column header is the group of relative aggregate MPG in time $t+1$. The last row shows the steady-state distribution of municipalities in the long run, that is, the Ergodic distribution. The last column shows the total number of municipalities in a certain group over the entire period. In the $10 * 10$ one period transition matrix, the value in $(i, j)$ indicates the probability that a municipality in Group $i$ in time $t$ ends in Group $j$ in time $t+1,1 \leq i, j \leq 10$ and $i, j \in N^{*}$. For example, 0.7765 in $(1,1)$ means the estimated probability that a municipality in Group 1 will still stay in Group 1 in the next quarter is 0.7765 , while 0.1647 in $(1,2)$ means the estimated probability that a municipality in Group 1 will move up to Group 2 in the next quarter is 0.1647 .

In the $10 * 10$ one period transition matrix the diagonal ranges from 0.5149 to 0.7972 , which means that more than half municipalities will stay in the same group in the next quarter. The municipalities in Group 5 are the most dynamic, showing the lowest persistence of staying in the same group. The group with the highest persistence is found to be Group 10 that is the most vehicle energy efficient. In one period, transition municipalities have a small probability to move up or move down to neighboring groups (ranging from 0.0706 to 0.2319 ), but have a very low probability to transit to the groups far away from their original groups. For example, municipalities finding themselves in the group with the lowest vehicle energy efficiency have a probability of 0.1647 to upgrade their vehicle energy efficiency to the second group, but only have a probability of 0.0235 to be successful in moving up to Group 3; less than $1 \%$ of them manage to improve.

Table 3.11 One period transition matrix of municipality level relative aggregate vehicle energy efficiency; relative to the state level; $2008 q 1-2011 q 4$

Group 1 Group 2 Group 3 Group 4 Group 5 Group 6 Group 7 Group 8 Group 9 Group 10 Total

number

\begin{tabular}{llllllllllll}
\hline Group 1 & 0.7765 & 0.1647 & 0.0235 & 0.0078 & 0.0078 & 0.0078 & 0.0039 & 0.0039 & 0.0039 & 0.0000 & 255 \\
Group 2 & 0.0776 & 0.7153 & 0.1624 & 0.0353 & 0.0024 & 0.0024 & 0.0000 & 0.0024 & 0.0000 & 0.0024 & 425 \\
Group 3 & 0.0137 & 0.1167 & 0.6339 & 0.2014 & 0.0206 & 0.0023 & 0.0092 & 0.0023 & 0.0000 & 0.0000 & 437 \\
Group 4 & 0.0047 & 0.0187 & 0.0950 & 0.6573 & 0.1573 & 0.0436 & 0.0171 & 0.0031 & 0.0016 & 0.0016 & 642 \\
Group 5 & 0.0000 & 0.0064 & 0.0170 & 0.1574 & 0.5149 & 0.2319 & 0.0638 & 0.0021 & 0.0043 & 0.0021 & 470 \\
Group 6 & 0.0000 & 0.0014 & 0.0028 & 0.0408 & 0.1254 & 0.6437 & 0.1704 & 0.0099 & 0.0056 & 0.0000 & 710 \\
Group 7 & 0.0011 & 0.0011 & 0.0034 & 0.0114 & 0.0182 & 0.1243 & 0.7184 & 0.1060 & 0.0125 & 0.0034 & 877 \\
Group 8 & 0.0000 & 0.0018 & 0.0000 & 0.0054 & 0.0018 & 0.0054 & 0.1720 & 0.6900 & 0.1147 & 0.0090 & 558 \\
Group 9 & 0.0000 & 0.0000 & 0.0017 & 0.0017 & 0.0017 & 0.0017 & 0.0202 & 0.1109 & 0.7916 & 0.0706 & 595 \\
Group 10 & 0.0000 & 0.0000 & 0.0000 & 0.0000 & 0.0000 & 0.0000 & 0.0107 & 0.0036 & 0.1886 & 0.7972 & 281 \\
Ergodic & 0.0232 & 0.0475 & 0.0566 & 0.1025 & 0.0814 & 0.1410 & 0.2053 & 0.1311 & 0.1482 & 0.0630 & \\
\hline
\end{tabular}

Group 1: $0 \%$ - 10\% quantile, $(-\infty, 0.8228]$, the lowest energy efficiency group;

Group 10: $90 \%-100 \%$ quantile, $[1.1057,+\infty)$, the highest energy efficiency group.

Source: Own elaboration. 
Figure 3.8 provides a comparison between the initial distribution and the Ergodic distribution. According to the grouping criteria all the municipalities are put into 10 equalsized groups, so that in the initial distribution each group contains $10 \%$ municipalities. In the long run steady state, however, the distribution changes significantly and provides evidence of improvement in vehicle energy efficiency. The shares of municipalities in the three lowest vehicle energy efficiency groups greatly reduce from $10 \%$ to around $5 \%$ or much lower than $5 \%$. The largest reduction of the share of municipalities is found in Group 1, the lowest vehicle energy efficiency group: the share of municipalities reduces to $2.32 \%$. On the other hand, most municipalities concentrate in high vehicle energy efficiency groups. In the long run steady state, about $20.53 \%$ of total municipalities are in Group 7 whose vehicle energy efficiency is slightly higher than the state average level. ${ }^{57}$ About 14.1\% municipalities are in Group 6 whose group bounds cover 1 , the state average level. Convergence mainly takes place in these two groups ( 6 and 7), i.e., this is where most municipalities move. For the higher efficiency Groups 8 and 9, the shares of municipalities increase to $13.11 \%$ and $14.82 \%$, respectively, while a small decline in the share of municipalities is observed in the highest vehicle energy efficiency group. Thus, long-run convergence does not seem to be complete. For high vehicle energy efficiency groups (Groups 7, 8, 9 and 10 that are absolutely more energy efficient than the state average level), the total share of municipalities is $54.76 \%$ in the long run steady state. As compared to the total share, $40 \%$, in the initial distribution, it is evident that there is an improvement in vehicle energy efficiency since more than half of municipalities' vehicle energy efficiency is higher than the state average level.

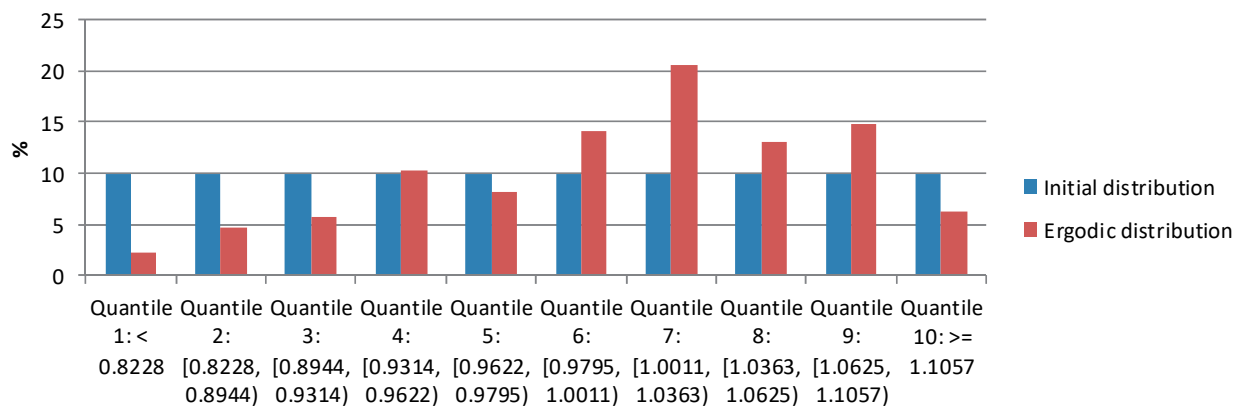

Figure 3.8 Comparison between initial distribution and Ergodic distribution Source: Own elaboration.

\subsubsection{Number of vehicles}

The purpose of this section is to characterize how socio-economic patterns influence the distribution of vehicles across municipalities over the entire period. The results can

\footnotetext{
${ }^{57}$ The state level vehicle energy efficiency is 1.
} 
provide useful information to deepen the knowledge regarding the role of socioeconomic factors in shaping the distribution of vehicles. Unlike the cluster analysis employed in Section 3.4.2 that shows the cross-sectional distribution patterns by collapsing the dynamic process into several decomposition factors, the focus of the analysis in this section is on the dynamic process of the distribution of vehicles. Following the analysis in the previous section that studies the distribution of aggregate vehicle energy efficiency, this section studies the distribution of vehicles measured by the number of vehicles across municipalities. The movement of vehicles across municipalities and states (due to migration or trade) causes changes in the distribution of vehicles across municipalities, that is, upsizing (due to net inflow of vehicles) or downsizing (due to net outflow of vehicles) of the vehicle population at municipality level, which eventually shapes the distribution of aggregate (state level) vehicle energy efficiency, as shown in the decompositions.

Panel data over the period 2008 to 2011 are used. The dependent variable is the number of vehicles in the municipality in 2008q4, 2009q4, 2010q4 and 2011q4. ${ }^{58}$ Three basic socio-economic variables are used as explanatory variables: municipality level income (measured by median household income and mean household income), population and unemployment rate over 2008 - 2011. The preferred empirical method employed in this section is the random-effects negative binomial regression, since the dependent variable is a count variable. Two commonly used econometric approaches allow researchers to deal with count dependent variables, that is, negative binomial regression and Poisson regression. The negative binomial regression with panel data is used because the mean and variance of the dependent variable are too different, which violates the basic assumption of the Poisson regression that requires that the mean and variance of the dependent variable are equal.

Table 3.12 summarizes the regression results. In Model 1 the municipality level mean household income is used, while it is replaced with the municipality level median household income in Model 2 as a comparison specification. $\ln \_r$ and $\ln \_s$ present the estimation of $r$ and $s$, respectively, which are parameters used in the regression: the assumption of the negative binomial regression is that the inverse of one plus the dispersion follows a $\operatorname{Beta}(r, s)$ distribution.

\footnotetext{
${ }^{58}$ Because the vehicle census data are recorded quarterly, while the municipality level socio-economic data are recorded yearly.
} 
Table 3.12 Random-effects negative binomial regression, using number of vehicles as dependent variable, $2008-2011$

\begin{tabular}{lll}
\hline & Model 1 & Model 2 \\
\hline Median household income (in logs) & & $0.4743^{* * *}$ \\
Mean household income (in logs) & $0.5740^{* * *}$ & \\
Population (in logs) & $(-0.0464)$ & \\
& $0.9874^{* * *}$ & $1.0049^{* * *}$ \\
Unemployment rate & $(-0.0107)$ & $(-0.0087)$ \\
& $-1.7077^{* * *}$ & $-1.4456^{* * *}$ \\
Constant & $(-0.2449)$ & $(-0.2483)$ \\
& $-10.9621^{* * *}$ & $-10.0453^{* * *}$ \\
In_r & $(-0.4838)$ & $(-0.393)$ \\
_cons & $2.8937^{* * *}$ & $3.2830^{* * *}$ \\
In_s & $(-0.1289)$ & $(-0.1102)$ \\
_cons & $6.7784^{* * *}$ & $7.3204^{* * *}$ \\
Number of observations & $(-0.164)$ & $(-0.1347)$ \\
Number of municipalities & 1404 & 1404 \\
\hline
\end{tabular}

Standard errors in parentheses; * $p<.05, * * p<.01, * * * p<.001$

Source: Own elaboration.

Both models are significant in the Wald test at $1 \%$ significance level (all the p-values < $1 \%)$ and both panel estimators are significantly different from the pooled estimators in the likelihood-ratio test ( $p$-values $<0.1 \%$ ). Population size is the variable that picks up the effect of differences in the scale of municipalities. In both models the coefficients of income (mean household income and median household income) and population are positive while the coefficients of unemployment rate are negative. The results clearly show that the municipalities that are richer, more populated and have lower unemployment rates are more likely to have a larger vehicle population.

\subsubsection{Determinants of exit from the state}

Finally, the analysis turns to the factors that determine the exit of vehicles from the state population. The results in Sections 3.4.2 and 3.4.4 illustrated some municipalitylevel distributional patterns correlated to socio-economic factors, but we do not know yet how these socio-economic factors are associated with vehicle level exit or entry. The decision of entry or exit, i.e., purchase or sale of a vehicle is the ultimate micro foundation of the aggregate level distributional patterns. Here the analysis focuses on the exit vs. stay decision, at the state level, and does not take into account the decision of moving to other municipalities within the same state. The results are of interest because the existing vehicle population is ageing over time, which leads to a decreasing aggregate 
vehicle energy efficiency, and the second hand market for vehicles can prolong the presence of these ageing vehicles in the state population. The crucial point is that the consequence of vehicle exiting is an update of population level vehicle energy efficiency.

The initially existing vehicles are defined as the vehicles that were in Massachusetts (that is, in the dataset) in 2008q4. ${ }^{59}$ The exit event is defined on whether the vehicle is in Massachusetts or not in 2010q4. If the initially existing vehicle is still in the state in the end quarter, it is classified as a stayer, otherwise it exits. Three municipality characteristics for the year 2008 are used: household income (median household income and mean household income), population and unemployment rate. In addition, other control variables include some vehicle characteristics such as MPG2008, original retail price, age, vehicle type dummies, fuel dummies and a dummy for whether the vehicle is a commercial vehicle or a passenger vehicle.

The econometric approach used is probit regression. A value of 1 for the dependent variable means that the vehicle is a stayer. The main results are shown in Table 3.13. In Models 1 and 3 the mean household income is used, while the income variable is replaced by the median household income in Models 2 and 4 . Models 1 and 2 only use the observations that contain precise municipality information. Models 3 and 4 include additional observations that have a 0 in the municipality ID in the end quarter. ${ }^{60}$ So there are more observations used in Models 3 and 4 . All the four models are significant in the Wald test at $1 \%$ significance level (P-values $<1 \%$ ) and have a high rate of correct classification ( $84.9 \%$ and $85.45 \%$ ). There are two crucial findings.

\footnotetext{
${ }^{59}$ According to Figure 3.1, there is a sharp increase in the total number of vehicles in Massachusetts between 2008q1 and 2008q4 probably due to data collection. Many vehicles that already existed might enter the dataset for the first time in a later quarter. From 2008q4 onwards the total number of vehicles is less fluctuant. Additionally, only yearly data for socio-economic variables are available. 2008q4 is a proper choice of initial quarter.

${ }^{60}$ In the dataset if the municipality ID is 0 , it means the vehicle is in the state but the location of the vehicle cannot be coded using a proper municipality ID.
} 


\section{Chapter 3}

Table 3.13 Probit regression results for initially existing vehicle's staying or exiting decision

Dependent variable: 1 means staying in the state; 0 indicates exiting to other states.

\begin{tabular}{|c|c|c|c|c|}
\hline & Model 1 & Model 2 & Model 3 & Model 4 \\
\hline Median household income (in logs) & & $\begin{array}{l}0.0885 * * * \\
(-0.0051)\end{array}$ & & $\begin{array}{l}0.0768 * * * \\
(-0.005)\end{array}$ \\
\hline Mean household income (in logs) & $\begin{array}{l}0.0721 * * * \\
(-0.0049)\end{array}$ & & $\begin{array}{l}0.0674 * * * \\
(-0.0048)\end{array}$ & \\
\hline Unemployment rate & $\begin{array}{l}0.3307 * * * \\
(-0.0767)\end{array}$ & $\begin{array}{l}0.4666 * * * \\
(-0.0761)\end{array}$ & $\begin{array}{l}0.3013 * * * \\
(-0.0754)\end{array}$ & $\begin{array}{l}0.3627 * * * \\
(-0.0748)\end{array}$ \\
\hline Population (in logs) & $\begin{array}{l}-0.0277^{* * *} \\
(-0.0009)\end{array}$ & $\begin{array}{l}-0.0232 * * * \\
(-0.001)\end{array}$ & $\begin{array}{l}-0.0301^{* * *} \\
(-0.0009)\end{array}$ & $\begin{array}{l}-0.0266 * * * \\
(-0.001)\end{array}$ \\
\hline MPG2008 & $\begin{array}{l}0.0111^{* * *} \\
(-0.0004)\end{array}$ & $\begin{array}{l}0.0112 * * * \\
(-0.0004)\end{array}$ & $\begin{array}{l}0.0102 * * * \\
(-0.0004)\end{array}$ & $\begin{array}{l}0.0104 * * * \\
(-0.0004)\end{array}$ \\
\hline Original retail price (in logs) & $\begin{array}{l}0.0900 * * * \\
(-0.0044)\end{array}$ & $\begin{array}{l}0.0908 * * * \\
(-0.0044)\end{array}$ & $\begin{array}{l}0.0953 * * * \\
(-0.0043)\end{array}$ & $\begin{array}{l}0.0965 * * * \\
(-0.0043)\end{array}$ \\
\hline Age & $\begin{array}{l}-0.0413 * * * \\
(-0.0003)\end{array}$ & $\begin{array}{l}-0.0412 * * * \\
(-0.0003)\end{array}$ & $\begin{array}{l}-0.0372 * * * \\
(-0.0003)\end{array}$ & $\begin{array}{l}-0.0371 * * * \\
(-0.0003)\end{array}$ \\
\hline
\end{tabular}

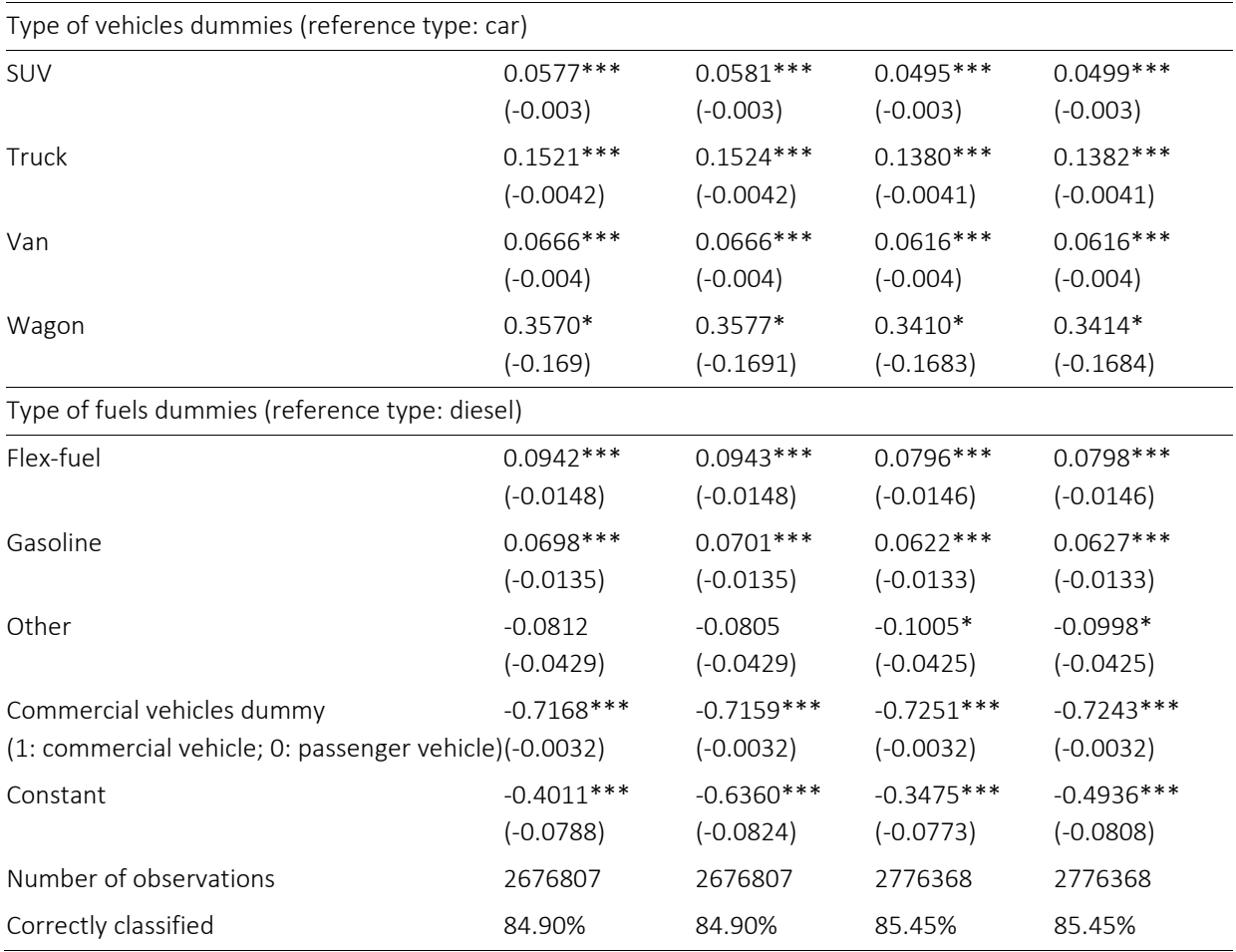

Standard errors in parentheses; ${ }^{*} p<.05,{ }^{* *} p<.01, * * * p<.001$. Source: Own elaboration.

All municipality level socio-economic variables are very significant and all four models provide consistent results. The coefficient of household income (including median 
household income and mean household income) is positive, which means that the vehicles that are more likely to stay are initially located in rich municipalities. The possible explanation is that rich municipalities buy more high-quality vehicles that last longer. This is a similar effect to the significant and positive coefficient of the vehicle's original retail price. The coefficient of unemployment rate is positive as well, which means that the vehicles initially located in the municipalities with higher unemployment rates have a higher possibility of staying in the state. This is reasonable because in the municipalities with high unemployment rates, the prospect of consumer's well-being is lower, which would restrict the trade of vehicles and eventually the update of vehicle population. The coefficient of population is negative, indicating that the vehicles located in less populated municipalities tend to stay in the state, possibly as an indication of differences between urban and rural areas.

The coefficient of MPG2008 is also positive, while the coefficient of vehicle age is significant and negative. This means that the vehicles that have higher initial energy efficiency, and a more recent model design are more likely to stay in the state. In addition, SUVs, trucks, vans and wagons tend to stay in the state as compared to other cars. Commercial vehicles are more likely to stay, compared to non-commercial passenger vehicles. The vehicles consuming flex-fuel and gasoline tend to be more durable, compared to those using diesel.

\subsection{CONCLUSIONS}

This paper has demonstrated that longitudinal micro data can provide very useful information for obtaining a more accurate aggregate indicator of population-level vehicle energy efficiency, and for answering questions that are related to heterogeneity in the vehicle population. As one of the first few studies of energy efficiency built on micro level evidence, this paper benefits from the newly released big data from the Massachusetts Vehicle Census that allows researchers to track the energy efficiency and location of almost every vehicle in Massachusetts over time. This paper is not only a recent application of extending the well-established approaches in productivity dynamics and growth theory to the field of energy efficiency dynamics, but also an example of providing comprehensive information that supports relevant policymaking in a data-intensive context.

For the issues related to energy efficiency and sustainable development, this paper provides some evidence that the dynamics of aggregate vehicle energy efficiency in Massachusetts are mainly driven by the reallocation of high energy efficiency vehicles. It should be pointed out that the analyses in this paper use a relatively short time period due to the data availability. Accordingly it is possible that some other important factors such as differences in regulations, energy prices and vehicle prices across municipalities 
and states have affected the results. The data for a longer period would be very useful for further research in the future.

Specifically, the main findings can be summarized as follows. Using the aggregate vehicle energy efficiency based on vehicle level micro data, this paper (1) decomposes the state level aggregate vehicle energy efficiency over the entire period into an unweighted average and a covariance term between vehicle level energy efficiency and share of miles per day; and (2) decomposes the growth of aggregate vehicle energy efficiency between 2008q4 and 2010q4 into a between effect, a within effect and a net entry effect aggregating two entry effects and two exit effects (at both state level and municipality level). The covariance term in the decomposition of time series is found to be positive in each quarter in the dataset, indicating that higher (lower) usage is found for higher (lower) energy efficiency vehicles. In other words, drivers choose energy efficient vehicles when they have to drive a lot. The growth decomposition at both state level and municipality level provides a consistent finding that the most important factor positively contributing to the growth of aggregate vehicle energy efficiency is the net entry effect, the reallocation due to the entering of high energy efficiency vehicles and the exiting of low energy efficiency vehicles.

The decomposition of changes (growth rates) of vehicle efficiency also suggests that the reallocation effect among continuing vehicles is important. These results show a positive between effect at the state level and in most municipalities, which implies more (less) miles per day are allocated in high (low) energy efficiency vehicles. The energy efficiency growth gain due to changes in consumers' behaviors, however, is much less than the energy efficiency growth loss due to vehicles' ageing measured by the within effect. For instance, at the state level the between effect can only compensate slightly more than half of energy efficiency loss caused by the ageing of vehicles. The reallocation due to vehicles' entering and exiting then fills the energy efficiency gap and leads to growth.

Also, this paper provides an empirical framework to analyze the update process of the vehicle (sub)population(s). This is an important determinant of overall energy efficiency: as a non-production unit, a vehicle's energy efficiency decreases as time progresses. Old vehicles can be replaced by newer vehicles that have higher energy efficiency. Without product substitution, the update process can occur through migration of vehicles, causing either upsizing or downsizing of the vehicle population. Looking into all of the four components of net entry effect, the interesting finding is that besides the two entry effects bringing energy efficiency gain, the exit effect can also be positive if inefficient vehicles exit the state (going out of service or moving to other states). However, an energy efficiency drain can result if high energy efficiency vehicles move.

In general, the aggregate vehicle energy efficiency at state level shows an upward sloping trend through 2008q4 and 2010q4, but this is only a small effect. A statistical inves- 
tigation of the growth of vehicle energy efficiency and its decomposition at the substate level shows an imbalanced development across municipalities. Rich municipalities located in the eastern side of the state tend to have the smallest reallocation effect related to vehicle's entering and exiting. However, various econometric approaches provide robust evidence that the gap in aggregate vehicle energy efficiency across municipalities tends to narrow down over time and converge to the state average level.

Finally, further investigation into the role of socio-economic factors in shaping the distribution of vehicles and the exit event (a vehicle leaving the state) provides several interesting findings. We find that vehicles are more likely to be distributed into the municipalities that are richer, more populated or have a lower unemployment rate. An interesting finding is that the update process of a vehicle population through product substitution or migration will take more time if the municipalities are richer, less populated or have a higher unemployment rate, since the initially existing vehicles in these types of municipalities are more likely to stay in the state.

With regard to policy implications, this paper can help policymakers as well as entrepreneurs to obtain a better understanding of the life cycle of vehicles: as durable consumer products, existing vehicles decline in energy efficiency and eventually exit. Meanwhile new vehicles enter the market and replace old ones. The timing and different impacts of this cycle will provide policy opportunities that can improve aggregate vehicle energy efficiency. Policymakers should be alert to the fact that benefits due to changes in consumers' behavior of vehicle usage cannot keep pace with the big energy efficiency loss caused by the ageing of vehicles. Another fact that all policymakers should be aware of is that consumers are actually less rational in terms of fuel economy than economic assumptions suggest and they are actually not very sensitive to changes in fuel expenditure of the vehicle (Turrentine \& Kurani, 2007). The most important contribution to the growth of aggregate vehicle energy efficiency comes from the reallocation due the entering and exiting of a vehicle. This may imply a public finance policy scenario (including policy instruments such as tax and subsidy) that can stimulate the update of the vehicle population and match specific municipality-related socioeconomic characteristics. Additionally, in the U.S. market the benefits of technological change and innovation have been often used to satisfy some specific consumer preferences regarding the vehicle, such as more power and larger size, but not necessary higher energy efficiency (Lutsey \& Sperling, 2005). A policy that promotes innovation towards vehicle fuel economy would be needed as well. 

Chapter

The Role of Technological Trajectories in Catching-up-based Development: An Application to Energy Efficiency

Technologies 
Abstract: We argue that the analysis level of a technological trajectory is very suitable to analyze the decisions of firms in latecomer countries with regard to the technological area that they should focus on. Technological trajectories are the main focal points along which technological innovation develops, and they are more detailed than the common sectors, such electronics or pharmaceuticals, that are used in the analysis of catching-up based growth. We present a collection of methods that have been proposed in the literature to identify technological trajectories. These methods use patent citation networks, and are applied to three separate fields in energy efficiency technologies. We identify the relevant technological trajectories, and analyze how the main countries active in these fields can be classified as either latecomer or incumbent countries. We then present a measure for assessing to what extent patents from a particular country contribute to the main technological trajectories in the field, and to what extent they are derived from these trajectories. We use an explorative regression model to establish that latecomer countries tend to contribute to a lesser extent than incumbents to the main technological trajectories in the fields under investigation.

Keywords: technological trajectories, patent citation networks, latecomer innovation strategy

This study was supported by the United Nations Industrial Development Organization (UNIDO). This paper is a joint work by Sheng Zhong and Bart Verspagen and has been published as UNIDO Inclusive and Sustainable Development Working Paper Series 6/2016. This paper was presented in the 2016 Globelics Conference in Bandung, Indonesia and the $3^{\text {rd }}$ Summer School on New Structural Economics at National School of Development at Peking University, China. 


\subsection{INTRODUCTION}

Technology plays a large role in the economic development of nations. For countries that lag behind the economic frontier, the assimilation of foreign technological knowledge is a potential way to achieve rapid growth, or, in other words, to catch up economically (Fagerberg \& Godinho, 2004). In all documented historical cases of successful catch-up growth, industrialization and technological upgrading have been the central process in economic development (Szirmai \& Verspagen, 2015).

While the process of investing in absorption capability necessary for technological catch-up has been documented extensively (Fagerberg, Srholec, and Verspagen (2010) provide a survey of this literature), there is generally less attention being given to the question as to which specific technological choices a country aiming to implement a catching-up strategy should make. K. Lee (2013) and K. Lee and Lim (2001) are exceptions, as they apply patents statistics to analyze the technological specialization profiles of latecomer countries.

The essence of a latecomer, or catching-up, strategy is that countries that enter a technological field relatively late can assimilate existing knowledge at a cost that is ultimately lower than the original cost taken to develop this knowledge. This is partly due to the fact that once knowledge has been developed and exists, more or less, in the open, information on what works and what does not work is available for followers to use.

However, catching-up based growth is not pure assimilation of knowledge. It also consists of adapting foreign knowledge to local circumstances, and, with increasing development levels, knowledge assimilation gradually changes into knowledge creation. This transition from assimilation to creation is the topic of the study in K. Lee (2013), and also in the current paper. When this transition happens, latecomer countries that have been assimilating knowledge need to make choices about the direction, or technological subfield, in which they will invest their creative efforts.

This choice is heavily influenced by the nature of the knowledge creation process, which is the topic of a different literature e.g., (Dosi, 1982). Technological knowledge tends to develop along specific trajectories, which can be seen as sequences of interdependent and cumulative innovations in small (incremental) steps. The nature of these trajectories is determined by the economic and other circumstances in the specific market in which the trajectory develops. The trajectory in a specific field is the result of joint efforts by multiple firms, and possibly other actors, rather than an individual effort.

Trajectories emerge after new technological opportunities open up as a breakthrough innovation. This is a relatively rare process, which implies that latecomer countries that want to enter a specific technological field will generally face a status quo of existing trajectories that are dominated by firms from the developed part of the world. The basic 
choice that these countries face is to either follow the existing trajectory and try to compete with the incumbent firms, for example on the basis of low production costs, or to develop technologies in new directions. This is what K. Lee and Lim (2001) call the distinction between a path-following catch-up strategy and a path creation strategy. Perez and Soete (1988) have also addressed this issue, and argue that a path creating strategy is most likely to succeed in a period in which breakthrough innovations are unfolding.

Technological trajectories are hard to quantify, which makes it difficult to use the notion in quantitative studies of catching-up growth. For example, the work by K. Lee (2013), which is probably the most extensive and detailed study of the process of shifting from technological assimilation to technological creation, mainly uses counts of patents by economic sector or by technological class as an indicator for the creative potential of firms in latecomer countries.

Given the importance of technological trajectories in the development of new knowledge, this may not be a very adequate way of measuring technological capabilities. For example, Verspagen (2007) identified distinct technological trajectories in a specialized field such as fuel cells, which comprises only one or several detailed technological classes. If the salient features of knowledge development occur at this level of aggregation, it makes sense to incorporate more detail into the analysis than is possible with the methods of K. Lee (2013). This is the goal of the current paper.

The idea of technological trajectories will be elaborated in the next section. This section will also formulate a precise research question, which is mainly explorative in nature, and which asks which strategy of technological specialization latecomer countries have followed in the particular technological fields under investigation. These fields are related to energy efficiency. In this paper, we study three cases: the first case is the technologies for power generation (electricity), the second is the energy efficiency technologies related to information and communication technologies (ICT) in buildings, and the third is technologies aimed at increasing the energy efficiency of vehicles.

There is no particular reason for focusing on these specific fields, other than that energy technologies and in particular energy efficiency technologies, are very important for sustainable development. If technological trajectories are indeed important for determining the development strategy of latecomer countries, more studies of different technological fields will be necessary to increase our insights into this question. As technological fields differ, so will trajectories, and therefore it is important to analyze a range of cases. We look at the current paper as a first step in such a research program, both in terms of proposed methods and in terms of deriving some first and preliminary results.

After discussing the idea of technological trajectories and why they matter for development, we discuss our database in Section 4.3. Section 4.4 covers the basic methods that we employ, and which are derived from network analysis. Section 4.5 presents our results, and Section 4.6 summarizes the argument and draws conclusions. 


\subsection{TECHNOLOGICAL TRAJECTORIES}

Technological and scientific knowledge evolves as a result of research and development $(R \& D)$, as well as more practical activities such as learning-by-doing or learning-byusing. R\&D is very much a search process, in which the knowledge that a researcher already possesses influences the nature of the search effort. In particular, R\&D often takes the form of a local search process, in which incremental pieces of knowledge are added to what already exists, for example because researchers look for improvements to existing knowledge. Nevertheless, major breakthroughs that change the direction of R\&D also occur, although they are not very frequent as compared to incremental improvements.

Various authors, for example, (Dosi, 1982; Sahal, 1981) have contributed to the economic history of technology describing these processes of local search combined with occasional major breakthroughs. Dosi (1982) used Kuhn (1970) terminology and posited the idea of a technological paradigm and, within the paradigm, technological trajectories. A paradigm corresponds to a major breakthrough in knowledge development, both in the sense that it is a radical break with the past, and in terms of its reach, i.e., it affects a wide variety of R\&D processes. A technological paradigm is agenda-setting, because it suggests the direction of R\&D efforts, as well we the basic approach that is used to solve technological problems. Derived from Kuhn (1970), a paradigm shift becomes more likely when an existing paradigm runs into decreasing returns, i.e., when its possibilities for technological improvement dry up.

A technological trajectory, in Dosi's terminology, corresponds to Kuhn's idea of "normal science". It is the "non-radical" development of technology within a paradigm. Multiple trajectories will normally exist within a paradigm, corresponding to different uses of the basic knowledge of the paradigm. The nature of trajectories is determined by the economic environment in which the trajectory develops. This results from the fact that researchers, engineers and practitioners respond to economic opportunities or bottlenecks when they develop the technology.

An example can illustrate the basic ideas. Steam power technology was a paradigm shift compared to water power. It was made possible by the development of the Newcomen engine, and later on the separate condenser as invented by James Watt. These inventions opened up a new range of possibilities, which were developed along many different trajectories. One of these trajectories was the use of steam power for pumping water out of mines. This led to large and bulky steam engines, which were very powerful and fuel efficient, for example, the Cornish engine (Nuvolari, 2004, 2006). Another trajectory was the use of steam power on trains. These engines were much smaller, because they had to be mobile, and as a way to generate more power within a smaller size, they developed by increasing steam pressure. As a result, after a period of devel- 
opment, even if the basic technology was identical, steam engines used in mines looked completely different from those used on trains.

Because R\&D and technology development in general is a search process, it also runs into dead ends, or, more generally, we can say that different development directions (trajectories) have different (technological and economic) forms of success. Firms that undertake R\&D and technology development have to make choices as to where to direct their efforts, i.e., which trajectory to follow. Due to fundamental uncertainty, this is a process that is not fully rational, as it is impossible to predict with certainty whether a trajectory will become, or remain, successful. The choices that firms make are boundedly rational (Nelson \& Winter, 1977), but also influenced by beliefs and culture. But there is an important difference between the way in which technological leaders make these decisions, as opposed to technological followers (Triulzi, 2015). Technological leaders face a larger degree of uncertainty, as they tend to develop technologies that are more uncertain. Followers, on the other hand, can benefit from the experience that has been accumulated in the trajectory that they are interested in, and therefore the uncertainty that they face will generally be lower.

This uncertainty translates to the level of countries, which can also be characterized as technological leaders or followers. Firms in latecomer (following) countries will generally encounter existing technological trajectories when they try to enter a market. They can then either try to contribute to the existing technological trajectories, or direct efforts away from these, by trying to create new trajectories, or at least new technological opportunities.

Our research question is related to this basic choice. We are interested in the latecomer countries that are making the transition from knowledge assimilation to knowledge creation, which we measure by counting the number of patents that emerge from a particular country, in a particular technological field. Those countries that are contributing in a significant way to the number of patents in the field, but have been doing so only recently, are characterized as the latecomer countries that draw our interest. Being able to identify the main technological trajectories in the field in the form of a small set of patents, we then ask how the latecomer countries relate to these trajectories. In particular, our research question is whether latecomer countries tend to contribute to the main technological trajectories at a higher or lower rate than the incumbent countries in the field.

The analysis of this research question requires the identification of technological trajectories in the fields under analysis. This task has been undertaken by a number of qualitative (historical) and quantitative research methodologies. Patent citation networks (Verspagen, 2007) are one way in which the very detailed information in patent documents can be used to do this. Although a number of technological fields have been analyzed using these methods (Fontana, Nuvolari, and Verspagen (2009); Martinelli 
(2010)), to our knowledge, this method has not been used so far to look at technological catching up of developing countries. We explain the method in the next section, and then undertake to apply it in Section 4.5.

\subsection{PATENT CITATION NETWORKS ${ }^{61}$}

The notion of a technological trajectory as outlined above points to technological innovations as sequential and interrelated events that are a selective draw from a large space of potential technological development. One way that has been proposed in the literature to measure the interrelatedness between innovations is by means of patent citations. ${ }^{62}$ Patent documents contain a detailed description of the patented innovation, as well as the name and address of the innovator and the applicant. But most importantly for the present study, patent documents also contain references to previous patents, i.e. patent citations. A reference to a previous patent indicates that the knowledge in the latter patent was in some way useful and/or relevant for developing the new knowledge described in the citing patent. This is exactly the type of interpretation that allows us to use patent citations as a tool for mapping technological trajectories. Obviously, a single patent may source knowledge from multiple previous patents. Also, citing patents may themselves become cited in the future, so that we will be able to map "chains" of ideas as they develop over time.

The set of patents and the citations between them naturally lend themselves to be viewed as a network of ideas and their relatedness. The notion of a technological trajectory suggests that within this network, several main streams (or main paths) of knowledge exist that summarize the major developments in the field. It will be the general aim of our analysis to describe these main paths of knowledge flows in the datasets that we employ. The methodology used to do this draws on Hummon and Doreian (1989) and extensions proposed by Verspagen (2007) and J. S. Liu and Lu (2012). Hummon and Doreian (1989) analyze the network of citations between scientific publications on the discovery of DNA. Their aim is to construct a "main path" through this network that corresponds to the main flow of ideas in this field as represented in the formal publications. This can also be seen as an operationalization of the idea of a technological trajectory (Verspagen, 2007).

\footnotetext{
${ }^{61}$ This section draws heavily on Verspagen (2007).

62 The use of patent data as a technology indicator has a long tradition, but the practice is not, however, undisputed. Griliches (1990) provides a survey of the main advantages and disadvantages of using patent statistics. Patent statistics are an output indicator of innovation rather than an input indicator (such as R\&D expenditures). Their main advantage is that patents are available for a rather long period, and provide detailed technological information. The main disadvantages are that simple patent counts do not take into account differences in the quality of innovations, that many patents do not lead to innovations (i.e. are not applied), and that the propensities to patent an innovation may differ between sectors and firms.
} 
The methodology rests on a number of basic concepts from network analysis, which will be explained first. We represent a patent citation network as a collection of vertices and edges. The vertices (patents) represent pieces of knowledge that depend on each other. The edges are connections between them, in this case citations between two patents. In the particular case of citation networks, the edges are directed, i.e. they have an origin (the cited patent) and a destination (the citing patent).

We represent the citation network by means of a matrix $C$, in which the element $c_{i j}$ is equal to 1 if patent $j$ cites patent $i$, and zero otherwise. Define the matrix $C^{*}$ as the symmetric matrix in which the elements are formed by taking the maximum value (in $C$ ) of below and above diagonal elements. A component in the network $C$ is defined as a subset of patents in which for every patent $i$ and $j$, a path from $i$ to $j$ exists in the network represented by $C^{*}$. A component represents a subset of the network that is somehow connected by a complex set of relations.

The citation networks that we consider are acyclic, i.e. if a path from $i$ to $j$ exists in $C$, no path exists from $j$ to $i$. This follows logically from the nature of a citation: a patent can only be cited by patents that are published after itself, but this implies at the same time that the original patent cannot cite these later patents. In the network matrix $C$, vertices may be distinguished into three categories: sources, sinks and intermediate points. Sources are vertices that make no citations, but are cited. Sinks are the opposite: they are not cited, but make citations. Intermediate points both cite and are cited.

The most important idea in Hummon and Doreian (1989) for our purpose is that we can use the network structure to say something about the importance of the various individual edges (citations) in the network. We use the search path count (SPC) indicator for this purpose, following J. S. Liu et al. (2013). For the patent citation $c_{i j}$, SPC measures the number of times that the citation lies on a path from one vertex in the network to another vertex in the network. Thus, SPC measures how often one visits a citation if all possible paths in the network are traveled.

Once a measure of the importance of the edges (SPC) is calculated, Hummon and Doreian propose to define the "main path" through a network using a heuristic algorithm. Their algorithm uses a local optimization strategy, i.e., when at a particular point at a path, it picks the outgoing edge (citation) that maximizes SPC among all outgoing ones. As recognized in Verspagen (2007) and J. S. Liu and Lu (2012), such a local search strategy does not necessarily lead to a maximum sum of SPC along the entire path. Thus, instead of Hummon and Doreian's original heuristic, we look for the path that maximizes the total sum of SPC along all of its edges. Such a path will necessarily go from a source to a sink. We call the path that is found using this procedure the top main path in the network $C$. The intuition behind why the top main path is of interest, is that it represents the largest flow of ideas in the network. 
We follow Liu and Lu's algorithm, but apply it in the way proposed by Verspagen (2007). This means that we identify the top main path for a network matrix $C_{t}$, where $C_{t}$ is defined as the subset of $C$ that includes only rows and columns corresponding to patents dated to a year smaller than or equal to $t$. Hence, $C_{t}$ corresponds to the citation network that reflects the flow of ideas up to and including the year $t$. The single top main path that results for year $t$ is called $p_{t}$. We then merge the paths $p_{t}$ for all values of $t=T_{0}, \ldots, T_{1}$, where $T_{0}$ is a start year that we will identify below, and $T_{1}$ is the last year in the dataset. The set of all paths $p_{t}$ is called the network of top main paths, and is depicted for our networks in Figures 4.8, 4.9 and 4.10.

As a final step of the analysis, we will take the network of top main paths and attempt to identify clusters in it. For this purpose, we will use the VOS algorithm, as proposed by Waltman and Van Eck (2013). These clusters will be the main unit of analysis when we look at how countries have contributed to the technological trajectory (network of top main paths).

\subsection{DATA}

In order to implement the methods explained in the previous section, we will draw on data from the EPO Worldwide Patent Statistical Database (PATSTAT, 2014 April version) developed by the European Patent Office (EPO). The version of PATSTAT that we use contains more than 90 million patent documents from all the leading economies in the world $^{63}$, covering patents since the beginning of the patent system (for some countries the records date back to the 1830s). Besides patent bibliographical data, PATSTAT also provides a comprehensive and up-to-date patent citation dataset that is based on patent publication and application documents. Table 4.1 lists the PATSTAT tables used in this paper.

Table 4.1 PATSTAT tables used in the analysis (2014 April version)

\begin{tabular}{ll}
\hline Name of the table & Description \\
\hline TLS201_APPLN & Patent application bibliographical data \\
TLS202_APPLN_TITLE & Patent application title \\
TLS206_PERSON & Data on patent applicants and inventors \\
TLS207_PERS_APPLN & Links between applicants and applications \\
TLS211_PAT_PUBLN & Patent publication bibliographical data \\
TLS_212_CITATION & Citation data linking between publications, applications and non-patent literature \\
TLS218_DOCDB_FAM & Patent family data, based on EPO DOCDB patent family \\
TLS224_APPLN_CPC & Cooperative Patent Classification (CPC) data \\
\hline
\end{tabular}

\footnotetext{
${ }^{63}$ See also: https://www.epo.org/searching-for-patents/business/patstat.html
} 
The technology fields that will be analyzed below are defined in terms of the Cooperative Patent Classification (CPC), and cover several parts of the recent OECD ENV-TECH list, which describes patent search strategies for the identification of selected environment-related technologies (Haščič \& Migotto, 2015). Specifically, this paper chooses three kinds of technologies from the OECD list: (1) combustion technologies under the CPC class Y02E2O in the section "climate change mitigation technologies related to energy generation, transmission and distribution", (2) energy efficiency technologies related to ICT in buildings, under the CPC class Y02B60 in the section "climate change mitigation technologies related to buildings", and (3) energy efficiency technologies related to road vehicles, under the CPC class Y02T10 in the section "climate change mitigation technologies related to transportation". The three chosen fields are subclasses related to energy efficiency in a larger list that covers a broad range of climate change mitigation technologies (Tables 4.2a, 4.2b and 4.2c). The use of CPC codes (or any other classification scheme) has the disadvantage that it may exclude relevant technologies that are classified under different codes. For example, it is evident that other CPC classes in the OECD ENV-TECH are also closely related to energy efficiency, for instance, "technologies for an efficient electrical power generation, transmission and distribution" under Y02E40, and "architectural or construction elements improving the thermal performance of buildings" under Y02B80. Also, there are several efficiency related technologies for rail and air transport under the CPC classes Y02T30 and Y02T50 in the section "climate change mitigation technologies related to transportation", which we also do not include in the analysis.

Table 4.2a. Climate change mitigation technologies related to energy generation, transmission and distribution

\begin{tabular}{lll}
\hline Category in OECD ENV-TECH & CPC class & Used in this paper \\
\hline Renewable energy generation & Y02E10 & No \\
Energy generation from fuels of non-fossil origin & Y02E50 & No \\
$\begin{array}{l}\text { Combustion technologies with mitigation potential (e.g. using fossil } \\
\text { fuels, biomass, waste, etc.): technologies for improved output } \\
\text { efficiency and input efficiency }\end{array}$ & Yes \\
$\begin{array}{l}\text { Nuclear energy } \\
\begin{array}{l}\text { Technologies for an efficient electrical power generation, } \\
\text { transmission and distribution }\end{array}\end{array}$ & Y02E30 & No2E40 \\
$\begin{array}{l}\text { Enabling technologies (technologies with potential or indirect } \\
\text { contribution to emissions mitigation) }\end{array}$ & No \\
$\begin{array}{l}\text { Other energy conversion or management systems reducing GHG } \\
\text { emissions }\end{array}$ & Y02E70 & No \\
\hline
\end{tabular}


Table 4.2b. Climate change mitigation technologies related to transportation

\begin{tabular}{|c|c|c|}
\hline Category in OECD ENV-TECH & CPC class & $\begin{array}{l}\text { Used in } \\
\text { this paper }\end{array}$ \\
\hline $\begin{array}{l}\text { Conventional vehicles (based on internal combustion engine, ICE), including: } \\
\text { 1) integrated approaches (technologies for the improvement of indicated } \\
\text { efficiency and mechanical efficiency of an ICE, energy recuperation, non- } \\
\text { reciprocating piston engines, varying inlet or exhaust valve operating } \\
\text { characteristics, engine management system and intelligent control systems) } \\
\text { 2) post-combustion approaches; } \\
\text { 3) fuel substitution }\end{array}$ & $\begin{array}{l}\text { YO2T } 10 \text { / } 12 \text { - 18; } \\
\text { YO2T } 10 \text { / } 40 \text {-48; } \\
\text { YO2T } 10 \text { / } 50 \text { - 56; } \\
\text { YO2T } 10 \text { / } 20 \text { - 26; } \\
\text { YO2T } 10 \text { / } 30-38\end{array}$ & Yes \\
\hline Hybrid vehicles & Y02T 10 / $62-6295$ & Yes \\
\hline $\begin{array}{l}\text { Electric vehicles, including electric machine technologies for applications in } \\
\text { electromobility, energy storage for electromobility; electric energy } \\
\text { management in electromobility }\end{array}$ & $\begin{array}{l}\text { Y02Т } 10 \text { / } 64-649 \\
\text { Y02Т } 10 \text { / } 70-7094 \\
\text { Y02T } 10 \text { / } 72-7291\end{array}$ & Yes \\
\hline Fuel-efficiency improving vehicle design (common to all road vehicles) & $\begin{array}{l}\text { YO2T } 10 \text { / } 80 \text { - 86; } \\
\text { YO2T } 10 \text { / } 90-92\end{array}$ & Yes \\
\hline Rail transport & Y02T30 & No \\
\hline Air transport & Y02T50 & No \\
\hline Maritime or waterways transport & Y02T70 & No \\
\hline Enabling technologies in transport & Y02Т90 & No \\
\hline
\end{tabular}

Table 4.2c. Climate change mitigation technologies related to buildings

\begin{tabular}{lll}
\hline Category in OECD ENV-TECH & CPC class & $\begin{array}{c}\text { Used in } \\
\text { this paper }\end{array}$ \\
\hline Integration of renewable energy sources in buildings & No \\
Energy efficiency in buildings, including energy efficient lighting, heating, ventilation & Y02B20 & No \\
or air conditioning, home appliances, elevators, escalators and moving walkways, & Y02B30 \\
end-user side & Y02B40 \\
& Y02B50 \\
& Y02B70
\end{tabular}

Energy efficiency in buildings, including information and communication technologies:Y02B60 Yes

1) Energy efficient computing: reducing energy-consumption at the single machine level, e.g. processors, personal computers, peripheral devices, power supply; reducing energy-consumption by means of multiprocessors or multiprocessing based techniques, other than acting upon the power supply (e.g. resource allocation, scheduling, virtualization, consolidation and load distribution); reducing energyconsumption in distributed systems (e.g. delegation or migration, resource sharing); reducing energy-consumption at software or application level (e.g. compilation, installation, feedback, predication, usage patterns, suspending or hibernating, performance or eco-modes, information retrieval in databases).

2) Techniques for reducing energy-consumption in wire-line communication networks: using reduced link rate; using subset functionality and by operating in lowpower or sleep mode.

3) High level techniques for reducing energy-consumption in communication networks: by proxying, by energy-aware routing, by signaling and coordination and green peer-to-peer.

4) Techniques for reducing energy-consumption in wireless communication networks. 


\begin{tabular}{lcc}
\hline Category in OECD ENV-TECH & CPC class & $\begin{array}{l}\text { Used in } \\
\text { this paper }\end{array}$ \\
\hline $\begin{array}{l}\text { Architectural or construction elements improving the thermal performance of } \\
\text { buildings }\end{array}$ & Y02B80 & No \\
Enabling technologies in buildings & Y02B90 & No \\
\hline
\end{tabular}

Source: own elaboration based on OECD ENV-TECH list (Haščič \& Migotto, 2015).

In choosing a relevant classification, we searched for a group of patents which are relatively strongly connected to each other, either directly or indirectly. The reason is that the methods that we will use work within a single component of a larger network, and hence a citation network that consists of many components will never identify a common trajectory for all the components. Including a broad class, like Y02E40, that includes topics that are only indirectly related to energy efficiency will tend to generate more components, which is why we do not include this. The three technology fields under investigation are well connected, as will be shown below.

In constructing our patent citation datasets, the first challenge is to choose a proper unit of analysis to deal with the problems of double counting and self-citation in patent data. It is very common that a firm patents the same technology with various patent authorities (countries) around the world. All the patents reflecting the same technology but documented in different patent authorities are recorded in PATSTAT separately using different IDs. Also, an invention can be represented in three levels in PATSTAT: patent publication, patent application and patent family. The relationship between them is shown in Figure 4.1. A patent application may cover multiple patent publications, but a patent publication can only be linked to a single patent application. A patent family is related to multiple patent applications, ${ }^{64}$ but a patent application cannot be included in multiple patent families. The PATSTAT citation dataset is based on publications and applications, which results in the problem that many citing and cited entities actually indicate the same technology, which leads to double counting.
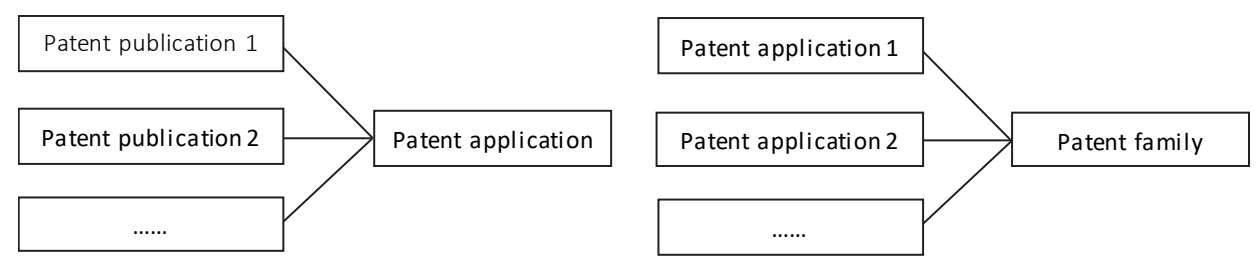

Figure 4.1 The relationship between patent publication, patent application and patent family in PATSTAT Source: own elaboration.

The problems of double counting and self-citation (between members of a family) are solved by identifying all patent publications and patent applications in the citation da-

\footnotetext{
${ }^{64}$ For example, patent applications authorized in different countries.
} 
taset to their corresponding patent families and performing the analysis on patent families. The EPO has developed its own DOCDB patent family system, which is what we use, where different patent publications and patent applications representing the same technology are assigned a unique and stable ID. In the raw dataset, a patent publication can cite (1) another patent publication, (2) another patent application, or (3) nonpatent literature. We do not include non-patent literature in our analysis, since it cannot be linked to any patent application or patent family. For patent citations, , we link all the citing and cited patent publications to their corresponding patent applications and only use those citation pairs under the CPC classes of interest. Then we link all the obtained citation pairs of patent application to their corresponding DOCDB patent families. ${ }^{65}$ We are then able to identify and remove all the self-citations and duplicated pairs in the citation dataset at family level.

Another problem is related to the timing of a patent family. Unlike patent application in the original patent bibliographical documents, DOCDB patent families do not have a specific filing date, while the temporal information greatly matters in our analyses. In this paper, we use the earliest application filing date (also known as priority date) within the same DOCDB patent family as the time indicator of the patent family. In the raw dataset, a patent publication cannot cite a patent publication or application earlier than itself. If we convert all the patent publications and patent applications into patent families, however, some "illogical" pairs where the citing patent family is earlier than the cited patent family do exist. For logical consistency, and to keep the network acyclical, we do not include these pairs. Also, we delete any citations that lead to cycles in the network when two families have the same priority date.

In the final citation dataset of energy efficiency technology related to energy generation, 18031 citation pairs formed by 7230 DOCDB patent families from the CPC class Y02E2O are found. We will refer to this data set as the power stations dataset. The date of cited patent family ranges from 1905 to 2012 and the citing patent family occurs for the period 1951 - 2013. For the Y02B60 class, which we will refer to as ICT energy efficiency technologies, the final citation dataset has 45694 citation pairs containing 15495 DOCDB patent families. The cited patent family exists for the period $1923-2012$ and the citing patent family appears for the period 1947 - 2013. For the Y02T10 class referred to as vehicle energy efficiency technologies, the final citation dataset is very large, containing 483733 citation pairs and 125111 DOCDB patent families. The cited patent family and citing patent family exist for the period $1898-2012$ and the period $1934-2013$, respectively.

\footnotetext{
${ }^{65}$ The source of citation data is the table "TLS_212_CITATION". The table "TLS211_PAT_PUBLN" contains the links between patent publication and patent application. The table "TLS218_DOCDB_FAM" contains the links between patent application and DOCDB patent family.
} 
The figures below illustrate the development of the citation networks for energy efficiency technology related to energy generation and buildings, respectively. ${ }^{66}$ Figure 4.2, Figure 4.3 and Figure 4.4 show the general evolution of the networks in terms of the number of patents (vertices in the networks), also by type of vertex. All three types of technologies show similar trends in development. Before 1980s the growth of the citation networks for all the types of technologies is rather slow: the curves indicating the total number of patent families, the number of sources, the number of sinks and the number of citation network components are very flat compared to those after the 1980s. ${ }^{67}$ After 1980 the development of both types of technologies takes off: all the relating curves have steep increases.

Also, in the early years, citations happen between only a small number of patent families, leading to a fragmented nature of the citation network. Figure 4.5, Figure 4.6 and Figure 4.7 document the share (in terms of the number of patents involved) of the largest citation network component in the complete networks. The shares for the power stations field and ICT energy efficiency field generally remain at a low level (below 60\%) and fluctuate significantly for the period until 1980. The share for the vehicle energy efficiency field, however, has stayed at a high level (above 60\%) since 1950s, probably because the dataset contains many more patents. For the power stations field, the share of the largest citation network component starts to continuously increase from 1984 onwards and gradually reaches a very high level (from 63\% in 1984 to 91\% in 2013). For the ICT energy efficiency field, the share of the largest citation network component sharply grows from $67 \%$ in 1988 to $92 \%$ in 2013 . For the vehicle energy efficiency field, the share of the largest citation network component already reaches $90 \%$ in 1978 and smoothly grows to $96 \%$ in 2013. The higher this share, the better connected the citation network, and the better our analysis will capture general trends in the field. We therefore choose 1984, 1988 and 1978 as the start years for the analysis in the next section.

\footnotetext{
${ }^{66}$ To obtain all the basic network statistics, we use the two complete citation datasets to construct subdatasets in which all the cited and citing patent families are earlier than or equal to the corresponding year on the $X$ axis of the figures. For example, the sub-dataset for 2012 only contains cited and citing patent families up to and including 2012. We do this for every year existing in the ranges of the citing patent families.

${ }^{67}$ In the early years all the curves are discontinuous because no patent families are found in some years.
} 


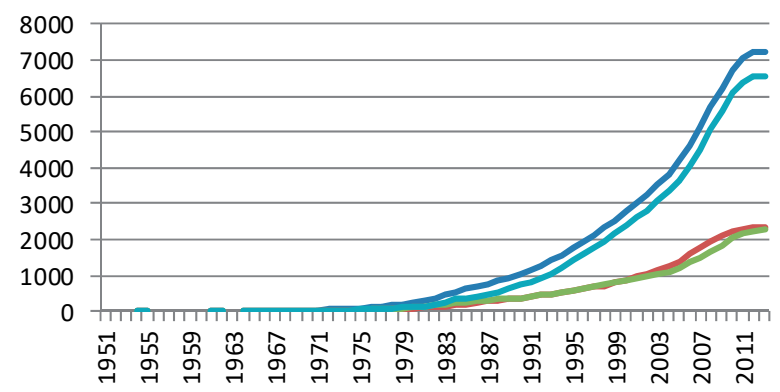

Total number of vertices

Number of First Vertices (Sources)

Number of Last Vertices (Sinks)

Size of the Largest Component

The earliestfiling year of citing patent within the DOCDB patent family

Figure 4.2 Development of the citation network for power stations

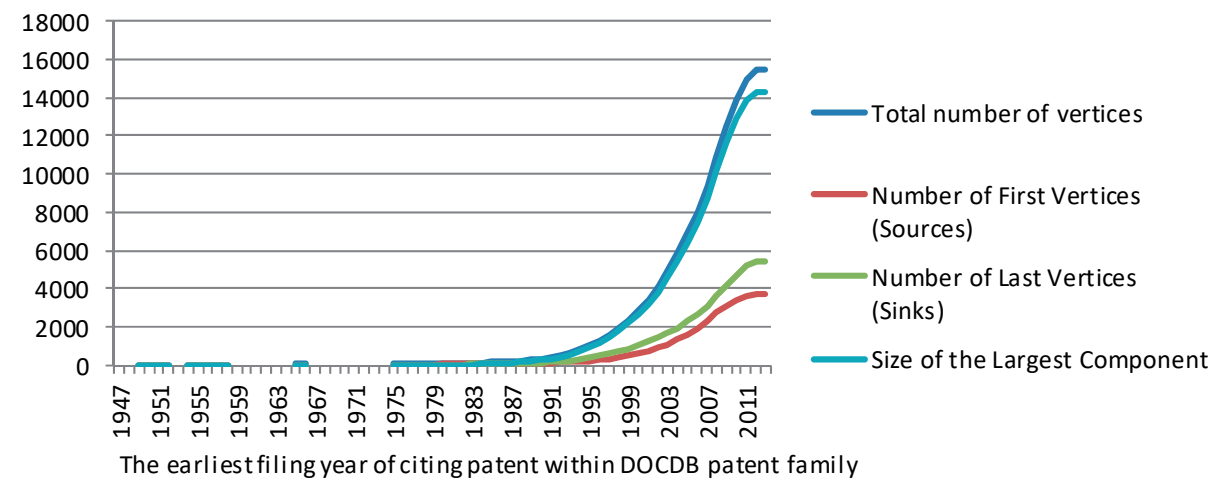

Figure 4.3 Development of the citation network for energy efficiency technologies, ICT in buildings

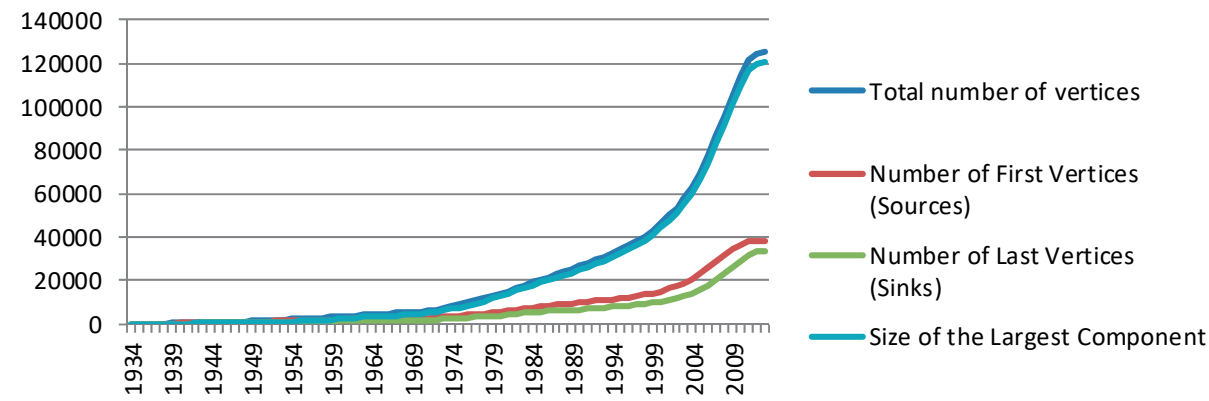

The earliest filing year of citing patent within DOCDB patent family

Figure 4.4 Development of the citation network for energy efficiency technologies related to vehicles 


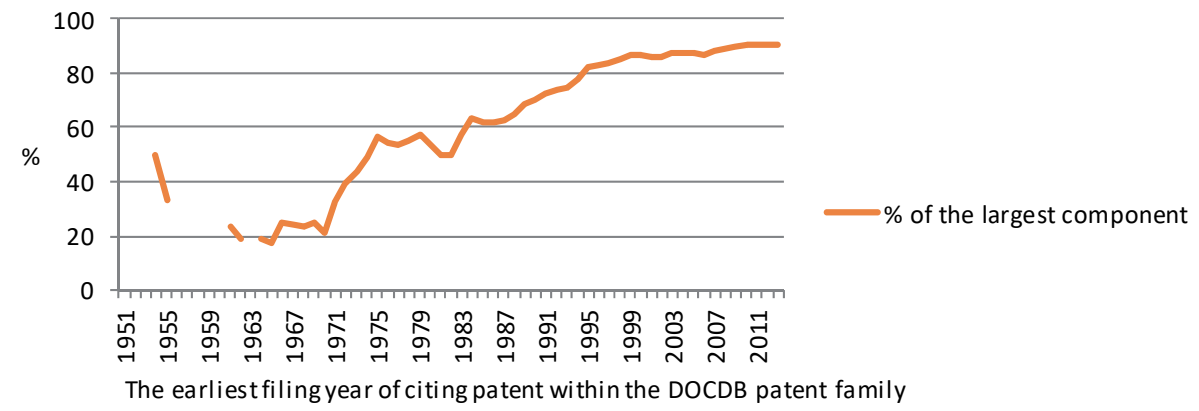

Figure 4.5 Evolution of the importance of the largest component, power stations citations network

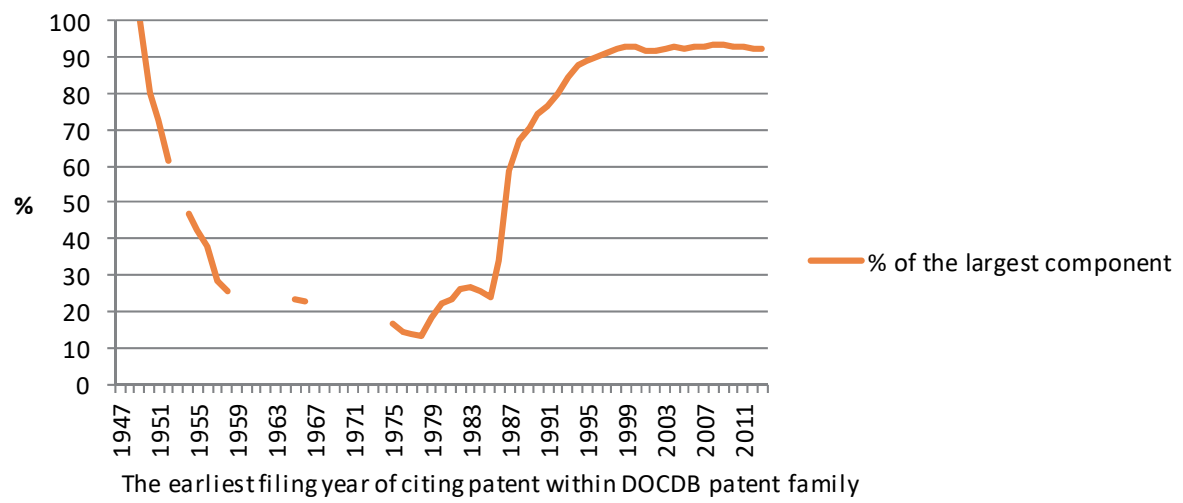

Figure 4.6 Evolution of the importance of the largest component, ICT citations network

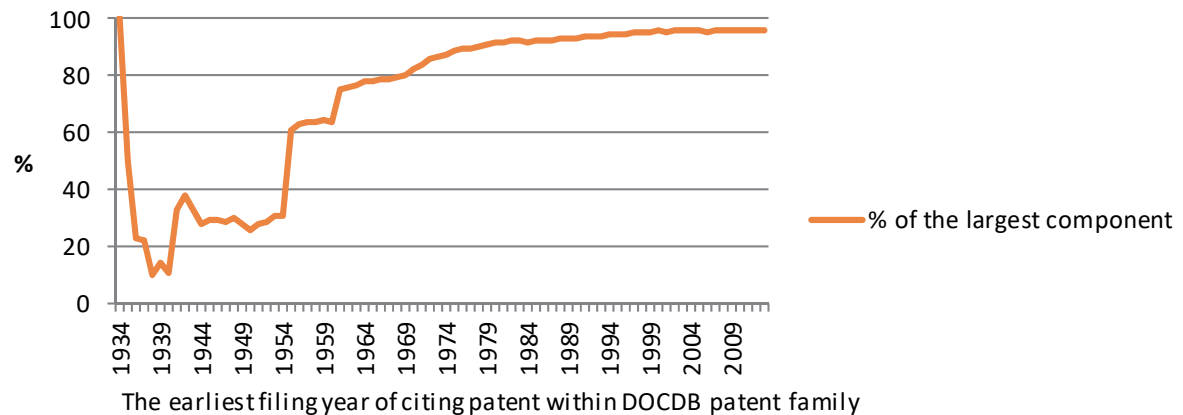

Figure 4.7 Evolution of the importance of the largest component, vehicle energy efficiency citations network

\subsection{RESULTS}

We will separately analyze the three particular groups of technologies in the field of energy efficiency that were introduced above. The cases are chosen to provide a certain degree of diversity. One case, broadly speaking the technology of power stations and 
power plants, is a scale-intensive technology that requires large investments to be applied. The second group of technologies, broadly speaking those that are aimed at increasing energy efficiency for information and communication equipment in buildings (e.g., in homes and offices) have a much smaller scale, but the main trajectories are also better connected. The third group, broadly speaking those related to energy efficiency of road vehicles (including vehicles consuming fossil fuels, hybrid vehicles and electric vehicles), is a field with a long history and also requires a large scale of investments. In the main trajectories that we will present and analyze below, we find an additional small separate group of technologies in the power stations field and the vehicle energy efficiency field, while the main trajectories of the ICT energy efficiency field have a single component only.

For each of these technology fields, we will use the methods explained above to identify the main paths in the technology field, which we will take as an indication of the most important technological trajectories that developed over time. We will start by discussing these results for the three fields. We will then revert back to the entire patent datasets for the fields (the identified trajectories are a subset) and look at the role of different countries over time. ${ }^{68}$ We will try to identify leaders (in time) and latecomers, at the country level. Finally, we will analyze how individual countries relate to the technological trajectories (main paths), and what role the timing of the technological efforts (i.e., whether they are latecomers or early players) plays a role in this relationship. We will use both a forward perspective and a backward perspective. The forward perspective asks into which parts of the main path a country's patents feed, while the backward perspective asks from which parts of the main path the country's patents are derived.

\subsubsection{Power stations}

In the dataset for the power station technology 6563 patent families are connected to each other by citations (i.e., they form the largest network component) in the final year 2013. We use this component for our analysis, i.e., we ignore the small number of patents (roughly 9\%) that are outside this component. Table 4.3 shows the number of patent families and the age of the patents in this component, by country. We count the number of inventors by country, and because a patent family can have more than a single inventor, the total number exceeds the number of patents in the sample. We include in the analysis only countries that have more than 50 patents (an admittedly arbitrary threshold), which yields the countries listed in the table. Together, these countries account for $55 \%$ of all inventors in the sample. Of the remaining 45\%, 41\%-points are inventors for which the country is not listed in the database. ${ }^{69}$

\footnotetext{
${ }^{68}$ In this section, when we speak about "patents", we generally mean "patent families".

${ }^{69}$ In many cases, the unlisted inventors will be the same ones that are listed in other members of the family, hence the problem of unlisted nationalities is less serious than it seems on the basis of the $45 \%$.
} 
The US and Germany are the largest countries in this technology field. Together, they account for $32 \%$ of all patents. The other countries in the table are either European or Asian. Many of the Asian countries are characterized as latecomers. This is done on the basis of two indicators for the age of the patents from a country. The first indicator is the average year of the patents in the country, the other the year of the oldest patent in the country. The average is about 1999 for the entire sample, while the earliest patent is from 1908. Thus, despite the fact that the database goes back more than a century, the majority of patents are less than 20 years old.

The countries that can be characterized as latecomers in terms of industrialization and catching-up are Korea, India and China, where the last two are clearly second-tier catching-up countries. In line with this characterization, their average patent is from 2005 or later. The other countries are all early industrializers, although some of them (e.g., Italy, Austria) have average patents from years that are close to those of Korea.

Table 4.3 Number of patents and age for power station technology, by country

\begin{tabular}{llll}
\hline & Average Year & Min year & Number \\
\hline All & 1999.2 & 1908 & 10254 \\
United States of America & 1999.5 & 1908 & 2132 \\
Germany & 1999.4 & 1962 & 1120 \\
Japan & 2000.7 & 1973 & 614 \\
Switzerland & 2001.0 & 1960 & 310 \\
France & 2001.7 & 1966 & 304 \\
United Kingdom & 2001.0 & 1965 & 232 \\
Sweden & 1997.6 & 1949 & 128 \\
Republic of Korea & 2006.0 & 1996 & 119 \\
Italy & 2003.5 & 1968 & 111 \\
Canada & 2001.8 & 1976 & 111 \\
Netherlands & 1998.9 & 1967 & 99 \\
India & 2007.6 & 1992 & 90 \\
Finland & 1999.4 & 1981 & 87 \\
Austria & 2001.8 & 1952 & 58 \\
Israel & 1999.1 & 1978 & 57 \\
China & 2004.6 & 1986 & 56 \\
\hline
\end{tabular}

Note that this table only contains economies with more than 50 patent families.

Table 4.4 presents the clusters in the top main paths group of patents in the power stations field. There are 214 patents in the top main paths since 1984, which is the year in which we start the analysis (this is also the year in which the largest component of the citation network becomes substantial). The VOS clustering algorithm that we apply divides this group into 13 clusters. The 214 patents are also spread over 2 separate 
components. Figure 4.8 displays a graph of the network of all top main paths over the period $1984-2013$, including an indication of the clusters. The table also gives an indication of the age of the patents in a cluster, with minimum, average and maximum year of the group of patents in the cluster.

Table 4.4 Clusters in the top main paths graphs of the power stations field, 1984-2013

\begin{tabular}{|c|c|c|}
\hline Cluster as labeled in figure & Description & Period (min - average - max) \\
\hline Cluster 2 (Core) & $\begin{array}{l}\text { Gasification of fuel, mainly companies from } \\
\text { USA and Germany }\end{array}$ & $1949-1979-1993$ \\
\hline Cluster 13 (Branch A final path) & $\begin{array}{l}\text { Oxygen combustion, started by companies } \\
\text { from USA, France and Norway, last part } \\
\text { Hitachi (Japan) }\end{array}$ & $1997-2006-2013$ \\
\hline $\begin{array}{l}\text { Cluster } 8 \text { (stable part of Branch B } \\
\text { final path) }\end{array}$ & $\begin{array}{l}\text { Combined cycle, mostly companies from } \\
\text { Japan (Mitsubishi) and USA }\end{array}$ & $1996-2002-2010$ \\
\hline $\begin{array}{l}\text { Cluster } 7 \text { (non-stable part of } \\
\text { Branch B final path) }\end{array}$ & $\begin{array}{l}\text { Hybrid fuel and solar, frequency stabilization, } \\
\text { heating, cooling, moisturization, mostly } \\
\text { companies from USA }\end{array}$ & $1994-2000-2006$ \\
\hline $\begin{array}{l}\text { Cluster } 12 \text { (non-stable part of } \\
\text { Branch B final path) }\end{array}$ & $\begin{array}{l}\text { Cogeneration, mostly companies from Korea } \\
\text { and Japan }\end{array}$ & $2001-2005-2007$ \\
\hline Cluster 4 (early dead end) & $\begin{array}{l}\text { Load control, combined cycle, mostly } \\
\text { companies from Japan and USA }\end{array}$ & $1973-1982-1990$ \\
\hline Cluster 1 (dead ends) & $\begin{array}{l}\text { Combined cycle, gasification, mainly } \\
\text { companies from Germany and USA }\end{array}$ & $1977-1986-1992$ \\
\hline Cluster 3 (dead ends) & $\begin{array}{l}\text { Use of biofuels, using fuel cells, mainly } \\
\text { companies from USA }\end{array}$ & $1977-1985-1994$ \\
\hline Cluster 5 (dead ends) & $\begin{array}{l}\text { Using waste as fuel, companies from Finland, } \\
\text { Germany }\end{array}$ & $1986-1992-1996$ \\
\hline Cluster 9 (dead ends) & $\begin{array}{l}\text { Combined cycle, companies from Germany, } \\
\text { USA }\end{array}$ & $1996-2000-2006$ \\
\hline Cluster 6 (mostly fringe) & $\begin{array}{l}\text { Reducing CO2 emissions, mainly companies } \\
\text { from USA }\end{array}$ & $1992-1998-2006$ \\
\hline $\begin{array}{l}\text { Cluster } 10 \text { (disconnected dead } \\
\text { end) }\end{array}$ & $\begin{array}{l}\text { Fuel burners, combustion, mainly companies } \\
\text { from USA }\end{array}$ & $1962-1986-1996$ \\
\hline $\begin{array}{l}\text { Cluster } 11 \text { (disconnected dead } \\
\text { end) }\end{array}$ & $\begin{array}{l}\text { Oxygen combustion, fuel injection, mainly } \\
\text { companies from USA and France }\end{array}$ & $1996-2001-2005$ \\
\hline
\end{tabular}

Source: own elaboration.

The technological trajectory in this field shows a dynamic evolution over time. At the end of the period, in 2013, the top main path consists of two separate branches and a core. But over time, other branches have been present, which disappeared before 2013. The two final branches are labeled Branch A and Branch B in the table and figure. They have clear technological characterizations. Branch A corresponds to a trajectory of oxygen combustion, a technique where a higher concentration of oxygen than is found in normal air is used to burn fuel. Branch B corresponds to a trajectory of a combined 
cycle, which means that gas or steam is used twice, at different pressures, to generate energy. These two branches emerged around the same time, as shown by the oldest age of patents in the clusters (1996 and 1997), but on average the patents in Branch A are younger (2006) than in Branch B (2002). The core of the network, which includes the single source patent from 1949, includes patents on gasification of fuel. This can be considered as the most basic technology in the trajectory, from which all other subbranches emerged. The core contains mostly older patents, with an average year equal to 1979 , i.e., pre-dating the average year of all patents in the sample by a full 20 years.

Cluster 4 is an early branch that turns into a dead end (by which we mean that it disappears from the top main path before 2013). This branch is present in the network from 1984 until 1991, but the oldest patent in this cluster is from 1973, and the average year of patents in the cluster is 1982, i.e., only slightly (3 years) younger than the core (Cluster 2). Technological topics in Cluster 4 are load control and the combined cycle.

There are other dead ends, some of which are closely linked to Branch B of the network. The latter clusters are indicated as non-stable parts of Branch B, and they comprise the clusters 7 and 12 . When they appear, these branches are linked to the stable part of Branch B. Their technological characterization is different, however, from the patents in the stable part of Branch B. In cluster 7, we find technologies that combine solar energy with turbines, and in Cluster 12, we find cogeneration technologies (generating electricity and useful heat at the same time).

Another dead end is formed by clusters 10 and 11, which together from a separate component in the network of top main paths (see Figure 4.8). This is a branch that appears for only three years in the top main path (1996, 2002 and 2006), and which is concerned with the combustion process itself, in the form of oxygen combustion, fuel injection, and the design of burners. The other dead ends in the network are Clusters 1 , 3, 5 and 9. Cluster 6 contains many patents that do not form a real trajectory over time, but which are fringe patents that appear for only one or two years in the network of top main paths.

Besides a coherent technological content, the clusters can also be characterized by the country of origin of the companies that are active in them. Many companies, across most of the clusters, are from the US, but some clusters are dominated by other countries. Germany plays an important role in the core cluster, together with the US, which is the same in Cluster 1, and Cluster 9. Japanese companies play an important role in both branches A and B, as well as in Cluster 12, a non-stable part of Branch B, where also Korea plays an important role (and the US is more absent than usual). Finnish companies play an important role Cluster 5 , with technologies aimed at using waste from the paper industry. 


\subsubsection{ICT energy efficiency in buildings}

The second field considered in this analysis is related to the energy efficiency of information and communication equipment in buildings. In fact, it is a collection of two types of technologies, that is, computer related technology and wire-line / wireless communication network, which share the fact that they are used indoors to save energy. The total number of patent families in the largest component in this field in 2013 is 14325 (roughly $7.5 \%$ is left out). Table 4.5 shows the number of inventors in patent families by country.

Table 4.5 Number of patents and age for energy efficiency technologies related to ICT in buildings, by country

\begin{tabular}{llll}
\hline & Average Year & Min year & Number \\
\hline All & 2004.1 & 1935 & 24289 \\
United States of America & 2004.0 & 1966 & 6343 \\
Japan & 2003.6 & 1975 & 2839 \\
Republic of Korea & 2005.5 & 1986 & 1236 \\
China & 2008.0 & 1992 & 709 \\
United Kingdom & 2004.5 & 1966 & 559 \\
Taiwan & 2006.2 & 1991 & 532 \\
Germany & 2004.3 & 1963 & 504 \\
Canada & 2005.3 & 1985 & 466 \\
India & 2007.2 & 1996 & 442 \\
France & 2004.4 & 1969 & 362 \\
Finland & 2004.7 & 1989 & 344 \\
Sweden & 2004.3 & 1982 & 340 \\
Israel & 2005.6 & 1983 & 306 \\
Netherlands & 2003.9 & 1986 & 296 \\
Switzerland & 2005.1 & 1993 & 106 \\
Singapore & 2005.5 & 1994 & 91 \\
Italy & 2004.4 & 1975 & 64 \\
\hline
\end{tabular}

Note that this table only contains economies with more than 50 patent families.

Interestingly, in the ICT energy efficiency field, the performance of latecomer countries is quite notable. The US is again the largest country in terms of patents in this field, followed by an incumbent country (Japan) and a latecomer country (South Korea). The next largest countries are two latecomer countries (China and Taiwan) and an incumbent country (the UK). The latest country entering this field is China, with an average patent filing year of 2008, while ranking fourth globally in this field in terms of patents. The average year in which all the patents were filed is 2004, which is much larger than the power stations field, indicating that the ICT energy efficiency field is a young field that attracts latecomer countries to participate actively. Besides South Korea, China and 
Taiwan, we also see India and Singapore as latecomer countries in the table. But also some developed economies such as Canada, Israel and Switzerland have relatively late years for the average patent.

Figure 4.9 presents the network of top main paths since 1988. There is only one wellconnected component in this network, while it is evident that the network has two directions, one that corresponds to wire-line and wireless communication network, and the other to energy saving in computers. We find 10 clusters using the VOS algorithm, of which three clusters are in communication network, and the remaining seven in the computer part. These two parts share a common origin from the computer part, that is, Cluster 3. They develop in a more or less linear fashion, with one founding cluster, a number of intermediate clusters and a number of final clusters.

Table 4.6 Clusters in the top main paths graphs of the ICT energy efficiency field, 1988-2013

\begin{tabular}{|c|c|c|}
\hline Cluster as labeled in figure & Description & Period (min - average - max) \\
\hline Cluster 3 (origin) & $\begin{array}{l}\text { Power saving / battery management } \\
\text { devices, mostly companies from USA and } \\
\text { Japan }\end{array}$ & $1935-1979-1993$ \\
\hline $\begin{array}{l}\text { Cluster } 2 \text { (Radio system and power } \\
\text { management, old) }\end{array}$ & $\begin{array}{l}\text { Power saving devices in radio system, } \\
\text { started by companies from Japan (NEC), } \\
\text { then followed by companies from USA, } \\
\text { Finland and Sweden }\end{array}$ & $1982-1993-2003$ \\
\hline $\begin{array}{l}\text { Cluster } 5 \text { (CPU and power } \\
\text { management) }\end{array}$ & $\begin{array}{l}\text { Power saving / cooling design for CPU, } \\
\text { mostly companies from USA }\end{array}$ & $1990-1995-2000$ \\
\hline $\begin{array}{l}\text { Cluster } 1 \text { (Radio system and power } \\
\text { management) }\end{array}$ & $\begin{array}{l}\text { Power management for radio system and } \\
\text { CPU, started by companies from Finland } \\
\text { (Nokia) and Sweden (Ericsson), mostly } \\
\text { companies from USA and Japan }\end{array}$ & $1992-1999-2003$ \\
\hline $\begin{array}{l}\text { Cluster } 4 \text { (Wireless system and } \\
\text { power management) }\end{array}$ & $\begin{array}{l}\text { Power saving devices for wireless Internet } \\
\text { system, mostly companies from USA }\end{array}$ & $1998-2004-2007$ \\
\hline $\begin{array}{l}\text { Cluster } 7 \text { (Adaptive power control, } \\
\text { old) }\end{array}$ & $\begin{array}{l}\text { Adaptive / dynamic power control, mostly } \\
\text { companies from USA }\end{array}$ & $1999-2002-2003$ \\
\hline $\begin{array}{l}\text { Cluster } 8 \text { (Dynamic power control for } \\
\text { CPU) }\end{array}$ & $\begin{array}{l}\text { Dynamic power control for multicore } \\
\text { processors, started by companies from } \\
\text { South Korea (LG) and Taiwan (Asustek), } \\
\text { mostly companies from USA and Taiwan }\end{array}$ & $2000-2006-2011$ \\
\hline Cluster 10 (Optimizing power usage) & $\begin{array}{l}\text { Optimizing energy consumption; power- } \\
\text { aware thread scheduling for computer, } \\
\text { mostly companies from USA }\end{array}$ & $2008-2009-2010$ \\
\hline $\begin{array}{l}\text { Cluster } 6 \text { (Power control for monitor } \\
\text { and memory) }\end{array}$ & $\begin{array}{l}\text { Power control for monitor and memory } \\
\text { system, mostly companies from USA and } \\
\text { South Korea (LG and Samsung) }\end{array}$ & $1993-2000-2005$ \\
\hline Cluster 9 (Optimizing power usage) & $\begin{array}{l}\text { Optimizing power usage, mostly companies } \\
\text { from USA }\end{array}$ & $2006-2006-2007$ \\
\hline
\end{tabular}

Source: own elaboration. 
The clusters are presented in Table 4.6. Cluster 3, in which patents go back, on average, to 1979 , is the foundational cluster for the computer part. This cluster is concerned with power saving / battery management devices in computers, as used in residential and commercial buildings. Cluster 8 and Cluster 10 are the last clusters (state of the art) in this part, which deals with more complex dynamic and optimal power control, which have applications in computers with multicore processors. In fact, these two clusters are quite similar to each other, since Cluster 10, as a divergent branch of Cluster 8 , develops based on Cluster 8. Interestingly, the original inventors in this field are mostly companies from the USA and Japan, and in the intermediate clusters there are several European companies such as Nokia from Finland and Ericsson from Sweden, while in the more recent clusters (Cluster 6, Cluster 8 and Cluster 10), some companies from latecomer countries, for instance, LG and Samsung from South Korea and Asustek from Taiwan, are already active inventors. Cluster 5, Cluster 7 and Cluster 9 are dead ends in this development, while Cluster 6 is an intermediate stage which includes power control for monitor and memory devices.

The other three clusters, that is, Cluster 1, Cluster 2 and Cluster 4, are related to energy consumption in communication systems, which are in fact based on Cluster 3 in the computer part. Cluster 2, with patents that on average go back to 1993, is the foundational or the earliest cluster in the communication network part of the graph. This cluster is concerned with power management in the radio system in general. The foundational cluster, becomes a dead end, and through Cluster 1, develops into three clusters in the computer part: 6, 7 and 8, which in general deal with power management systems for CPUs (in particular multicore CPUs), monitor and memory. The final cluster in the communication part, Cluster 4 related to power saving devices for wireless Internet system, is also a dead end.

\subsubsection{Energy efficiency technologies related to vehicles}

The third case that we will analyze deals with a very large technological field in terms of patent families involved and a much more homogenous technology. It focuses on technologies that can improve emission efficiency and energy efficiency of all the types of road vehicles, covering traditional vehicles that consume fossil fuels, electric vehicles and hybrid vehicles. In 2013 around 96\% of the patent families in this field are included in the largest citation network component, that is, 120163 patent families. Because the dataset has more observations, we are able to apply a higher threshold of patents to include countries in the table, as shown below, and as a result we have more countries. The threshold is 100 patents, and in the table we still include the Soviet Union, which has 211 patents. In the next section, however, patents from the Soviet Union are left out in the econometric analysis. 
Table 4.7 contains economies with more than 100 patent families. In Table 4.7, the largest country, defined as the number of patents held, is Japan (23716 patents) followed by four developed incumbent countries: Germany, the USA, France and the UK. The top five incumbent countries contribute roughly $44.1 \%$ of total patents in this field. Among all the countries in the table, there is a significant discrepancy in the number of patents held between top three countries (Japan, Germany and the USA, more than 20000 patents) and the others (below 6500 patents), indicating that this field is much dominated by the three incumbent countries. The average patent filing year in this field is 1997, which is the smallest in all three technological fields under consideration, showing that this field is relatively "old". The best performing latecomer country is South Korea in the sixth place (2432 patents). The other latecomer countries include China (746 patents), Taiwan (414 patents) and India (250 patents). Some developed countries such as Finland and Luxembourg also entered this field quite late.

Table 4.7 Number of patents and age for energy efficiency technologies related to vehicles, by country

\begin{tabular}{|c|c|c|c|}
\hline & Average Year & Min year & Number \\
\hline All & 1997.1 & 1898 & 168401 \\
\hline Japan & 2000.4 & 1918 & 23176 \\
\hline Germany & 2000.7 & 1901 & 21319 \\
\hline United States of America & 1999.3 & 1898 & 20598 \\
\hline France & 1999.9 & 1902 & 6452 \\
\hline United Kingdom & 1996.3 & 1898 & 2706 \\
\hline Republic of Korea & 2006.8 & 1980 & 2432 \\
\hline Italy & 1999.0 & 1944 & 1227 \\
\hline Sweden & 2001.6 & 1910 & 1172 \\
\hline Austria & 2002.0 & 1909 & 1168 \\
\hline Canada & 2000.0 & 1913 & 1079 \\
\hline Switzerland & 1987.0 & 1911 & 831 \\
\hline China & 2006.3 & 1985 & 746 \\
\hline Netherlands & 2000.5 & 1909 & 490 \\
\hline Australia & 1997.6 & 1917 & 436 \\
\hline Taiwan & 2002.2 & 1975 & 414 \\
\hline Belgium & 2001.7 & 1904 & 337 \\
\hline Spain & 2000.6 & 1960 & 325 \\
\hline India & 2007.5 & 1974 & 250 \\
\hline Russian Federation & 2000.6 & 1911 & 213 \\
\hline Soviet Union & 1983.6 & 1962 & 211 \\
\hline Finland & 2003.2 & 1917 & 202 \\
\hline Denmark & 2002.7 & 1912 & 190 \\
\hline Luxembourg & 2003.6 & 1967 & 146 \\
\hline Israel & 1999.1 & 1952 & 112 \\
\hline Czech Republic & 2000.1 & 1929 & 110 \\
\hline
\end{tabular}


Figure 4.10 illustrates the network of top main paths in this field since 1978. Employing the VOS algorithm generates 11 clusters. As in the power stations filed, two separate network components are found, one that is a small cluster and concentrated on exhaust gas recirculation apparatus, and the other that is much larger and well-connected, including 10 clusters.

Table 4.8 summarizes all 11 clusters in the network of top main paths in this field. The small disconnected component (Cluster 1), mainly contains Japanese, German and American companies, and stops development in 1979. In the larger network component, interestingly, it shows a very different technological development trajectory, compared to the other two fields: it has two separate technological origins, the old one (Cluster 2) that corresponds to flow control device or fuel injection for internal combustion engine (ICE), started by individual inventors from Germany and followed by Japanese companies, and the new one (Cluster 3 ) that is related to the ignition system and spark timing control for ICE, started by GM from the USA and mostly followed by American and Japanese companies.

Table 4.8 Clusters in the top main paths graphs of the vehicle energy efficiency field, 1978- 2013

\begin{tabular}{|c|c|c|}
\hline Cluster as labeled in figure & Description & $\begin{array}{l}\text { Period } \\
\text { (min - average - max) }\end{array}$ \\
\hline Cluster 1 (Separated component, old) & $\begin{array}{l}\text { Exhaust gas recirculation apparatus, mostly } \\
\text { companies from Japan (Toyota, Honda and } \\
\text { Nissan), Germany (Bosch) and USA (Ford) }\end{array}$ & 1925 - $1969-1979$ \\
\hline $\begin{array}{l}\text { Cluster } 2 \text { (Flow control / fuel injection, } \\
\text { old origin) }\end{array}$ & $\begin{array}{l}\text { Flow control device / fuel injection, started by } \\
\text { individual inventor from Germany, mostly } \\
\text { companies from Japan (Toyota) }\end{array}$ & $1923-1968-1986$ \\
\hline $\begin{array}{l}\text { Cluster } 3 \text { (Ignition system and timing } \\
\text { control for ICE, new origin) }\end{array}$ & $\begin{array}{l}\text { Ignition system / spark timing control / } \\
\text { knocking control device, started by companies } \\
\text { from USA (GM), most from USA and Japan }\end{array}$ & $1958-1978-1990$ \\
\hline Cluster 5 (Air intake system for ICE) & $\begin{array}{l}\text { Air intake system for internal combustion } \\
\text { engine, mostly companies from Japan } \\
\text { (Mitsubishi, Nissan, Hitachi, Toyota, Yamaha, } \\
\text { Fuji Heavy Industries), and some companies } \\
\text { from Germany, Sweden and Taiwan }\end{array}$ & $1985-1993-1996$ \\
\hline Cluster 6 (Engine control system, old) & $\begin{array}{l}\text { Engine control system / ignition timing control } \\
\text { system / Valve timing, mostly companies from } \\
\text { Japan (Nissan, Mazda, Toyota, Mitsubishi, } \\
\text { Denso, Honda and Fuji Heavy industries), and } \\
\text { some companies from and USA }\end{array}$ & 1985 - 1991 - 1999 \\
\hline Cluster 8 (Direct injection, old) & $\begin{array}{l}\text { Direct fuel injection for ICE, companies from } \\
\text { Austria, Germany, France, Belgium and Japan }\end{array}$ & $1994-1998-1999$ \\
\hline Cluster 7 (Air and fuel supply system) & $\begin{array}{l}\text { Combined cycle / direct fuel injection / air and } \\
\text { fuel supply, most from Japan and USA, and } \\
\text { some companies from Germany and Austria }\end{array}$ & $1994-2001-2007$ \\
\hline Cluster 4 (Pressure control for ICE, old) & Pressure control for a turbocharger / air supply & $1981-1988-1996$ \\
\hline
\end{tabular}




\begin{tabular}{|c|c|c|}
\hline & $\begin{array}{l}\text { control / ICE with turbocharger, mostly } \\
\text { companies from Japan and USA, and some } \\
\text { companies from Sweden and Germany }\end{array}$ & \\
\hline $\begin{array}{l}\text { Cluster } 9 \text { (Hybrid vehicle control } \\
\text { system) }\end{array}$ & $\begin{array}{l}\text { Adaptive control system / ignition timing } \\
\text { control / control device for hybrid vehicle / } \\
\text { power output apparatus, mostly companies } \\
\text { from Japan and USA }\end{array}$ & $1987-1999-2005$ \\
\hline $\begin{array}{l}\text { Cluster } 10 \text { (Valve timing control } \\
\text { system, old) }\end{array}$ & $\begin{array}{l}\text { Valve timing control apparatus for engine, } \\
\text { mostly companies from Japan and USA }\end{array}$ & $1991-1995-1999$ \\
\hline $\begin{array}{l}\text { Cluster } 11 \text { (Engine control and hybrid } \\
\text { powertrain, new) }\end{array}$ & $\begin{array}{l}\text { Valve timing control / emission control device / } \\
\text { hybrid electric powertrain / hybrid } \\
\text { transmissions, most from USA (GM, Ford, } \\
\text { Chrysler) and Germany (Daimler, BMW) }\end{array}$ & $1999-2007-2011$ \\
\hline
\end{tabular}

Source: own elaboration.

Based on the two origins, technologies in this field develop in general into two directions separately, and finally into several final clusters. The two directions have a common final cluster (Cluster 6). The clusters based on the old origin (Cluster 2) are Cluster 5 (air intake system for ICE), Cluster 6 (engine control system), Cluster 7 (air and fuel supply system) and Cluster 8 (direct injection). All these clusters are related to vehicles consuming fossil fuels and turn out to be dead ends, since the latest final cluster among them, Cluster 7, only has patents filed before 2007. The clusters developed from the new origin (Cluster 3) include Cluster 4 (pressure control for ICE), Cluster 6 (engine control system), Cluster 9 (hybrid vehicle control system), Cluster 10 (valve timing control system) and Cluster 11 (engine control and hybrid powertrain). Of these clusters, two deal with traditional ICE (Cluster 4 and Cluster 6 ), while the others deal with hybrid vehicles or electric vehicles (Cluster 9, Cluster 10 and Cluster 11). The last cluster (state of the art) is Cluster 11, and all the others are dead ends in this development.

The finding that Cluster 11 is the most recent state of the technological development in this field is very inspiring, because this cluster mainly deals with engine control and electric powertrain for hybrid vehicles. It is evident that in this field the technological trend has gradually moved from improving energy efficiency in the traditional ICE toward more environmental friendly hybrid vehicles. Another surprising finding is that the largest country in this field, Japan, is not in Cluster 11 which is dominated by companies from the USA (GM, Ford and Chrysler) and Germany (Daimler and BMW). This is probably a result of a strategic technological alliance between these companies: BMW, GM, Daimler, and Chrysler formed an alliance called "Global Hybrid Cooperation" in 2005 to develop hybrid vehicles. 


\subsubsection{How countries relate to the technological profiles}

We now come to the final stage of the analysis, which consists in investigating the way in which countries' technological efforts (patents) relate to the technological trajectories that were identified in each of the three fields. To analyze this, we ask, for each patent in the dataset (largest component) whether a path exists from that patent to one of the patents on the network of top main paths, or vice versa, i.e., from a patent on the network of top main paths to any other patent. The first of these perspectives, i.e., from a patent to the network of top main paths, is called the forward perspective, while the latter (from the network of top main paths to a different patent) is called the backward perspective. The forward perspective asks to which part (e.g., Cluster) of the trajectories a patent (and its inventor country) contributes, while the backward perspective asks from which part (Cluster) it is ultimately derived.

We are particularly interested in the clusters that appear, in Figure 4.8, Figure 4.9 and Figure 4.10, as parts of the network that are present at the end of the period. These clusters embody the most recent technological trajectories in their field, and therefore are a good reference to assess how latecomer countries relate to the main technological trajectory in the fields under investigation. Thus we focus on (1) Clusters 13 and 8 (Branch A and B) for the power stations field, (2) on Clusters 8 and 10 for the ICT energy efficiency field, and (3) on Cluster 11 for the vehicle energy efficiency field. The two clusters in the power stations field and those in the ICT energy efficiency field are considered as separate cases.

Our main variable of interest for the research question whether latecomer countries tend to contribute to the main technological trajectories at a higher or lower rate than the incumbent countries in the field, is the forward linkages. It measures whether the patents of a country lead into the main technological trajectory. Because latecomer countries, by definition, have the majority of their patents concentrated towards the end of the period, we measure the forward linkages for the clusters represented the recent development of the fields as discussed above. For a particular technological trajectory (a certain cluster) and a particular country, the forward linkages variable measures the fraction of patents in the entire period that have a forward linkage to at least one patent on the technological trajectory.

We will use this variable as the dependent in a simple regression analysis. The purpose is not to estimate a theoretical model aimed at identifying causality, but instead simply to explore the nature of the correlations. The main independent variable of interest is an indicator for the timing of a country's technological effort in the field. For this purpose, we use the average year in Table 4.3, Table 4.5 and Table 4.7, from which we calculate the difference between 2013 and the average year (2013 is the final year found in the dataset). In other words, this variable is designed to reflect how much time a particular country has been in the technology field: the larger (smaller) this variable, 
the more (less) time the country has been in the field, which means that the country is an incumbent (a latecomer) country. If this variable has a positive (negative) sign in the regression, then latecomer countries tend to have a lower (higher) proportion of their total patents with forward linkages to the main technological trajectory.

We include two main control variables. The first is a measure for the vested interest that a country has in the main technological trajectories. We measure this as the backward linkages for all clusters in the relevant fields. For all three technology fields, this is the sum of all backward linkages for all clusters in the relevant main technological trajectories. This means that for the two separate clusters that are used as dependent variable in the power stations field and the ICT energy efficiency field, this variable is identical within a country. The backward linkages indicator is measured over the entire period, in order to reflect the entire history of a country in the field. The other control variable is the number of patents that a country has, in the entire period. Finally, we include intercept dummies for four of the five technology fields, using Cluster 10 in the ICT energy efficiency field as the reference group. We express all variables, except the four dummies, in natural logs. In the vehicle energy efficiency field, we remove three observations that represent the Soviet Union, the German Democratic Republic and Czechoslovakia. Also, since some countries' dependent variable is zero (before taking logs), finally the number of observations is 173 , including 57 countries.

In the regression, two estimation methods are employed. The first method (and also the basic method) is the ordinary least squares regression (OLS) in which the robust standard errors are used and clustered by country. The standard OLS method, however, can only estimate the average effect of the independent variable that might not be robust (or even misleading) if there are some influential outliers in the data. In the three technology field of interest, however, there is a very large discrepancy across countries within the same cluster. Accordingly, the second method, which is the quantile regression for cross-sectional data proposed by Koenker and Bassett (1978), is used. Although quantile regression is only robust to certain types of outliers (e.g., the observations that have outlying values for the corresponding error term), it allows us to look at the effects across the conditional distribution. Specially, the quantile regression technique is applied at three representative quantiles of the forward linkages, that is, 25\%, 50\% (median) and $75 \%$, conditional on the independent variable and other control variables. The median regression is the counterpart to the OLS model. 
Table 4.9 Regression results for forward linkages

\begin{tabular}{|c|c|c|c|c|}
\hline & OLS & $\begin{array}{l}\text { Quantile } \\
\text { regression 25\% }\end{array}$ & $\begin{array}{l}\text { Quantile } \\
\text { regression 50\% }\end{array}$ & $\begin{array}{l}\text { Quantile } \\
\text { regression 75\% }\end{array}$ \\
\hline Log of (2013 - year) & $\begin{array}{l}1.879 * * * \\
(0.218)\end{array}$ & $\begin{array}{l}2.321^{* * *} \\
(0.234)\end{array}$ & $\begin{array}{l}1.680 * * * \\
(0.214)\end{array}$ & $\begin{array}{l}1.781^{* * *} \\
(0.221)\end{array}$ \\
\hline $\begin{array}{l}\text { Log of the sum of backward } \\
\text { linkages over all the years }\end{array}$ & $\begin{array}{l}0.547 * * \\
(0.173)\end{array}$ & $\begin{array}{l}0.590 * * \\
(0.181)\end{array}$ & $\begin{array}{l}0.366^{*} \\
(0.165)\end{array}$ & $\begin{array}{l}0.588^{* * *} \\
(0.171)\end{array}$ \\
\hline $\begin{array}{l}\text { Log of number of patent families } \\
\text { for all the years }\end{array}$ & $\begin{array}{l}-0.0527 \\
(0.0343)\end{array}$ & $\begin{array}{l}0.0221 \\
(0.0306)\end{array}$ & $\begin{array}{l}-0.0584 * \\
(0.0279)\end{array}$ & $\begin{array}{l}-0.0763 * * \\
(0.0289)\end{array}$ \\
\hline \multicolumn{5}{|c|}{ Industry dummies: reference group: ICT_10 } \\
\hline ICT_8 & $\begin{array}{l}-0.360 * * * \\
(0.0667)\end{array}$ & $\begin{array}{l}-0.496 * * \\
(0.166)\end{array}$ & $\begin{array}{l}-0.350^{*} \\
(0.152)\end{array}$ & $\begin{array}{l}-0.278 \\
(0.157)\end{array}$ \\
\hline Power_13 & $\begin{array}{l}-0.600 * * * \\
(0.141)\end{array}$ & $\begin{array}{l}-0.693 * * * \\
(0.199)\end{array}$ & $\begin{array}{l}-0.485^{* *} \\
(0.181)\end{array}$ & $\begin{array}{l}-0.535^{* *} \\
(0.188)\end{array}$ \\
\hline Power_8 & $\begin{array}{l}-0.581 * * * \\
(0.148)\end{array}$ & $\begin{array}{l}-0.794 * * * \\
(0.196)\end{array}$ & $\begin{array}{l}-0.485^{* *} \\
(0.179)\end{array}$ & $\begin{array}{l}-0.535 * * \\
(0.185)\end{array}$ \\
\hline Vehicle_11 & $\begin{array}{l}-0.903 * * * \\
(0.147)\end{array}$ & $\begin{array}{l}-1.150 * * * \\
(0.197)\end{array}$ & $\begin{array}{l}-0.748 * * * \\
(0.18)\end{array}$ & $\begin{array}{l}-0.863 * * * \\
(0.186)\end{array}$ \\
\hline Constant & $\begin{array}{l}-6.277^{* * *} \\
(0.559)\end{array}$ & $\begin{array}{l}-7.869 * * * \\
(0.595)\end{array}$ & $\begin{array}{l}-5.659 * * * \\
(0.543)\end{array}$ & $\begin{array}{l}-5.714 * * * \\
(0.562)\end{array}$ \\
\hline $\mathrm{N}$ & 173 & 173 & 173 & 173 \\
\hline R-squared & 0.5095 & & & \\
\hline
\end{tabular}

Standard errors in parentheses; * $p<.05, * * p<.01, * * * p<.001$.

Table 4.9 presents the regression results. The first column shows the basic OLS result. The timing variable and backward linkages are significant. The number of patents is not. All four dummies are also significant. The timing variable has a positive sign, which indicates that latecomer countries tend to contribute less, proportionally, to the main technological trajectories in the field that we analyze. The number of backward linkages also has a positive sign, which adds to this effect: those countries with large vested interests in the dominant technological trajectories are also the ones with strongest forward linkages, i.e., they contribute in the strongest way to the further development of the trajectory. Though it has a negative sign, the insignificance of the number of patents suggests that economies of scale do not play a major role, beyond what is already related to the backward linkages. All the four cluster specific dummy variables for three technology fields are negative, which indicates that forward linkages are smaller in the power station field, vehicle energy efficiency field and Cluster 8 of the ICT energy efficiency field than in the Cluster 10 of the ICT energy efficiency field. Columns 2, 3 and 4 present the quantile regression results at $25 \%, 50 \%$ and $75 \%$ quantiles, respectively. They show that the OLS results are very robust, since the most important findings from OLS remain the same: (1) the coefficients of the timing variable and backward linkages are significant and positive, and (2) most coefficients (except one) of the dummies are significant and negative. In the 
$50 \%$ and $75 \%$ quantile regressions, the number of patents has a significant and negative coefficient, which implies that among countries with very high level of forward linkages, countries with larger economies of scale tend to have relatively lower forward linkages. This is mainly because the countries with extremely high forward linkages (outliers) in the dataset are countries with very small economies of scale, for example, small EU members such as Lithuania in the vehicle energy efficiency field and small island states such as Cayman Islands in the ICT energy efficiency field. These small countries in general have a very small number of patents, while they also have several important patents that are cited by the main technological trajectories, which leads to very high forward linkages. Overall, all four regressions provide consistent findings.

What do the results tell us about the technological choices of latecomer countries in the technological fields that we analyzed? Latecomer countries tend to contribute less (proportionate to their number of patents) to the main technological fields. This could be an indication of the technological choices made by the firms in these countries. These firms may have assessed that competition is too strong in the dominant technological trajectory, and hence that it is better to search for new opportunities in a different direction. But it may also be a reflection of the technological capabilities of the firms in these countries. Citations are also often used as a measure of the quality of a patent (K. Lee, 2013). Because only citations can link a patent (forward) to a technological trajectory, receiving few citations will tend to decrease the forward citations. Thus, our regressions have little to say about the causal mechanisms behind the observed tendency of a positive relationship between forward linkages and the timing variable.

\subsection{CONCLUSIONS AND DISCUSSION}

This paper has looked at the role of technological trajectories in the dynamics of technological catch-up. It has focused on a small number of countries that contribute significantly, in terms of the number of patents, to technological developments in three fields related to energy efficiency: energy efficiency in power stations, energy efficiency related to ICT in buildings and energy efficiency technologies related to vehicles. We identified a number of main technological trajectories in each of these fields, and were able to specify which specific technological issues were dealt with in these trajectories, as well as which firms were involved. We were also able to put an average date (year) on the patents of the countries in the fields, thus enabling us to measure the extent to which a country is a latecomer. Our database includes China, South Korea, India, Taiwan and Singapore as countries that are traditionally seen as catching-up economies in the postwar period, e.g., (Fagerberg \& Godinho, 2004).

Our findings indicate that latecomer countries tend to contribute to the main technological trajectory in the fields under investigation in a less strong way than incumbent 
countries. By this we mean that the timing variable of a particular country is correlated positively, in both OLS and quantile regression framework, to the forward linkages of that country's patent. The forward linkages measure which fraction of a country's patents is linked by forward citations to the recent or the promising clusters of the main technological trajectory in the field. This is lower for latecomer countries. This tendency is reinforced by the tendency that countries with vested interests in the main technological trajectory also tend to have higher forward linkages. The vested interests are measured by backward linkages, which is a measure for which fraction of a country's patents is linked to the main technological trajectory by backward citations.

Our results do not tell us anything about the causal mechanisms that can explain the observed correlations. Our research question is explorative, and first of all asks whether the notion of technological trajectories is relevant for the study of technological capabilities in latecomer countries. This question is answered affirmatively: we are able to identify technological trajectories that make sense from a technological point of view, and there is a systematic tendency of latecomer countries to be related to these trajectories in a different way than incumbent players. Thus, the concept of technological trajectories seems a useful one for studying technological choices in latecomer countries, as shown in K. Lee (2013). The importance measure for patents is based on citations. However, the database we use does not contain the economic value of patents. Latecomer countries may a different view of the importance of patent. So it is difficult to identify whether it is a missed opportunity that the latecomer countries contribute less, or it is a rational market choice. Additionally, though this paper is only an application to energy efficiency technologies, the analysis can be applied to any technological field by following the same concept and methodology, since the big data on patents are already available. This would be greatly useful for policymakers and business investors. Once policymakers or investors plan to develop a specific technological field where the country has a comparative advantage, the analysis based on this paper can provide a reasonable and clear guidance for decision-making about which sub-technological fields are promising among lots of complex technological trends.

For this to become a useful research area, we need more research, in at least two forms. First, we need more cases, for a wide variety of technological fields. The methods explored here can be applied, and possibly refined, to different fields in a more or less direct fashion. Second, we also need more research, empirical and theoretical, on how firms in latecomer countries deal with technological trajectories. For this question, patent data alone are probably not enough. Patent data, including citations, can tell us many things about the structure of a technological field, but very little about the motivations of firms to search in particular technological directions. In order to understand how firms in latecomer countries or in incumbent countries, contribute and relate to technological trajectories, this is the key process that we need to analyze. 
Chapter 4

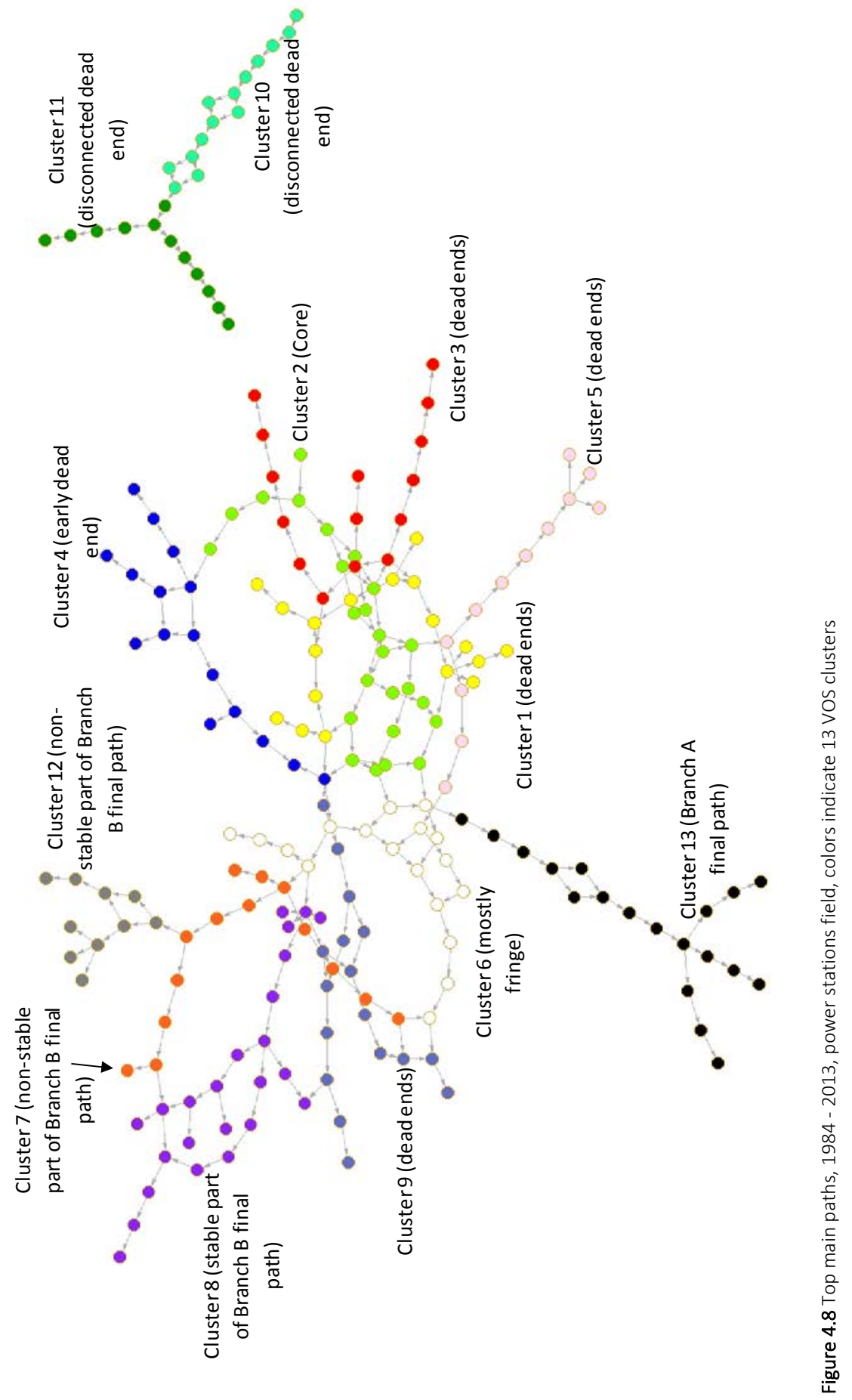


The Role of Technological Trajectories in Catching-up-based Development
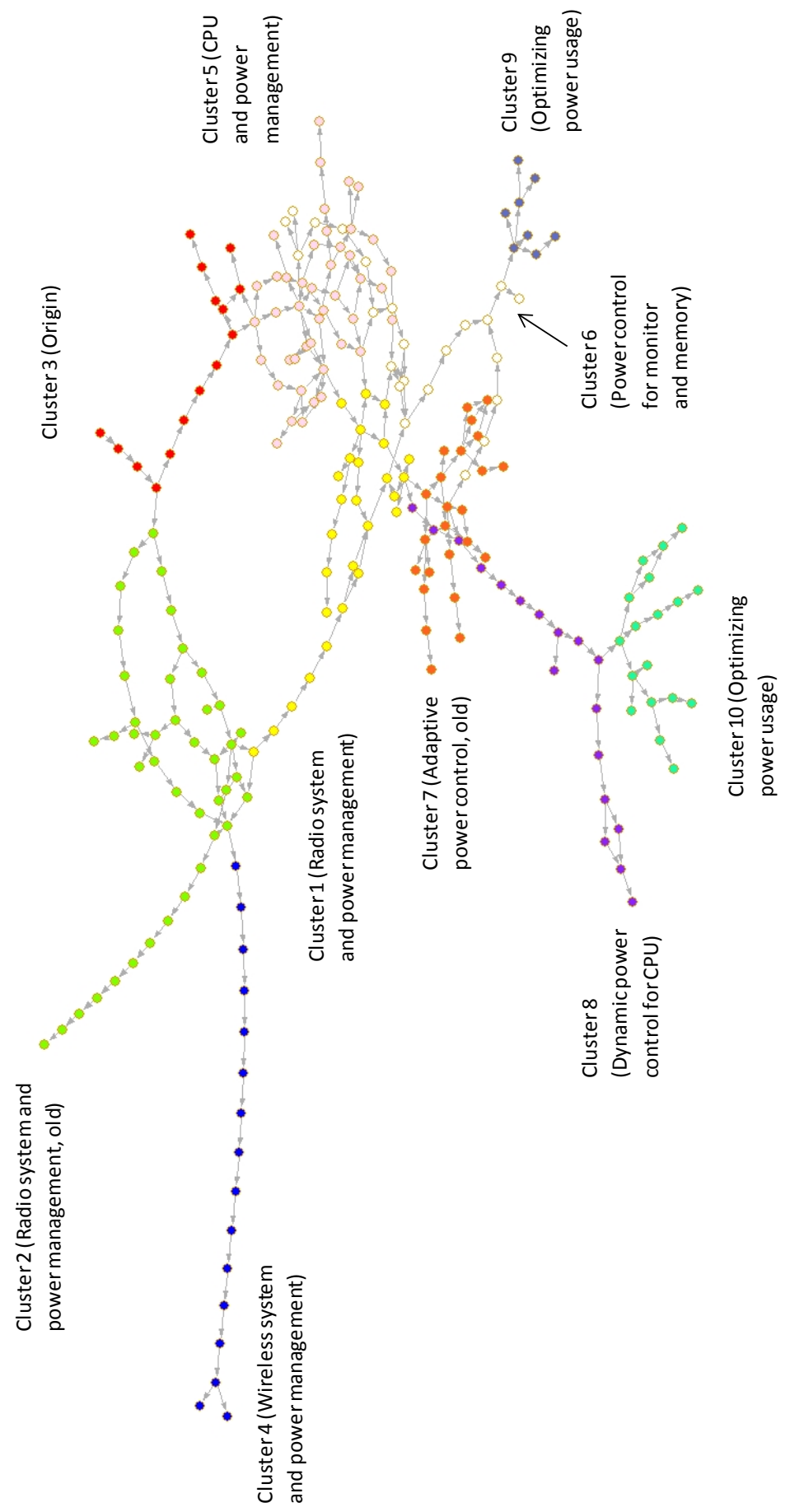
Chapter 4

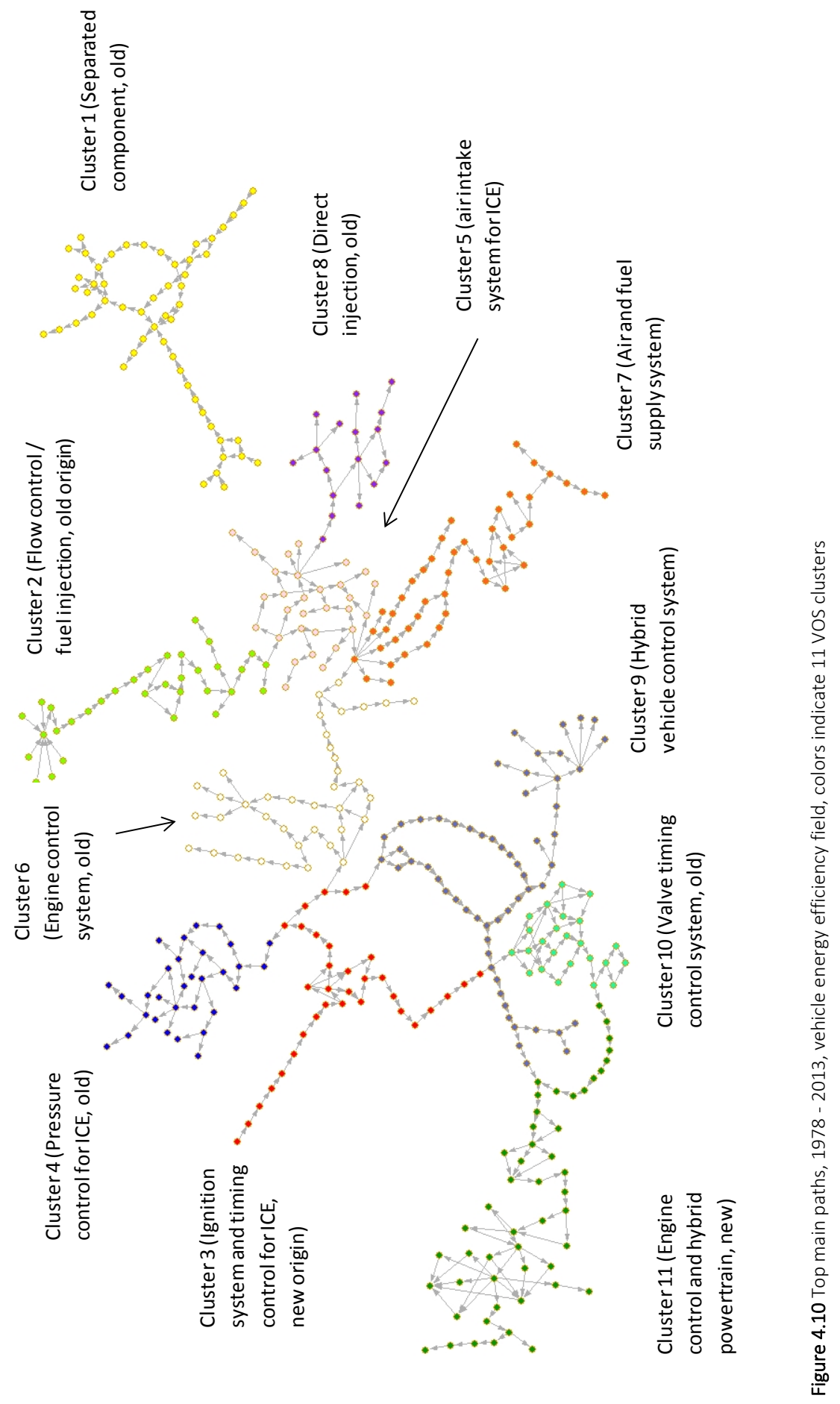


Chapter

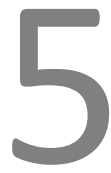

Conclusions 
In this thesis, we choose energy efficiency, one of the most important themes in sustainable development and analyze the complex dynamics of energy efficiency across sectors, regions and economies. In the study of energy efficiency, many policy-relevant areas that require numerous research and financial inputs and careful empirical analysis are involved. Due to data availability and the feasibility of this study to be effectively conducted, as an early step, we narrow down our research to the following aspects: the energy consumption and energy efficiency at sectoral and economy levels, the energy efficiency of energy-using durable products as reflected by vehicles and the technologies related to energy efficiency as measured by patents. To do so, we develop several methodological frameworks on the basis of well-documented literature on input-output analysis, aggregate productivity, development economics and complex networks to explore the evolution of energy efficiency. We then precisely derive the influential factors that affect the growth of energy efficiency, discover the crucial empirical patterns at hand and investigate the long run trends. Moreover, the optimization technique for complex networks enables us to identify the most important patents and their citation relations for energy efficiency technologies, and more importantly, allows us to rigorously assess countries' profiles in the technological fields under study: how much does a country contribute to the technological development of energy efficiency, and how much effort does a country make to develop energy efficiency technologies. In this conclusive chapter, we summarize the contributions and main findings of this thesis and discuss its policy implications and further research. 


\subsection{SUMMARY, CONTRIBUTIONS AND MAIN FINDINGS}

In the introduction (Chapter 1 ), we show the potential importance of energy efficiency issues by using several simple but useful empirical investigations, present the motivation and research questions of this thesis, and briefly survey the literature on (1) the relationship between economic development and environmental sustainability, (2) the role of technology, energy efficiency gap, potential causes and relevant policy options, and (3) the national and global strategies, initiatives, programs, funds, facilities, and mechanisms that have a special focus on energy efficiency. With energy efficiency becoming one of the major themes of sustainable development, national governments, civil societies and international organizations are making an increasing policy effort to promote energy efficiency. We argue that the policies or strategies with a focus on energy efficiency should be properly designed and based on solid empirical evidence because market failures as well as behavioral failures may lead to slow improvement of energy efficiency. The first and also the most fundamental step, we believe, is to acquire a deep and comprehensive understanding of the evolution of energy efficiency and technology across sectors, regions and economies. In particular, we highlight the need for constructing aggregate measures that are based on detailed and micro-level data.

This thesis provides a series of contributions to the study of energy efficiency. We systematically design a set of statistical and econometric methods to (1) assess the factors that cause dynamics of aggregate energy consumption and aggregate energy efficiency on both demand side and supply side across various sectors and economies (Chapter 2), (2) test the convergence trend of energy efficiency and the relationship between energy efficiency and economic development at economy level (Chapter 2), (3) describe the regional aggregate energy efficiency of road vehicles and the determinants of its growth (Chapter 3), (4) investigate the mobility of aggregate vehicle energy efficiency (Chapter 3 ), and (5) explore the geographical, social and economic distribution patterns of aggregate vehicle energy efficiency (Chapter 3). Furthermore, in Chapter 4 we develop a collection of patent citation network methods to quantify the technological trajectories, that is, the most important patents and their citation relations for energy efficiency technologies (also called top main paths in this thesis), identify incumbent countries and latecomer countries in relevant technological fields related to energy efficiency and measure countries' contributions and efforts in those technological fields of interest. The focus and level of analysis in this thesis are diverse and vary from chapter to chapter. Consequently, in developing the results, the data at our disposal in this thesis are taken from different sources: trade data between sectors and economies (Chapter 2), microdata at vehicle level (Chapter 3) and patent data (Chapter 4). Also, this thesis benefits a lot from recent development of data collection, storage and processing. All the datasets used in this thesis are large datasets. The vehicle and patent data provide rich 
information of the entire population, which makes this thesis depart from previous studies that are based on data with limited sample sizes: these data not only provide much more detailed information, but also enable us to conduct research that is only feasible by using population information. The main findings of each chapter are the following.

To fully understand the salient trends in the interconnections between energy and economic development, we begin our analysis in Chapter 2 by employing input-output analysis methods (Miller \& Blair, 1985) and revising the input-output models of structural decomposition by Dietzenbacher et al. (2000) that decompose labor productivity. The analysis in this chapter is backward-looking by nature, and the main purpose of such an analysis is to identify the trends and patterns that are necessary for policymakers to focus on, rather than to present a better prediction or forecast of future trends. The revised models are explained in Chapter 2 and provide more rigorous measures of the relative changes of aggregate energy consumption and aggregate energy efficiency. Unlike prior studies and traditional methods that employ index decomposition techniques directly using aggregate national accounts data, this chapter constructs the aggregate measures of energy consumption and energy efficiency by looking into detailed transaction flows across various sectors and economies. More importantly, this chapter explicitly distinguishes between two crucial perspectives about where the energy flows are attributed: (1) the energy use that is attributed to the processes where production actually takes place (i.e., goods and services), or direct household consumption (referred to supply side energy consumption / energy efficiency in this thesis), and (2) the energy use that is embodied in consumption: the goods and services consumed in either intermediate production or in direct consumption (defined as demand side energy consumption / energy efficiency in this thesis). Our simple empirical evidence for selected major economies in Chapter 2 clearly shows that the energy consumption based on these two perspectives significantly differs. Without the detailed information of trade between sectors and economies, traditional index decomposition techniques in energy economics are unable to analyze the demand side energy footprints and often neglect the trade taking place in intermediate production, while Chapter 2 contributes to filling this research gap. The existing similar structural decomposition studies of energy or emissions mostly focus on specific countries or sectors. This chapter develops a generalized methodological framework and applies it to an extensive range of major economies and sectors. Another related methodological contribution of this chapter is that we seriously take into account the measurement issue of monetary data, which is rarely found in prior studies. Since energy intensity, energy use (in TJ) per unit of gross outputs (in US dollars), is used as the indicator for energy efficiency, the change in the value of monetary unit as time progresses may lead to misleading results. We accordingly design a chain mechanism for deflation by jointly using the trade data in both current prices and previous years' prices. Also, since the structural decomposition equa- 
tion is not unique (Dietzenbacher \& Los, 1998), we derive two version of decomposition equations and obtain final results by using the average log points of the two versions.

The data we use in Chapter 2 are the newly developed World Input-Output Database (WIOD), including the World Input-Output Tables (WIOT) in both current prices and previous years' prices and the Environmental Accounts. We extend the structural decomposition of labor productivity by Dietzenbacher et al. (2000) into the structural decomposition of energy consumption and energy intensity. At economy level, we break the relative changes in aggregate energy consumption and aggregate energy intensity between 1995 and 2009 into six influencing factors: energy intensity effect, inter-industry structure effect, inter-industry trade effect, structural change effect, total final demand effect and household expenditure effect. We apply the structural decompositions to 40 major economies in the world and two groups of economies (the EU and the countries joining the EU in the 2004 enlargement) on both demand side and supply side. Also, we apply the analysis to 35 sectors. Additionally, we are particularly interested in the trends of economy level energy intensity. Once we have obtained the economy level energy intensity, we examine the convergence trend based on the econometric techniques in development economics (Barro, 1991; Barro \& SalaiMartin, 1991, 1992) and use Multilevel Mixed-Effect model (MME) to investigate the relationship between economic development and energy efficiency based on Grossman and Krueger (1995)'s specification. There are several crucial findings on both demand side and supply side. (1) Compensation effect in aggregate energy consumption change, which refers to the empirical pattern that the energy consumption raised by economic development (measured by changing total final demand) was roughly (or partly) offset by energy intensity effect. (2) Trade structure effect in intermediate inputs was relatively small. (3) Some developing economies (e.g., China and India) have larger changes in energy consumption and energy intensity. (4) Lowering energy intensity within sectors is the overwhelming factor for decline in aggregate energy intensity in most economies. (5) The gaps of energy intensity between economies tend to narrow down over time. (6) Rather than an inverted- $U$ shaped relationship, the relationship between energy intensity and GDP per capita is strictly decreasing. At sectoral level, the compensation effect in energy consumption change, small trade effect in intermediate inputs and the key role of intensity effect still hold.

In Chapter 3, the analysis focuses on the energy efficiency of road vehicles. We are interested in vehicles because there exist an extremely large number of vehicles in the market, and as a typical energy-using durable manufacturing product, most vehicles still consume fossil fuels. The vehicle market is a typical place where the energy efficiency gap may occur. However, probably due to data constraint, there lacks a suitable indicator for aggregate vehicle energy efficiency, e.g., at regional level, and little is known about how the vehicle energy efficiency of a region changes, while such information is of great importance for designing proper policy or strategies. This chapter accordingly 
contributes to filling this gap by providing a better understanding of the nature and timing of vehicle energy efficiency dynamics, and how this is affected by the life cycle of vehicles, such as the diffusion of new vehicles and the substitution of the old ones. Similar to Chapter 2, this chapter does not aim to predict the vehicle energy efficiency or the technological development of any specific vehicle, but tries to comprehensively describe the aggregate vehicle energy efficiency. To do so, we propose an empirical methodological framework to measure aggregate vehicle energy efficiency and its growth, on the basis of well-established literature on aggregate productivity using firmlevel microdata (Aw et al., 2001; Baily et al., 1996, 2001; Baily et al., 1992; Bartelsman \& Dhrymes, 1998; Bartelsman \& Doms, 2000; Bartelsman \& Wolf, 2014; Foster et al., 1998, 2006; Griliches \& Regev, 1995; Olley \& Pakes, 1996). Note that the approaches used in this chapter are not limited to vehicles, but can be applied to the study of energy efficiency dynamics of other energy-using products. The main data we use in Chapter 3 are taken from the Massachusetts Vehicle Census over the period 2008q1-2011q4, a vehicle-level quarterly panel dataset for almost all the vehicles registered in the state of Massachusetts, USA. This dataset provides extremely rich information of vehicle characteristics such as retail price, make, model year, type (passenger or commercial), fuel, location, theoretical and adjusted Miles per Gallon (MPG), records in the odometer and so on. The aggregate indicator we use in Chapter 3 is an average of all the vehicles' energy efficiency weighted by their shares of miles per day. The reason is that in designing the indicator of aggregate vehicle energy efficiency, we notice the difference between actual energy efficiency and technological energy efficiency: the actual vehicle energy efficiency does not only depend on the technological energy efficiency (measured as adjusted MPG in this chapter), but also is closely related to how frequently the vehicle is used. In other words, our finding implies that if energy efficient vehicles are used less frequently, the aggregate vehicle energy efficiency may still be low even if there are many energy efficient vehicles in the market. The availability of odometer information allows us to measure the usage of every individual vehicle (miles the vehicle travels on average every day). Together with the MPG information for the entire vehicle population, we are able to employ a simple but useful statistical approach to measure aggregate vehicle energy efficiency, without having any additional assumptions, representative agents, sampling errors or the issue of heterogeneity in the models. These are great advantages compared to prior studies using sample data. More importantly, the changes in the vehicle population are very complex. The entry of vehicles may be due to migration across regions or the introduction of new vehicle models. The energy efficiency of individual vehicles decreases over time because of the ageing of vehicle. Old vehicles may be out of service or leave the market through migration or second-hand market. Fortunately, the dataset allows us to include all the aspects above in a coherent methodological framework by tracking the location of every individual vehicle over time. 
We apply the indicator of aggregate vehicle energy efficiency to the whole state as well as to every municipality in Massachusetts, and then conduct two types of decomposition analyses: (1) decomposing the time series of aggregate vehicle energy efficiency into an unweighted average and a covariance term, using the approach proposed by Olley and Pakes (1996), and (2) breaking down the growth of aggregate vehicle energy efficiency into within effect (changes in individual vehicle's energy efficiency), between effect (changes in the usage of vehicle), entry effect due to entering vehicles and exit effect due to exiting vehicles. Similarly, we are particularly interested in the long run trends and the distributional patterns of aggregate vehicle energy efficiency. We examine the convergence trends of aggregate vehicle energy efficiency at municipality level by employing a variety of econometric estimations (e.g., OLS, quantile regression, bootstrapping quantile regression and nonparametric regression) in the classical convergence analysis framework (Barro, 1991; Barro \& SalaiMartin, 1991, 1992). In addition to that, we adopt the distribution approach (Quah, 1993a, 1993b, 1996, 1997) to calculate one-period transition matrix of municipalities' aggregate vehicle energy efficiency and estimate the stable distribution in the long run (Ergodic distribution). Moreover, we use a set of methods (clustering analysis, random-effects negative binomial regression and probit regression) to investigate the distribution of vehicles over municipalities and the socio-economic factors associated with vehicles' staying or exiting decision. We obtain several crucial findings. (1) A positive covariance term is found in every quarter in the time series decomposition, meaning that higher (lower) usage is found for higher (lower) energy efficiency vehicles. (2) The growth decomposition of aggregate vehicle energy efficiency shows that the most important factor positively contributing to the growth is the net entry effect, which is the reallocation due to the entering of high energy efficiency vehicles and the exiting of low energy efficiency vehicles. The results also show that the energy efficiency gain due to changes in consumers' behavior (between effect) is much less than the energy efficiency loss due to vehicle's ageing (within effect). (3) The aggregate vehicle energy efficiency of municipalities tends to converge to the state level and this convergence trend is very robust. (4) Vehicles are more likely to be distributed into municipalities that are richer, more populated or have lower unemployment rates. The vehicle is more likely to stay in the state if it is initially located in the municipalities that are richer, less populated and have higher unemployment rates.

The analytical focus of Chapter 4 lies on the technologies associated with energy efficiency, because technology plays a key role in the development of energy efficiency. The first challenge we are facing is the identification of energy efficiency technologies: what are they exactly? We solve this problem by looking into the OECD's Search Strategies for the Identification of Selected Environment-Related Technologies, that is, the OECD ENV-TECH list (Haščič \& Migotto, 2015). This list provides a wide range of technologies related to the environment. We are particularly interested in energy efficiency. Consequently, we choose three technological fields from the entire ENV-TECH list: en- 
ergy generation, road vehicles and ICT in buildings. The next challenging issue is how to measure technology and technological development. We use patent statistics to measure technology ${ }^{70}$ because the patent data can provide much more detailed information compared to other approaches. Also, we adopt the patent citation based concept of technological trajectories (Dosi, 1982) to measure technological development: they are the main focal points along which technological innovation develops. This chapter is initially motivated by the recent study of catching-up using patent data (K. Lee, 2013). But in K. Lee (2013)' study, the data source is the NBER patent citation dataset which is mainly based on the US patents and not up-to-date. To overcome this limitation and in order to have a comprehensive picture of the technological development, our solution is quite straightforward: just use all the documented patents in human history. Such big data on patents are available in the Worldwide Patent Statistical Database (PATSTAT) developed by the European Patent Office (EPO). This database covers patent bibliographical data and up-to-date patent citation based on publications and applications for all the leading economies in the world since the beginning of the patent system. As constantly found in prior studies using patents, there are serious problems of selfcitation and double counting in the patent dataset. In order to solve these problems, we link all the patent publications and patent applications to their corresponding patent families and conduct our analysis at the level of patent family, by using the unique EPO DOCDB patent IDs. To our knowledge, using patent family may be the best way of analyzing patent data.

In developing the results, we successfully construct three patent citation datasets for the technological fields of interest using the Cooperative Patent Classification (CPC) codes in the OECD ENV-TECH list, in which the citation networks are acyclic and directed. ${ }^{71}$ Although we use a narrow definition of energy efficiency technologies, there is still a very large number of patent families in the citation datasets. We think that the distinction between radical and incremental innovation is crucial (Fagerberg \& Verspagen, 2002), and the question is how to identify the most important patents and the corresponding citations, that is, the technological trajectories. We employ an optimization technique for complex networks following previous studies (J. S. Liu \& Lu, 2012; J. S. Liu et al., 2013; Verspagen, 2007). To do so, we calculate the Search Path Count (SPC) for each citation as the measure of importance. ${ }^{72}$ The target function therefore is a sum of SPC weights of the path from any source to any reachable sink. The paths with the maximum sum of SPC weights are exactly the technological trajectories we are looking for. We apply this optimization technique to the citation networks for different years and successfully obtain the temporal technological trajectories. Fur-

\footnotetext{
70 The patent statistics are output approach of measuring technology. The other two approaches are R\&D (inputs) and higher productivity (the effect of technology) (Keller, 2004).

${ }^{71}$ The reason is that the new patents can cite old ones, but not vice versa.

72 The SPC measures how often one visits a citation if all the possible paths in the networks are travelled. The larger the SPC weight, the more important the citation.
} 
thermore, we develop a measure to classify incumbent and latecomer counties in the technological fields by using the average filing years of patent families. Once the technological trajectories have been quantified, we are able to identify the recent development of the technologies and precisely measure how much a country contributes to the technological development (forward linkages, measured by the patents cited by the technological trajectories), and how much a country is interested in / makes an effort to the technological development (backward linkages, measured by the patents citing the technological trajectories). Using OLS and quantile regression, we find that (1) latecomer countries tend to contribute less to the main technological trajectories in the fields under investigation, and (2) those countries with large vested interests in the dominant technological trajectories are also the ones that contribute more.

\subsection{POLICY IMPLICATIONS AND FURTHER RESEARCH}

With regard to policy implications, the theories, methods and findings of this thesis offer some profound insights. First, this thesis has demonstrated that with the development of large datasets the policy-oriented empirical research can overcome some of the limitations shown by prior studies with sample information, and provide more precise results concerning crucial policy themes. By looking into the detailed processes of trade in production and consumption, life cycle of products and technological development, this thesis contributes to a better understanding of the dynamics of energy efficiency in various aspects and manages to extract useful patterns hidden in the dynamics, which is of great importance for decision-makers or leaders in civil societies, firms, governments, international organizations who want to design strategies or policies that better fit the evolution of energy efficiency. Second, as shown in Chapter 1, a very large population is living in developing countries, and overall the world still heavily replies on fossil fuels. This suggests a fundamental dilemma faced by policymakers. The development mission promises to provide access to better material well-being to the large population who has been denied decent living standard. If the global heavy dependency on fossil fuels would persist, however, the development targets would be greatly challenged. This thesis presents a possible solution to sustainable development (Chapter 2): by reducing energy intensity through technological change (especially the energy intensity within sectors). The policies related to energy efficiency should be properly designed to fit the industry-specific characteristics as industries perform differently in terms of energy consumption and energy efficiency. The policies in favor of technological change toward higher efficiency in medium/low-tech manufacturing would be preferable. Third, this thesis links aggregate dynamics of energy efficiency to the technological characteristics and collective behaviors of millions of micro-agents (Chapter 3 ). It provides profound insights for policymakers that technology, product life cycle as well as consumers' behaviors matter, when assessing the energy efficiency performance of 
energy-using durable products. The aggregate trends are jointly shaped by the three aspects. A smartly-designed policy package that aims to improve the energy efficiency of energy-using durables should not neglect any of these aspects if we want to achieve the desirable policy outcomes. For example, the policy should include a range of instruments that can stimulate the innovation and diffusion of new energy efficient products (e.g., hybrid and electric vehicles), the more efficient substitution of products with low energy efficiency and the more effective usage of energy efficient products. The policy can be implemented through providing financial incentives, information disclosure and by stimulating as much public involvement as possible. Additionally, policymakers should be alert to the fact that benefits due to changes in consumers' behavior of vehicle usage cannot keep pace with the big energy efficiency loss caused by the ageing of vehicles. The public finance policy scenario (e.g., tax and subsidy) should stimulate the update of vehicle population and match specific regional socio-economic characteristics. Fourth, this thesis extends its concern about micro-agents to technological development. Under the context of globalization, knowledge, capital and labor move within and across regions and countries. This leads to an incredible expansion of technology and the cooperation of innovation (in terms of the number of global patents and the complexity of patent citations). Innovation efforts made by numerous microagents (e.g., individuals, research institutes, universities and firms), coupled with uncertainty, shape technological development. For policymakers, however, the difficulty of designing proper industrial policies is also significantly increased. For instance, policymakers can identify priority industries based on comparative advantages. In developing these priority industries, technology matters. The related problem is how to identify the most important technologies (or inventions) and the recent development of the technology in the priority industries given the complexity of patents nowadays. The technological trajectory analysis in Chapter 4 provides a reasonable and clear guidance about which sub-technological fields are promising among lots of complex technological trends that both policymakers and entrepreneurs should focus on, even though this thesis does not discuss the exact innovation / imitation strategies. A proper policy package should target the promising sub-technological fields in the priority industries by providing financial incentives and information. Fifth, policies with a focus on energy efficiency should be integrated: they should target not only the aggregate energy efficiency at the sectoral, regional and economy levels, but also the consumer market and innovation. It may not be necessary to have a fully specialized energy efficiency policy that is independent from public finance, environmental or innovation policies. But energy efficiency, as a key policy theme, should be clearly included and addressed in the design and implementation of public finance, environmental and innovation policies. These policies should be interrelated, support the implementation of each other and avoid conflicts of interest. Additionally, policymakers should be aware that the policy outcomes may be of little effect or be undesirable because of improper design, market failure and behavioral failure, as shown in Chapter 1 . The policies that are effective 
currently may not be useful as time progresses. Continued support and efforts by both political authorities and civil societies are strongly needed to maintain and update the policies related to energy efficiency.

This thesis only provides empirical analyses for several aspects in the study of energy efficiency. Further studies, either empirical or theoretical, are strongly needed, such as, for example, the study of some more energy-using durable products other than vehicles, and the study of any other technological fields. Furthermore, rigorous studies of many aspects in sustainable development other than energy efficiency can benefit from this work as well. For further research, specifically, the methods used in this thesis are very useful. In fact, the input-output approaches used in Chapter 2 can be applied to the study of other important aspects related to sustainable development, such as emissions, water and land use. The methodological framework presented in Chapter 3 can be used for analyzing other product cycles. The patent citation network analysis and optimization technique in Chapter 4 can also be extended to any other technological field since the big data on patents are already available. However, the econometric analyses used in this thesis, such as, for example, the relationship between economic development and aggregate energy intensity (Chapter 2), the socio-economic factors associated with vehicles' distribution over locations and the staying / exiting decision (Chapter 3) and the relationships between forward linkages, timing and backward linkages (Chapter 4), do not tell us anything about causality. In addition, as shown in Chapter 1 , there are currently many policies, strategies, initiatives, programs, funds, facilities and mechanisms that aim to improve energy efficiency and require a very large number of resources for implementation. Accordingly, further research that can precisely evaluate the actual impacts of these policies or identify causal relationships, i.e., using randomized field experiments and quasi-experimental methods, will be of great importance. 

Valorisation 
In accordance with article 23.5 of the Regulation Governing the Attainment of Doctoral Degrees at Maastricht University, this addendum discusses the valorization opportunities presented by this Ph.D. thesis.

Sustainable development is a process that involves a wide range of dimensions and tailored strategies or policies are strongly needed, but there is a lack of data-driven and micro-founded studies of those detailed processes hidden in the aggregate dynamics. The focus of this thesis is on energy efficiency, one of the most important themes in sustainable development. The fundamental research questions in this dissertation are: (1) how do the aggregate energy consumption, aggregate energy efficiency and technologies related to energy efficiency evolve over time? (2) What are the driven factors that affect the growth of aggregate energy consumption and aggregate energy efficiency across sectors, regions and economies? How do countries perform in the technological fields related to energy efficiency? To explore the complex dynamics of energy efficiency across sectors, regions and economies, we developed several methodological frameworks based on well-documented economic literature from various fields such as input-output analysis, aggregate productivity, development economics and complex networks.

Unlike most prior studies on energy issues that use the aggregate data directly, in this work, we presented a series of statistical methods that rigorously construct the aggregate variable of interest using large datasets on (1) transactions between various sectors and economies across the world, (2) technological characteristics and behaviors of micro-agents (individual vehicles and their owners), and (3) patent related to energy efficiency in three fields (power station, ICT in buildings and vehicles). We showed how aggregate energy efficiency (sectoral, regional and economy levels) evolves: we precisely derived the influential factors affecting the growth of energy efficiency, discovered the crucial empirical patterns and investigated the long run trends. Also, we employed optimization technique for complex networks to identify the most important patents and their citation relations for energy efficiency technologies and assess countries' profiles in the technological fields under study.

The theories, methods and findings of this thesis offer some profound insights. First, this thesis has shown that the policy-oriented empirical research can greatly benefit from the development of large datasets and overcome some limitations of prior studies using sample data only and provide more precise results concerning crucial policy themes. By looking into the detailed processes of trade in production and consumption, life cycle of vehicles and technological development, this thesis provides a better understanding of the dynamics of energy efficiency at various levels, which is of great importance for policymakers and experts in relevant fields. Second, the strategies or policies concerning energy efficiency should better fit the evolution of energy efficiency. For instance, since industries perform differently in terms of energy consumption and 
energy efficiency, the industrial policies in favor of technological change towards higher efficiency in medium/low-tech manufacturing would be preferable (Chapter 2). Third, this thesis links dynamics of aggregate energy efficiency to the technological characteristics of millions of individual vehicles and the collective behaviors of their owners (e.g., usage of vehicles, purchase of vehicles and migration, etc.). A smartly-designed policy package should take into account all of these aspects, for example, providing a range of policy instruments to stimulate the innovation and diffusion of new energy efficient products, the more efficient substitution of products with low energy efficiency and more effective usage of energy efficient products. Also, the policy scenario should match specific regional socio-economic characteristics. Fourth, the technological trajectory analysis in Chapter 4 provides a reasonable and clear guidance about which subtechnological fields are promising among lots of complex technological trends that both policymakers and entrepreneurs should focus on. In fact, globalization leads to an incredible expansion of technology and the cooperation of innovation, coupled with uncertainty, which significantly increased the difficulty of designing proper policies and strategies. The methods developed in this thesis are relevant beyond the study of energy efficiency. They can be applied to any other technological fields and commercially viable for business strategy and intelligence.

The target audiences of this dissertation include students, scholars, policymakers and experts in the fields of energy studies or studies related to sustainable development, business strategists, entrepreneurs, investors, innovators as well as everyone who is interested. The methods and findings of this dissertation have been disseminated with a wide range of audiences within and beyond academia during the course of this Ph.D. dissertation. Chapters 2, 3 and 4 have been presented to academic audiences and policy experts in various workshops and international conferences. Also, these three chapters have been included in the UNIDO Inclusive and Sustainable Industrial Development Working Paper Series. In particular, Chapter 2 has been a background paper for the UNIDO Industrial Development Report 2016. 



\section{About the Author}

Sheng Zhong was born in 1987 in Guangdong, China. Funded by the United Nations Industrial Development Organization (UNIDO), he joined the United Nations University Maastricht Economic and Social Research Institute on Innovation and Technology (UNUMERIT) and Maastricht University in the Netherlands as a Ph.D. Fellow in 2012. His research interests include the dynamics of energy efficiency, technological change, sustainable development and quantitative methods. Prior to that, Sheng completed an MA in Development Economics at the University of Warsaw in Poland, funded by the European Commission Erasmus Mundus Programme. Before that, Sheng earned a Bachelor's Degree in Laws from Fudan University, China.

Sheng has extensive academic and professional working experience. During his Ph.D., he tutored in the bachelor's program at the Maastricht University School of Business and Economics and in the master's program at Maastricht Graduate School of Governance. He served as a supervisor for several bachelor theses at the Faculty of Arts and Social Sciences (FASOS) and University College Maastricht (UCM), Maastricht University. Also, Sheng worked as an intern and a consultant at UNIDO on various projects, including the UNIDO Industrial Development Report 2016 and UNIDO Inclusive and Sustainable Industrial Development Working Paper Series. 



\section{References}

Acemoglu, D. (2002). Directed Technical Change. Review of Economic Studies, 69(4), 781-809. doi: 10.1111/1467-937x.00226

Acemoglu, D., Aghion, P., Bursztyn, L., \& Hemous, D. (2012). The Environment and Directed Technical Change. American Economic Review, 102(1), 131-166. doi: 10.1257/aer.102.1.131

Acemoglu, D., Johnson, S., \& Robinson, J. A. (2001). The Colonial Origins of Comparative Development: An Empirical Investigation. American Economic Review, 91(5), 1369-1401. doi: 10.1257/aer.91.5.1369

Adams, J., \& Griliches, Z. (1996). Measuring Science: An Exploration. Proceedings of the National Academy of Sciences of the United States of America, 93(23), 12664-12670. doi: 10.1073/pnas.93.23.12664

Aghion, P., \& Howitt, P. (1992). A Model of Growth Through Creative Destruction. Econometrica, 60(2), 323351. doi: $10.2307 / 2951599$

Allcott, H. (2011). Social Norms and Energy Conservation. Journal of Public Economics, 95(9-10), 1082-1095. doi: 10.1016/j.jpubeco.2011.03.003

Allcott, H., \& Greenstone, M. (2012). Is There an Energy Efficiency Gap? Journal of Economic Perspectives, 26(1), 3-28. doi: 10.1257/jep.26.1.3

Allcott, H., \& Mullainathan, S. (2010). Behavior and Energy Policy. Science, 327(5970), 1204-1205. doi: 10.1126/science. 1180775

Andreoni, J., \& Levinson, A. (2001). The Simple Analytics of the Environmental Kuznets Curve. Journal of Public Economics, 80(2), 269-286. doi: 10.1016/s0047-2727(00)00110-9

Andrew, R. M., \& Peters, G. P. (2013). A Multi-region Input-output Table Based on the Global Trade Analysis Project Database (GTAP-MRIO). Economic Systems Research, 25(1), 99-121. doi: 10.1080/09535314. 2012.761953

Ang, B. W. (2005). The LMDI Approach to Decomposition Analysis: A Practical Guide. Energy Policy, 33(7), 867871. doi: 10.1016/j.enpol.2003.10.010

Ang, B. W., \& Lee, P. W. (1996). Decomposition of Industrial Energy Consumption: The Energy Coefficient Approach. Energy Economics, 18(1-2), 129-143. doi: 10.1016/0140-9883(95)00049-6

Ang, B. W., \& Lee, S. Y. (1994). Decomposition of Industrial Energy Consumption: Some Methodological and Application Issues. Energy Economics, 16(2), 83-92. doi: 10.1016/0140-9883(94)90001-9

Ang, B. W., \& Zhang, F. Q. (2000). A Survey of Index Decomposition Analysis in Energy and Environmental Studies. Energy, 25(12), 1149-1176. doi: 10.1016/s0360-5442(00)00039-6

Arrow, K., Bolin, B., Costanza, R., Dasgupta, P., Folke, C., Holling, C. S., . . . Pimentel, D. (1995). Economic Growth, Carrying Capacity, and the Environment. Science, 268(5210), 520-521. doi: 10.1126/science. 268.5210 .520

Arrow, K., Cropper, M. L., Eads, G. C., Hahn, R. W., Lave, L. B., Noll, R. G., . . Stavins, R. N. (1996). Is There A Role for Benefit-Cost Analysis in Environmental, Health, and Safety Regulation? Science, 272(5259), 221222. doi: 10.1126/science.272.5259.221

Aw, B. Y., Chen, X. M., \& Roberts, M. J. (2001). Firm-Level Evidence on Productivity Differentials and Turnover in Taiwanese Manufacturing. Journal of Development Economics, 66(1), 51-86. doi: 10.1016/s03043878(01)00155-9

Ayres, I., Raseman, S., \& Shih, A. (2013). Evidence from Two Large Field Experiments that Peer Comparison Feedback Can Reduce Residential Energy Usage. Journal of Law Economics \& Organization, 29(5), $992-$ 1022. doi: 10.1093/jleo/ews020

Azomahou, T., Laisney, F., \& Van, P. N. (2006). Economic Development and CO2 Emissions: A Nonparametric Panel Approach. Journal of Public Economics, 90(6-7), 1347-1363. doi: 10.1016/j.jpubeco.2005.09.005

Babiker, M. H. (2005). Climate Change Policy, Market Structure, and Carbon Leakage. Journal of International Economics, 65(2), 421-445. doi: 10.1016/j.jinteco.2004.01.003 
Backlund, S., Thollander, P., Palm, J., \& Ottosson, M. (2012). Extending the Energy Efficiency Gap. Energy Policy, 51, 392-396. doi: 10.1016/j.enpol.2012.08.042

Baily, M. N., Bartelsman, E. J., \& Haltiwanger, J. (1996). Downsizing and Productivity Growth: Myth or Reality? Small Business Economics, 8(4), 259-278. doi: 10.1007/bf00393276

Baily, M. N., Bartelsman, E. J., \& Haltiwanger, J. (2001). Labor Productivity: Structural Change and Cyclical Dynamics. Review of Economics and Statistics, 83(3), 420-433. doi: 10.1162/00346530152480072

Baily, M. N., Hulten, C., \& Campbell, D. (1992). Productivity Dynamics in Manufacturing Plants. Brookings Papers on Economic Activity, 187-267.

Barro, R. J. (1991). Economic Growth in a Cross Section of Countries. The Quarterly Journal of Economics, 106(2), 407-443.

Barro, R. J., \& SalaiMartin, X. (1991). Convergence Across States and Regions. Brookings Papers on Economic Activity(1), 107-182.

Barro, R. J., \& SalaiMartin, X. (1992). Convergence. Journal of Political Economy, 100(2), 223-251. doi: $10.1086 / 261816$

Bartelsman, E. J., \& Dhrymes, P. J. (1998). Productivity Dynamics: U.S. Manufacturing Plants, 1972-1986. Journal of Productivity Analysis, 9(1), 5-34. doi: 10.1023/a:1018383629341

Bartelsman, E. J., Dobbelaere, S., \& Peters, B. (2014). Allocation of Human Capital and Innovation at the Frontier: Firm-Level Evidence on Germany and the Netherlands. Industrial and Corporate Change. doi: 10.1093/icc/dtu038

Bartelsman, E. J., \& Doms, M. (2000). Understanding Productivity: Lessons from Longitudinal Microdata. Journal of Economic Literature, 38(3), 569-594. doi: 10.1257/jel.38.3.569

Bartelsman, E. J., \& Wolf, Z. (2014). Forecasting Aggregate Productivity Using Information from Firm-Level Data. Review of Economics and Statistics, 96(4), 745-755. doi: 10.1162/REST_a_00395

Basu, S., \& Fernald, J. G. (1997). Returns to Scale in U.S. Production: Estimates and Implications. Journal of Political Economy, 105(2), 249-283. doi: 10.1086/262073

Berry, S., Levinsohn, J., \& Pakes, A. (2004). Differentiated Products Demand Systems from A Combination of Micro and Macro Data: The New Car Market. Journal of Political Economy, 112(1), 68-105. doi: 10.1086/379939

Borensztein, E., De Gregorio, J., \& Lee, J. W. (1998). How Does Foreign Direct Investment Affect Economic Growth? Journal of International Economics, 45(1), 115-135. doi: 10.1016/s0022-1996(97)00033-0

Boyd, G. A., Hanson, D. A., \& Sterner, T. (1988). Decomposition of Changes in Energy Intensity: A Comparison of the Divisia Index and Other Methods. Energy Economics, 10(4), 309-312. doi: 10.1016/01409883(88)90042-4

Bresnahan, T. F., \& Trajtenberg, M. (1995). General Purpose Technologies "Engines of Growth?". Journal of Econometrics, 65(1), 83-108. doi: 10.1016/0304-4076(94)01598-t

Brown, M. A. (2001). Market Failures and Barriers as A Basis for Clean Energy Policies. Energy Policy, 29(14), 1197-1207. doi: 10.1016/s0301-4215(01)00067-2

Brownstone, D., \& Train, K. (1999). Forecasting New Product Penetration with Flexible Substitution Patterns. Journal of Econometrics, 89(1-2), 109-129.

Buchinsky, M. (1994). Changes in the U.S. Wage Structure 1963-1987: Application of Quantile Regression. Econometrica, 62(2), 405-458. doi: 10.2307/2951618

Chang, N. (2013). Sharing responsibility for carbon dioxide emissions: A perspective on border tax adjustments. Energy Policy, 59, 850-856. doi: 10.1016/j.enpol.2013.04.046

Christensen, L. R., Cummings, D., \& Jorgenson, D. W. (1981). Relative Productivity Levels, 1947-1973: An International Comparison. European Economic Review, 16(1), 61-94. doi: http://dx.doi.org/10.1016/ 0014-2921(81)90049-0

Copeland, B. R., \& Taylor, M. S. (2004). Trade, Growth, and the Environment. Journal of Economic Literature, 42(1), 7-71. doi: 10.1257/002205104773558047

Daily, G. C., Soderqvist, T., Aniyar, S., Arrow, K., Dasgupta, P., Ehrlich, P. R., . . Walker, B. (2000). Ecology - The Value of Nature and the Nature of Value. Science, 289(5478), 395-396. doi: 10.1126/science.289. 5478.395 
Daly, H., \& Ó Gallachóir, B. P. (2011). Modelling Private Car Energy Demand Using A Technological Car Stock Model. Transportation Research Part D: Transport and Environment, 16(2), 93-101. doi: http://dx.doi.org/10.1016/j.trd.2010.08.009

Dasgupta, S., Laplante, B., Wang, H., \& Wheeler, D. (2002). Confronting the Environmental Kuznets Curve. Journal of Economic Perspectives, 16(1), 147-168. doi: 10.1257/0895330027157

De Bruyn, S. M., van den Bergh, J., \& Opschoor, J. B. (1998). Economic Growth and Emissions: Reconsidering the Empirical Basis of Environmental Kuznets Curves. Ecological Economics, 25(2), 161-175. doi: 10.1016/s0921-8009(97)00178-x

DeCanio, S. J. (1998). The Efficiency Paradox: Bureaucratic and Organizational Barriers to Profitable EnergySaving Investments. Energy Policy, 26(5), 441-454. doi: 10.1016/s0301-4215(97)00152-3

DeCanio, S. J., \& Watkins, W. E. (1998). Investment in Energy Efficiency: Do the Characteristics of Firms Matter? Review of Economics and Statistics, 80(1), 95-107. doi: 10.1162/003465398557366

Dietzenbacher, E., Hoen, A. R., \& Los, B. (2000). Labor Productivity in Western Europe 1975-1985: An Intercountry, Interindustry Analysis. Journal of Regional Science, 40(3), 425-452. doi: 10.1111/00224146.00182

Dietzenbacher, E., \& Los, B. (1998). Structural Decomposition Techniques: Sense and Sensitivity. Economic Systems Research, 10(4), 307-324. doi: 10.1080/09535319800000023

Dietzenbacher, E., Los, B., Stehrer, R., Timmer, M., \& de Vries, G. (2013). The Construction of World InputOutput Tables in the WIOD Project. Economic Systems Research, 25(1), 71-98. doi: 10.1080/09535314. 2012.761180

Dinda, S. (2004). Environmental Kuznets Curve Hypothesis: A Survey. Ecological Economics, 49(4), 431-455. doi: 10.1016/j.ecolecon.2004.02.011

Dosi, G. (1982). Technological Paradigms and Technological Trajectories. Research Policy, 11(3), 147-162. doi: http://dx.doi.org/10.1016/0048-7333(82)90016-6

Dosi, G. (1988). Sources, Procedures, and Microeconomic Effects of Innovation. Journal of Economic Literature, 26(3), 1120-1171.

Dowell, G., Hart, S., \& Yeung, B. (2000). Do Corporate Global Environmental Standards Create or Destroy Market Value? Management Science, 46(8), 1059-1074. doi: 10.1287/mnsc.46.8.1059.12030

Easterly, W., \& Levine, R. (2003). Tropics, Germs, and Crops: How Endowments Influence Economic Development. Journal of Monetary Economics, 50(1), 3-39. doi: 10.1016/s0304-3932(02)00200-3

Eskeland, G. S., \& Harrison, A. E. (2003). Moving to Greener Pastures? Multinationals and the Pollution Haven Hypothesis. Journal of Development Economics, 70(1), 1-23. doi: 10.1016/s0304-3878(02)00084-6

European Commission. (2010). Europe 2020: A European Strategy for Smart, Sustainable and Inclusive Growth. Brussels.

Fagerberg, J., \& Godinho, M. M. (2004). Innovation and Catching-Up Fagerberg, J., Mowery, D., and Nelson, $R$ (eds.): The Oxford Handbook of Innovation (pp. 514-543): Oxford University Press, New York.

Fagerberg, J., Srholec, M., \& Verspagen, B. (2010). Chapter 20 - Innovation and Economic Development. In H. H. Bronwyn \& R. Nathan (Eds.), Handbook of the Economics of Innovation (Vol. Volume 2, pp. 833-872): North-Holland.

Fagerberg, J., \& Verspagen, B. (2002). Technology-Gaps, Innovation-Diffusion and Transformation: An Evolutionary Interpretation. Research Policy, 31(8-9), 1291-1304. doi: 10.1016/s0048-7333(02)00064-1

Farla, J., Blok, K., \& Schipper, L. (1997). Energy Efficiency Developments in the Pulp and Paper Industry - A Cross-Country Comparison Using Physical Production Data. Energy Policy, 25(7-9), 745-758. doi: 10.1016/s0301-4215(97)00065-7

Federal Democratic Republic of Ethiopia. (2011). Ethiopia's Climate - Resilient Green Economy.

Fischer, C., \& Newell, R. G. (2008). Environmental and Technology Policies for Climate Mitigation. Journal of Environmental Economics and Management, 55(2), 142-162. doi: 10.1016/j.jeem.2007.11.001

Flores, C. A., Flores-Lagunes, A., \& Kapetanakis, D. (2014). Lessons From Quantile Panel Estimation of the Environmental Kuznets Curve. Econometric Reviews, 33(8), 815-853. doi: 10.1080/07474938. 2013.806148 
Fontana, R., Nuvolari, A., \& Verspagen, B. (2009). Mapping Technological Trajectories as Patent Citation Networks. An Application to Data Communication Standards. Economics of Innovation and New Technology, 18(4), 311-336.

Foster, L., Haltiwanger, J., \& Krizan, C. J. (1998). Aggregate Productivity Growth: Lessons from Microeconomic Evidence. National Bureau of Economic Research Working Paper Series, No. 6803. doi: 10.3386/w6803

Foster, L., Haltiwanger, J., \& Krizan, C. J. (2006). Market Selection, Reallocation, and Restructuring in the U.S. Retail Trade Sector in the 1990s. Review of Economics and Statistics, 88(4), 748-758. doi: 10.1162/ rest.88.4.748

Frankel, J. A., \& Romer, D. (1999). Does Trade Cause Growth? American Economic Review, 89(3), 379-399. doi: 10.1257/aer.89.3.379

French Republic. (2010). National Sustainable Development Strategy: Towards a Green \& Fair Economy.

Gillingham, K., Newell, R., \& Palmer, K. (2006). Energy Efficiency Policies: A Retrospective Examination Annual Review of Environment and Resources (Vol. 31, pp. 161-192). Palo Alto: Annual Reviews.

Gillingham, K., Newell, R. G., \& Palmer, K. (2009). Energy Efficiency Economics and Policy Annual Review of Resource Economics (Vol. 1, pp. 597-619). Palo Alto: Annual Reviews.

Gillingham, K., \& Palmer, K. (2014). Bridging the Energy Efficiency Gap: Policy Insights from Economic Theory and Empirical Evidence. Review of Environmental Economics and Policy, 8(1), 18-38. doi: 10.1093/reep/ ret021

Griliches, Z. (1988). Productivity Puzzles and R\&D: Another Nonexplanation. Journal of Economic Perspectives, 2(4), 9-21.

Griliches, Z. (1990). Patent Statistics as Economic Indicators: A Survey. Journal of Economic Literature, 28(4), 1661-1707.

Griliches, Z., \& Regev, H. (1995). Firm Productivity in Israeli Industry 1979-1988. Journal of Econometrics, 65(1), 175-203. doi: 10.1016/0304-4076(94)01601-u

Grossman, G. M., \& Helpman, E. (1994). Endogenous Innovation in the Theory of Growth. Journal of Economic Perspectives, 8(1), 23-44.

Grossman, G. M., \& Krueger, A. B. (1995). Economic Growth and the Environment. Quarterly Journal of Economics, $110(2)$, 353-377. doi: 10.2307/2118443

Grossman, G. M., \& Rossi-Hansberg, E. (2008). Trading Tasks: A Simple Theory of Offshoring. American Economic Review, 98(5), 1978-1997. doi: 10.1257/aer.98.5.1978

Guan, D., Hubacek, K., Weber, C. L., Peters, G. P., \& Reiner, D. M. (2008). The Drivers of Chinese CO2 Emissions from 1980 to 2030. Global Environmental Change-Human and Policy Dimensions, 18(4), 626-634. doi: 10.1016/j.gloenvcha.2008.08.001

Hall, B. H., Jaffe, A., \& Trajtenberg, M. (2005). Market Value and Patent Citations. Rand Journal of Economics, 36(1), 16-38.

Hall, R. E., \& Jones, C. I. (1999). Why Do Some Countries Produce So Much More Output Per Worker than Others? Quarterly Journal of Economics, 114(1), 83-116. doi: 10.1162/003355399555954

Han, X. L., \& Chatterjee, L. (1997). Impacts of Growth and Structural Change on CO2 Emissions of Developing Countries. World Development, 25(3), 395-407. doi: 10.1016/s0305-750x(96)00110-6

Haščič, I., \& Migotto, M. (2015). Measuring Environmental Innovation Using Patent Data. OECD Environment Working Papers, No. 89.

Haščič, I., Silva, J., \& Johnstone, N. (2015). The Use of Patent Statistics for International Comparisons and Analysis of Narrow Technological Fields. OECD Science, Technology and Industry Working Papers, 2015/05.

Hassett, K. A., \& Metcalf, G. E. (1995). Energy Tax Credits and Residential Conservation Investment: Evidence from Panel Data. Journal of Public Economics, 57(2), 201-217. doi: 10.1016/0047-2727(94)01452-t

Hausman, J. A. (1979). Individual Discount Rates and the Purchase and Utilization of Energy-Using Durables. The Bell Journal of Economics, 10(1), 33-54. doi: 10.2307/3003318

Hertwich, E. G., \& Peters, G. P. (2009). Carbon Footprint of Nations: A Global, Trade-Linked Analysis. Environmental Science \& Technology, 43(16), 6414-6420. doi: 10.1021/es803496a 
Hoekstra, R., \& Van den Bergh, J. (2002). Structural Decomposition Analysis of Physical Flows in the Economy. Environmental \& Resource Economics, 23(3), 357-378. doi: 10.1023/a:1021234216845

Holtzeakin, D., \& Selden, T. M. (1995). Stoking the Fires? CO2 Emissions and Economic Growth. Journal of Public Economics, 57(1), 85-101. doi: 10.1016/0047-2727(94)01449-x

Hsieh, C. T., \& Klenow, P. J. (2009). Misallocation and Manufacturing TFP in China and India. Quarterly Journal of Economics, 124(4), 1403-1448.

Hummon, N. P., \& Doreian, P. (1989). Connectivity in a Citation Network: The Development of DNA Theory. Social Networks, 11(1), 39-63. doi: 10.1016/0378-8733(89)90017-8

Jaffe, A. B., \& Kerr, S. (2015). The Science, Economics, and Politics of Global Climate Change: A Review of The Climate Casino by William Nordhaus. Journal of Economic Literature, 53(1), 79-91. doi: 10.1257/jel. 53.1.79

Jaffe, A. B., Newell, R. G., \& Stavins, R. N. (2002). Environmental Policy and Technological Change. Environmental \& Resource Economics, 22(1-2), 41-69. doi: 10.1023/a:1015519401088

Jaffe, A. B., Newell, R. G., \& Stavins, R. N. (2005). A Tale of Two Market Failures: Technology and Environmental Policy. Ecological Economics, 54(2-3), 164-174. doi: 10.1016/j.ecolecon.2004.12.027

Jaffe, A. B., \& Palmer, K. (1997). Environmental Regulation and Innovation: A Panel Data Study. Review of Economics and Statistics, 79(4), 610-619. doi: 10.1162/003465397557196

Jaffe, A. B., Peterson, S. R., Portney, P. R., \& Stavins, R. N. (1995). Environmental Regulation and the Competitiveness of U.S. Manufacturing: What Does the Evidence Tell Us? Journal of Economic Literature, 33(1), 132-163.

Jaffe, A. B., \& Stavins, R. N. (1994a). The Energy-Efficiency Gap: What Does It Mean? Energy Policy, 22(10), 804-810. doi: 10.1016/0301-4215(94)90138-4

Jaffe, A. B., \& Stavins, R. N. (1994b). Energy-Efficiency Investments and Public Policy. Energy Journal, 15(2), 4365.

Jaffe, A. B., \& Stavins, R. N. (1994c). The Energy Paradox and the Diffusion of Conservation Technology. Resource and Energy Economics, 16(2), 91-122. doi: 10.1016/0928-7655(94)90001-9

Jaffe, A. B., \& Stavins, R. N. (1995). Dynamic Incentives of Environmental Regulations: The Effects of Alternative Policy Instruments on Technology Diffusion. Journal of Environmental Economics and Management, 29(3), S43-S63. doi: 10.1006/jeem.1995.1060

Jaffe, A. B., Trajtenberg, M., \& Fogarty, M. S. (2000). Knowledge Spillovers and Patent Citations: Evidence from A Survey of Inventors. American Economic Review, 90(2), 215-218. doi: 10.1257/aer.90.2.215

Jovanovic, B., \& Nyarko, Y. (1996). Learning by Doing and the Choice of Technology. Econometrica, 64(6), 1299-1310. doi: 10.2307/2171832

Kahrl, F., Roland-Holst, D., \& Zilberman, D. (2013). Past as Prologue? Understanding Energy Use in Post-2002 China. Energy Economics, 36, 759-771. doi: 10.1016/j.eneco.2012.11.018

Kanemoto, K., Lenzen, M., Peters, G. P., Moran, D. D., \& Geschke, A. (2012). Frameworks for Comparing Emissions Associated with Production, Consumption, And International Trade. Environmental Science \& Technology, 46(1), 172-179. doi: 10.1021/es202239t

Kanemoto, K., Moran, D., Lenzen, M., \& Geschke, A. (2014). International trade undermines national emission reduction targets: New evidence from air pollution. Global Environmental Change-Human and Policy Dimensions, 24, 52-59. doi: 10.1016/j.gloenvcha.2013.09.008

Keller, W. (2004). International Technology Diffusion. Journal of Economic Literature, 42(3), 752-782. doi: 10.1257/0022051042177685

Kemp, R., Schot, J., \& Hoogma, R. (1998). Regime Shifts to Sustainability through Processes of Niche Formation: The Approach of Strategic Niche Management. Technology Analysis \& Strategic Management, 10(2), 175-195. doi: 10.1080/09537329808524310

Kemp, R., \& Soete, L. (1992). The Greening of Technological Progress: An Evolutionary Perspective. Futures, 24(5), 437-457. doi: 10.1016/0016-3287(92)90015-8

King, R. G., \& Levine, R. (1993). Finance and Growth: Schumpeter Might be Right. Quarterly Journal of Economics, 108(3), 717-737. doi: 10.2307/2118406 
Knack, S., \& Keefer, P. (1997). Does Social Capital Have An Economic Payoff? A Cross-Country Investigation. Quarterly Journal of Economics, 112(4), 1251-1288. doi: 10.1162/003355300555475

Koenker, R., \& Bassett, G. (1978). Regression Quantiles. Econometrica, 46(1), 33-50. doi: 10.2307/1913643

Koenker, R., \& Bassett, G. (1982). Robust Tests for Heteroscedasticity Based on Regression Quantiles. Econometrica, 50(1), 43-61. doi: 10.2307/1912528

Koenker, R., \& Hallock, K. F. (2001). Quantile Regression. The Journal of Economic Perspectives, 15(4), 143156.

Kuhn, T. S. (1970). The Structure of Scientific Revolutions (2nd Edition): University of Chicago Press.

Lee, K. (2013). Schumpeterian Analysis of Economic Catch-Up: Knowledge, Path-Creation, and the MiddleIncome Trap: Cambridge University Press.

Lee, K., \& Lim, C. (2001). Technological Regimes, Catching-Up and Leapfrogging: Findings from the Korean Industries. Research Policy, 30(3), 459-483.

Lee, Y., \& Mukoyama, T. (2015). Entry and Exit of Manufacturing Plants over the Business Cycle. European Economic Review, 77, 20-27. doi: 10.1016/j.euroecorev.2015.03.011

Lele, S. M. (1991). Sustainable Development: A Critical Review. World Development, 19(6), 607-621. doi: 10.1016/0305-750x(91)90197-p

Lenzen, M., Kanemoto, K., Moran, D., \& Geschke, A. (2012). Mapping the Structure of the World Economy. Environmental Science \& Technology, 46(15), 8374-8381. doi: 10.1021/es300171x

Lenzen, M., Moran, D., Kanemoto, K., \& Geschke, A. (2013). Building Eora: A Global Multi-Region Input-Output Database At High Country And Sector Resolution. Economic Systems Research, 25(1), 20-49. doi: 10.1080/09535314.2013.769938

Li, Q., \& Racine, J. S. (2007). Nonparametric Econometrics: Theory and Practice: Princeton University Press.

Liu, J. S., \& Lu, L. Y. Y. (2012). An Integrated Approach for Main Path Analysis: Development of the Hirsch Index as An Example. Journal of the American Society for Information Science and Technology, 63(3), 528-542. doi: $10.1002 /$ asi.21692

Liu, J. S., Lu, L. Y. Y., Lu, W. M., \& Lin, B. J. Y. (2013). Data Envelopment Analysis 1978-2010: A Citation-Based Literature Survey. Omega-International Journal of Management Science, 41(1), 3-15. doi: 10.1016/j.omega.2010.12.006

Liu, N., \& Ang, B. W. (2007). Factors Shaping Aggregate Energy Intensity Trend for Industry: Energy Intensity Versus Product Mix. Energy Economics, 29(4), 609-635. doi: 10.1016/j.eneco.2006.12.004

Lutsey, N., \& Sperling, D. (2005). Energy Efficiency, Fuel Economy, and Policy Implications Energy and Environmental Concerns 2005 (pp. 8-17). Washington: Transportation Research Board Natl Research Council.

Maasoumi, E., Racine, J., \& Stengos, T. (2007). Growth and Convergence: A Profile of Distribution Dynamics and Mobility. Journal of Econometrics, 136(2), 483-508. doi: 10.1016/j.jeconom.2005.11.012

Machado, G., Schaeffer, R., \& Worrell, E. (2001). Energy and Carbon Embodied in the International Trade of Brazil: An Input-Output Approach. Ecological Economics, 39(3), 409-424. doi: 10.1016/s09218009(01)00230-0

Mankiw, N. G., Romer, D., \& Weil, D. N. (1992). A Contribution to the Empirics of Economic Growth. Quarterly Journal of Economics, 107(2), 407-437. doi: 10.2307/2118477

Martinelli, A. A. (2010). The Dynamics of Technological Discontinuities: A Patent Citation Network Analysis of Telecommunication Switches. Technische Universiteit Eindhoven.

Mauro, P. (1995). Corruption and Growth. Quarterly Journal of Economics, 110(3), 681-712. doi: $10.2307 / 2946696$

Miller, R. E., \& Blair, P. D. (1985). Input-Output Analysis: Foundations and Extensions.

Millimet, D. L., List, J. A., \& Stengos, T. (2003). The Environmental Kuznets Curve: Real Progress or Misspecified Models? Review of Economics and Statistics, 85(4), 1038-1047. doi: 10.1162/003465303772815916

Nelson, R. R., \& Winter, S. G. (1977). In Search of Useful Theory of Innovation. Research Policy, 6(1), 36-76. doi: http://dx.doi.org/10.1016/0048-7333(77)90029-4

Newell, R. G., Jaffe, A. B., \& Stavins, R. N. (1999). The Induced Innovation Hypothesis and Energy-Saving Technological Change. Quarterly Journal of Economics, 114(3), 941-975. doi: 10.1162/003355399556188 
Nuvolari, A. (2004). Collective Invention during the British Industrial Revolution: the Case of the Cornish Pumping Engine. Cambridge Journal of Economics, 28(3), 347-363. doi: 10.1093/cje/beh011

Nuvolari, A. (2006). The Making of Steam Power Technology: A Study of Technical Change during the British Industrial Revolution. The Journal of Economic History, 66(2), 472-476.

Olley, G. S., \& Pakes, A. (1996). The Dynamics of Productivity in the Telecommunications Equipment Industry. Econometrica, 64(6), 1263-1297. doi: 10.2307/2171831

Owen, A., Steen-Olsen, K., Barrett, J., Wiedmann, T., \& Lenzen, M. (2014). A Structural Decomposition Approach to Comparing MRIO Databases. Economic Systems Research, 26(3), 262-283. doi: 10.1080/ 09535314.2014 .935299

Patterson, M. G. (1996). What Is Energy Efficiency? Concepts, Indicators and Methodological Issues. Energy Policy, 24(5), 377-390. doi: 10.1016/0301-4215(96)00017-1

Perez, C., \& Soete, L. (1988). Catching Up in Technology: Entry Barriers and Windows of Opportunity. Technical change and economic theory, 479.

Quah, D. (1993a). Empirical Cross-Section Dynamics in Economic Growth. European Economic Review, 37(2-3), 426-434. doi: 10.1016/0014-2921(93)90031-5

Quah, D. (1993b). Galton's Fallacy and Tests of the Convergence Hypothesis. Scandinavian Journal of Economics, 95(4), 427-443. doi: 10.2307/3440905

Quah, D. (1996). Regional Convergence Clusters across Europe. European Economic Review, 40(3-5), 951-958. doi: 10.1016/0014-2921(95)00105-0

Quah, D. (1997). Empirics for Growth and Distribution: Stratification, Polarization, and Convergence Clubs. Journal of Economic Growth, 2(1), 27-59. doi: 10.1023/A:1009781613339

Republic of Korea. (2009). Road to Our Future: Green Growth. Seoul.

Romer, P. M. (1990). Endogenous Technological Change. Journal of Political Economy, 98(5), S71-S102. doi: $10.1086 / 261725$

Rose, A., \& Casler, S. (1996). Input-Output Structural Decomposition Analysis: A Critical Appraisal. Economic Systems Research, 8(1), 33-62. doi: 10.1080/09535319600000003

Rose, A., \& Chen, C. Y. (1991). Sources of Change in Energy Use in the U.S. Economy, 1972-1982: A Structural Decomposition Analysis. Resources and Energy, 13(1), 1-21. doi: http://dx.doi.org/10.1016/01650572(91)90017-W

Sahal, D. (1981). Patterns of Technological Innovation: Addison-Wesley Publishing Company, Advanced Book Program/World Science Division.

SalaiMartin, X. (1996). The Classical Approach to Convergence Analysis. Economic Journal, 106(437), 10191036. doi: $10.2307 / 2235375$

Salgado-Ugarte, I. H., Shimizu, M., \& Taniuchi, T. (1994). Exploring the Shape of Univariate Data Using Kernel Density Estimators. Stata Technical Bulletin, 3(16).

Salgado-Ugarte, I. H., Shimizu, M., \& Taniuchi, T. (1996a). ASH, WARPing, and Kernel Density Estimation for Univariate Data. Stata Technical Bulletin, 5(26).

Salgado-Ugarte, I. H., Shimizu, M., \& Taniuchi, T. (1996b). Practical Rules for Bandwidth Selection in Univariate Density Estimation. Stata Technical Bulletin, 5(27).

Sallee, J. M., West, S. E., \& Fan, W. (2016). Do Consumers Recognize the Value of Fuel Economy? Evidence from Used Car Prices and Gasoline Price Fluctuations. Journal of Public Economics, 135, 61-73. doi: 10.1016/j.jpubeco.2016.01.003

Selden, T. M., \& Song, D. Q. (1994). Environmental Quality and Development: Is There a Kuznets Curve for Air Pollution Emissions? Journal of Environmental Economics and Management, 27(2), 147-162. doi: 10.1006/jeem.1994.1031

Sinton, J. E., \& Fridley, D. G. (2000). What Goes Up: Recent Trends in China's Energy Consumption. Energy Policy, 28(10), 671-687. doi: 10.1016/s0301-4215(00)00053-7

Statistics Netherlands. (2009). Green Growth in the Netherlands.

Steenblik, R. (2005). Environmental Goods: A Comparison of the APEC and OECD Lists Trade that Benefits the Environment and Development: Opening Markets for Environmental Goods and Services. Paris: OECD Publishing. 
Steenhof, P. A. (2006). Decomposition of Electricity Demand in China's Industrial Sector. Energy Economics, 28(3), 370-384. doi: 10.1016/j.eneco.2006.02.006

Stern, D. I. (2002). Explaining Changes in Global Sulfur Emissions: An Econometric Decomposition Approach. Ecological Economics, 42(1-2), 201-220. doi: 10.1016/s0921-8009(02)00050-2

Stern, D. I. (2004). The Rise and Fall of the Environmental Kuznets Curve. World Development, 32(8), 14191439. doi: 10.1016/j.worlddev.2004.03.004

Stern, D. I. (2006). Reversal of the Trend in Global Anthropogenic Sulfur Emissions. Global Environmental Change-Human and Policy Dimensions, 16(2), 207-220. doi: 10.1016/j.gloenvcha.2006.01.001

Stern, D. I., \& Common, M. S. (2001). Is There An Environmental Kuznets Curve for Sulfur? Journal of Environmental Economics and Management, 41(2), 162-178. doi: 10.1006/jeem.2000.1132

Stern, D. I., Common, M. S., \& Barbier, E. B. (1996). Economic Growth and Environmental Degradation: The Environmental Kuznets Curve and Sustainable Development. World Development, 24(7), 1151-1160. doi: 10.1016/0305-750x(96)00032-0

Stokey, N. L. (1998). Are There Limits to Growth? International Economic Review, 39(1), 1-31. doi: $10.2307 / 2527228$

Sugathan, M. (2013). Lists of Environmental Goods: An Overview. Geneva: International Centre for Trade and Sustainable Development.

Szirmai, A., \& Verspagen, B. (2015). Manufacturing and Economic Growth in Developing Countries, 19502005. Structural Change and Economic Dynamics, 34, 46-59. doi: 10.1016/j.strueco.2015.06.002

The Government of UK. (2011). Enabling the Transition to a Green Economy: Government and Business Working Together.

The State Council of the People's Republic of China. (2011). China's 12th Five-Year Plan.

Timmer, M. (2012) The World Input-Output Database (WIOD): Contents, Sources and Methods. WIOD Working Paper Number 10.

Timmer, M., Erumban, A. A., Los, B., Stehrer, R., \& de Vries, G. (2014). Slicing Up Global Value Chains. Journal of Economic Perspectives, 28(2), 99-118. doi: doi: 10.1257/jep.28.2.99

Triulzi, G. (2015). Looking for the Right Path: Technology Dynamics, Inventive Strategies and Catching-Up in the Semiconductor Industry. Maastricht University.

Turrentine, T. S., \& Kurani, K. S. (2007). Car Buyers and Fuel Economy? Energy Policy, 35(2), 1213-1223. doi: 10.1016/j.enpol.2006.03.005

UN-Energy. (2009). Policies and Measures to Realize Industrial Energy Efficiency and Mitigate Climate Change. Vienna.

UNCTAD. (2010). Promoting Poles of Clean Growth to Foster the Transition to A More Sustainable Economy.

UNDESA. (2012). A Guidebook to the Green Economy Issue 1: Green Economy, Green Growth, and LowCarbon Development - History, Definitions and A Guide to Recent Publications. New York.

UNDESA. (2013). A Guidebook to the Green Economy Issue 4: A Guide to International Green Economy Initiatives. New York.

UNIDO. (2012). Industrial Development Report 2011: Industrial Energy Efficiency for Sustainable Wealth Creation: Capturing Environmental, Economic and Social Dividends. Vienna.

UNIDO. (2015). Industrial Development Report 2016: The Role of Technology and Innovation in Inclusive and Sustainable Industrial Development. Vienna.

United Nations. (2000). United Nations Millennium Declaration. Retrieved from http://www.un.org/millennium/ declaration/ares552e.pdf.

United Nations. (2015). Transforming Our World: The 2030 Agenda for Sustainable Development. New York.

Upadhyaya, S. (2010). Compilation of Energy Statistics for Economic Analysis. UNIDO Working Paper 01/2010. UNIDO.

Verardi, V., \& Croux, C. (2009). Robust regression in Stata. Stata Journal, 9(3), 439-453.

Verspagen, B. (1992). Endogenous Innovation in Neo-Classical Growth Models: A Survey. Journal of Macroeconomics, 14(4), 631-662. doi: 10.1016/0164-0704(92)90004-r

Verspagen, B. (2007). Mapping Technological Trajectories as Patent Citation Networks: A Study on the History of Fuel Cell Research. Advances in Complex Systems, 10(1), 93-115. doi: 10.1142/s0219525907000945 
Voigt, S., De Cian, E., Schymura, M., \& Verdolini, E. (2014). Energy Intensity Developments in 40 Major Economies: Structural Change or Technology Improvement? Energy Economics, 41, 47-62. doi: 10.1016/j.eneco.2013.10.015

Waltman, L., \& Van Eck, N. J. (2013). A Smart Local Moving Algorithm for Large-Scale Modularity-Based Community Detection. European Physical Journal B, 86(11), 14. doi: 10.1140/epjb/e2013-40829-0

Wang, F., Yin, H. T., \& Li, S. D. (2010). China's Renewable Energy Policy: Commitments and Challenges. Energy Policy, 38(4), 1872-1878. doi: 10.1016/j.enpol.2009.11.065

Weber, C. L. (2009). Measuring Structural Change and Energy Use: Decomposition of the U.S. Economy from 1997 to 2002. Energy Policy, 37(4), 1561-1570. doi: 10.1016/j.enpol.2008.12.027

Wiedmann, T., Lenzen, M., Turner, K., \& Barrett, J. (2007). Examining the Global Environmental Impact of Regional Consumption Activities - Part 2: Review of Input-Output Models for the Assessment of Environmental Impacts Embodied in Trade. Ecological Economics, 61(1), 15-26. doi: 10.1016/j.ecolecon.2006.12.003

Wiedmann, T., Wood, R., Minx, J. C., Lenzen, M., Guan, D. B., \& Harris, R. (2010). A Carbon Footprint Time Series of the UK-Results from a Multi-Region Input-Output Model. Economic Systems Research, 22(1), 19-42. doi: 10.1080/09535311003612591

Wood, R., \& Lenzen, M. (2009). Structural Path Decomposition. Energy Economics, 31(3), 335-341. doi: 10.1016/j.eneco.2008.11.003

Worrell, E., Price, L., Martin, N., Farla, J., \& Schaeffer, R. (1997). Energy Intensity in the Iron and Steel Industry: A Comparison of Physical and Economic Indicators. Energy Policy, 25(7-9), 727-744. doi: 10.1016/s03014215(97)00064-5

Xu, Y., \& Dietzenbacher, E. (2014). A Structural Decomposition Analysis of the Emissions Embodied in Trade. Ecological Economics, 101, 10-20. doi: 10.1016/j.ecolecon.2014.02.015

Zhang, Z. X. (2003). Why Did the Energy Intensity Fall in China's Industrial Sector in the 1990s? The Relative Importance of Structural Change and Intensity Change. Energy Economics, 25(6), 625-638. doi: 10.1016/s0140-9883(03)00042-2

Zhong, S. (2015). Structural Decompositions of Energy Consumption, Energy Intensity, Emissions and Emission intensity - A sectoral Perspective: Empirical Evidence from WIOD over 1995 to 2009. UNIDO Inclusive and Sustainable Development Working Paper Series 11/2015. 


\section{UNU-MERIT/MGSoG Dissertation Series}

2017

Sheng Zhong

Moving towards An Energy Efficient Future; Essays on Energy Efficiency, Technology and Development

UNU-MERIT/MGSoG Dissertation Series № 187

Julieta Marotta

Access to Justice and Legal Empowerment of Victims of Domestic Violence through Legal Organizations in the City of Buenos Aires; A Qualitative Empirical Legal Study UNU-MERIT/MGSoG Dissertation Series, № 186

Andrea Franco-Correa

On the Measurement of Multidimensional Poverty as a Policy Tool; Empirical Applications to Chile, Colombia, Ecuador and Peru

UNU-MERIT/MGSoG Dissertation Series, № 185

2016

Yesuf Awel

Insurance for Growth; Empirical Essays on Insurance Demand and Impacts in Africa UNU-MERIT Dissertation Series, № 108

Tigist Mekonnen Melesse

Grow More Food using Fewer Resources;

Agricultural Technology Adoption and Innovation Practices for Inclusive and

Sustainable Development

UNU-MERIT Dissertation Series, № 107

Eleni Yitbarek

Getting Ahead or left Behind?; Essays on Poverty Dynamics and Social Mobility in Africa

UNU-MERIT Dissertation Series, № 106

Thuy Dieu Nguyen

Firm-Level Theory and Evidence of Corruption

UNU-MERIT Dissertation Series, № 105 
Raquel Tsukada Lehman

Essays on Household Production with Labor-Saving Technology

UNU-MERIT Dissertation Series, № 104

\section{Eva Barteková}

Multi-Problem Challenges for a Renewable Future; Empirical Studies on Competitive

Disadvantages from Electricity Price Differentials and Mineral Supply Risk in an Open

Economy

UNU-MERIT Dissertation Series, № 103

Jocelyn Olivari

Entrepreneurial Traits and Innovation; Evidence from Chile

UNU-MERIT Dissertation Series, № 102

\section{Muhammad Shafique}

Essays on the role of knowledge, RED, and Technology-based Firms in the Evolution of Socio-techno-economic System

UNU-MERIT Dissertation Series, № 101

\section{Serdar Türkeli}

Governance of Innovation Policy; Empirical Studies on Applied Political Economy by Multi-Methods Analysis

UNU-MERIT Dissertation Series, № 100

\section{Ayokunu Adedokun}

Pathways to Sustainable Peacebuilding in Divided Societies; Lessons and Experiences from Mozambique

MGSoG Dissertation Series, № 75

\section{Luiz Rothier Bautzer}

Organizing Concurrent Engineering through ICT Platforms

Blueprinting Product Lifecycle Management Platforms across Disciplinary Agencies

MGSoG Dissertation Series, № 74

\section{Natalia Popova}

Migration in the Periphery of the European Union;

Determinants of Successful and Sustainable Labour Market Integration of Return Migrants in Albania, Egypt, Moldova and Tunisia

MGSoG Dissertations Series, № 73 
Richard A. Martina

Uncertainty and Resource Constraint in the Small Island Developing States;

Essays in Entrepreneurial Cognition

MGSoG Dissertations Series, № 72

Cécile Cherrier

The Expansion of Basic Social Protection in Low-income Countries;

An Analysis of Foreign Aid Actors' Role in the Emergence of Social Transfers in SubSaharan Africa

MGSoG Dissertations series, № 71

Paul Caldron

The Tacit Bargain in Short-Term Medical Missions; Why U.S. physicians go and what it costs

MGSoG Dissertation Series, № 70

Mahmut Kobal

Customs E Excellence: A Comparative Approach on Administrative and Regulatory

Compliance Perspectives of the EU-Turkey Customs Union

MGSoG Dissertation Series, № 69

Craig Loschmann

Essays on Conflict-related Migration and Development in the Case of Afghanistan

MGSoG Dissertations Series, № 68

Andrea Milan

Rural Livelihoods, Location and Vulnerable Environments; Approaches to Migration in Mountain areas of Latin America

MGSoG Dissertation Series, № 67

Farida Lada

On Guarding the Welfare of Clinical Trial Subjects While Promoting Novel Drug Innovation

A Game Theoretical Approach

MGSoG Dissertation Series, № 66 
Hibret Belete Maemir

Dissecting Aggregate Productivity; International Integration and Growth with

Heterogeneous Firms

UNU-MERIT Dissertation Series, № 96

Giorgio Triulzi

Looking for the Right Path; Technology Dynamics, Inventive Strategies and Catchingup in the Semiconductor Industry

UNU-MERIT Dissertation Series, № 95

Abdul Baseer Qazi

Knowledge flows and networks in the ICT sector; The case of Pakistan

UNU-MERIT Dissertation Series, № 94

Ajay Thutupalli

Technology Paradigm Shifts in Agriculture; Drivers of Sustainability and Catch up UNU-MERIT Dissertation Series, № 93

Eduardo Urias

Improving access to HIVIAIDS treatment in Brazil; When are Compulsory Licenses effective in Price Negotiations?

UNU-MERIT Dissertation Series, № 92

Francesca Guadagno

Why have so few Countries Industrialised?

UNU-MERIT Dissertation Series, № 91

Daniel Opolot

The Evolution of Beliefs and Strategic Behaviour

UNU-MERIT Dissertation Series, № 90

Alejandro Lavopa

Structural Transformation and Economic Development; Can Development Traps be Avoided

UNU-MERIT Dissertation Series, № 89

Jinjin Zhao

Urban water management reform; The Case of China

UNU-MERIT Dissertation Series, № 88 
Simona Vezzoli

Borders, Independence and Post-colonial Ties; the Role of the State in Caribbean

Migration

MGSoG Dissertation Series, № 65

Silvia Consuelo Gómez Soler

Civil Conflict and Education; How Does Exposure to Civil Conflict Affect Human

Capital Accumulation? Evidence from Standardized Exit Exams in Colombia

MGSoG Dissertation Series, № 64

Paula Nagler

Occupational Choice in the Developing World

MGSoG Dissertation Series, № 63

Jasmin Kientzel

Determinants of Professional Commitment to Environmental Sustainability

MGSoG Dissertation Series, № 62

Mehmet Güney Celbiş

Regional Policies; Convergence, Trade, and the Allocation of Public Capital

MGSoG Dissertation Series, № 61

Florian Henning

Living Up to Standard; Interoperability Governance and Standards Adoption in

Government Information Networks

MGSoG Dissertation Series, № 60

Niels P. Groen

The Never-Ending Project

Understanding E-Government Project Escalation

MGSoG Dissertation Series, № 59

Derek Copp

Teacher-Based Reactivity to Provincial Large-scale Assessment in Canada

MGSoG Dissertation Series, № 58

Michaella Vanore

Family-Member Migration and the Psychosocial Health Outcomes of Children in Moldova and Georgia

MGSoG Dissertation Series, № 57 


\section{Sonja Fransen}

The Economic and Social Effects of Remittances and Return Migration in ConflictAffected Areas; The Case of Burundi

MGSoG Dissertation Series, № 56

Ibrahim Khalil Conteh

The Impact of Floods on Primary School Education in Zambia

MGSoG Dissertation Series, № 55

Richard Bluhm

Growth Dynamics and Development

Essays in Applied Econometrics and Political Economy

MGSoG Dissertation Series, № 54

Nevena P. Zhelyazkova

Work-Family Reconciliation and Use of Parental Leave in Luxembourg; Empirical Analysis of Administrative Records

MGSoG Dissertation Series, № 53

2014

Dirk Crass

The Impact of Brands on Innovation and Firm Performance; Empirical Evidence from Germany

UNU-MERIT Dissertation Series, № 87

Samyukta Bhupatiraju

The Geographic Dimensions of Growth and Development

UNU-MERIT Dissertation Series, № 86

François Lafond

The Evolution of Knowledge Systems

UNU-MERIT Dissertation Series, № 85

Annalisa Primi

Promoting Innovation in Latin America; What Countries Have Learned (and What

They Have Not) in Designing and Implementing Innovation and Intellectual Property Policies

UNU-MERIT Dissertation Series, № 84 
Fatoumata Lamarana Diallo

Evaluation of Meal and Deworming Programs for Primary Schools in Rural Senegal UNU-MERIT Dissertation Series, № 83

Sachin Kumar Badkas

Metachoice and Metadata; Innovating with Environmental Policy Analysis in Europe MGSoG Dissertation Series, № 52

Irina S. Burlacu

An Evaluation of Tax-Benefit Systems Impact on the Welfare of Frontier Worker;

The Case of Luxembourg and Belgium

MGSoG Dissertation Series, № 51

Özge Bilgili

Simultaneity in Transnational Migration Research; Links Between Migrants' Host and Home Country Orientation

MGSoG Dissertation Series, № 50

Yulia Privalova Krieger

Reshaping the Big Agenda; Transnational Politics and Domestic Resistance Financial crisis and social protection reform in Bosnia and Herzegovina

MGSoG Dissertation Series, № 49

Marieke van Houte

Moving Back or Moving Forward? Return migration after Conflict

MGSoG Dissertation Series, № 48

Oxana Slobozhan

Global Governance in the Management of Natural Resources; The Case of the

Extractive Industries Transparency Initiative (EITI)

MGSoG Dissertation Series, № 47

Luis Bernardo Mejia Guinand

The Changing Role of the Central Planning Offices in Latin America; A Comparative Historical Analysis Perspective (1950-2013)

MGSoG Dissertation Series, № 46

Cheng Boon Ong

Ethnic Segregation in Housing, Schools and Neighbourhoods in the Netherlands

MGSoG Dissertation Series, № 45 
Luciana V. Cingolani

Bureaucracies for Development; Oxymoron or Reality? Studies on State Capacity in

Challenging Governance Contexts

MGSoG Dissertation Series, № 44

Carlos Cadena Gaitán

Green Politics in Latin American Cities - Sustainable Transport Agendas

MGSoG Dissertation Series, № 43

Katie Kuschminder

Female Return Migration and Reintegration Strategies in Ethiopia

MGSoG Dissertation Series, № 42

Metka Hercog

Highly-Skilled Migration and New Destination Countries

MGSoG Dissertation Series, № 41

Margaret Agaba Rugadya

Can Remittances Influence the Tenure and Quality of Housing in Uganda?

MGSoG Dissertation Series, № 40

Ilire Agimi

New Governance Under Limited Statehood; The Case of Local Government Reform in Kosovo

MGSoG Dissertation Series, № 39

2013

Anant Kamath

Information Sharing through Informal Interaction in Low-Tech Clusters

UNU-MERIT Dissertation Series, № 82

Flavia Pereira de Carvalho

What we talk about when we talk about Brazilian Multinationals; An Investigation on Brazilian FDI, Economic Structure, Innovation and the Relationship between them UNU-MERIT Dissertation Series, № 81

Jun Hou

Complementarity in Innovation and Development; A Cross-country Comparison UNU-MERIT Dissertation Series, № 80 
Rufin Baghana

Impacts of Government Incentives to RED, Innovation and Productivity;

A Micro econometric Analysis of the Québec Case

UNU-MERIT Dissertation Series, № 79

Lilia I. Stubrin

High-Tech Activities in Emerging Countries; A Network perspective on the

Argentinean Biotech Activity

UNU-MERIT/MGSoG Dissertation Series, № 78

Kristine Farla

Empirical Studies on Institutions, Policies and Economic Development

MGSoG Dissertation Series, № 38

Marina Petrovic

Social Assistance and Activation in the Pursuit of Happiness; Shedding New Light on

Old Policy Solutions to Social Exclusion

MGSoG Dissertation Series, № 37

Laura Torvinen

Assessing Governance Assessments; The Case of Mozambique; Governance

Assessments in the Context of Aid Effectiveness Discourse

MGSoG Dissertation Series, № 36

Biniam Egu Bedasso

Institutional Change in the Long Shadow of Elite; Essays on Institutions, Human

Capital and Ethnicity in Developing Countries

MGSoG Dissertation Series, № 35

Sepideh Yousefzadeh Faal Deghati

Childhoods Embargoed; Constructing and Reconstructing Multidimensional Child

Poverty in Iran 1984-2009

MGSoG Dissertation Series, № 34

Robert Bauchmüller

Investing in Early Childhood Care and Education; The Impact of Quality on Inequality MGSoG Dissertation Series, № 33 


\section{Martin Rehm}

Unified Yet Separated; Empirical Study on the Impact of Hierarchical Positions within Communities of Learning

MGSoG Dissertation Series, № 32

2012

Abdul Waheed

Innovation Determinants and Innovation as a Determinant; Evidence from Developing Countries

UNU-MERIT Dissertation Series, № 77

Bilal Mirza

Energy Poverty and Rural Energy Markets in Pakistan

UNU-MERIT Dissertation Series, № 76

Benjamin Engelstätter

Enterprise Software and Video Games; An Empirical Analysis

UNU-MERIT Dissertation Series, № 75

Fulvia Farinelli

Natural Resources, Innovation and Export Growth; The Wine Industry in Chili and Argentina

UNU-MERIT Dissertation Series

Rodolfo Lauterbach

Innovation in Manufacturing; From Product Variety and Labor Productivity Growth to Economic Development in Chile

UNU-MERIT Dissertation Series

Kirsten Wiebe

Quantitative Assessment of Sustainable Development and Growth in Sub-Saharan Africa

UNU-MERIT/MGSoG Dissertation Series, № 74

Julio Miguel Rosa

Organizational Strategies, Firms' Performance and Spatial Spillovers; The Canadian Case in Research and Development.

UNU-MERIT Dissertation Series, № 73 
Johannes Wilhelmus Marie Boels

Joseph Schumpeter, Honderd Jaar Economische Ontwikkeling; Een Historisch-

theoretische Beschouwing.

UNU-MERIT Dissertation Series

Dorcas Mbuvi

Utility Reforms and Performance of the Urban Water Sector in Africa

MGSoG Dissertation Series, № 31

Lina Salanauskaite

Distributional Impacts of Public Policies; Essays in Ex-Ante and Ex-Post Evaluation

MGSoG Dissertation Series, № 30

Esther Schüring

To Condition or not - is that the Question?

An Analysis of the Effectiveness of Ex-Ante and Ex-Post Conditionality in Social Cash

Transfer Programs

MGSoG Dissertation Series, № 29

Joe Abah

Strong Organisations in Weak States; Atypical Public Sector Performance in

Dysfunctional Environments

MGSoG Dissertation Series, № 28

Zina Samih Nimeh

Social Citizenship Rights; Inequality and Exclusion

MGSoG Dissertation Series, № 27

2011

Daniel Vertesy

Interrupted Innovation; Emerging Economies in the Structure of the Global Aerospace Industry

UNU-MERIT Dissertation Series, № 72

Tina Saebi

Successfully Managing Alliance Portfolios; An Alliance Capability View

UNU-MERIT Dissertation Series, № 71 


\section{Nora Engel}

Tuberculosis in India; A Case of Innovation and Control

UNU-MERIT/MGSoG Dissertation Series, № 70

Evans Mupela

Connectivity and growth in Sub-Saharan Africa; The Role of Communication Satellites UNU-MERIT Dissertation Series, № 69

Nantawan Kwanjai

Cross Cultural Intelligence amid Intricate Cultural Webs; A Tale of the UnDutchables in the Land of 1002 Smiles

UNU-MERIT Dissertation Series, № 68

\section{Lina Sonne}

Innovation in Finance to Finance Innovation; Supporting Pro-poor Entrepreneur-based Innovation

UNU-MERIT Dissertation Series, № 67

Lenka Eisenhamerová

Legitimacy of 'Humanitarian Military Intervention'

MGSoG Dissertation Series, № 26

Sonila Tomini

Informal Payments for Health Care Services in Albania

MGSoG Dissertation Series, № 25

\section{Jinjing Li}

Dynamic Microsimulation in Public Policy Evaluation

MGSoG Dissertation Series, № 24

\section{Aziz Atamanov}

Rural Nonfarm Employment and International Migration as Alternatives to Agricultural Employment; The Case of Kyrgyzstan

MGSoG Dissertation Series, № 23

Frieda Vandeninden

Poverty Alleviation; Aid and Social Pensions

MGSoG Dissertation Series, № 22 
Juliana Nyasha Tirivayi

The Welfare Effects of Integrating AIDS Treatment with Food Transfers; Evidence from Zambia

MGSoG Dissertation Series, № 21

Agnieska Ewa Sowa

Who's Left Behind? Social Dimensions of Health Transition and Utilization of Medical Care in Poland

MGSoG Dissertation Series, № 20

Emmanaouil Sfakianakis

The Role of Private Actors in the Provision of Public Goods with Applications to Infrastructure and Financial Stability

MGSoG Dissertation Series, № 19

Siu Hing Lo

White Collars Green Sleeves; An Inter-organizational Comparison of Determinants of Energy-Related Behaviors among Office Workers

MGSoG Dissertation Series, № 18

Treena $\mathrm{Wu}$

Constraints to Human Capital Investment in Developing Countries;

Using the Asian Financial Crisis in Indonesia as a Natural Experiment

MGSoG Dissertation Series, № 17

Henry Espinoza Peña

Impact Evaluation of a Job-Training Programme for Disadvantaged Youths;

The Case of Projoven

MGSoG Dissertation Series, № 16

2010

Fernando Santiago

Human Resources Management Practices and Learning for Innovation in Developing Countries; Pharmaceutical Firms in Mexico

UNU-MERIT Dissertation Series, № 66

Zakaria Babutsidze

Essays on Economies with Heterogeneous Interacting Consumers

UNU-MERIT Dissertation Series, № 65 
Bertha Vallejo

Learning and Innovation Under Changing Market Conditions; The Auto Parts

Industry in Mexico

UNU-MERIT Dissertation Series, № 64

Donatus Ayitey

Technical Change, Competitiveness and Poverty Reduction; A Study of the Ghanaian Apparel Industry

UNU-MERIT Dissertation Series, № 63

\section{Sergey Filippov}

Multinational Subsidiary Evolution; Corporate Change in New EU Member States

UNU-MERIT Dissertation Series, № 62

Asel Doranova

Technology Transfer and Learning under the Kyoto Regime; Exploring the

Technological Impact of CDM Projects in Developing Countries

UNU-MERIT Dissertation Series, № 61

Florian Tomini

Between Family and Friend; Understanding the Interdependency of Private Transfers MGSoG Dissertation Series, № 15

Michał Polalowski

The Institutional Transformation of Social Policy in East Central Europe; Poland and Hungary in Comparative and Historical Perspective

MGSoG Dissertation Series, № 14

Maha Ahmed

Defining, Measuring and Addressing Vulnerability; The Case of Post Conflict

Environments

MGSoG Dissertation Series, № 13

Pascal Beckers

Local Space and Economic Success; The Role of Spatial Segregation of Migrants in the Netherlands

MGSoG Dissertation Series, № 12 


\section{Victor Cebotari}

Conflicting Demands in Ethnically Diverse Societies; Ethno political Contention and Identity Values in Europe

MGSoG Dissertation Series, № 11

Dennis Gyllensporre

Competing and Complementary Perspectives on the EU as a Crisis Management Actor; An Examination of the Common Security and Defence Policy through the Lenses of Idealism and Realism

MGSoG Dissertation Series, № 10

Judit Vall Castello

Business Cycle and Policy Effects on Labour Market Transitions of Older and Disabled Workers in Spain

MGSoG Dissertation Series, № 9

Keetie Roelen

False Positives or Hidden Dimensions; The Definition and Measurement of Child Poverty

MGSoG Dissertation Series, № 8

Denisa Maria Sologon

Earning Dynamics in Europe

MGSoG Dissertation Series, № 7

Melissa Siegel

Money and Mobility; Migration and Remittances

MGSoG Dissertation Series, № 6

Jessica S. Hagen-Zanker

Modest Expectations; Causes and Effects of Migration on Migrant Households in Source Countries

MGSoG Dissertation Series, № 5

2009

Alexis Habiyaremye

From Primary Commodity Dependence to Diversification and Growth; Absorptive Capacity and Technological Catch Up in Botswana and Mauritius.

UNU-MERIT Dissertation Series, № 60 
Yoseph Getachew

The Role of Public Capital in Economic Development

UNU-MERIT Dissertation Series, № 59

Sandra Leitner

Embodied Technological Change and Patterns of Investment in Austrian

Manufacturing

UNU-MERIT Dissertation Series, № 58

Semih Akçomak

The Impact of Social Capital on Economic and Social Outcomes

UNU-MERIT Dissertation Series, № 57

Abraham Garcia

The Role of Demand in Technical Change

UNU-MERIT Dissertation Series, № 56

Saurabh Arora

Coherence in Socio-technical Systems; A Network Perspective on the Innovation

Process

UNU-MERIT Dissertation Series, № 55

Mirtha R. Muniz Castillo

Human Development and Autonomy in Project Aid; Experiences from four bilateral projects in Nicaragua and El Salvador

MGSoG Dissertation Series, № 4

Christiane Arndt

Governance Indicators

MGSoG Dissertation Series, № 3

Britta Augsburg

Microfinance; Greater Good or Lesser Evil?

MGSoG Dissertation Series, № 2

2008

Rutger Daems

Medicines for the Developing World

UNU-MERIT Dissertation Series, № 54 
Johannes Hanel

Assessing Induced Technology; Sombart's Understanding of Technical Change in the History of Economics

UNU-MERIT Dissertation Series, № 53

Rifka Weehuizen

Mental Capital; the Economic Significance of Mental Health

UNU-MERIT Dissertation Series, № 52

Danielle Cloodt

The Relationship between RED Partnership Formation, Social Embeddedness and Innovative Performance

UNU-MERIT Dissertation Series, № 51

Sabine Fuss

Sustainable Energy Development under Uncertainty

UNU-MERIT Dissertation Series, № 50

Geranda Notten

Measuring and Managing Poverty Risks

MGSoG Dissertation Series, № 1

2007

Tobias Kronenberg

Reconciling Environmental Conservation with Economic Prosperity; The Feasibility of Double Dividends in the Short and Long Run

UNU-MERIT Dissertation Series, № 49

Viktoria Kravtsova

Assessing the Impact of Foreign Direct Investment in Transition Economies

UNU-MERIT Dissertation Series, № 48

Suhail Sultan

The Competitive Advantage of Small and Medium Sized Enterprises; The Case of Jordan's Natural Stone Industry

UNU-MERIT Dissertation Series, № 47 
Bulat Sanditov

Essays on Social Learning and Imitation

UNU-MERIT Dissertation Series, № 46

Mamata Parhi

Dynamics of New Technology Diffusion; A Study of the Indian Automotive Industry UNU-MERIT Dissertation Series, № 45

Andreas Reinstaller

Social Structures and the Innovation Process; Their Role in the Demand of Firms and Consumers

UNU-MERIT Dissertation Series, № 44

Rose Kiggundu

Innovation systems and Development; The Journey of a Beleaguered Nile Perch Fishery in Uganda

UNU-MERIT Dissertation Series, № 43

Thomas Pogue

The Evolution of Research Collaboration in South African Gold Mining; 1886-1933

UNU-MERIT Dissertation Series, № 42

Geoffrey Gachino

Foreign Direct Investment, Spillovers and Innovation; The Case of Kenyan

Manufacturing Industry

UNU-MERIT Dissertation Series, № 41

Önder Nomaler

Technological Change, International Trade and Growth; An Evolutionary, Multi-

Agents-Based Modeling Approach

UNU-MERIT Dissertation Series, № 40

2005

Samia Satti Osman Mohamed-Nour

Change and Skill Development in the Arab Gulf Countries

UNU-MERIT Dissertation Series, № 39 
Elad Harison

Intellectual Property Rights; Economics and Policy Analysis

UNU-MERIT Dissertation Series, № 38

Daniel Dalohoun

The Relationship between RED Partnership Formation, Social Embeddedness and Innovative Performance; a Multi-level Approach of Social Embeddedness

UNU-MERIT Dissertation Series, № 37

Müge Ozman

Networks, Organizations and Knowledge

UNU-MERIT Dissertation Series, № 36

Bas Straathof

Product Variety and Economic Growth; The Counteracting Effects of Scale and Idiosyncrasy

UNU-MERIT Dissertation Series, № 35

Wilfred Schoenmakers

Knowledge Flows between Multinational Companies; A Patent Data Analysis

UNU-MERIT Dissertation Series, № 34

Myriam Cloodt

Mergers and Acquisitions ( $M$ and As) in High-Tech Industries; Measuring the Post-M and A Innovative Performance of Companies

UNU-MERIT Dissertation Series, № 33

2004

Paola Criscuolo

RED Internationalisation and Knowledge Transfer; Impact on MNEs and their Home Countries

UNU-MERIT Dissertation Series, № 32

Maarten Verkerk

Trust and Power on the Shop Floor

UNU-MERIT Dissertation Series, № 31

Gottfried Leibbrandt

Adoption, Harmonization and Succession of Network Technologies across Countries UNU-MERIT Dissertation Series, № 30 
Mark Sanders

Skill Biased Technical change; Its Origins, the Interaction with the Labour Market and Policy Implications

UNU-MERIT Dissertation Series, № 29

2003

Nadine Roijakkers

Inter-firm Cooperation in High-tech Industries; a Study of RED Partnerships in

Pharmaceutical Biotechnology

UNU-MERIT Dissertation Series, № 28

Viki Sonntag

Speed, Scale and Sustainability

UNU-MERIT Dissertation Series, № 27

Masaru Yarime

From End-of-Pipe Technology to Clean Technology

UNU-MERIT Dissertation Series, № 26

Stéphane Malo

The Combinatorial Chemistry Revolution; Sustaining a Superior Performance Position through Technological Learning

UNU-MERIT Dissertation Series, № 25

2002

Annelies Hogenbirk

Determinants of Inward Foreign Direct Investment; the Case of the Netherlands

UNU-MERIT Dissertation Series, № 24

Bastiaan Johan ter Weel

The Computerization of the Labour Market

UNU-MERIT Dissertation Series

2001

John Adeoti

Technology Investment in Pollution Control in Sub-Saharan Africa; The Case of the

Nigerian Manufacturing Industry

UNU-MERIT Dissertation Series, № 23 
Edward Huizenga

Innovation Management; How Frontrunners Stay Ahead; An Empirical Study on Key Success Factors in the ICT sector

UNU-MERIT Dissertation Series, № 22

2000

Machiel van Dijk

Technological Change and the Dynamics of Industries; Theoretical Issues and Empirical evidence from Dutch Manufacturing

UNU-MERIT Dissertation Series, № 21

1999

Jan Cobbenhagen

Managing Innovation at the Company Level; A Study on Non-Sector-Specific Success

Factors

UNU-MERIT Dissertation Series, № 20

Marjolein Caniëls

Regional Growth Differentials; The Impact of Locally Bounded Knowledge Spillovers

UNU-MERIT Dissertation Series, № 19

1998

Aldo Geuna

Resource Allocation and Knowledge production; Studies in the Economics of University Research

UNU-MERIT Dissertation Series, № 18

1996

Reinoud Joosten

Dynamics, Equilibria, and Values

UNU-MERIT Dissertation Series, № 17

Hugo Kruiniger

Investment, RED, and the Financing Decisions of the Firm

UNU-MERIT Dissertation Series, № 16 
Hans van Meijl

Endogenous Technological Change; The Case of Information Technology, Theoretical Considerations and Empirical Results

UNU-MERIT Dissertation Series, № 15

René Kemp

Environmental Policy and Technical Change; A Comparison of the Technological Impact of Policy Instruments

UNU-MERIT Dissertation Series, № 14

Rohini Acharya

The Impact of New Technologies on Economic Growth and Trade; A Case Study of Biotechnology

UNU-MERIT Dissertation Series, № 13

Geert Duysters

The Evolution of Complex Industrial Systems; The Dynamics of Major IT Sectors

UNU-MERIT Dissertation Series, № 12

\section{Marjan Groen}

Technology, Work and Organisation; A Study of the Nursing Process in Intensive Care Units

UNU-MERIT Dissertation Series, № 11

\section{4}

\section{Huub Meijers}

On the Diffusion of Technologies in a Vintage Framework; Theoretical Considerations and Empirical Results

UNU-MERIT Dissertation Series, № 10

Theon van Dijk

The Limits of Patent Protection; Essays on the Economics of Intellectual Property Rights

UNU-MERIT Dissertation Series, № 9 
Hans Voordijk

Naar Integrale Logistiek in Bedrijfsketens; Ontwikkelingen in de Bouw

UNU-MERIT Dissertation Series, № 8

1993

Paul Diederen

Technological Progress in Enterprises and Diffusion of Innovation;. Theoretical

Reflections and Empirical Evidence

UNU-MERIT Dissertation Series, № 7

Ben Dankbaar

Economic Crisis and Institutional Change; The Crisis of Fordism from the Perspective of the Automobile Industry

UNU-MERIT Dissertation Series, № 6

Hanno Roberts

Accountability and Responsibility; The Influence of Organisation Design on

Management Accounting

UNU-MERIT Dissertation Series, № 5

1992

Bart Verspagen

Uneven Growth Between Interdependent Economies; An Evolutionary View on

Technology Gaps, Trade and Growth

UNU-MERIT Dissertation Series, № 4

Sjoerd Romme

A Self-organization Perspective on Strategy Formation

UNU-MERIT Dissertation Series, № 3

1989

John Spangenberg

Economies of Scale, and Atmosphere in Research Organisations

UNU-MERIT Dissertation Series, № 2 
John Hagedoorn

Evolutionary and Heterodox Innovation Analysis; A Study of Industrial and Technological Development in Process Control and Information Technology UNU-MERIT Dissertation Series, № 1 